\title{
Embryonic axial curvature : relationships to neuropore closure
}

Citation for published version (APA):

Peeters, M. C. E. (1998). Embryonic axial curvature : relationships to neuropore closure. [Doctoral Thesis, Maastricht University]. Universiteit Maastricht. https://doi.org/10.26481/dis.19980611mp

Document status and date:

Published: 01/01/1998

DOI:

10.26481/dis. $19980611 \mathrm{mp}$

Document Version:

Publisher's PDF, also known as Version of record

\section{Please check the document version of this publication:}

- A submitted manuscript is the version of the article upon submission and before peer-review. There can be important differences between the submitted version and the official published version of record.

People interested in the research are advised to contact the author for the final version of the publication, or visit the DOI to the publisher's website.

- The final author version and the galley proof are versions of the publication after peer review.

- The final published version features the final layout of the paper including the volume, issue and page numbers.

Link to publication

\footnotetext{
General rights rights.

- You may freely distribute the URL identifying the publication in the public portal. please follow below link for the End User Agreement:

www.umlib.nl/taverne-license

Take down policy

If you believe that this document breaches copyright please contact us at:

repository@maastrichtuniversity.nl

providing details and we will investigate your claim.
}

Copyright and moral rights for the publications made accessible in the public portal are retained by the authors and/or other copyright owners and it is a condition of accessing publications that users recognise and abide by the legal requirements associated with these

- Users may download and print one copy of any publication from the public portal for the purpose of private study or research.

- You may not further distribute the material or use it for any profit-making activity or commercial gain

If the publication is distributed under the terms of Article $25 \mathrm{fa}$ of the Dutch Copyright Act, indicated by the "Taverne" license above, 


\section{Embryonic Axial Curvature}

Relationships to neuropore closure 
(C) 1998 Peeters, Maastricht, the Netherlands

ISBN $90-9011670-2$

Druk: Datawyse Maastricht|Universitaire Pers Maastricht

Cover: Curbl tail embryo of the 27 somite stage (scanning electron microscopy) 


\title{
Embryonic Axial Curvature Relationships to neuropore closure
}

\author{
PROEFSCHRIFT
}

ter verkrijging van de graad van doctor aan de Universiteit Maastricht,

op gezag van de Rector Magnificus, Prof. dr. A.C. Nieuwenhuijzen Kruseman, volgens het besluit van het College van Decanen, in het openbaar te verdedigen

op donderdag 11 juni 1998 om 16.00 uur

door

\section{Maria Catharina Elisabeth Peeters}




\section{Promotores}

Prof. dr J. Drukker

Prof. dr J.P.M. Geraedts

\section{Copromotor}

Dr H.W.M. van Straaten

\section{Beoordelingscommissie}

Prof. dr J.L.H Evers (voorzitter)

Prof dr ].-W. Arends

prof. dr E.A.M. Beuls

Prof. dr P.W.J. Peters (Universiteit Utrecht)

Dr Chr. Viebahn (Rheinische Friedrich-Wilhelms-Universität, Bonn)

This study was financially supported by the Netherlands Scientific Organization. 
Aari mijn ouders 



\section{Contents}

1 Introduction

2 Phenotypes and penetrance in the curby tail mouse strain and its recombinant

2.1 The curly tail mouse colony at the University of Maastricht

2.2 The recombinant mouse strain

3 Relationship between axial curvature and neural tube closure

3.1 The spatio-temporal curvature pattern in the mouse

3.2 Effects of axial curvature alterations in the mouse

3.3 Neurulation in the rabbit embryo

3.4 Comparisons in five species

4 Determinants of axial curvature

4.1 Role of cel] proliferation in the tail bud

4.2 Role of embryonic glucose consumption

5 General discussion

Summary

Samenvatting

Curriculum Vitae

List of Publications 185

Dankwoord 



\section{Chapter 1}

Introduction 


\section{Neural Tube Defects}

Congenital anomalies have become more important causes of infant morbidity and mortality since the prevalence rates of infectious diseases and diet problems during childhood have decreased in Western Europe. Congenital anomalies are abnormalities in structure or function which are inherited or acquired during the prenatal or perinatal period, and which become manifest before, at or shortly after birth. In the period 1981-1986, congenital anomalies were observed in $2.5 \%$ of all Jiveborns and stillborns in the Northern Netherlands (Cornel et al. 1991). Causative factors of the anomalies have been suggested to be single gene disorders (e.g. phenylketonuria), chromosome abnormalities (e.g. trisomy 21) and environmental exposures (e.g. alcohol). In two-thirds of all congenital anomalies, however, the causative factor is unknown (Beaudet et al. 1995).

Neural tube defects (NTD), of which anencephaly and spina bifida are the two most common forms, constitute a category of most distressing congenital anomalies (EUROCAT 1987). The prevalence varies with environmental and demographic factors, such as season, ethnicity, socioeconomic status, matemal age and geographic location. The highest reported prevalence accounts for Mexico, which amounts to 34.3 per 10,000 infants. For Japan and the United States, prevalence rates of 12.0 and 8.4 are reported (Clearinghouse 1991). Within Europe, the highest prevalence in the period 1980-1992 is reported for the United Kingdom and Jreland (about 25 per 10,000). In the same period, the prevalence in the Netherlands is the highest of continental Europe and amounts to 12.6 per 10,000 (Cornel et al. 1997). Of course, the reported prevalence rates are only a fraction of the total number of embryos exhibiting NTD, since the prenatal mortality rate of N'TD has been estimated to amount to $98.4 \%$; most of the affected embryos are even lost by the end of the first trimester of pregnancy (Shiota 1993). Nevertheless, the reported prevalence rates are useful in estimating the amount of help which is needed for this category of congenital anomalies and in evaluating prevention programmes.

The aetiology of NTD is frequently described by a multifactorial threshold model in which both genetic and environmental factors are involved. Over $95 \%$ of infants with N'TD are bom to women who have not previously had an affected pregnancy (Wald 1994). The risk for NTD in families which already comprises an affected member is, however, higher than in unaffected families. For instance, the risk for N'TD in siblings of affected individuals amounted to 3-6\% (Smithells et al. 1983; Hunter 1984; Smithells et al. 1989; Vergel et al. 1990; Wald et al. 1991), which is up to 100 times higher than in the general population. In addition, the risk turned out to increase further if more than one sibling was affected (Hunter 1984; Papp et al. 1997). Furthermore, the risk was reported to be higher in twins than in full-siblings, 
and higher in full-siblings than in half-siblings (Janerich 1978; Hunter 1984). All these familial aggregation data point towards a polygenic mode of inheritance.

The involvement of environmental factors in the aetiology of NTD is suggested by the variation in prevalence as mentioned for e.g. geogtaphy, season and socioeconomic status. Additional evidence emerged from the associations between NTD on the one hand and matemal nutrition, drug therapy and metabolic disorders on the other. A reduced matemal folate intake was repeatedly correlated with the occurrence of NTD (Laurence et al. 1980; Yates et al. 1987; Bower and Stanley 1989), and folate supplementation (mostly in combinations with other vitamins) was found to reduce the risk for an NTD affected child (Lautence et al 1981; Smithells et al. 1989; Vergel et al. 1990; Wald et al. 1991; Czeizel and Dudas 1992). Drug therapy, like the use of anticonvulsant valproic acid, turned out to increase the risk for NTD (Lammer et al. 1987). Moreover, both hyperglycemic and hypoglycemic conditions in maternal diabetes appeared associated with an increased risk for NTD (Mills 1982; Becerra et al. 1990; Smoak and Sadler 1990; Maeda et al. 1993; Reece et al. 1993). Thus, besides the genetic factors, various environmental factors have been suggested to be involved in the aetiology of NTD.

When NTDs are subdivided according to their underlying defect, two main categories emerge: one with an "open" defect in which the formation of the neural tube is defective and one with a "closed" defect in which the mesenchymal tissue is poorly developed (Table 1). In the former category, the neural tube is open due to non-closure or to reopening of a closed tube. Because of this defect at embryonic stages, the subsequent development of the surrounding tissues becomes disturbed as well, resulting in exposure of neural tissue at the surface. Initially, the neural tissue shows a considerable overgrowth (which in the cranial region is known as exencephaly), but the excess tissue becomes necrotic shortly before or after birth. The defects are named anencephaly, spina bifida aperta or craniorachischisis depending on whether the cranial, spinal or both parts of the neural tube are involved. The defect is sometimes covered by a thin membrane before or even after birth. Subsequent fluid accumulation in the subarachnoid space ventral to the neural tissue may displace this tissue dorsally as a protrusion, resulting in meningomyelocele. Since the neural tube, which is the precursor of the central nervous system, is affected, patients exhibit severe neurological symptoms. In the other category of NTD, the defect involves primarily mesenchymal tissue resulting in abnormal meninges, vertebral arches or skull bones. These defects are known as meningocele, spina bifida occulta and cranium bifidum occultum. Neurological symptoms may be absent, because the formation of the neural tube is not primarily affected.

As this thesis deals with open NTDs, the formation of the neural tube is described in more detail in the next section. This is followed by the description of one 
important factor in neurulation, i.e. axial curvature, and finally the model system which is studied to reveal underlying mechanisms of NTD.

\section{Neurulation}

The process of neurulation leads to the formation of the neural tube. This initially mono-layered tube is the precursor of the entire central nervous system and of part of the peripheral nervous system. Its formation is generally subdivided into a primary and secondary neurulation phase. Primary neurulation starts in the primitive streak embryo with the formation of a neural plate in the epiblast (Fig. 1). In subsequent stages, the lateral extensions of this plate elevate to form the walls of a neural groove. "The dorsal extremities of these walls, the neural folds, converge to the dorsal midline. When they reach each other in the midline, the paired folds fuse. This initial closure occurs at the cervical level. Secondary neurulation occurs at the sactal levels and involves canalization of a medullary cord, which is a condensation of mesenchymal cells (Schoenwolf 1984). The resulting neural tube is a continuous structure formed by both primary and secondary neurulation.

This thesis focuses on defects in primary neurulation. The processes involved in the primary neurulation events have been extensively reviewed (Karfunkel 1974; Gordon 1985; Copp et al. 1990; Schoenwolf and Smith 1990; Smith and Schoenwolf 1997) and will be described briefly in what follows.

\section{Formation}

During the formation of the neural plate, the ectodermal cells increase in height, due to inductive signals of the underlying mesoderm. Subsequently, the neural plate narrows transversely and lengthens longitudinally; an event known as convergent

Table 1. Classification of neural tube defects

\section{Neutal Tube Defects}

open

closed

neural tube primarily affected

- ancenceplady

- spina bifida aperta

(= lumbosicale myeloschisis)

- craniorachischisis

- meningomyelocele

(= spina bifida cystica) mesenchymal tissue primarily affected

- cranium bifidum occultum

- spina bifida occulta

- meningocelie

(= spina bifida cystica) 
extension. "This is the result of a combination of cellular changes: the neuroepithelial cells increase further in height, the cell number uncreases and the mutual positions of cells change due to cell intercalation.

\section{Elevation}

In the midline of the flat neural plate, neuroepithelial cells are anchored to the notocord undemeath them. As a result of the action of inductive factors, which originate from the notochord, the cells of this floor plate decrease in height and become wedge-shaped. The mechanisms of wedging is suggested to involve both apical constriction by contraction of the apically atranged microfilament bundles and basal expansion by withdrawing cells from the cell cycle resulting in basally positioned nuclei. Due to this wedging of cells, the floot plate becomes a medial hinge point that forms a furrow in the dorsal midline and evokes elevation of the neural walls. Because convergent extension still continues while the notochord and floor plate are anchored, the neural plate is proposed to buckle in dorsal direction. Elevation of the neural walls would further be facilitated by a general contraction of the apically artanged microflament bundles, resulting in decteased apical cell area. Additionally, expansion of the mesoderm is proposed to lead to a passive elevation of the neural walls.

\section{Conuergence}

Next, two other hinge regions form furrows near the connection of the neural walls to the remainder of the ectoderm. These dorsolateral hinge points are anchored to the ectoderm. "The cells are suggested to become wedge-shaped by a combined action of microtubules and microflaments on the one hand, and the above mentioned effect of cell cycle regulation on the other. Together with expansion of the ectoderm, as caused by changes in ectodermal cell number, shape and position, both processes will subsequently facilitate the convergence of the neural folds.

\section{Fusson}

The neural tube closes as the paired noural folds are brought together at the dorsal midline. The folds adhere and, subsequently, fuse. The closure is effectuated by cell adhesion molecules which are expressed at the neuroepithelial cell surface and by protrusive activity of the cells.

Traditionally, the closure at the cervical level was considered to be the only initial one, succeeded by a continuation of closure in rostral ancl caudal direction by a zipper-mechanism. However, studies on neurulation in the mouse embryo pointed to three additional sites of initial closure in the cranial region (Golden and Chernoff 1983, 1993; MacDonald et al. 1989; Juriloff et al. 1991; Tom et al. 1991). Slight differences in the closure sites do exist among several mouse stratins and an additional closure site is suggested to be present at the most caudal aspect of the neural folds (Sakai 1989). The neural tube closure in other mammalian species 


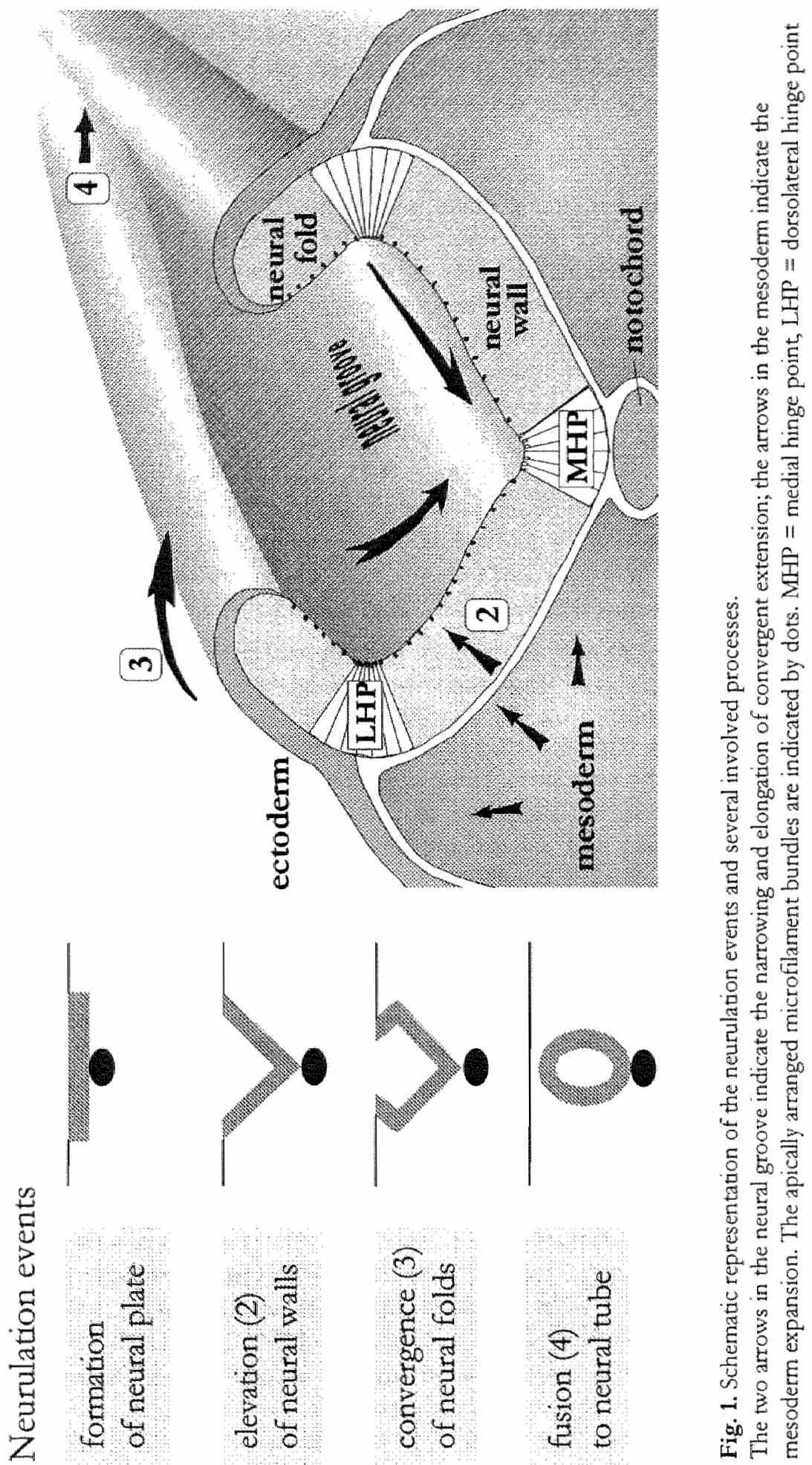


(reviewed by Golden and Chemoff (1993)) and in the chick (Jaskoll et al. 1991; Van Straaten et al. 1996) resembles this multi-site closure model as well. In addition, several initial closure sites have also been suggested for the human embryo, because the observed pattems of NTDs appeared to fit better in such a model than in a mono-site closure model (Van Allen et all. 1993). In the multi-site closure model, several openings of the neural tube are temporarily present. These neuropores close subsequently. Primary neurulation is completed after the closure of the neuropore in the sacral region, i.e. the posterior neuropore (PNP) (Tam 1986; Müller and O'Rahilly 1987; Copp and Brook 1989).

The fact that at several axial levels the neural tube closure is an initial one and at other levels it is a continuation or completion of closure indicates that the precise neurulation events and processes vary along the embryonic axis. Moreover, an initial closure in the chick embryo differs from the general description by the absence of convergence of the neural folds prior to fusion. (Van Straaten et al. 1997). In addition, along the spinal axis of mouse embryos, a region of continuation and completion of closure, variations in hinge point formations have led to the postulation of three different modes of primary neurulation in this region (Shum and Copp 1996). It may therefore be concluded that the impact of each process upon neurulation events depends on the embryonic axial level as on the species.

\section{Axial curvature}

An extrinsic process in neurulation, hitherto hardly mentioned in literature, is axial curvation. For example, the dorsal bending in the cervical region of the mouse embryo is considered to assist in the elevation and convergence of the neural walls and folds, and initial fusion of the neural folds indeed occurs in this region (Jacobson and Tam 1982). In addition, subsequent closure of the cranial neutal tube coincides with a pause in the progression of the mesencephalic flexure, i.e a pronounced ventral bending. Moreover, the mesencephalon, which is the most curved part of the cranial neural tube, is the region where the neural folds reach each other last (Jacobson and Tam 1982). At more caudal levels, closure of the PNP is observed to correlate with a decrease in axial curvature (Brook ct all. 1991). These coincidences suggest that elevation and convergence of the neural walls in mouse embryos are facilitated by a decrease in ventral bending of the longitudinal axis. Also for other species, a role for axial curvature in neurulation has been suggested. Even in the chick embryo with its rather straight axis, expetimentally altered curvatures appear to result in neural tube closure delays of which both the incidence and extent ate correlated with the degrees of curvature imposed (Van Straaten et al. 1993). Thus, axial curvation may be an important process in primary 
neurulation. However, its precise role in caudal neural tube closure remains to be determined.

\section{Determinants in axial curvation}

The impact of axial curvature upon primary neurulation events thus seems to depend on the degree of curvature. Axial curvature is the resultant of several determinants. Influences on curvation may originate from the developmental processes which are spatially and temporally related to the curvation. For instance, the looping of the heart is thought to pull the cervical region into an atch (Flynn et al. 1991). The detachment of the yolk sac likely affects axial curvation as well, as is suggested by differences between chick and mouse embryos: the caudal region of the chick embryo remains situated on top of the yolk sac during neutulation and remains flat, whereas the caudal region of the mouse embryo is curved and not closely attached to the yolk sac. A sudden change in axial curvature which is characteristic of the rodent embryo is the conversion from a dorsally concave to dorsally convex configuration.

Influences on curvation may also originate from dorsoventral growth differences. In the chick embryo it has been determined that during formation of the mesencephalic flexure the length, thickness and volume of the roof of the mesencephalon increase mote than that of its floor (Goodrum and Jacobson 1981). These dorsoventral differences may be the result of dorsoventral differential proliferation during and even before flexure formation, since proliferation appeared to be decreased in the notochord, floor plate and foregut at the future regions of flexures (Takamatsu and Fujita 1987). Additionally, overgrowth of the neural tube compared to the foregut may also result in flexure formation since both structures are firmly attached at the level of the prosencephalon, and this fixation acts as a pivotal point around which the neural tube hinges Jacobson et al. 1979; Pikalow et al. 1994). The role of differential cell proliferation in the curvation of the spinal region of mammalian embryos is unknown. (Chapter 4.1)

Cell proliferation can only occur when the energy supply is sufficient. During neurulation, glucose is the main energy source for embryonic cells (Cockroft 1979). Aberrant glucose levels, as occurs in diabetic mothers, are associated with neurulation defects, as stated above. However, it is unknown whether axial curvation is correlated with embryonic glucose utilization. (Chapter 4.2)

\section{Axial curvature and neurulation are studied in the curly tail mouse model}

In the past decade, it became obvious that the mouse mutant curby tail can serve as a model to study the role of axial curvature in primary neurulation. Mouse mutants are frequently studied to unravel pathways leading to disturbances of the neurulation events. By gene homology and linkage homology, these pathways are 
extrapolated to other species, such as the human, which has recently been petformed for 40 mouse mutations (Harris and Juriloff 1997).

The ary tail mutation arose spontaneously in 1950 (Gruneberg 1954). The of gene is localized to distal chromosome 4, but neither this gene nor one of its modifiers has been characterized so far Neumann et al. 1994; Beier et al. 1995; Letts et al. 1995). The mutation demonstrated an incomplete penetrance with $37 \%$ of the offspring affected at birth and $50 \%$ at embryonic stages; the affected offspring comprised curled tail, spina bifida aperta and anencephaly (Grüneberg 1954). Both the cutled tail and spina bifida aperta are the likely result of a delay in closure of the PNP. The PNP in non-mutant mouse embryos decreases rapidly in size and closes at the developmental stage of 30 somites, while a delay in closure can be recognized in about half of the ourly ail embryos (i.e affected ones) from the 25 somite stage onwards by an abnormal sized PNP (Fig. 2). This abnormal size is due to a reduced progression of neural tube closure (Copp 1985; Copp and Brook 1989; Van Straaten et al. 1992). Measurement of the angle of curvature of the caudal body axis at the 27-29 somite stage has revealed that affected curby tail embryos exhibit an incteased wentral curvature compared to their unaffected littermates (Brook et al. 1991). This increased curvature was suggested to be the result of an imbalanced gtowth in the caudal region: a diminished cell proliferation of the ventrally located

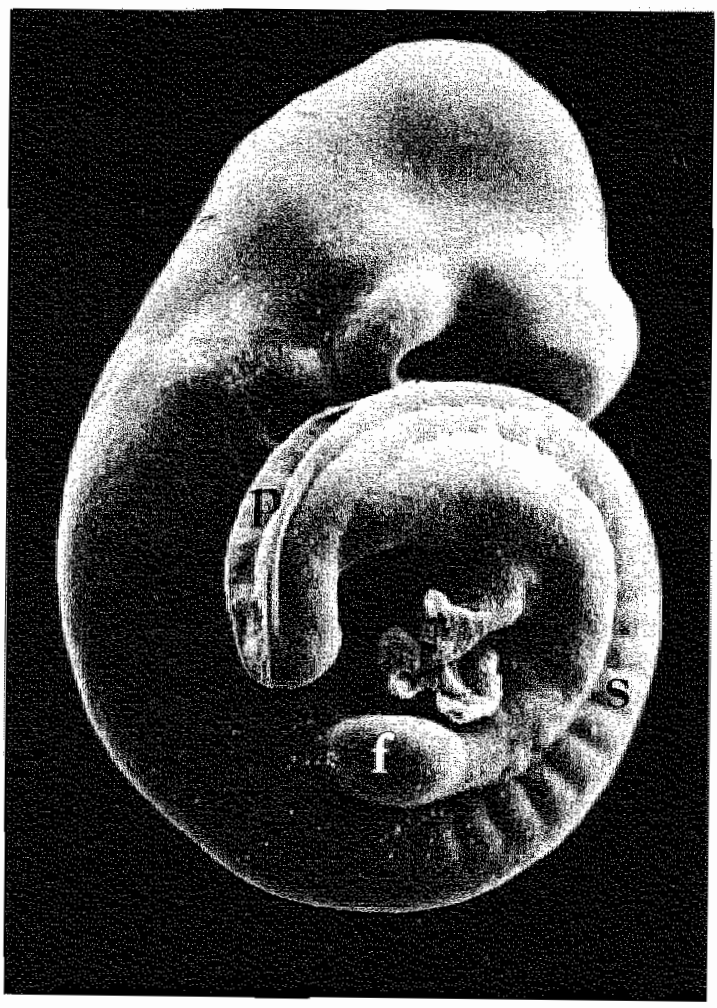

Fig. 2. Carty tail embryo of the 27 somite stage (scanning electron microscopy). The large posterior neuropore is characteristic for the subgroup of affected embryos. $\mathrm{f}=$ forelimb bud, $\mathrm{p}=$ posterior neuropore, $s=$ somite 
notochord and hindgut endoderm, accompanied by normal proliferation of the overlying neuroepithelium (Copp et al. 1988a). In this study, curvature and proliferation were determined at identical stages in identical regions, while it may be expected that proliferation is also disturbed in the progenitor structure of the caudal tegion, i.e. the tail bud, at stages preceding the abertant curvature. (Chapter 4.1)

Support for the idea that the imbalanced growth in the caudal region was involved in the corly tail pathogenesis emerged from an experimental study. Culturing curly tail embryos at an elevated temperature re-balanced the growth rates in the caudal region and normalized PNP closure, but it was not determined whether this was accompanied by a normalization of curvature (Copp et al. 1988b). (Chapter 3.2). Prevention of the increased curvature by eyelash insertion in the hindgut lumen or by isolation of the neuroepithelium from the adjacent tissues did normalize the closure of the PNP (Brook et al. 1991; Van Straaten et al. 1993). It was therefore postulated that the increased curvature of affected curly tail embryos results in mechanical forces that oppose the elevation, convergence and subsequent fusion of the neural folds, thereby causing a delay in PNP closure (Brook et al. 1991). However, it was not determined whether this relationship between axial curvature and PNP closure would be a mote general principle, and would be accordingly applicable to other mouse strains and other species. (Chapter 3.2-3.4). Moreover, the extent of the caudal region expressing aberrant curvature in curly tail embryos as well as the curvation during development were unknown. (Chapter 3.1)

The proposed steps in the pathogenetic pathway of the curly tail leading to NTD are summarized in Figure 3. It suggests that axial curvation is an important process in the neurulation events, but the extent of the relationship remains to be

arty railgene and modifiers

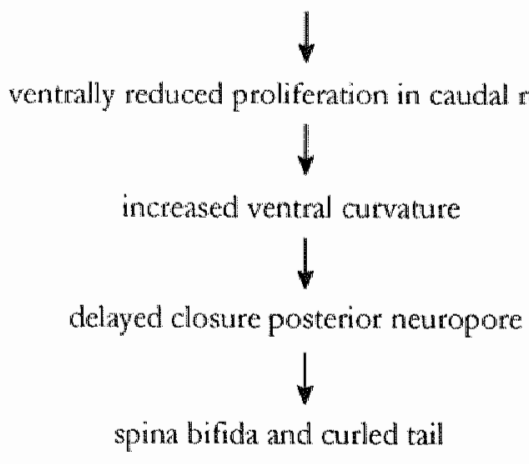

Fig. 3. The proposed steps in the pathogenetic pathway of the curty tail mouse strain 
determined. Besides, the aberrant curvation in why lail embryos seems to be due to a cell proliferation defect at a developmental stage during which glucose is reported to be the main energy source. Moreover, the gene for the glucose transporter GLUT-1, which is abundantly expressed at this stage (Matsumoto et al. 1993; Trocino et al. 1994), is mapped to the same region on chromosome 4 as the at gene (Hogan et al. 1991; Neumann et al. 1994). Both genes might be identical. However, the role of glucose or GLUT-1 in the carly tail pathogenesis has not been studied up to now. (Chapter 4.2)

\section{Aims and outline of the thesis}

The aims of this thesis are twofold: first, to determine the extent of the relationship between axial curvature and neural tube closure in non-mutant and corby tail mutant mouse strains and other species, and second, to determine the impact of two factors, cell proliferation and glucose, on this relationship. These subjects are preceded by a description of the model system curly tail.

In Chapter 2, the corry tail stock which is kept at the University of Maastricht is characterized with respect to its phenotypes and penetrance (2.1). Because a background-matched control strain did not exist for the arrby wil mouse, a recombinant strain was constructed, and subsequently characterized (2.2). This yielded additional information regarding the atrly tail trait itself. Because of its matched genetic background, the recombinant strain is studied in combination with curly tail and non-mutant mouse strains in Chapter 4.

The central theme of Chapter 3 is the relationship between axial curvature and neural tube closure. The extent of aberrant curvature in affected carby tail embryos is investigated (3.1). Next, the effects of experimentally altered curvature upon PNP closure in non-mutant mouse embryos, as well as the re-balancing of growth upon curvature in carly tail embryos were studied (3.2). To determine the relationship between axial curvature and neural tube closure in other species, rabbit (3.3), rat and human (3.4) embryos were studied. Finally, the relationship between axial curvature and neurall tube closure as observed in mouse, rat, rabbit, human and chick embryos are placed into a general model (3.4).

In Chapter 4, the role of two determinants in axial curvation are studied in the mouse mutant twrly tail, its recombinant and in non-mutant mouse strains. Cell proliferation is determined in the tal bud at stages preceding the aberrant curvature and at stages preceding the normalized curvature (4.1). Next, the role of glucose and its transporter GLUT-1 in neurulation defects which are due to increased axial curvature is studied (4.2). 


\section{References}

Beaudet AL, Schrrver CR, Sly WS. (1995). Genetics, biochemistry, and molecular basis of variant human phenotypes. In "The metabolic and molecular basis of inherited disease" (C. R. Schriver, A. L. Beaudet, and W. S. Sly, Eds), Vol. 1, pp. 53-118. McGraw-hill, Inc., New York.

Becerra JE, Khoury MJ, Cordero JF Erickson JD (1990) Diabetes mellitus during pregnancy and the tisks for specific birth defects: a population-based case-control study. Pediatrics 85: 1-9

Beier DR, Dushkin $H$, Telle T (1.995) Haplotype analysis of intra-specific backcross curly tail mice confirms the localization of ct to chromosome 4. Mamm Genome 6: 269-272

Bower C, Stanley F (1989) Dietary folate as a risk for neural-tube defects: evidence from a casecontrol study in Western Austria. Med J Aust 150:613-619

Brook FA, Shum ESW, Van Straten HWM, Copp AJ (1991) Curvature of the caudal region is responsible for failure of neural tube closure in the curly tail (ct) mouse embryo. Development 113: 671-678

Clearinghouse. (1991). "Congenitall Malformations Worldwide: a report from the International Clearinghouse for birth defects monitoring systems." Filsevier, Amsterdam.

Cockroft DL (1979) Nutrient requirements of tat embryos undergoing organogenesis in vitro.J Reptod Fert 57: 505-510

Copp AJ (1985) Relationship between timing of posterior neuropore closure and development of spinal neural tube defects in mutant (curly tail) and normal mouse embryos in culture. I Embryol Exp Morphol 88: 39-54

Copp AJ, Brook AJ, Estibeiro JP, Shum ASW, Cockroft DL (1990) The embryonic development of mammalian neural tube defects. Prog Neurobiol 35: 363-403

Copp AJ, Brook FA (1989) Does lumbosacral spina bifida arise by failure of neural folding or by defective canalisation? J Med Genet 26: 160-166

Copp AJ, Brook FA, Roberts HJ (1988a) A cell-type-specific abnormality of cell proliferation in mutant (curly tail) mouse embryos dleveloping spinal neural tube defects. Dievelopment 104: 285-295

Copp AJ, Crolla JA, Brook FA (1988b) Prevention of spinal neural tube delects in the mouse embryo by growth retardation during neurulation. Development 104: 297-303

Cornel MC, De Walle HEK, Haveman TM, Spreen JA, Breed AC, Ten Kate LP (1991) Prevalenties bij de geboorte van meer dan 30 aangeboren afwijkingen in Noord-Nederland. Ned Tijdschr Geneeskd 135: 2032-2036

Comel MC, Ieurquin P, De Walle HEK, Staal-Schteinemachers AL, Beckhuis JR (1997) Epidemiologie wan prenatale diagnostiek en selectieve zwangerschapsafbreking vanwege foetale neuralebuisdefecten in Nederland in vergeliking met andere Europese landen. Ned Tiidschr Geneeskd 141: 2239-2244

Czetzel AE, Dudas 1 (1992) Prevention of the first occurence of neural tube defects by periconceptional vitamin supplementation. N Engl J Med 327: 1832-1835

EUROCAT (1987) Prevalence of neural tube defects in 16 regions of Europe, 1980-1983. The EUROCAT Working Group. Int I Epidemiol 16: 246-251

Flynn ME, Pikalow AS, Kimmelmani: RS, Searls RL (1991) The mechanism of cervical flexure formation in the chick. Anat Embryol 184: 411-420

Golden $J A$, Chernoff $G F$ (1983) Anterior neural wbe closure in the mouse: fuel for disagrement with the classical theory. Clin Res 31: 127A

Golden JA, Chemoft GF (1993) Intermittent pattern of neural tube closure in two strains of mice Teratology 47: 73-80

Goodrum GR, Jacobson AG (1981) Cephalic flexure formation in the chick embryo. I Exp Zool $216: 399-408$ 
Gordon R (1985) A review of the theories of vertebrate neurulation and thein relationship to the mechanics of neural tube birth defects. J Embryol Exp Morphol 89: 229-255

Grüneberg H (1954) Genetical studies on the skeleton of the mouse. VIII curly tall. Genet 52: $52-67$

Harris MJ, Jurilof DM (1997) Genetic landmarks for defects in mouse neural tube closure. Teratology 56:177-187

Hogan A, Heyner S, Charron MJ, Copeland NG, Gibert DJ, Jenkins NA, Thorens B, Schultz GA (1991) Glucose transporter gene expression in early mouse embryos. Development 113 : 363-372

Hunter AGW (1984) Neural tube defects in Eastern Ontario and Western Quebec: demography and family data. Am J Med Genet 19: 45-63

Jacobson AG, Miyamoto DM, Mai SH (1979) Rathke's pouch morphogenesis in the chick embryo. J. Exp. Zool. 207: 351-366

Jacobson AG, Tam PPL (1982) Cephalic neurulation in the mouse embryo analyzed by SEM and morphometry. Anat Rec 203: 375 396

Janerich DT (1978) Shifting genetic patterns in anencephaly and spina bifidu. J Med Genet 15: 101-105

Jaskoll 'T, Greenberg G, Melnick M (1991) Neural tube and neural crest - a new view with timelapse high-definition photomicroscopy. Am J Med Genet 41: 333-345

Juriloff DM, Harris MJ, Tom C, MacDonald KB (1991) Normal mouse strains differ in the site of initiation of closure of the cranial neural tube. Teratology 44: 225-233

Karfunkel P (1974) The mechanisms of neural tube formation. Int Rev Cytol 38:245-271

Lammer EJ, Sever LE, Oakley GP, Jr. (1987) Teratogen update: valproic acid. "Teratology 35: 465-73

Laurence $K M_{x}$ James $N$, Miller. $M$, Campbell $H$ (1980) Increased risk of recurrence of pregnancies complicated by fetal neural tube defects in mothers receiving poor diets, and possible benefit of dietary counselling. Br Med J 281: 1502-1594

Laurence KM, James N, Miller MH, Tennant GB, Campbell H (1981) Double-blind randomised controlled trial of folate treatment before conception to prevent recurrence of neural tube defects. Br Med J 282: 1509-1511

Letts VA, Schork NJ, Copp AJ, Bernfield M, Frankel WN (1995) A curly-tail modifier locus, mct1, on mouse chromosome 17. Genomics 29: 719-724

MacDonald KB, Juriloff DM, Harris MJ (1989) Developmental study of neural tube closure in a mouse stock with a high incidence of exencephaly. Teratology 39: 195-213

Maeda Y, Akazawa S, Akazawa M, Takao Y, Trocino RA, Takino H, Kawasaki E, Yokota $A$, Okuno S, Nagataki $S$ (1993) Glucose transporter gene expression in rat conceptus during early organogenesis and exposure to insulin-induced hypoglycemic serum. Aca Diabetol 30: $73-78$

Matsumoto K, Takao Y, Akazawa S, Yano M, Uotani S, Kawasaki E, Takino H, Yamasaki $H$, Okuno S, Yamaguchi X, Nagataki S (1993) Developmental change of facilitative glucose transporter expression in rat embryonal and fetal intestine. Biochem Biophys Res Comm 193: $1275-1282$

Mills JI: (1982) Malformations in infants of diabetic mothers. Teratology 25: 385-394

Möller F, O'Rahilly R (1987) The development of the human brain, the closure of the caudal neuropore, and the beginning of the secondary neunulation at stage 12. Anat Embryol 176: $413-430$

Neumann PE, Frankel WN, Letts VA, Coffn JM, Copp AJ, Bernfield M (1994) Multifactorial inheritance of neural tube defects: localization of the major gene and recognition of nodifiets in ct mutant mice. Nature Genet 6: 357-362

Papp C, Adam Z, Toth-Pal E, Törok O, Varadi V, Papp Z (1997) Risk of recurrence of ctaniospinal anomalies. J Matern-fretall Med 6: $53-57$ 
Pikalow AS, Flynn ME, Searls NL (1994) Development of cranial flexure and Rathke's pouch in the chick embryo. Anat Rec 238: 407-414

Reece EA, Homko C), Wu YK, Wiznitzer A (1993) Metabolic fuell mixtures and diabetic embryopathy. Clin Perinatol 20:517-532

Sakai $Y$ (1989) Neurulation in the mouse: manner and timing of neural fube closure. Anat Rec 223: $194-203$

Schoenwolf GC (1984) Histological and ultrastructural studies of secondary neurulation in mouse embryos. Am J Anat 169:361-376

Schoenwolf GC, Smith JL (1990) Mechanisms of neurulation: traditional viewpoint and recent advances. Development 109: 243-270

Shiota K (1993) Teratothanasia: prenatal loss of abnormal cenceptuses and the prevalence of warious malformations during human gestation. Birth Defects 29: 189-199

Shum ASW, Copp AJ (1996) Regional differences in morphogenesis of the neuroepithelium suggest multiple mechanisms of spinal neunulation in the mouse. Anat Embryol 194: 65-73

Smith JI, Schoenwolf GC (1997) Neurulation: coming to closure. Trends Neurosci 20: $510-517$

Smithells $R W$, Nevin NC, Seller MI, Sheppard S, Harris $R$, Read AP, Fielding DW, Walker $S$, Schorah C), Whld $f(1983)$ Further experience of vitamin supplementation for prevention of neural tube defect recurrences. Iancet $1: 1027-1031$

Smithells RW, Sheppard S, Wild J, Schorah CJ (1989) Prevention of neural tube defect recurrences in Yorkshire: Fnal report [letter]. Lancet 2: 498-499

Smoak IW, Sadler TW (1990) Embryopathic effects of short-term exposure to hypoglycemia in mouse embryos in vitro. Am J Obstet Gynecol 163:619-624

Takamatsu T, Fuita $S$ (1987) Growth of notochord and formation of cranial and mesencephalic Aexures in chicken embryo. Develop Growtin \& Differ 29: 497-502

Tam PP (1286) A study of the pattern of prospective somites in the presomitic mesoderm of mouse embryos. I Embryol Exp Morphol 92: 269-85

"Tom C, Juriloff DM, Harriss M] (1991) Studies of the effect of retinoic acid on anterior neural tube closure in mice genetically liable to exencephaly. Teratology 43:27-40

Trocino RA, Akazawa S, Takino H, Takao Y, Matsumoto K, maeda Y, Okuno SI, Nagataki $S$ (1994) Cellular-tissue localization and regulation of the GLUT-1 protein in both the embryo and the visceral yolk sac from normal and expermental diabetic rats during the early postimplantation period. Endocrinology 134: 869-878

Van Allen MI, Kalousek DK, Chemoff GF, Juriloff D, Harris M, McGillwray BC, Yong SL, Langlois S, Macleod PM, Chitayat D, Friedman JM, Wilson RD, McFadden D, Pantzar J, Ritchie $\$$, Hall JG (1993) Evidence for multi-site closure of the neural tube in humans. Am J Med Genst $47: 723-743$

Van Straten HWM, Hekking IWM, Consten C, Copp AJ (1993) Intrinsic and extrinsic factors in the mechanism of neurulation: effect of curvature of the body axis on closure of the posterior neuropore. Dexeloptment 117: 1163-1172

Van Straten HWM, Hekking JWM, Copp AJ, Bernfield M (1992) Deceleration and acceleration in the rate of posterior neuropore closure during neurulation in the curly tail (ct) mouse embryo. Anat Embryol 185: 169-174

Van Straten HWM, Janssen HCJP, Peeters MCE, Copp AJ, Hekking JWM (1996) Neural tube closure in the chick embryo is mulciphasic. Dev Dyn 207: 309-318

Van Straten HWM, Peeters MCE, Szpak KFW, Hekking JWM (1997) Initial closure of the mesencephalic neural groove in the chick embryo involves a releasing zipping-up mechanism. Dev Dyn 209: 333-341

Vergel RG, Sanchez LR, Heredero BL, Rodriguez PL, Martinez A.j (1990) Primary prevention of newal tube defects with folic acid supplementation: Cuban experience. Prenatal Diagn 10: $149-152$

Wald N, Sneddon J, Densem J, Frost C, Stone R, Group MVRS (1991) Prevention of neural tube defects: results of the Medical Research Council Vitamin Study. Lancet 338: 131-137 
Wald NJ (1994) Folic acid and neural tube defects: the curtent evidence and implications for prevention. Ciba Foundation Symposium 181: 192-211

Yates JR, Ferguson Smith MA, Shenkin A, Guzman Rodriguez R, White M, Clark BJ (1987) Is disordered folate metabolism the basis for the genetic predisposition to neural tube defects? Clin Genet 31: $279-87$ 
Chapter 1 


\title{
Chapter 2
}

Phenotypes and penetrance in the curly tail

\author{
mouse strain and its recombinant
}

2.1 The curly tail mouse colony at the University of Maastricht

2.2 The recombinant mouse strain 
Chapter 2 


\title{
Chapter 2.1
}

\section{The curly tail mouse colony at the University of Maastricht}

\begin{abstract}
The curly tail mutation arose spontaneously in 1950. In the last decade, this mouse strain has been used as a model to study developmental processes underlying neural tube defects. The penetrance of the mutation is incomplete and several phenotypes are recognized. Since 1988, a curly lail colony is housed at the University of Maastricht; in the present study, the penetrance and phenotypes of this colony are described. Newborns exhibited tail anomalies and spina bifida aperta with an overall penetrance of $55 \%$ and, at embryonic stages, exencephaly has been observed as well.
\end{abstract}

Literature regarding the influence of parental phenotype on penetrance is rather controversial. Breeding experiments in our stock indicated that neither the parental phenotype not the penetrance of the previous generation affected penetrance. This suggests that the colony is genetically homogeneous. However, penetrance and litter size did inctease during five subsequent generations; this might be due to alterations in the envitonmental conditions.

It is concluded that both the average penetrance over the five generations and the observed phenotypes are in concordance with those of other curly tail colonies. Therefore, results of studies in the various corly tail colonies, which reveal parts of the pathogenetic pathway leading to neural tube defects, will complement each other. 


\section{Introduction}

The mouse mutant curly tail is used to study developmental processes underlying neural tube closure. The curly tail phenotype arose spontaneously in a litter of the GFF stock of the Glaxo Laboratonies (Greenford, Middlesex) in 1950 (Grüneberg 1954). The litter constituted of one male with two rigid kinks in the distal half of the tail, two females with spiral twists in the proximal half of their tails and one female of which the tail was only a stump. Only the latter female produced offspring after mating with a male of the CBA/Gr strain. The curly tail strain is derived from this offspring and has been maintained ever since as a random-bred closed collony. Besides tail anomalies, the mouse with the spontaneous mutation exhibited polydactyly. However, this was not transmitted to the carby tail strain.

Several carly lail phenotypes are distinguished at birth and at embryonic stages. In newborns, the phenotypes spina bifida aperta (SB), spirally curled tail, kinked tail and anencephaly have been reported, whereas part of the offspring exhibited no obvious abnormality. At embryonic days E13-E15 a cutled tait, SB and exencephaly have been noticed too, but, the proximal twist in the curled tail is consistent towards dorsal (Grüneberg 1954; Embury et al. 1979; Copp et al. 1982). At E9.5 and E10, an open posterior neuropore (PNP), a dorsally flexed tail bud and an open cranial neural tube (mesencephalic / rhombencephalic region) have been observed. The open PNP at this stage indicates a delay in PNP closure and is thought to be the preliminary phase of both the $\mathrm{SB}$ and tail flexion defects as seen in newborns (Grüneberg 1954; Copp et al. 1982; Copp 1985). Although the kind of anomaly is thus considered identical for $\mathrm{SB}$ and tail flexions, the degree of anomaly varies between an absence of closure and a delay in closure, respectively.

From the original study by Grüneberg (1954), the percentages at which the various phenotypes occur appeared mutually dependent; a frequency at birth of $18 \%$ for curled tail, $0.3 \%$ for $\mathrm{SB}$ and $18 \%$ for $\mathrm{SB}$ together with a curled tail were reported; anencephaly was only sporadically seen. From these data it was concluded that the phenotype $\mathrm{SB}$ is generally associated with a curled tail; likewise, the few anencephalics appeared associated with SB. Because severely affected offspring, like $S B$ and anencephaly, might be missed systematically due to prenatal or perinatal death, the penetrance ( $=$ total percentage of affected phenotypes) was also determined at embryonic stages. This percentage amounted to 50 , which is higher than at birth (37\%), as expected (Grüneberg 1954). After 25 years, the penetrance in the curly iat stock has been reported to be about $50 \%$ both at birth and at embryonic stages (Embury et al. 1979; Copp et al. 1982). The frequencies of the various phenotypes were similar as in the original teport, except for exencephaly 
which occurred more frequently $(9 \%)$ in the study by Embury ct al. (1979) but which could not be confirmed (3\%) by Copp et al. (1982).

The incomplete penetrance in the awry tail strain implies that about half of the mice are bom without any obvious abnormality. Breeding of these unaffected curty tat mice was reported to result in a reduced penetrance in the offspring (Grüneberg 1954; Embury et al. 1979). However, others reported an equal penetrance in offspring of affected and unaffected orrly tail mice (Copp et al. 1982; Neumann et al. 1994). Moreover, selection against the carly lail phenotype for six generations did not decrease the penetrance (Embury et al. 1979). This suggested that the genetic defect which is responsible for the curly tail phenotype was likely identical in affected and unaffected mice, and that the offspring of both phenotypes were equally at risk.

Based on the results of breeding experiments, the genetic defect has been considered an autosomal recessive trait with incomplete penetrance (Grüneberg 1954; Embury et al. 1979). Results of mapping experiments using microsatellite markers indicated that the trait is polygenic, involving a $a$ gene on distal chromosome 4 and at least three modifier genes, for which regions on chromosomes 3, 5 and 17 have been suggested (Neumann et al. 1994; Beier et al. 1995; Letts et al. 1995). Moreover, the $c t$ mutation probably exhibits dominance in the presence of particular combinations of modifier alleles and can therefore not be indicated as completely recessive (Neumann et al. 1994; Beier et al. 1995). Neither the $d$ gene not one of its modifiers have been characterized yet.

Since 1988, part of the arrby tail strain is kept as a separate colony at the University of Maastricht. In order to check whether this colony still exhibited the carly tail features as mentioned above, the colony was characterized with regard to its penetrance and its various phenotypes at embryonic stages and at birth. Moreover, the influences of parental phenotype and parental breeding results upon penetrance were determined.

\section{Material and Methods}

Origin of the curly tail mouse colony at the Animal Care Facility of the University of Maastricht

Two pairs of curby tail mice were originally obtained from H. Grüneberg (Galton Laboratory, University College, London, UK) in 1976 and were maintained as a random-bred closed colony at Guy's Hospital (London). In 1982, some of the mice were taken from London to Oxford. Two females (one with curled tail and one with straight tail) and one male (curled tail) of this latter colony were acquired in 1988 and kept at the Animal Care Facility of the University of Maastricht. 


\section{Breeding conditions}

Mice were housed at a temperature of $21^{\circ} \mathrm{C}$ and humidity of $48-58 \%$. The lightdark cycle was regulated as follows: a light period of 12 hours with a maximal intensity of 200 lux or a 14 hours light period with a maximal intensity of 600 lux. In 1996, the mice were moved within the Animal Care Facility whereby the lightdark regime changed to 12 hours light period with maximally 300 lux. Mice received water and commercial diet pellets (SRM-A diet, Hope Farms, Woerden, the Netherlands) ad libitum. From December '96 through April '97, mice received a diet supplemented with trimethoprim $(500 \mathrm{mg} / \mathrm{kg}$ ) and sulphamethoxazole (2500 $\mathrm{mg} / \mathrm{kg}$ ), and wete vaccinated in March 1997 with the ribosomal Pasieurella pneumotropica vaccin (Animal Care Facility, Maastricht).

\section{Penetrance in the curly tail mouse colony}

Since 1988, the curty tail mouse is kept by random breeding within the closed colony at the University of Maastricht. Each generation consisted of about 10 couples of which the offspring was used for experiments or for breeding the subsequent generation, the latter starting every half year. Up to 1995 the penetrance in the curly tail strain was not systematically registered. In order to chatacterize the colony and to be able to compare its penetrance with original reports regarding the curly tail, all litters and anomalies were registered since then. The first generation registered was the 12 th generation of this particular colony. Because it was presumed that penetrance was decreasing, it was decided to select mice for breeding only if they exhibited an affected phenotype.

From that moment on, all couples of mice were screened for new litters at least once a day. The following parameters were registered: number of living and of dead newborns, number of (living or dead) newborns having one of the following affected phenotypes: SB with curled tail, SB with straight tail, curled tail, kinked tail and anencephaly. After two weeks each litter was checked again for kinked tails, because this anomaly was not always obvious at birth. A curled tail was defined as a clearly visible twist in the tail or a bending of the tail of near $180^{\circ}$; a kinked tail as a clearly visible and palpable kink in the tail.

\section{Breeding experiments}

In order to check whether unaffected curby tail mice were genetically similar to their affected littermates, especially with respect to their ability to transmit the corby tail phenotype, the penetrance in the offspting of the unaffected ones was determined too.

Couples of curly tail mice were subdivided, according to their breeding results, into a high-, mediate- and low-penetrant group. Offspring of five high-penetrant and four low-penetrant couples were bred by brother-sister matings and the penetrance in their litters was determined and compared with the penetrance of their parents. 


\section{Curly tail phenotypes at embryonic stages}

Males and females of the arby tail mouse colony were paired for mating ovemight and checked for a copulation plug the next morning (E0). At E9-10.5, embryos were collected; the numbers of somites were counted and the length of the PNP was measured using an eyepiece graticule fitted on a stereomicroscope. Another series of embryos was derived from phenotypically affected and unaffected parents at E13. The embryos were scored for SB, curled tail and exencephaly, and penetrance was determined. These embryos have been described previously (Van Straaten et al. 1995). Some of these embryos were processed for viewing with a scanning electron microscope (SEM) (Philips 505): fixed in Bodian's fluid, dehydrated in a graded series of ethanols, critical point dried using liquid $\mathrm{CO}_{2}$, attached to aluminium stubs by silver paint and coated with gold/palladium. A newborn exhibiting SB was also processed for the SEM. To study the SB in light microscopy, the newborn was, after viewing with SEM, immersed in ethanol $100 \%$, embedded in Technovit 7100, sectioned and stained with toluidin blue (Van Straaten et al. 1988).

\section{Statistics}

A regression analysis was used to test for systematic and significant changes in penetrance and litter size during the period of registration and during subsequent cleliveries, and to study the correlation between litter size and penetrance. The penetrance and litter size as produced by the unaffected and affected phenotypes were compared using the chi-square test and / test, respectively. The Spearman correlation coefficient was calculated for the high-penetrant respectively lowpenetrant couples and the penetrance in the subsequent generation.

Table 1. Penetrance in the curly tail collony

\begin{tabular}{|c|c|c|c|c|c|c|c|c|c|}
\hline \multirow[t]{2}{*}{ Generation } & \multicolumn{2}{|c|}{ number of } & \multicolumn{5}{|c|}{ number of newborms } & \multirow[t]{2}{*}{ litter size } & \multirow[t]{2}{*}{ penetrance } \\
\hline & couples & litters & living & dead & $S B(\%)$ & $\mathrm{CT}(\%)$ & $\mathrm{KT}(\mathrm{V})$ & & \\
\hline $1(1995)$ & 5 & 29 & 150 & 5 & $10(6)$ & $58(37)$ & $3(2)$ & 5.34 & $46 \%$ \\
\hline $2(1995)$ & 14 & 79 & 414 & 3 & $14(3)$ & $193(46)$ & $4(1)$ & 5.28 & $51 \%$ \\
\hline $3(1996)$ & 9 & 46 & 254 & 8 & $23(9)$ & $111(42)$ & $0(0)$ & 5.70 & $51 \%$ \\
\hline $4(96 / 97)$ & 10 & 56 & 339 & 10 & $24(T)$ & $177(511)$ & $10(3)$ & 6.23 & $60 \%$ \\
\hline $5(1997)$ & 10 & 51 & 337 & 18 & $29(8)$ & $191(54)$ & $2(1)$ & 6.96 & $63 \%$ \\
\hline Average & & & & & $7 \%$ & $47 \%$ & $1 \%$ & 5.94 & $55 \%$ \\
\hline
\end{tabular}

Only 1 newborn with SB exhibited a straight tail; anencephaly was not registered. "The number (and percentage) of each phenotype are indicated. The increases in penctrance and litter size during the five subsequent generations are statistically significant. Abbrevations: $\mathrm{SB}=$ spina bifida aperta, $\mathrm{CT}=$ curled tail, $\mathrm{KT}=$ kinked tail. 


\section{Results}

\section{Curly tail breeding}

The data of breeding five successive generations of curby tail mice are listed in Table 1. The average penetrance of all affected phenotypes taken together amounts to $55 \%$. Most $(86 \%)$ of them exhibited a curled tail only, $12 \% \mathrm{SB}$ together with a curled tail and $2 \%$ a kinked tail (Fig. 1A). In one newborn SB was accompanied by a straight tail. Anencephaly was not seen at all. During the period of data acquisition, the penetrance in the curby lail mouse colony increased significantly from 46 to $63 \%$ and litter size increased from 5.34 to 6.96 (Table 1). However, the contributions of the three phenotypes remained similar (Fig. 1A). No correlation was found between penetrance and litter size (Fig. 2). The average inter-litter period is an indication for the breeding performance and appeated to be 31 days for a couple after first delivery. During the subsequent deliveries of couples, litter size decreased $(\mathrm{P}<0.01$ ), whereas penetrance remained similar (data not shown).

The penetrance in offspring of unaffected phenotypes was determined in the first and fourth generation (Table 2) and appeared identical to that of the affected phenotypes (Table 1). The contribution of each phenotype to penetrance was independent of the parental phenotype (Fig. 1A, B).

Figure 3 shows the relationship between the penetrance of parents and the penetrance as produced by their offspring. All mice of the low-penetrant group produced an increased penetrance in the subsequent generation, whereas all mice of the high-penetrant group produced a decreased penetrance. As a result, the penetrance as produced by the offspring could not be related to their parental penetrance.

Table 2. Penetrance produced by unaffected mice of te curly tail colony

\begin{tabular}{|c|c|c|c|c|c|c|c|c|c|}
\hline \multirow[t]{2}{*}{ Generation } & \multicolumn{2}{|c|}{ number of } & \multicolumn{5}{|c|}{ number of newbontos } & \multirow[t]{2}{*}{ litter size } & \multirow[t]{2}{*}{ penetrance } \\
\hline & couples & livters & living & dead & $\mathrm{SB}(\%)$ & $C T(\%)$ & $\mathrm{KT}(\%)$ & & \\
\hline $1(1995)$ & 5 & 28 & 137 & 3 & $4(3)$ & $57(41)$ & $4(3)$ & 5.00 & $46 \%$ \\
\hline $4(96 / 97)$ & 9 & 40 & 246 & 9 & $18(7)$ & $127(50)$ & $9(4)$ & 6.38 & $60 \%$ \\
\hline Averuge & & & & & $6 \%$ & $47 \%$ & $3 \%$ & 5.81 & $55 \%$ \\
\hline
\end{tabular}

The number (and percentage) of each phenotype are indicated. Abbrewations: $\mathrm{SB}=$ spina bifida aperta, $\mathrm{CT}=$ curled tail, $\mathrm{KT}=$ kinked tail. 

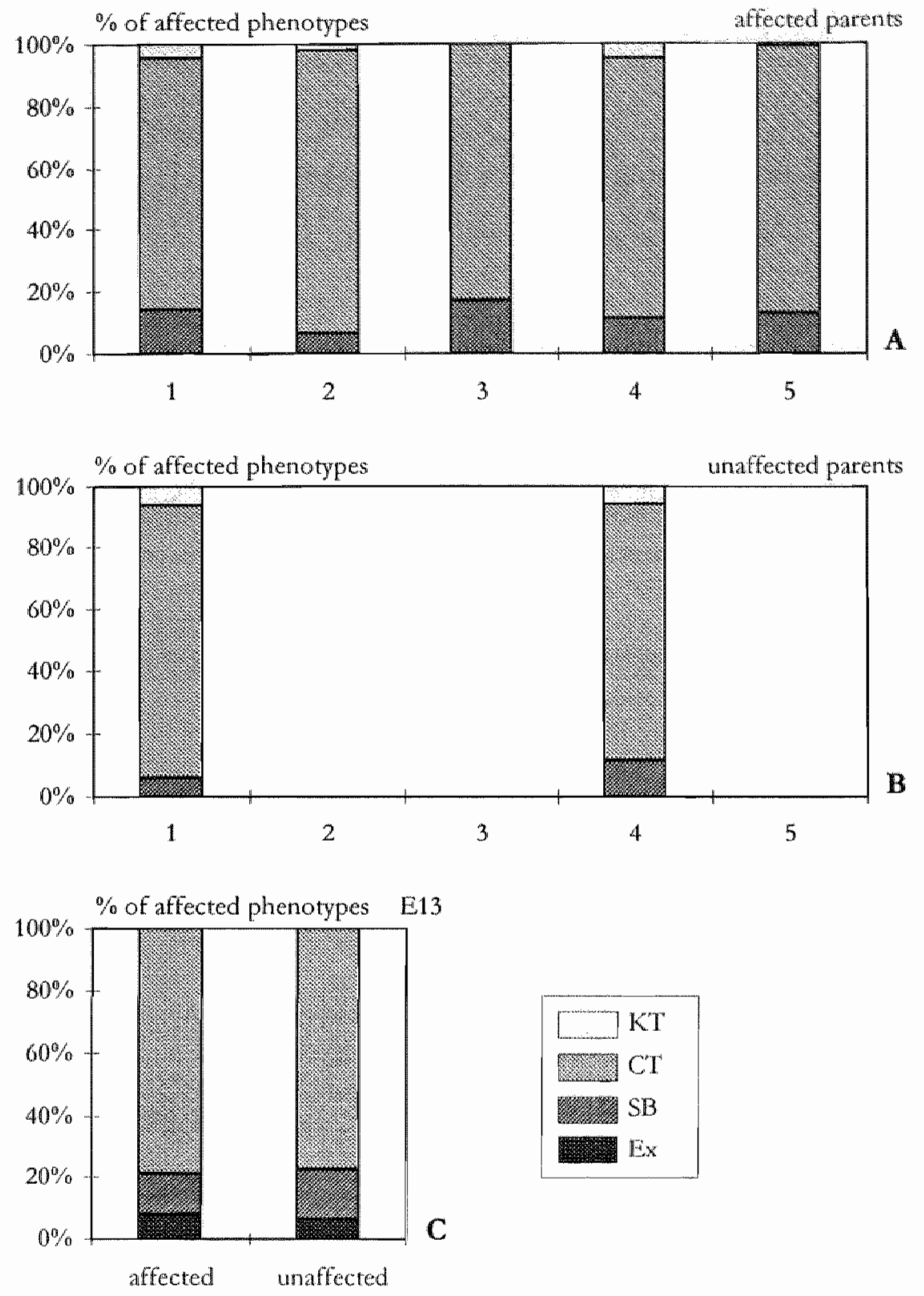

Fig. 1 . The contribution of each phenotype to the penetrance for newborns of five subsequent generations of affected curly tail mice (A), for newborns of two generations of unaffected canty wal mice (B) and at embryonic stages (E13) for offspring of phenotypically affected and unaffected parents $(\mathrm{C})$. Abbreviations: $\mathrm{KT}=$ kinked tail, $\mathrm{CT}=$ curled tail, $\mathrm{SB}=$ spina bifida aperta, $\mathrm{Ex}=$ exencephaly. 


\section{Curly tail phenotypes}

The lengths of the PNPs at E9-E10.5 varied considerably; especially from somite stage 25 onwards, the range increased (Fig. 4). The smallest PNPs were all within the unsegmented caudal region. However, the cranial fusion point of the largest PNPS reached as far as or even proximal to the last formed somites.

The following affected phenotypes were observed at E13: curled tail, SB, exencephaly and combinations of these; kinked tails, which were observed at birth, were not observed at E13 (Fig. 5). The penetrance at E13 and at birth appeared to be similar. The frequencies of the various phenotypes in litters of affected and unaffected classified parents are extracted from a previous study (Van Straaten et al. 1995) and listed in Table 3 and Figure $1 \mathrm{C}$.

A newbotn exhibiting $S B$ viewed with SEM revealed that the neural tissue was covered by a membraneous structure. This observation was confirmed by light microscopy. When the $\mathrm{SB}$ was covered with skin within a few days, a newbom appeared to be able to survive, to function normally and to yield similar breeding performances as its curled tailed littermates. Some (less than 20\%) of the mice which had a curled tail at birth did not show any tail anomaly at weaning, indicating that the curled tail could uncoil during the first three weeks. No additional abnormality was reported after the screening at birth.

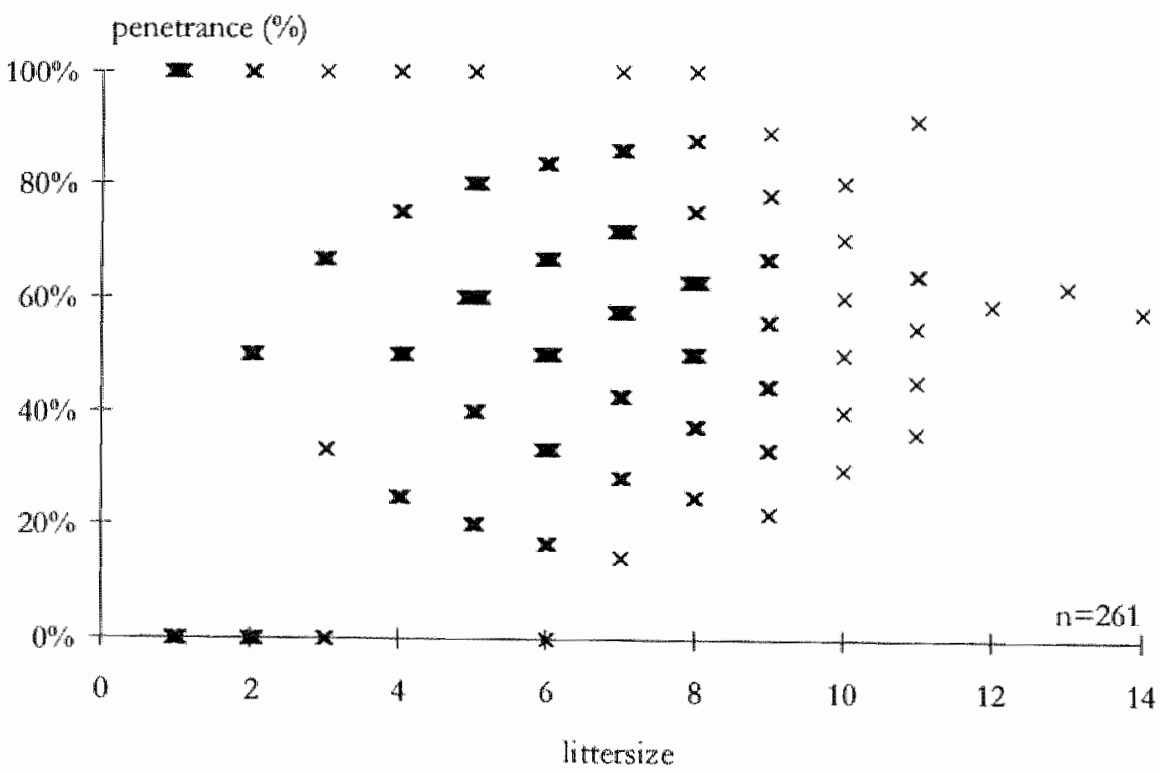

Fig. 2. Relationship between litter size and penetrance. Each mark represents an individual litter. Marks from litters with identical size and penetrance are placed close to each other. No correlation between the parameters was found. 


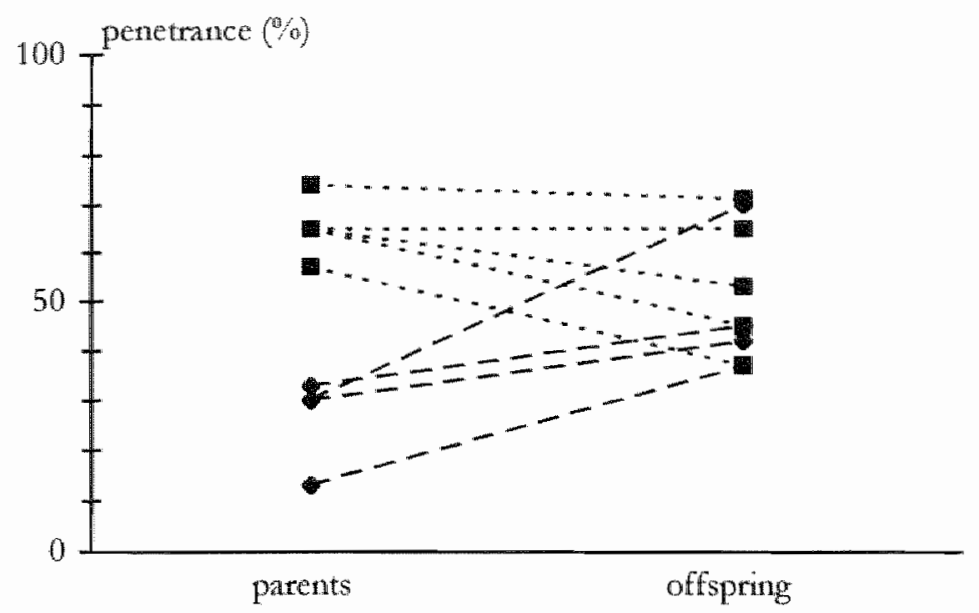

Fig. 3. Relationship between parental and offspring penetrance. Four low-penetrant and five high-penetrant couples were selected and the penetrance as produced by their offspring was determined. Each line connects the penetrance of a given parental couple with the penctrance of its offspring. Although the penetrance of the parents differed, the penetrance as produced by their offspring tended towards the mean.

\section{Discussion}

\section{Penetrance and phenotypes in the curly tail mouse colony}

During the course of this study, the curly lail mouse colony at the University of Maastricht exhibited an average penetrance of $55 \%$. Most of the affected offspring had a curled tail. Both the penetrance and the observed phenotypes appeared to be similar to other reports regarding this mouse mutant (Grüncberg 1954; Embury et al. 1979; Copp et al. 1982). Likewise, the abnormal sized PNP at E9-10.5 as well as the curled tail, SB and exencephaly at E13 turned out to be alike those reported previously (Grünebetg 1954; Copp 1985; Van Straten et al. 1992).

Table 3. Penetrance in the curly tail colony at the embryonic stage $E 13$

\begin{tabular}{|c|c|c|c|c|c|c|c|c|}
\hline \multirow{2}{*}{$\begin{array}{l}\text { Parental } \\
\text { phenotype }\end{array}$} & \multirow{2}{*}{$\frac{\text { number of }}{\text { litters }}$} & \multicolumn{5}{|c|}{ number of newborns } & \multirow[t]{2}{*}{ litter size } & \multirow[t]{2}{*}{ penctrance } \\
\hline & & living & dead & $\operatorname{Ex}(\%)$ & $S B(\%)$ & $\mathrm{Cl}^{+}(\%)$ & & \\
\hline affected & 10 & 66 & 11 & $3(4)$ & $5(0)$ & $30(39)$ & 7.70 & $49 \%$ \\
\hline unaffected & 17 & 104 & 11 & $4(3)$ & $10(9)$ & $48(42)$ & 6.76 & $54 \%$ \\
\hline Average & & & & $4 \%$ & $8 \%$ & $41 \%$ & 7.11 & $52 \%$ \\
\hline
\end{tabular}

The number (and percentage) of each phenotype are indicated. Abbreviations: $\mathrm{Ex}=$ exencephaly $\mathrm{SB}=$ spina bifida aperta, $\mathrm{CT}=$ curled tail. 


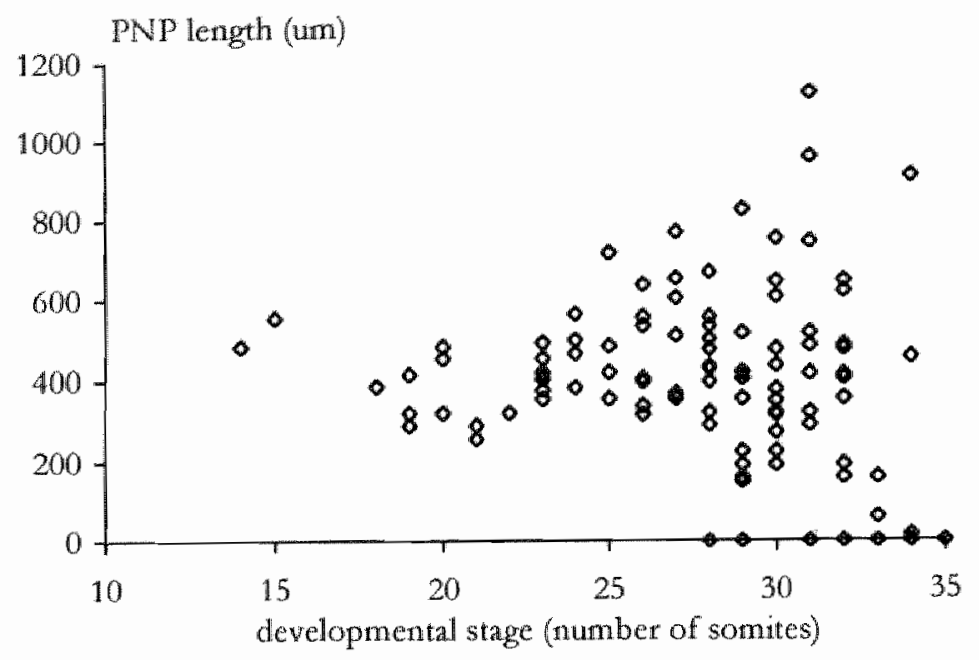

Fig. 4. Length of the posterior neutopore in E9-10.5 embryos. Individual data points are plotted as dots, except for the 4 cmbryos with closed PNP at somite stage 34 which are combined in 1 dot. The length of the PNP demonstrates an wide range of values.

One of the previously mentioned curly tail phenotypes is anencephaly. It occurs only sporadically (Grüneberg 1954; Copp et al. 1982) and was not detected at all in the present study. This could be due to the habits of the females to eat their abnormal and dead offspring. Since exencephaly, which is a preliminary stage of anencephaly, was observed in $4 \%$ of the E13-embryos, it is unlikely that this cranial neural tube defect has diminished in the Maastricht colony. The prevalence of exencephaly corresponded to the number reported by Copp et al. (1982).

In the present study, all except one newborns which exhibited $S B$ also had a curled tail. Such a high degree of association has already been described by Grüneberg (1954). SB and curled tail are thought to share a common pathogenetic mechanism recognizable at embryonic stages by an abnormal closure of the PNP. An absence of PNP closure would consequently result in SB and, because the defect is at the base of the tail bud, would disturb the outgrowth of this structure as well. If the PNP closure is only delayed, the outgrowth of the tail bud would be disturbed solely (Grüneberg 1954; Copp et al. 1982; Copp 1985). Although SB and curled tail therefore only differ in severity and not in kind of anomaly, a less tight association has recently been suggested since tetinoic acid (RA) administration to pregnant carly wil mice resulted in an increased percentage of embryos exhibiting $S B$ with a straight tail (Chen et al. 1994). This effect is not inevitably contradictory to the joint mechanism because it might be due to the fact that the period of RA-mediated. prevention is more resticted for SB than for curled tail. 

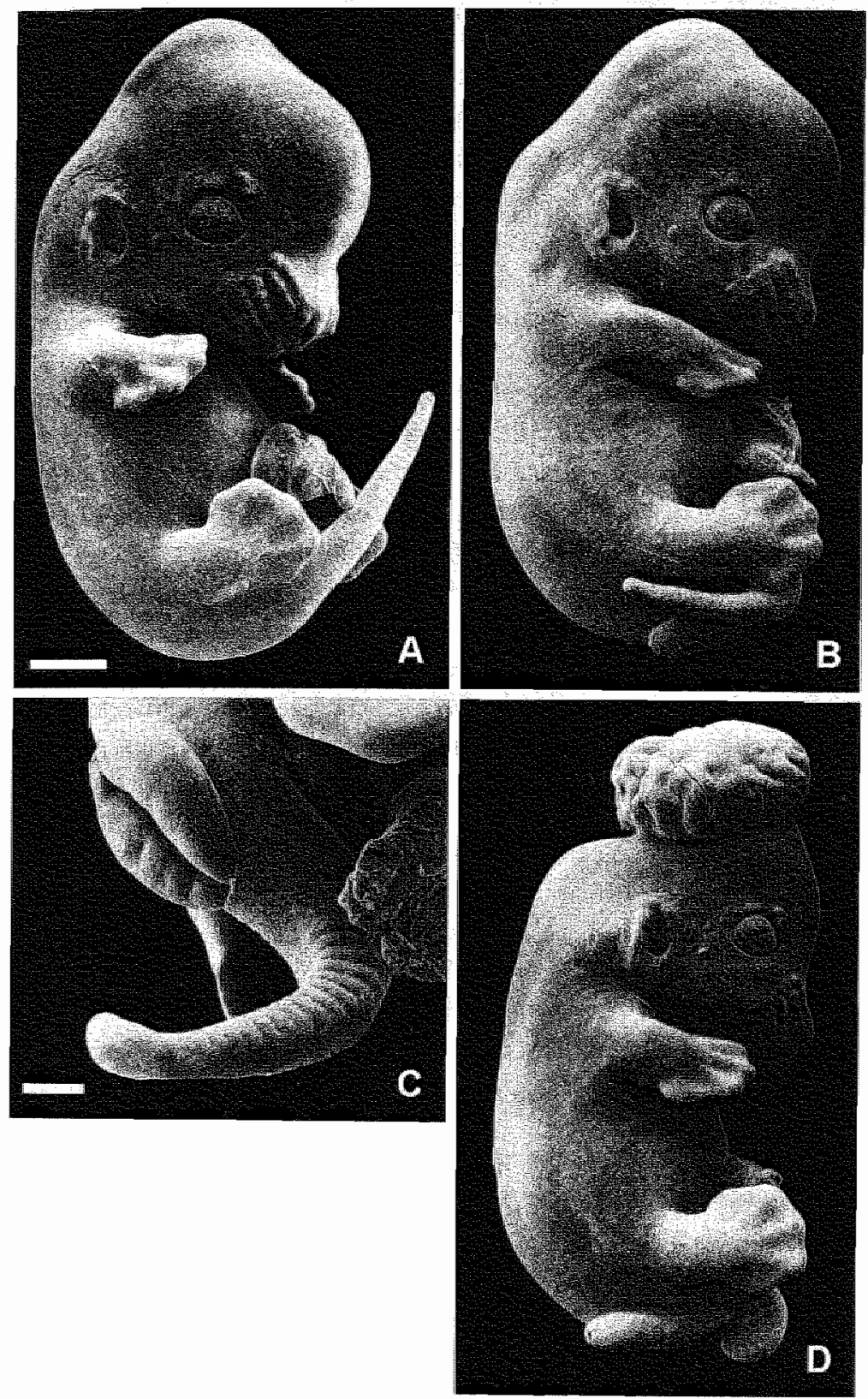

Fig. 5. SEM photographs of E13 embryos. A. Embryo classified as unaffected phenotype. Bar $=1.0 \mathrm{~mm}$. B. Embryo exhibiting SB together with a dorsally flexed tail. C. Detail of an opening in caudal neural tube together with a bent tail. Bar $=0.3 \mathrm{~mm}$. D. Embryo of the most severely affected phenotype exhibiting exencephaly, SB and a curled tail. 
It can be concluded that, in our carby tail mouse colony, the average penetrance and the observed phenotypes, as well as the association between phenotypes correspond with previously reported data.

\section{Subgroups of curly tail mice are probably genetically homogeneous}

In the present study, the penetrance and phenotypes at E13 and at birth appeared to be independent of the parental phenotype. It contradicts data from previous studies, in which breeding of unaffected mice resulted in reduced penetrance and was accompanied by a shift in phenotypes (Grüneberg 1954; Embury et al. 1979). However, subsequent studies could not confirm this (Copp et al. 1982; Neumann et al. 1994), nor did selection against the affected phenotype for several generations decrease penetrance (Embury et al. 1979). Since the owty tail mouse strain has been maintained as a closed colony for decades and out colony is derived from these mice, a high degree of imbreeding might be expected, and the breeding results of a particular couple would therefore not influence the breeding results of their offspring. This was demonstrated in the present study as the penetrance produced by the offspring was not related to the penetrance of their parents. Additionally, the curly lail mouse has recently been demonstrated to be homozygous for 22 marker loci, which are used for genetic quality control (Neumann et al. 1994). Therefore, we suppose that curly tail mice, whatever their phenotypes are, are genetically closely similar and, as a consequence, equally transmit the risk on anomalies to their offspring.

In contrast, differential effects have recently been reported when phenotypically affected and unaffected dams were exposed to agents during early pregnancy: RA had a reduced SB-preventive effect upon offspring of affected dams (Chen et al. 1994) and methionine teduced the embryonic weight of offspring of unaffected but not of affected dams (Van Straaten et al. 1995). "This suggests that some differences in genetic backgtound are still present and that these can be triggered by the two agents.

\section{Penetrance and litter size increased during subsequent generations}

Penetrance appeared to increase significantly during breeding of five successive generations. Due to consequent selection in favor of the affected phenotype for subsequent generations, such an increase in penetrance might be expected if genetical inhomogeneity exists between unaffected and affected curby tail mice. However, as stated above, this is not confirmed by our breeding results.

It has previously been suggested that an increase in penetrance likely correlates with an inctease in severity of anomalies and consequendy, due to the intra-uterine death of severely affected ones, in a decreased litter size (Neumann et al. 1994). However, in the present study, both penetrance and litter size increased, indicating that increased intra-uterine death is unlikely to play a role. Moreover, because the contributions of the various phenotypes remained similar, a shift towards severely 
affected phenotypes is improbable. The increased litter size and penetrance might therefore be the result of an increased survival of all affected phenotypes.

An increased litter size and survival of the affected phenotypes might result from better parental condition due to changes in environmental factors. Several studies have indeed demonstrated a relationship between environmental factors and penetrance: exposure during early pregnancy to $R A$, hydroxyurea, mitomycin $C$, raised body temperature or food deprivation, resulted in a changed penetrance (Seller et al. 1979; Seller and Perkins 1983, 1986; Seller and Perkins-Cole 1987; Copp et al. 1988). During breeding the fourth generation, the carby tail mice were moved within the Animal Care Facility, whereby the light-dark cycle and light intensity changed, and stress caused by the number and frequency of people entering the room, ether exposure and vicinity of rats was decreased. Additionally, mice of the fourth generation received a supplemented diet and were waccinated. The acute effects of the vaccination resulted in sick mice for several days, but afterwards the mice seemed to have got an improved condition. This can explain that the increase in penetrance in this period appeared to be enthanced. The improved condition is confirmed by the fact that the mean inter-litter period was 31.8 days before vaccination, whereas it appeared only 28.9 days thereafter. The influence of parental condition on breeding results is also suggested from other data: it appeared that litter size decreased during subsequent deliveries, and thus during parental aging, which is likely associated with a decrease in parental condition.

From the present study it is concluded that the penetrance of $55 \%$ and the phenotypes curled and kinked tail, spina bifida aperta and exencephaly in the curly tail mouse colony at the University of Mastricht are similar to those of their ancestors. Additionally, all cwrly tail mice, irrespective of their parental phenotype and parental breeding results, are equally at risk for an affected phenotype, which is indicative for a genetically homogeneous colony. During five successive generations described in the present study, penetrance increased, which might be the result of altered environmental factors. Since our curly tail mouse colony appears comparable to other colonies, data from the various colonies, which reveal parts of the pathogenetic pathway leading to neural tube defects, might complement cach other.

\section{References}

Beier DR, Dushkin H, Telle T (1905) Haplotype analysis of intra-specific backcross curly tail mice confirms the localization of ct to chromosome 4. Mamm Genome 6: 269-272

Chen WH, Morriss-Kay GM, Copp AJ (1994) Prevention of spinal neural tube defects in the curly tail mouse mutant by a specific effect of retinoic acid. Dev Dyn 199: 93-102 
Copp A] (1985) Relationship between timing of posterior neuropore closure and development of spinal neural tube defects in mutant (curty ast) and normal mouse embryos in culture. I Embryol Exp Morphol 88: 39-54

Copp AJ, Crolla JA, Brook FA (1988) Prevention of spinal neural tube defects in the mouse embryo by growth retardation during neurulation. Development 104: 297-303

Copp AJ, Seller MJ, Polani PE (1982) Neural tube development in mutant (curly tail) and normal mouse embryos: the timing of posterior neuropore closure in vivo and in witra. I Embryol Exp Morphol 69: 151-167

Embury S, Seller MJ, Adinolf M, Polani PE (1979) Neural tube defects in curly tail mice. 1 . Incidence, expression and similarity to the human condition. Proc. R. Soc. London. B 206: $85-94$

Grïneberg H (1954) Genetical studies on the skeleton of the mouse. VIII curly tail. I Genet 52: $52-67$

Letts VA, Schork NJ, Copp AJ, Bernfield M, Frankel WN (1995) A curly-tail modifter locus, mat1, on mouse chromosome 17. Genomics 29: 719-724

Netumann PE, Frankel WN, Letts VA, Coffin JM, Copp A], Bernfield M (1994) Multifactorial inheritance of neural tube defects: localization of the major gene and recognition of modifiers in ct mutant mice. Nature Genet 6:357-362

Seller MJ, Embury S, Polani PE, Adinolf M (1979) Neural tube defects in curly-tail mice. II. Effect of maternal administration of vitamin A. Proc R Soc Lond B Biol Sci 206: 95 107

Seller MJ, Perkins KJ (1983) Effect of hydroxyurea on neural tube defects in the curly-tail mouse. J Craniofac Genet Dev Biol 3: 11-17

Seller MJ, Perkins KJ (1986) Effect of mitomycin $C$ on the neural tube defects of the curly tail mouse. Teratology 33: 305-309

Seller MJ, Perkins-Cole KJ (1987) Hyperthermia and neural tube defects of the curly-tail mouse. J Craniofac Genet Dev Biol 7: 321-30

Van Straten HWM, Blom HJ, Peeters MCE, Rousseau AM], Cole KJ, Seller MJ (1995) Dietary methionine does not recluce penetrance in curly tail mice but causes a phenotype-specific decrease in embryonic growth. J Nutr 125: 2733-2740

Van Straaten HWM, Hekking JWM, Copp AJ, Bernfield M (1992) Deceleration and acceleration in the rate of posterior neuropore closure during neurulation in the curly tail (o) mouse embryo. Anat Embryol 185: 169-174

Van Strataten HWM, Hekking JWM, Drukker J (1988) A HCl-toluidine blue staining procedure specific for nuclei, mitotic figures and axons in GMA embedded embryonic neural tissue. Stain technology $362: 360-362$ 


\title{
Chapter 2.2
}

\section{The recombinant mouse strain}

\begin{abstract}
In studies regarding the pathogenetic pathway leading to neutal tube defects (NTD) in the mouse mutant curly tail, features (e.g. the length of the posterior neuropore) of this strain are compared with those of a control strain. However, the genetic background of any control strain differs from that of the corly tail, reducing the significance of such comparisons. Because the penetrance in the carly tail strain is incomplete (about $55 \%$ is affected), phenotypic differences can also be studied within the strain. However, this apptoach has a disadvantage since all mice carry the curby tail genotype. To overcome these problems, a congenic strain is desirable, in which the curly tail genotype is present on the genetic background of a control strain. In the present study, the cross-intercross breeding design was used to construct such a background-matched curly tail mouse strain. Initially, one line was set up for the $\mathrm{CBA} / \mathrm{J}$ and one line for the BALB/c background, but only the latter was continued. The penetrance after each cross-intercross cycle amounted to 1.7 $4 \%$. Subsequent inbreeding the offspring of the intercross in the BALB/c line increased the penetrance considerably. In both lines penetrance was also determined at embryonic stages and appeared higher than at birth. It was also found that the curly tail mutation did not have a completely recessive pattern of heredity with respect to phenotypes at birth. Moreover, the breeding results suggest that, besides the $t$ gene, more than 3 modifier genes are involved in the carly tail trait. The impact of each modifier is presumably highest in the homozygous state. It is concluded that the recombinant strain indeed carries the arly tail mutation on a $\mathrm{BALB} / \mathrm{c}$ genetic background and thus will be helpful in revealing the ourly tail pathogenetic pathway leading to NTD.
\end{abstract}




\section{Introduction}

The mouse mutant arby lail develops spinal neural tube defects (NTD) and is therefore used to study developmental mechanisms of neurulation. The mutation arose spontaneously and the genetic defect has not been characterized so far. The penetrance in the carly tail mouse strain is incomplete, resulting in both unaffected and affected phenotypes (Gruneberg 1954; Copp 1985). Originally, the defect was considered monogenic, with a pattern of heredity of curly tail phenotypes in newborns pointing towards a recessive allele (Gruneberg 1954). Nowadays, the defect is considered polygenic, involving a $a t$ gene on distal chromosome 4 , and at least 3 modifier genes for which chromosomes 3,5 and 17 have been nominated (Neumann et al. 1994; Letts et al. 1995). Additionally, the heredity of phenotypes in newborns did not behave as completely recessive (Neumann et al. 1994; Beier et al. 1995)

Attempts have been made to elucidate the pathogenetic pathway leading to NTD. For that purpose, features (e.g. the length of the posterior neuropore (PNP)) of the arry tail mice have been compared with those of other mouse strains. However, because the genetic background of nowadays used inbred mouse strains likely differs considerably from that of the curly tail mouse, it is impossible to ascribe an observed strain difference to the curly tail mutation and to rule out the role of other genes. Part of this problem has been overcome by making comparisons between individuals with and without affected phenotypes from the curby tail mouse strain, which is possible due to the incomplete penetrance. However, the strain is considered genetically homogeneous, which implies that all mice are thought to carry the same genetic defect, although they exhibit different phenotypes. Early defects in the pathogenetic cascade are therefore considered hard to detect.

It would be most preferable to study two mouse strains with identical genetic constitution except for one or more of the genes responsible for the curby tail defect. Because such a congenic strain did not exist for the arib tail, we decided to create one. For that purpose, the genes responsible for the curty tail phenotype were combined with the genetic background of a control strain. Since the carby tail genes are unknown, selection in favor of these genes in the breeding-design could be done on the phenotype only. The pattern of heredity of curby tail phenotypes had been shown to resemble most a pattern of a recessive allele (Grüneberg 1954; Embury et al. 1979). Therefore, a cross-intercross breeding system had to be performed in order to increase the genetic background of the control strain in the presence of the carty tail phenotype.

The penetrance and amb tail phenotypes are affected by the genetic backgtound as demonstrated by the variation in penetrance from 0 for CAST/Ei, to $13-18 \%$ for 
the $\mathrm{C} 57 \mathrm{Bl} / 6$ and $8-24 \%$ for the $\mathrm{BALB} / \mathrm{c}$ in a cross-backcross system in which each cross is followed by a backcross to the awby tail strain (Embury et al. 1.979; Neumann et al. 1994; Beier et al. 1995; Letts et al. 1995). Therefore, it was decided to start with two separate lines, for which the $B A L B / C$ and the $C B A / J$ mouse control strains were selected: the $B A L B / c$ because of its penetrance in the crossbackcross system (see above) and the CBA/J because CBA was one of the curby tail parental strains (Grüneberg 1954). In the present study, the cross-intercross breeding-design is described as well as the results from four generations, especially with respect to penetrance and observed phenotypes at birth and at embryonic stages. Because the new strain is not congenic (= differs only at carly tail loci) yet, it will be referred to as recombinant.

\section{Materials and Methods}

\section{Mouse strains and their housing}

The mutation which was at the origin of the mouse strain nowadays known as curly tail arose spontaneously in 1950 (Gtüneberg 1954). The origin, penetrance and phenotypes of the curly tail mouse colony, as kept at the Animal Care Facility at the University of Maastricht, are described in Chapter 2.1. The BALB/c and CBA/J mice were obtained commercially (Charles River Wiga GmbH, Germany).

Mice were housed at a temperature of $21^{\circ} \mathrm{C}$ and humidity of $48-58 \%$. They were exposed to one of the following light-dark regimes: a 12 hours light period with a maximal intensity of 200 lux or a 14 hours light period with a maximal intensity of 600 lux. In 1996, the mice were moved within the Animal Care Facility whereby the light-dark regime changed to 12 hours light period with maximally 300 lux. Mice received water and commercial diet pellets (SRM-A diet, Hope Farms, Woerden, the Netherlands) ad libitum. From December '96 through April '97, mice received a diet supplemented with trimethoprim $(500 \mathrm{mg} / \mathrm{kg})$ and sulphamethoxazole $(2500$ $\mathrm{mg} / \mathrm{kg}$ ), and were vaccinated in March 1997 with the ribosomal Pasteterella pheumotropica vaccin (Animal Care Facility, Maastricht). For identification, numbered ear tags were used, which were applied to mice at 9-weeks of age.

\section{Construction of two separate lines of the recombinant mouse strain}

The new strain was constructed via an $\mathrm{M}$-line, which implies a cross-intercross design as illustrated in Figure 1. Initially, two separate M-lines were constructed, one with $\mathrm{BALB} / \mathrm{c}$ and one with $\mathrm{CBA} / \mathrm{J}$ as the first parent. For the second parent, curby tail mice which exhibited an affected phenotype were selected. The first mating was followed by an intercross of the heterozygous offspring at the age of 10 weeks. The descendants of the intercross were subdivided according to their phenotype into affected (see beyond) and unaffected. At the age of 10 weeks, mice exhibiting an affected phenotype were selected for mating with the first parent in the second 


\section{Construction of the BALB/c - curly tail M-line}

BAIB/c:ardytal

$50: 50$

$75: 25$

$87: 13$

$94: 6$

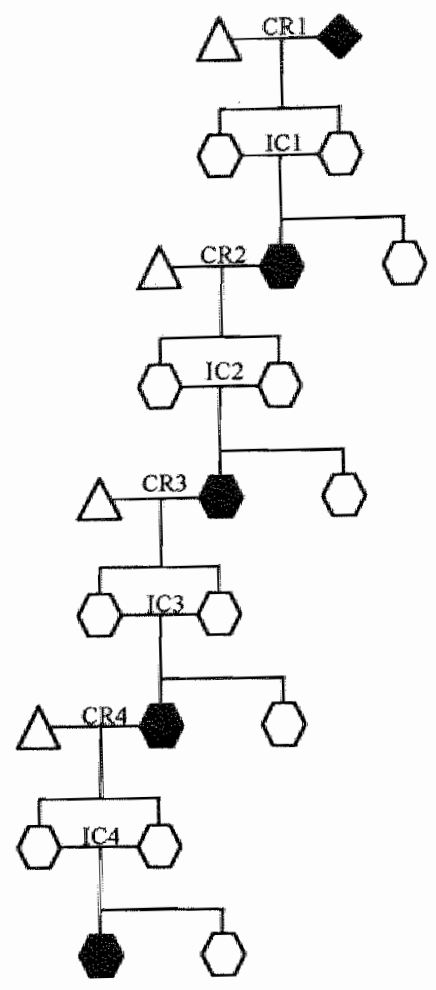

Identity

CRI

IC1

$\mathrm{CR} 2$

102

CR3

IC3

CRA

IC4

rnouse strains

phenotypes

$\triangle \mathrm{BALB} / \mathrm{C}$

$\square$ unaffected

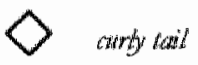

affected

(BALB/c-ath'twit recombinant

Fig. 1. Cross-intercross design which is used to construct the recombinant strain. The first column indicates the proportion of the generic background being theoretically derived from $\mathrm{BALB} / \mathrm{c}$ or amby wail "The column "identity" lists the names used for the recombinant mice at respective rows. The names of the matings are indicated above the lines. "The mouse strains are indicated with symbols, which are open or closed depending on the phenotype. The CBA/J line had an identical design up to intercross 3 ; the line was stopped thereafter. 
cross, again followed by an intercross. In the present study, four cross-intercross cycles are described for the BALB/c line, and 3 cycles for the $C B A / J$ line. The former is still under construction, while the latter was stopped.

\section{Inbreeding of the second and third generation}

Males and females of the affected offspring of the second cross-intercross cycle in the BALB/c line were mated to produce the intercross-2 F1 generation (Fig. 2); affected phenotypes in this offspring were accordingly selected and mated. In this $\mathrm{BALB} / \mathrm{c}$ - curly tail recombinant- 2 line five generations are currently produced. In the recombinant-3 line, four generations were created by inbreeding the offspring of the third cross-interctoss cycle of the M-line. The recombinant- 4 line has just been started, and therefore no data of this line are reported. For the $\mathrm{CBA} / \mathrm{J}$ line, no recombinant lines were created.

\section{Phenotypes and penetrance}

All mouse couples in the $M$-lines and recombinant-lines were checked for new litters at least once a day. The number of living and dead newborns were registered and their phenotypes were classified as unaffected or affected; the latter was subdivided into kinked tail, curled tail, spina bifida aperta (SB) with curled tail and $\mathrm{SB}$ with straight tail. After two weeks the tails were studied again because the kinked tail anomaly was not always obvious at birth. A curled tail was defined at birth as a clearly visible twist in the tail or a bending of the tail of near $180^{\circ}$ and a kinked tail as a clearly visible and palpable kink in the tail which was still present 2 weeks later and was not classified as curled tail. For each generation in the M-lines and in the recombinant lines, the frequencies at which the various phenotypes occurred were determined as well as the proportion of the newborns exhibiting an affected phenotype (= penetrance).

The relationship between parental phenotype and penetrance was determined in the F4 of the BALB/C - curby tail recombinant-2 line (Fig. 2) and in the F3 of the recombinant-3 line by additionally mating the unaffected mice. Moreover, some of the matings between affected ones regarded kinked tail $x$ kinked tail, curled tail $x$ curled tail or SB $\times$ SB.

The intercross -2 in both the $C B A / J$ and $B A L B / c$ M-lines and the intercross- 3 in the $B A L B / C M$-line were repeated and offspring was examined at embryonic stages. For that purpose, mice were paired for mating overnight and the females were checked for copulation plugs the next morning. On embryonic day E13, females were sacrificed by cervical dislocation and their uterus horns werc temoved. The embryos were dissected free from the extraembryonic membranes in prewarmed $\left(37^{\circ} \mathrm{C}\right)$ Hanks' buffered salt solution. The number of liwing embryos and resorptions as well as their phenotypes were registered. Some embryos of the F3 recombinant-3 line were isolated on E9-10 accordingly; their numbers of somites 


\section{Construction of the BALB/c-curly tail recombinant-2 line}

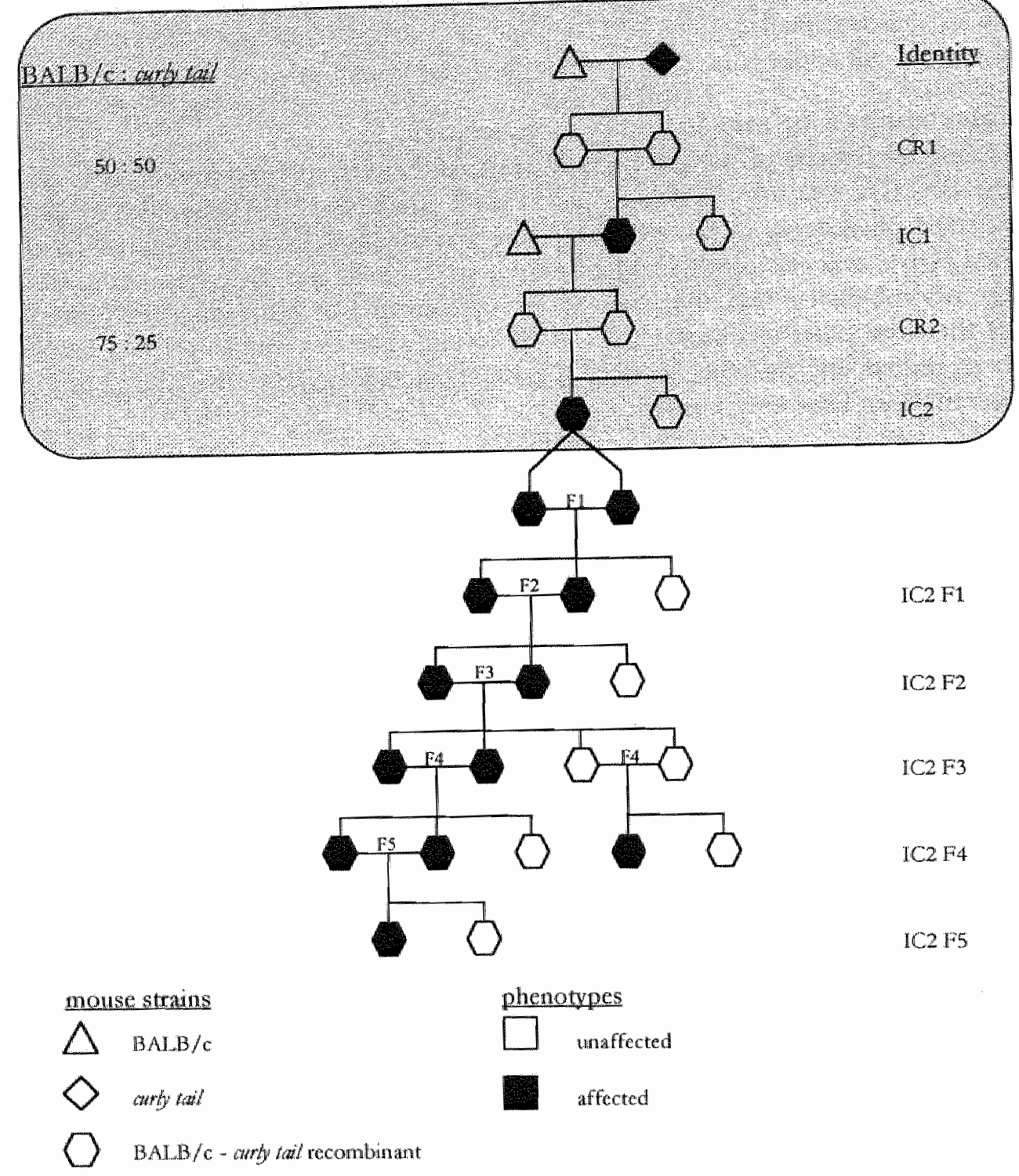

Fig. 2. Design used to create the recombinant-2 line. After the second cross-intercross cycle of the M-line ( $=$ grey box, from Fig. 1) the affected phenotypes were paired for mating. Each next generation was created by mating of affected phenotypes. Additionally, unaffected IC2 F3 phenotypes were pared for mating in the intercross- 2 F4. The names of the generations are indicated above the lines. The tecombinant-3 line was created accordingly after the third crossintercross cycle of the $M$-line. 
were counted and the length of the PNP was measured using an eyepiece graticule fitted on a stereomicroscope.

\section{Statistics}

Differences in penetrance between groups were tested using chi-square test and were considered statistically significant if $\mathrm{P}<0.05$. The changes in litter size and penetrance in subsequent generations of both recombinant lines were tested using regression analysis.

\section{Results}

\section{Penetrance and phenotypes of the CBA/J and BALB/c M-lines}

In the present study, the results of 3 cross-intercross cycles in the $C B A / J$ line and 4 cycles in the BALB/c line are described. The results of the crosses are listed in Table 1. Litter sizes and percentages of dead newborns were rather constant in both lines. Some of the offspring of both lines exhibited a kinked tail. Litters with such an affected newborn were bred in the next intercross by brother-sister matings; however, penetrance did not change significantly and these lines were stopped.

In Table 2, the results of the intercrosses of the $\mathrm{CBA} / \mathrm{J}$ and $\mathrm{BAL} B / \mathrm{c}$ line are listed. The phenotypes observed were $\mathrm{SB}$ with a curled tail, curled tail and kinked tail; the one $\mathrm{SB}$ in the $\mathrm{CBA} / \mathrm{J}$ line also exhibited anencephaly. In the $\mathrm{CBA} / \mathrm{J}$ line, penetrance varied from $1.8 \%$ to $2.8 \%$, and the contributions of the various phenotypes shifted in the subsequent cycles from curled tail towards kinked tail (Fig. 3A). In the BALB/c line, penetrance amounted to 1.7-4.0\% (Table 2). Like in the $\mathrm{CBA} / \mathrm{J}$ line, the phenotypes shifted from curled tail towards kinked tails; however, the shift was less pronounced after three cross-intercross cycles (Fig. 3).

Initially, the $\mathrm{CBA} / \mathrm{J}$ and $\mathrm{BALB} / \mathrm{c}$ lines were split in a male and female sub-line after each cross, depending on the gender of the first parent. However, no differences in penetrance were observed between matching sub-lines in the intercrosses, and the data of the sub-lines are therefore fointly presented in Table 2 .

\section{Penetrance and phenotypes of the BALB/c - curly tail recombinant lines}

During the course of the 5 generations which were created in the BALB/c - curly tail recombinant-2 line (Fig. 2), the penetrance increased significantly to $48.5 \%$, while litter size decreased (Table 3). The observed phenotypes comprised SB, of which $18 \%$ exhibited a straight tail, curled tails and kinked tails. The contribution of kinked tails to the penetrance decreased significantly in subsequent generations, whereas $\mathrm{SB}$ increased (Fig. 4A). 
Table 1. Results of the crosses in the CBA/J and BALB/c line

\begin{tabular}{|c|c|c|c|c|c|c|c|}
\hline \multirow[t]{2}{*}{ Cross } & \multicolumn{2}{|c|}{ number of } & \multicolumn{3}{|c|}{ number of nexpoms } & \multirow[t]{2}{*}{ livter size } & \multirow[t]{2}{*}{ penetrance } \\
\hline & $\mathrm{E} / \mathrm{m}$ & litters & living. & dead $(\%)$ & affected & & \\
\hline$C R \| C D A / J$ & $10 / 7$ & 10 & 69 & $4(5)$ & 0 & 7.30 & $1.4 \%$ \\
\hline $\mathrm{CR2CBA} / \mathrm{J}$ & $27 / 9$ & 25 & 159 & $16(9)$ & 2 & 7.00 & $1.1 \%$ \\
\hline $\mathrm{CR} 3 \mathrm{CBA} / \mathrm{J}$ & $62 / 7$ & 119 & 615 & $97(14)$ & 1 & 5.98 & $0.1 \%$ \\
\hline CR1 BALB/C & $11 / 5$ & 10 & 57 & $5(8)$ & 1 & 6.20 & $1.6 \%$ \\
\hline $\mathrm{CR} 2 \mathrm{BALB} / \mathrm{C}$ & $21 / 16$ & 26 & 178 & $14(7)$ & 0 & 7.38 & $0.0 \%$ \\
\hline $\mathrm{CR} 3 \mathrm{BACB} / \mathrm{C}$ & $55 / 25$ & 86 & 582 & $20(3)$ & 5 & 7.00 & $0.8 \%$ \\
\hline $\mathrm{CR} 4 \mathrm{BALB} / \mathrm{C}$ & $44 / 37$ & 52 & 307 & $34(10)$ & 1 & 6.56 & $0.3 \%$ \\
\hline
\end{tabular}

Affected phenotypes were all classified as kinked tails; in CR1 CBA/J, 1 meningohydrocele was observed. Abbreviations: $\mathrm{f}=$ fernale, $\mathrm{m}=\mathrm{male}$.

Table 2. Penetrance in the intercrosses of the CBA/J and BALB/c line

\begin{tabular}{|c|c|c|c|c|c|c|c|c|c|}
\hline \multirow[t]{2}{*}{ Intercross } & \multicolumn{2}{|c|}{ number of } & \multicolumn{5}{|c|}{ number of newborns } & \multirow[t]{2}{*}{ litter size } & \multirow[t]{2}{*}{ penetrance } \\
\hline & $\mathrm{f} / \mathrm{m}$ & litters & living & dead & $S B$ & $\mathrm{CT}$ & $\mathrm{KT}$ & & \\
\hline$\Upsilon \mathrm{ClCBA} / \mathrm{I}$ & $36 / 12$ & 103 & 717 & 0 & 0 & 18 & 2 & 6.96 & $2.8 \%$ \\
\hline $1 \mathrm{C} 2(\mathrm{BA} / \mathrm{J}$ & $70 / 39$ & 270 & 2023 & 160 & 0 & 14 & 25 & 8.09 & $1.8 \%$ \\
\hline $1 \mathrm{C} 3 \mathrm{CBA} / \mathrm{J}$ & $168 / 111$ & 210 & 1107 & 125 & 1 & 0 & 31 & 5.87 & $2.6 \%$ \\
\hline ICI BALB/C & $21 / 7$ & 56 & 568 & 0 & 1 & 22 & 0 & 10.14 & $4.0 \%$ \\
\hline $1 \mathrm{C} 2 \mathrm{~B} A \mathrm{DB} / \mathrm{C}$ & $49 / 28$ & 193 & 1730 & 50 & 0 & 34 & 19 & 9.22 & $3.0 \%$ \\
\hline $1 C 3 \mathrm{BAI} B / \mathrm{C}$ & $150 / 90$ & 346 & 3635 & 164 & 0 & 39 & 27 & 10.98 & $1.7 \%$ \\
\hline$\triangle \mathrm{CABAB} / \mathrm{C}$ & $50 / 25$ & 197 & 1504 & 86 & 1 & 6 & 29 & 8.07 & $2.3 \%$ \\
\hline
\end{tabular}

The SB in the CBA/J line was accompanied by a curled tail and anencephaly; the SB in the $B A J B / c$ line were accompanied by a curled tail only. Abbreviations: $f=$ Female, $m=$ male, $S B=$ spina bifida aperta, $\mathrm{CT}=$ curled tail, $\mathrm{KT}=$ kinked tail. 
The observed phenotypes of the recombinant-3 line were identical as those from the recombinant -2 line (Table 4); $\mathrm{SB}$ was observed in combination with a straight tail in $16 \%$ of the cases. During subsequent generations, penetrance increased significantly from $1.7 \%$ in the first to $31.8 \%$ in the fourth generation, while litter size decreased. The penetrance in each generation was lower when compared to matching generations of the recombinant-2 line, except for F3. The percentage of affected phenotypes exhibiting a kinked tail decreased, as in the recombinant-2 line (Fig. 4B). The changes in contributions of curled tail and SB were not consistent.
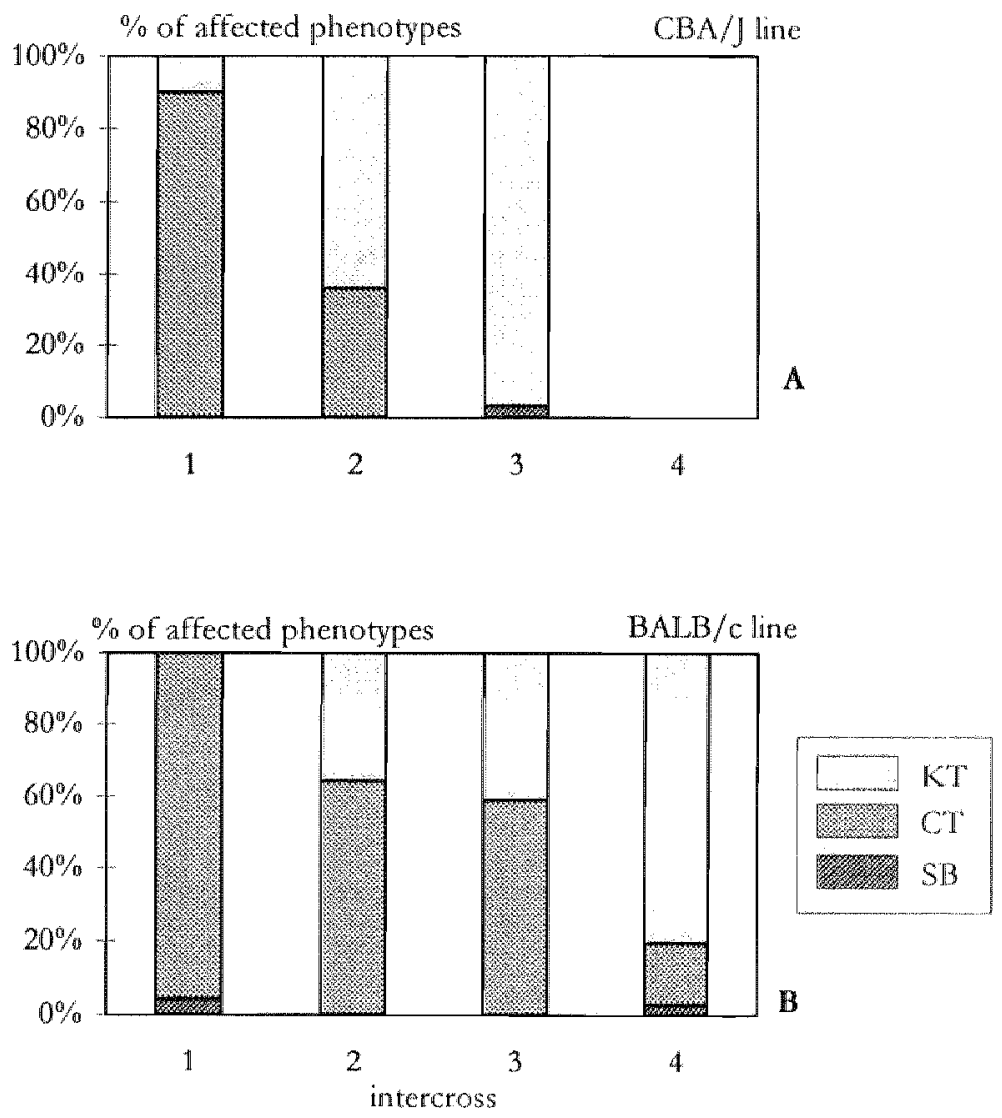

Fig. 3. The contribution of each phenotype to the total penetrance for the $\mathrm{CBA} / \mathrm{J}$ line $(\mathrm{A})$ and the $B A L B / c$ line (B). In both lines, the proportion kinked tails increased after each crossintercross cycle. Abbreviations: $\mathrm{KT}=$ kinked tail, $\mathrm{CT}=$ curled tail, $\mathrm{SB}=$ spina bifida aperta. 
rable 3. Results of the BALB/c - curly tail recombinant-2 line

\begin{tabular}{|c|c|c|c|c|c|c|c|c|c|}
\hline \multirow[t]{2}{*}{ Generation } & \multicolumn{2}{|c|}{ number of } & \multicolumn{5}{|c|}{ number of newborns } & \multirow[t]{2}{*}{ litter size } & \multirow[t]{2}{*}{ penetrance } \\
\hline & $\mathrm{f} / \mathrm{m}$ & litters & living & dead & $S B$ & $\mathrm{CT}$ & $\mathrm{KT}$ & & \\
\hline$I C 2$ & $49 / 28$ & 193 & 1730 & 50 & 0 & 34 & 19 & 9.22 & $3.0 \%$ \\
\hline $\mathrm{IC} 2 \mathrm{~F} 1$ & $25 / 21$ & 59 & 484 & 15 & 11 & 47 & 22 & 8.46 & $16.0 \%$ \\
\hline $\operatorname{IC2} \sqrt{12} 2$ & $15 / 14$ & 41 & 244 & 32 & 14 & 64 & 15 & 6.73 & $33.7 \%$ \\
\hline $1 \mathrm{C} 2 \mathrm{~F} 3$ & $10 / 10$ & 31 & 178 & 24 & 7 & 33 & 6 & 6.52 & $22.8 \%$ \\
\hline $102 \mathbb{P}$ & $9 / 5$ & 52 & 324 & 30 & 42 & 98 & 4 & 6.81 & $40.7 \%$ \\
\hline $1 C 2 F 5$ & $10 / 10$ & 18 & 74 & 23 & 11 & 36 & 0 & 5.39 & $48.5 \%$ \\
\hline IC2 F4 ST & $10 / 10$ & 34 & 245 & 17 & 22 & 70 & 1 & 7.71 & $35.5 \%$ \\
\hline
\end{tabular}

The first line is identical to "Table 2. Most SB phenotypes exhibited also a curled tail, except 2 (F1), 1 (F2), 3 (F3), 6 (F4), 3 (F5) and 4 (F4 ST) newborns which exhibited a straight tail. The decrease in litter size and the increase in penetrance along subsequent generations is statistically significant. The bottom line shows the results of the mating between phenotypical unaffected parents. The penetrances labeled with ${ }^{\circ}$ were compared and appeared not statistically significant. Abbreviations: $\mathrm{E}=$ Female, $\mathrm{m}=$ male, $\mathrm{SB}=$ spina bifida aperta, $\mathrm{CT}=$ curled tall, $\mathrm{KT}=$ kinked tail.

Table 4. Results of the BALB/c - curly tail recombinant-3 line

\begin{tabular}{|c|c|c|c|c|c|c|c|c|c|}
\hline \multirow[t]{2}{*}{ Generation } & \multicolumn{2}{|c|}{ number of } & \multicolumn{5}{|c|}{ number of newborns } & \multirow[t]{2}{*}{ litter size } & \multirow[t]{2}{*}{ penetrance } \\
\hline & $E / \mathrm{m}$ & litters & living & dead & $\mathrm{SB}$ & $\mathrm{CT}$ & $\mathrm{KT}$ & & \\
\hline 163 & $150 / 90$ & 346 & 3635 & 164 & 0 & 39 & 27 & 10.98 & $1.7 \%$ \\
\hline $1 \mathrm{Cs} \mathrm{Fl}$ & $23 / 23$ & 92 & 638 & 50 & 8 & 40 & 11 & 7.48 & $8.6 \%$ \\
\hline $103 \sqrt{102}$ & $24 / 19$ & 60 & 476 & 33 & 16 & 70 & 4 & 7.71 & $17.7 \%$ \\
\hline 10313 & $32 / 17$ & 76 & 524 & 60 & 43 & 121 & 6 & 7.68 & $29.1 \%$ \\
\hline $1 \mathrm{C} 3 \mathrm{I}_{4}$ & $22 / 22$ & 68 & 420 & 51 & 20 & 125 & 5 & 6.93 & $31.8 \%$ \\
\hline $1 \mathrm{C} 3 \mathrm{FST}$ & $15 / 6$ & 73 & 519 & 42 & 11 & 83 & 7 & 7.68 & $18.0 \%$ \\
\hline
\end{tabular}

The first line is identical to Table 2. Most SB phenotypes exhibited also a curled tail, except 1 $(\mathrm{Fi}), 7(\mathrm{~F} 2), 2$ (F3), 4 (F4) and 2 (F3 ST) newborns which exhibited a straight tail. The decrease in litter size and the increase in penetrance along subsequent generations are statistically significant. The bottom line shows the results of the mating between phenotypical unaffected parents. The penetrances labeled with ${ }^{\circ}$ and ${ }^{*}$ were compared and appeared statistically significant. $A$ bbreviations: $\mathbb{E}=$ fernale, $m=$ male, $S B=$ spina bifida aperta, $C T=$ curled tail, $\mathrm{KT}$ $=$ kinked tail. 


\section{Parental phenotype and penetrance}

In the F4 of the recombinant-2 line (Fig. 2), the penetrance and observed phenotypes in offspring of phenotypically unaffected and affected parents appeared to be identical (Table 3). In the F3 of the recombinant-3 line, the phenotypes were identical too. However, penetrance was significantly lower in the offspring of the phenotypically unaffected parents (Table 4).

In the recombinant-3 line, some matings of the phenotypically affected parents were between kinked tails, curled tails or SB phenotypes. In the F1, the penetrance of the 3 kinked tail couples $(6 \%)$ was lower than of the 3 curled tail couples $(12 \%)$. In the F4, the penetrance of the 1 kinked tail couple (24\%) was lowest, followed by the $5 \mathrm{SB}$ couples $(27 \%)$ while it was highest for the 16 curled tail couples $(33 \%)$. These differences were not statistically significant.
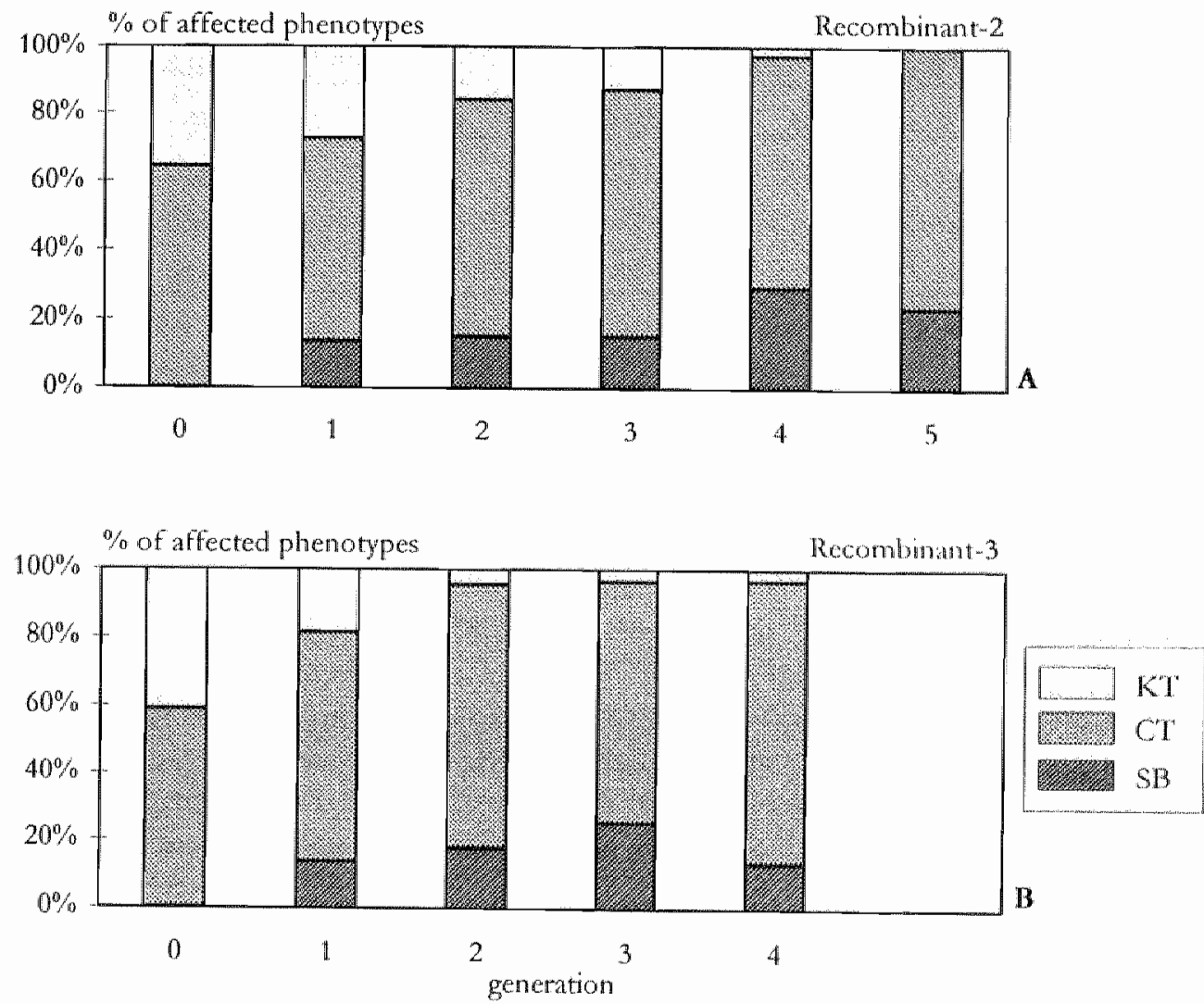

Fig. 4. The contribution of each phenotype to the total penetrance for several gencrations of the recombinant-2 (A) and recombinant-3 (B) lines. The decrease in proportion kinked tails in subseguent generations was significant for the recombinant -2 and -3 lines. In the recombinant -2 line, the proportion of $\mathrm{SB}$ increased significantly. Abbreviations: $\mathrm{KT}=$ kinked tail, $\mathrm{CT}=$ curled tail, $S B=$ spina bifida aperta. 


\section{Embryonic phenotypes and penetrance}

In both the $C B A / J$ and $B A L B / C$ M-lines, the following phenotypes were observed at E13: exencephaly, SB with a straight or curled tail, a curled tail, a kinked tail and a split tail. The split tail occurred unexpectedly and comprised a small ventrally or dorsally located bulge at the distal part of the tail. In both lines, the penetrance at E13 appeared to be significantly higher than in matching intercrosses at birth (Table 5 versus 2).

In the BALB/c - curly tail tecombinant-3 line, the length of the PNP at E9-10 reduced gradually between somite stages 13-24, from somite stage 25 onwards, the variation in PNP length increased (Fig. 5). The youngest embryo with a closed PNP was observed at somite stage 35 .

Table 5. Embryonic phenotypes and penetrance

\begin{tabular}{|c|c|c|c|c|c|c|c|c|c|c|c|}
\hline \multirow[t]{2}{*}{ E13 } & \multicolumn{2}{|c|}{ number of } & \multicolumn{7}{|c|}{ number of embryos } & \multirow{2}{*}{$\begin{array}{c}\text { Litter } \\
\text { size }\end{array}$} & \multirow[t]{2}{*}{ Penetrance } \\
\hline & $\mathrm{E} / \mathrm{m}$ & litters & living & dead & Ex & $S B$ & $\mathrm{CI}$ & $\mathrm{KH}$ & SpT & & \\
\hline $1 C 2 \mathrm{CBA} / \mathrm{J}$ & $65 / 32$ & 62 & 502 & 119 & 1 & 0 & 8 & 110 & 13 & 10.02 & $21.3 \%$ \\
\hline $1 \mathrm{C} 2 \mathrm{BAI} B / \mathrm{c}$ & $46 / 21$ & 40 & 364 & 63 & 1 & 1 & 13 & 24 & 2 & 10.68 & $9.6 \%^{\circ}$ \\
\hline$I C 3 \mathrm{BAIB} / \mathrm{C}$ & $42 / 7$ & 39 & 333 & 32 & 2 & 2 & 4 & 1 & 5 & 9.36 & $3.8 \% \%^{x}$ \\
\hline
\end{tabular}

Only $1 \mathrm{SB}$ of the $\mathrm{IC} 3 \mathrm{BALB} / \mathrm{c}$ exhibited a curled tail, the other 2 a straight tail. Penetrances labeled with ${ }^{\circ}$ and "were compared and differed significantly. Abbreviations: $f=$ female, $m=$ male, $S B=$ spina bifida aperta, $C T=$ curled tail, $K T=$ kinked tail, $S_{p} T=$ split tail.

\section{Discussion}

\section{Penetrance and genetic background}

In the present study, two separate lines for the construction of a curby tail recombinant strain were created: $\mathrm{a} C \mathrm{CBA} / \mathrm{J}$ and a $\mathrm{BALB} / \mathrm{c}$ line. This was performed because penetrance of the curby tail phenotype has been reported to depend on the genetic background (Embury et al. 1979; Neumann et al. 1994; Beier et al. 1995; l.uetts et al. 1995). Grüneberg (1954) performed 1 cross-intercross cycle for CBA with corby tail, resulting in offspring with a penetrance of $4.8 \%$, which was slightly higher than the $2.8 \%$ we found. Penetrance after the first cycle in the $B A L B / c$ line was of the same magnitude as in the $\mathrm{CBA} / \mathrm{J}$ line. Also for subsequent cycles, no obvious difference in penetrance emerged between the two lines. Thus, the previously demonstrated influence of genetic background upon penetrance of the carly fail phenotype could not be confirmed in the present study by the CBA/J and $\mathrm{BALB} / \mathrm{c}$ lines. However, especially after the third cycle, penettance was mainly determined by kinked tails in the CBA/J line and by curled tails in the BALB/c 
line. Because of economic reasons and because a kinked tail is considered to be a less severely affected phenotype compared to a curled tail (Chapter 2.1), it was decided to continue only the BALB/c line after the third cycle.

\section{Recessive or dominant curly tail genotype}

Originally, based on data of breeding experiments, the curly tail mutation had been described as a recessive one (Grüneberg 1954; Embury et al. 1979). However, linkage analysis pointed towards dominance for the curly tail mutant (Neumann et al. 1994; Beier et al. 1995). Moreover, an unexpected high penetrance was observed when the curly tail mutation was combined with the mutation Splotch (Estibeiro et al. 1993), indicating that the former is not completely recessive. In both the CBA/J and $B A L B / c$ lines of the present study, affected phenotypes (i.e. kinked tails) were observed in the offspring of crosses. These findings support the idea that the heredity of the carly tail phenotypes in newborns is not completely recessive. Breeding these affected CR-mice did not yield a systematic different penetrance in comparison with unaffected ones. Thus, it is not likely that the affected CR-mice represented a genetically defined subgroup.

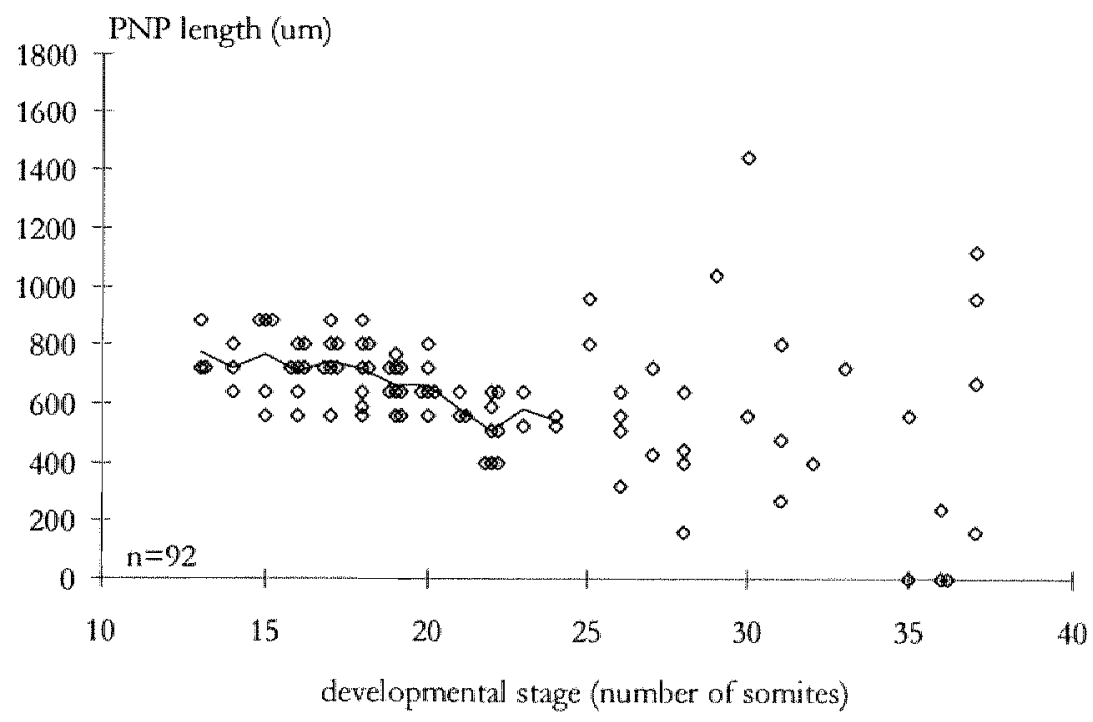

Fig. 5. The length of the posterior neuropore during development of embryos of the recombinant -3 line. Individual data points are shown; the line links the mean PNP Jength for each somite stage between 13-24. From somite stage 25 onwards, the variation in PNP length increased. Closure was first seen at the 35 somite stage. 


\section{Modifiers in the curly tail genotype}

The genes which are responsible for the carby tail phenotype have not been chatacterized yet. The $a$ gene, which is mapped to distal chromosome 4 , is necessary for an affected phenotype but appears not sufficient as illustrated by the incomplete penetrance (Neumann et al. 1994; Beier et al. 1995; Letts et al. 1995). Neumann (1994) estimated a number of effective loci of 3.2, and concluded that at least three modifiets have to be involved, which might be located on chromosome 3 and 5. Letts (1995), however, mapped a modifier (mol) to chromosome 17, and suspected additional modifiers. But, the observed associations for chromosome 1, 5 , and 14 were only weak and consequently yielded only marginal evidence.

In the present study, half of the genetic constitution is replaced by genes of the first parent in each cross. In the subsequent intercross, part of the offspring exhibited an affected phenotype and could be selected for the next cross, whereby the genes necessary for the curly lail phenotype were selected consequently. It is expected that the at gene is homozygous in most affected phenotypes, except for a low frequency of heterozygous affected ones as illustrated in the CR-mice (see above). If penetrance would be $100 \%$ and only dependent on the at gene, a quarter of the ICmice would demonstrate an affected phenotype. The fact that only $2-4 \%$ is affected indicates that modifier genes are indeed involved. It is unknown whether the modifiers have to be homozygous, but if they do, the frequency of $2-4 \%$ affected phenotypes in the IC-mice can be explained by the existence of 3 modifiers.

We suggest that more than 3 modifiers are involved, which do not have to be homozygous to exert influence on phenotypes and consequently penetrance, but which might have more impact when homozygous. Due to the repeatedly selection of affected phenotypes in the subsequent generations of the $B A L B / c$ - curly tail recombinant -2 and -3 lines, more modifiers are likely to become homozygous, and the impact of the modifiers on penetrance will therefore increase. Indeed, penetrance appeared to increase. Additional support for this hypothesis emerges from the shift in contribution of the various phenotypes to penetrance from kinked tatl to $\mathrm{SB}$; the former is considered to be a less severely affected phenotype than the latter (Chapter 2.1). A decreased influence of modifiers might be expected in the cross-intercross cycles, in which the number of homozygous modifiers in the IC-mice is not increased prior to the next cross. Indeed, a shift in contribution towards less severely affected phenotypes was observed for both the $C B A / \rrbracket$ and $B A L B / c$ line. Thus, it is concluded that, besides the a gene, more than 3 modifiers are likely involved in the axty lail genotype, and the impact of the modifiers upon phenotypes and penetrance depends on whether they are homozygous or heterozygous. 


\section{Parental phenotype and penetrance}

The idea that the number of homozygous modifier genes increases in each generation of the recombinant lines implies that the affected phenotypes exhibit more homozygous modifiers as their unaffected littermates. Consequently, the affected and unaffected phenotypes would represent genetically defined subgroups with the lowest penetrance in the unaffected subgroup. This was indeed observed in the $\mathrm{F} 3$ of the recombinant- 3 line. In the the F4 of the recombinant-2 line, however, the reduction of penetrance among offspring of unaffected parents was not significant. This might be due to the fact that more modifier genes involved in the curly tail trait are already homozygous in the fourth generation, resulting in minor differences between the phenotypically defined subgroups. In addition to this reduction by unaffected phenotypes, penetrance seemed also to reduce within the group of affected ones if the parental phenotype is less severe. However, the possible genetic differences between those subgroups are probably very small, which could not be determined with the low number of mice used for these comparisons.

It is expected that the number of modifiers which are fixed in the genome of the curby tail strain increases in each generation of the recombinant line. Finally, this is expected to result in recombinant mice in which all modifiers are homozygous. Consequently, penetrance would then not be influenced by parental phenotype anymore.

\section{BALB/c genetic background in the recombinant mice}

Nike the increase of modifiets derived from the curly tail in the recombinant lines, it might be expected that also other genes were selected in favor of the curly tail genetic background, whereby the proportion of $B A L B / c$ derived genetic background decreased. However, the risk for outcrossing $B A L B / c$ genes depends on the distance of each particular gene to the $a t$ gene or to a modifier. It was not tested whether the actual proportion $B A L B / c$ derived backgtound differed considerably from the theoretical one (Fig. 1).

The BALB/c strain is albino while the curly tail has a dark-brown fur. However, most (more than 90\%) IC4 and recombinant-2 and -3 mice are albino. This indicates that at least fur colour is already determined by genes of the BALB B/c. Since one of these genes, brown, is mapped to chromosome 4 at 1.0-20 cM distance from the $a$ gene, it might be expected that the genetic background, for which the theoretical proportion of $\mathrm{BALB} / \mathrm{c}$ is mentioned, comprises the whole genome except for regions of $10-20 \mathrm{cM}$ up and downstream of the $a$ gene and the modifiers.

\section{Embryonic phenotypes and penetrance}

The wide range of PNP lengths, as observed at EO in the BALB/c - curly tait recombinant-3 line, was similar to that of the curly tail strain (Chapter 2.1). In both 
M-lines, similar phenotypes became manifest at E13 as in embryos of the curly tail strain, except for the kinked and split tail (Chapter 2.1). The penetrance at E13 appeared to be higher than at birth, which was mainly due to the higher frequency of kinked and split tails. Because these phenotypes were considered as minor affected, it is unlikely that they died prenatally and thereby causing the lower penetrance at birth. We presume that some of the kinked and split tails recovered prenatally. In the curly lail colony from which these recombinants are derived, penetrance at E13 and at birth were found to be equal (Chapter 2.1). But, the original report regarding the curly tail mouse did report a higher penetrance at embryonic stages than at birth (Grüneberg 1954).

The frequency of SB with a straight tail at E13 appeared to be higher in the M-lines than in the curly tail strain. Moreover, it was frequently observed in newborns as well. Such a reduction in association between SB and curled tail had also been achieved in the curbly tail strain after administration of retinoic acid (Chen et al. 1994). We suggest that the reduced association in the present study is determined by the presence of heterozygous modifiers.

Because the embryonic phenotypes at E9 and E13 are thought to be the preliminaty phase of the phenotypes in newborns, the similarity suggests that the phenotypes in the recombinant mice are caused by the curly tail genotype.

Part of the mice of the BALB/c - curly lail tecombinant 2 and -3 lines exhibit curly lail phenotypes and exhibit consequently the genes necessary for these phenotypes. Since the background in recombinant mice is partly matched to that of a control strain, these recombinants are useful in studies regarding the corry tail pathogenetic pathway.

\section{References}

Beicr DR, Dushkin H, Telle T' (1995) Haplotype analysis of intra-specific backcross curly tail mice confirms the localization of ct to chromosome 4. Mamm Genome 6:269-272

Chen WH, Morriss-Kay GM, Copp AJ (1994) Prevention of spinal neural tube defects in the curly tail mouse mutant by a specific effect of retinoic acid. Dev Dyn 199: 93-102

Copp AJ (1985) Relationship between timing of posterior neuropore closure and development of spinal neural tube defects in mutant (arty rail) and normal mouse embryos in culture. J
Embryol Exp Morphol 88: 39-54

Embury S, Seller M], Adinole M, Polani PE (1979) Neural tube defects in curly tail mice. I. Incidence, expression and similarity to the human condition. Proc. R. Soc. London. B 206:
85-94

Estibeiro JP, Brook FA, Copp AJ (1993) Interaction between splotch (Sp) and curly tail (ct) mouse mutants in the embryonic development of neural tube defects. Development 119: 113-
121

Grüneberg H (1954) Generical studies on the skeleton of the mouse. VIII curly tail. J Genet 52:
$52-67$ 
Letts VA, Schork NJ, Copp AJ, Bernfield M, Frankel WN (1995) A curly-tail modifier locus, mot1, on mouse chromosome 17. Genomics 29: 719-724

Neumann PE, Frankel WN, Letts VA, Coffin JM, Copp AJ, Bernfield M (1994) Multifactorial inheritance of neural tube defects: localization of the major gene and recognition of modifiers in ct mutant mice. Nature Genet 6: 357-362 
Chapter 2.2 


\title{
Chapter 3
}

\section{Relationship between axial curvature}

\author{
and neural tube closure
}

3.1 The spatio-temporal curvature pattern in the mouse

3.2 Effects of axial curvature alterations in the mouse

3.3 Neurulation in the rabbit embryo

3.4 Comparisons in five species 
Chapter 3 


\section{Chapter 3.1}

\section{The spatio-temporal curvature pattern in the mouse}

\section{Published as:}

Spatio-temporal curvature pattern of the caudal body axis for non-mutant and corby tail mouse embryos during the period of caudal neural tube closure. Marian C.E. Peeters, Johan W.M. Hekking, Tryfon Vainas, Jan Drukker, Henny W.M. van Straaten. Anatomy and Embryology (1997) 195: 259-266

\section{Abstract}

During the period of early organogenesis the mouse embryo has a curved body shape, which is thought to interact with ongoing developmental processes. Curly tail is a mouse mutant causing spina bifida, in which aberrant axial curvature is considered to be responsible for a delay in the closure of the posterior neuropore (PNP). Since detailed descriptions of axial curvature have never been made in either the normal or the mutant embryo, the onset and development of the aberrant axial curvature in the curly tail embryo are unknown. In the present study, axial curvature and segmental growth during closure of the PNP are described using circle segments at each somite level in two non-mutant mouse strains. Using the radius and angle of the segments as parameters, $C D-1$ and $\mathrm{Balb} / \mathrm{c}$ mouse embryos showed maxima of curvature at the levels of the limb buds. Throughout development, a general axial unbending occurred that was due to a level-specific combination of general outgrowth and other factors. A marked additional decrease in the axial curvature was spatially and temporally related to the final closure of the PNP, indicating that this decrease of curvature facilitates the final closure of the PNP. In the curly tail embryo the segment parameter radius was used to relate the axial curvature to an aberrant neural tube closure pattern. These embryos exhibited an enhanced curvature over the entire neuropore region as soon as a delay in the PNP closure could be distinguished. A steep decrease in curvature during final closure of the PNP did also occur, but at a more caudal level. Both the axial level of straightening and the rate of curvature were normalized at advanced developmental stages. The aberrant spatio-temporal curvature patten in the curly tail mouse embryo indicates that both the rate of curvature and the axial level of unbending are important for a correct PNP closure. 


\section{Introduction}

During early organogenesis embryos are characterized by a general body curvature with marked flexures at the head and tail regions. This implies an intricate relationship between axial curvature and many developmental processes. Neural tube development is both spatially and temporally related to axial curvature. It has been thought that axial curvature arises because the neural tube, on the dorsal side of the embryo, exhibits a higher growth rate than ventral structures. But the curvature itself has also an impact on neurulation. The head region of the mouse embryo demonstrates a correlation between the cranial neural tube closure and the rate of ventral curvature (Jacobson and Tam 1982). More recently, a role for axial curvature in the closure of the posterior neuropore (PNP) has been proposed for the curly cail mouse. In this mutant, part of the offspring has caudal neural tube defects, resulting in tail flexion defects and spina bifida (Grüneberg 1954; Embury et al. 1979), which are caused by a delayed or absent PNP closure (Copp 1985). The deviation of closure appeared related to enhanced ventral curvature of the caudal region (Brook et al. 1991). When such enhanced axial curvature was prevented experimentally, PNP closure was normalized (Brook et al. 1991; van Straaten et al. 1993). Further evidence for a relationship between curvature and PNP closute came from a study in non-mutant mouse embryos. After experimentally increasing the ventral curvature of the caudal region, a linear relationship was found between the rate of axial curvature and the probability of an open PNP (Peeters et al. 1996). The undetlying mechanism of this relationship is not elucidated, but it has been proposed that an enhanced curvature generates ventrally directed mechanical forces on the neural folds that counteract the elevation and convergence, thereby preventing normal PNP closure (Brook et al. 1991; Peeters et al. 1996).

Consequently, it appears that axial curvature is an important factor in PNP closure. The relationship between delayed closure of the PNP and enhanced curvature in curly tail embryos has been measured at only one axial level so far (Btook et al. 1991). However, it would be interesting to know the craniocaudal extent of the aberrant curvature, as well as how this aberrant curvature evolves during development. Therefore, a need exists for a detailed description of the normal curvature pattern for the whole caudal region at developmental stages during which the PNP closes.

In previous studies, curvatures of the embryo have been measured by defining an angle of curvature using three reference points (Jacobson and Tam 1982; Männer et al. 1995) or two lines (Newgreen et al. 1981; Brook et al. 1991; Peeters et al. 1996). This yields angles of curvatures at one position in the embryo only. Morcover, in order to follow curvature during development, developmental-independent reference points have to be chosen. We have designed a method which describes 
the curvature on lateral view photographs as circle segments at each (pre-)somite level. The determined circle segments were used for two purposes:

1. With two segment parameters, the development of the axial curvature of the caudal region is described in non-mutant embryos.

2. With the segment parameter directly related to the rate of ventral bending of the neural tube, the relationship between curvature and caudal neural tube closure is studied in non-mutant and corly tail embryos.

It appeared that the neural tube showed unbending at a specific level and a specific developmental stage that were both related to the final closure of the PNP. This relationship was disturbed in the curly tail embryos with a delayed closure of the PNP.

\section{Materials and Methods}

\section{Mouse strains and embryo preparation}

The carby tail mutation arose spontaneously in the GFF strain. After subsequently mating with the $\mathrm{CBA} / \mathrm{Gr}$ strain (Grüneberg 1954), the atry tail strain has since then been maintained as a homozygous, closed, random-bred colony. The affected genes are unknown, but the major gene is mapped to distal chromosome 4, and two or three modifier genes are probably involved in determining its penetrance and expression, of which one is mapped to chromosome 17 (Neumann et al. 1994; Beier et al. 1995; Letts et al. 1995). The penetrance in our stock was $44 \%$ for curled and kinked tails, and $3 \%$ for spina bifida combined with curled tails. Mice with no predisposition for neural tube defects (the outbred $C D-1$ and the inbred Balb/c) were commercially obtained (Charles River Wiga GmbH, Germany).

Mice were paired for mating overnight, after which females were checked for copulation plugs. The day of finding a plug was designated day 0 of gestation. Females were sacrificed by cervical dislocation on day $9,9.5$ or 10 and the uterus was taken out and put into Hanks" buffer (Hanks and Wallace 1949) containing $10 \%$ newborn calf serum (Gibco). Embryos were dissected free of their extraembryonic membranes. The number of somites was counted and only embryos with 22-34 somites (the period of PNP closure) were processed further. Embryos were subdivided according to their somite number into the developmental stages 22-24, 25-27, 28-29, 30-31 and 32-34. The PNP length was measured using an eyepiece graticule fitted on a stereo microscope as well as classified according to the degree of delayed PNP closure (Copp 1985): the embryo was noted as "normal" when the PNP length did not exceed half of the presomitic caudal region and as "delayed" when the cranial site of the PNP reached or even went beyond the somitic area. Until the stage $28-29$, curly tail embryos were 
phenotypically non-discriminative, whereas from that stage onwards both phenotypes could be distinguished. All $\mathrm{CD}-1$ and $\mathrm{Balb} / \mathrm{c}$ embryos were of the normal phenotype.

After classification, the embryos were fixed in Bodian's fluid $(90 \mathrm{ml}$ of $80 \%$ ethanol, $5 \mathrm{ml}$ of $99 \%$ acetic acid and $5 \mathrm{ml}$ of $37 \%$ formaldehyde) and dehydrated in a graded series of ethanol. The embryos were critical point dried using liquid $\mathrm{CO}_{2}$, attached to aluminium stubs with silver paint, coated with gold/palladium and observed at $15 \mathrm{keV}$ using a scanning electron microscope (SEM) (505 Philips). Photographs from the lateral side of the embryonic caudal region were taken. The SEM makes it possible to position the embryo for the best lateral view, as previously shown (Jacobson and Tam 1982; Pceters et all 1996). Moreover, the detalled photographs allow accurate definition of marker positions (see below). During the fixation or critical point drying shrinkage does occur, but it has been noticed that the angle of curvature, as measured at one level, did not differ whether it was measured before fixation or after SEM examination (Peeters et al. 1996).

\section{Measurement of axial curvature}

At each somite level, the dorsal contour of an embryo on a lateral-view SEM photograph can be regarded as part of a circle. A circle with radius $\mathbf{r}$ and center coordinates $\left(\mathrm{C}_{\mathrm{x}}, \mathrm{C}_{\mathrm{y}}\right)$ is mathematically defined by the equation:

$$
\left(x-C_{x}\right)^{2}+\left(y-C_{y}\right)^{2}=r^{2}
$$

This implies that with the $x-y$ coordinates of three points on a circle the position of the center and the tadius of that circle can be calculated. Therefore, per somite level three points were placed on the dorsal contour of the embryo corresponding to the middle of each somite and their $x-y$ coordinates were digitized (Fig. 1). The best fitting circle segment with the highest reproducibility was obtained when the point at somite position $N$ was used in combination with the points at positions $N+2$ and $N-2$. From the determined circle segments both radius and angle were used as parameters. The curvature was expressed as radius". Data were smoothed once with a moving average over five somite levels and plotted in Figs. 3 and 5 . This curvature parameter is referred to as curvature-radius. Thus, the axial curvature incteases if the radius of the circle segment decteases. Both the inter- and intraobserver variation of such determined curvature-radius turned out to be less than $5 \%$

In the non-mutant embryos, the segment-angle was also used as a parameter of the determined circle segments (Fig. 1), because segmental growth is reflected both by the radius and angle of the segment.

In order to measure the parameters in the caudal region associated with the unsegmented paraxial mesoderm, somite levels were extrapolated, using the mean 
length of the two most recently formed somites. In the younger embryos, the relative llength of this presomitic egion is larget compared with older embryos and, moreover, the somites are smaller. So, the extrapolation yielded an equal total number of somite levels for the younger and older embryos.
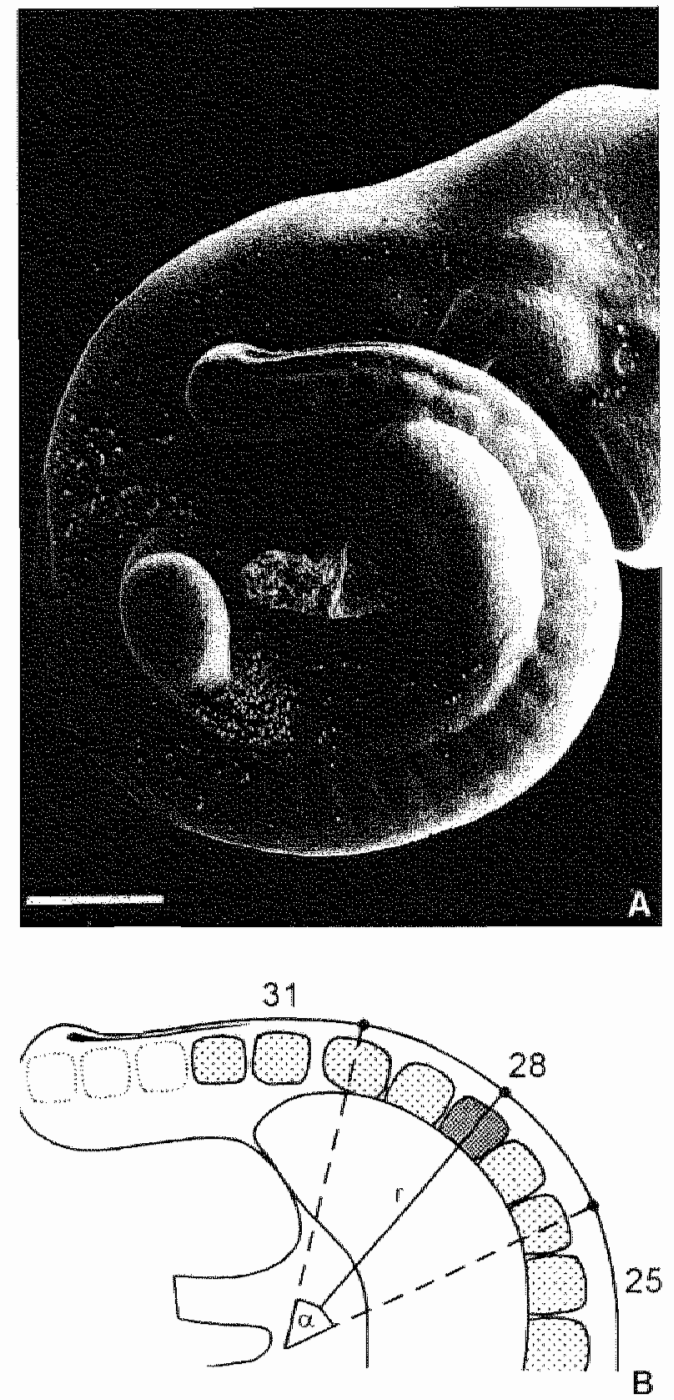

Fig. 1. Definition of the circle segments. A Lateral SEM view of a mony tail embryo of the delayed phenotype at the developmental stage of 32 somites, such as used for the determination of the curvature. Bar 500 um. B Schematic overview of the circle segment with its parameters radius $(0)$ and angle $(\alpha)$. The arc that fits the body curvature at the level of the Nth somite (e.g. 28th somite as shown in this ligure) is defined by three pounts on the dorsal contour of the body that correspond to the middle part of somites $\mathbb{N}-2, N$ and $\mathrm{N}+2$. For the body region associated with the unsegmented paraxial mesoderm, the segmental position of the landmarks is determined on the basis of the size of the two most recently formed somites. 


\section{Statistics}

Table 1 shows the number of embryos in cach group defined by mouse strain, developmental stage and PNP category. Within each group, the curvatures of the embryos were averaged at each somite level and the $95 \%$ confidence limits of the mean were calculated $( \pm 1.96 * \mathrm{SE})$. A difference in curvature is considered statistically significant if a curvature is outside the confidence interval of the other; if this was the case it is mentioned in the text.

Table 1. Number of embryos used, for each mouse strain, at several developmentall stages and for the PNP categories.

\begin{tabular}{|c|c|c|c|c|c|c|}
\hline \multirow[b]{2}{*}{ Mouse strain } & \multirow[b]{2}{*}{ PNP } & \multicolumn{5}{|c|}{ Developmental stage (somite number) } \\
\hline & & $22-24$ & $25-27$ & $28-29$ & $30-31$ & $32-34$ \\
\hline $\mathrm{CD}-1$ & normal & 8 & 9 & 4 & 8 & 15 \\
\hline $\mathrm{Ba} b / \mathrm{c}$ & normal & & 4 & & 5 & 7 \\
\hline ardy wal & normal & & & 11 & 4 & 7 \\
\hline and tail & non-discriminative & 11 & 16 & & & \\
\hline curby lati & delayed & & & 5 & 5 & 13 \\
\hline
\end{tabular}

\section{Results}

\section{PNP closure in the three mouse strains}

Figure 2 shows the PNP closure patterns of the three mouse strains. The PNP lengths in both non-mutant strains $C D-1$ and $B a l b / c$, decrease gradually with increasing developmental stage and the PNP is closed from the stage of 30 and 31 somites onwards, respectively. Curby tail embryos lack the general decrease in PNP length with increasing developmental stage and they exhibit a considerable variation of PNP lengths, as previously reported by van Straaten et al. (1992). Up to the 33 somite stage, no PNP closure occured in these embryos, with one exception.

\section{Axial curvature of non-mutant mouse embryos}

Figure 3 shows the axial curvature expressed as curvature-radius for non-mutant CD-1 cmbryos during development, as measured at each somite level. The axial curvature decreases with increasing developmental stage. This general axial unbending is statistically significant. Embryos of all developmental stages show maxima of curvatures at the levels of somite $9-11$ and 26-28, which correspond with the regions of the forelimb and the hindlimb bud respectively. From somite level 28 onwards, embryos at and beyond the developmental stages 30-31 show a steep decrease in curvature - a decrease of $50 \%$ between somite levels 28 and 32 . This decrease in curvature is statistically significant. It is also statistically significant compared with the curvature of the most caudal region at younger stages. Due to 
the decreased caudal curvature, the maximum of curvature at the level of the hindlimb bud appears even more pronounced.

The axial curvatures of the Balb/c embryos conform to the pattern and tate of curvature of the CD-1 (Fig. 3B), although the maxima at the levels of the limb buds are only apparent in the older embryos.

Figure 4 shows that the segment-angle in the CD-1 and Balb/c embryos, like the curvature-radius, decreases with increasing developmental stage in the anterior part. On the contraty, the segment-angle in the caudal part increases with increasing developmental stage. The transition is located between somite levels 20-25. The segment-angle also exhibits two local maxima at the limb bud levels; especially the older embryos show a prominent maximum at the level of the hindlimb bud. The sudden axial unbending beyond somite level 28 as observed in embryos of the developmental stages 30-31 and 32-34 in the curvature-radius presentation, is accompanied by a sudden decrease of the segment-angle.

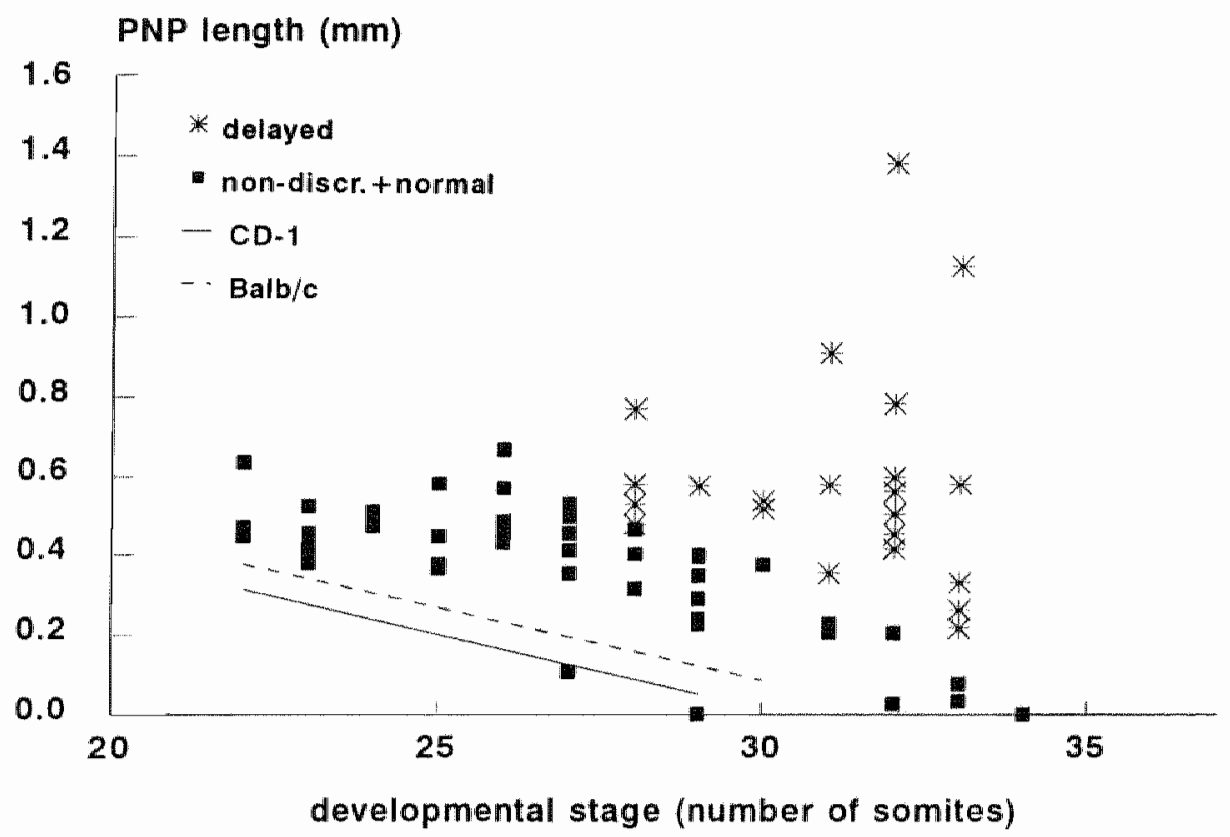

Fig. 2. PNP length of CD-1, Balb/c and carly rait embryos throughout development. The regression lines indicate the PNP lengths of the two non-mutant mouse strains. From the stage of 30 and 31 somites onwards the PNP of all CD-1 and Balb/c embryo's were closed, respectively. For the curly tail embryos, individual PNP lengths ane indicated for both phenotypes; in fact embryos with a delayed phenotype showed larger PN]'s than embryos with a normal phenotype at matching developmental stages. "Non-discriminative" (non-discr) refers to the group of carly tail embryos up to the stage of 28 somites. 

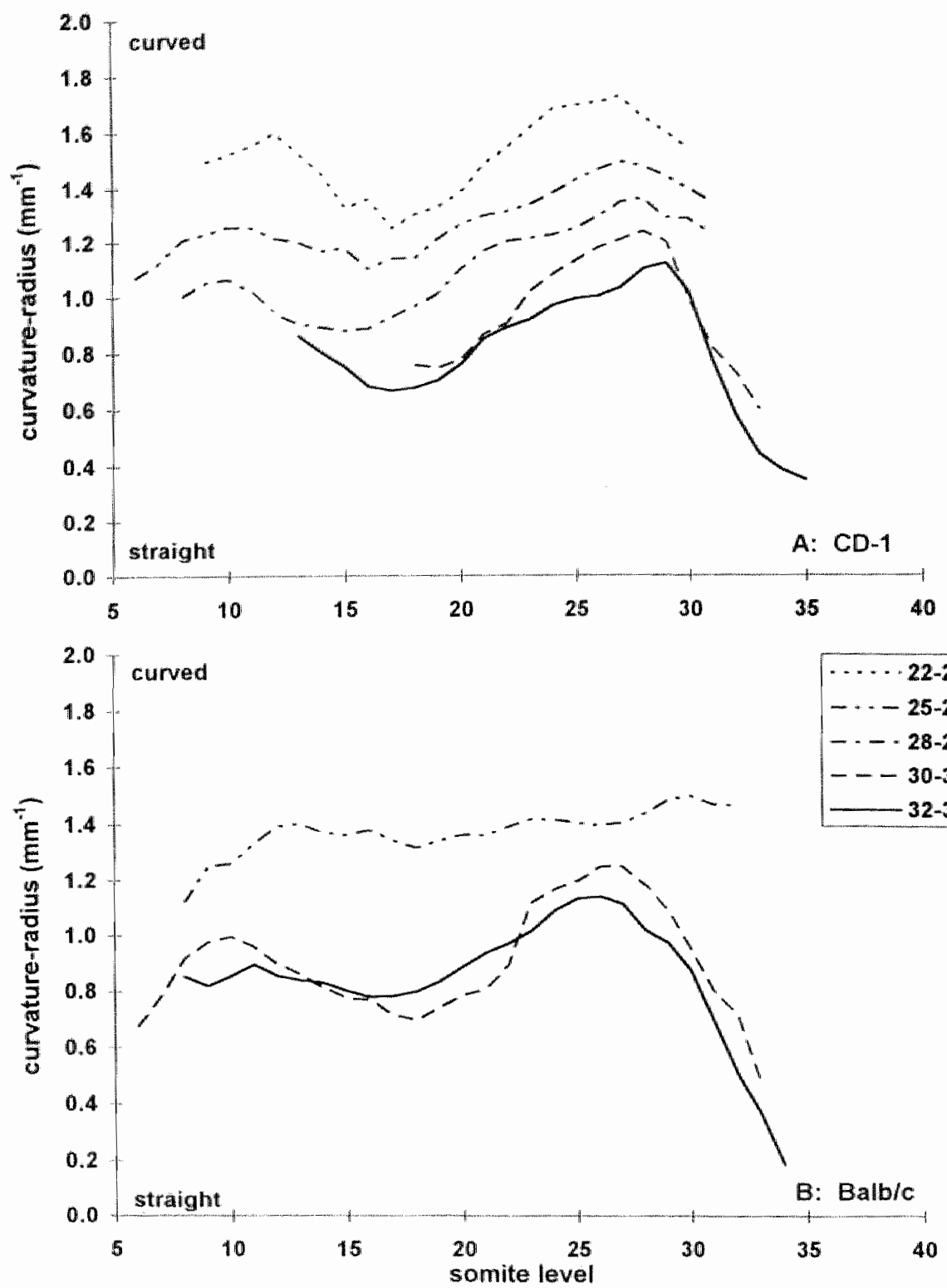

Fig. 3. Curvaturemadius of CD-1 (A) and Balb/c (B) embryos throughout development. Each doth liw represents the average values for a specific developmental stage, the latter indicated by the somite range as specified in the legend. On the ordinate, the topographic level along the cranio-caudal axis is indicated. "The somite levels in the presomitic caudal part have been extrapolated, as has been described in Fig. 1. Both mouse strains show analogous patterns of axial curvature. With increasing developmental stage, a general decrease of axial curwature can be noticed. Maxima of curvature are present at the somite levels of 9-11 and 26 -28. From stage 30 31 onwards, the caudal part shows a marked decrease in curvature, which is statistically significant. 


\section{Axial curvature of curly tail compared with non-mutants}

$U_{P}$ to developmental stage $28-29$, curly tail embryos cannot be discriminated between "delayed" and "nomal" phenotype. The curvature-radii of the phenotypically undivided curly tail embryos are identical in rate and pattern to those of the CD-1, with one exception (Fig. 5): the embryos of stage 22-24 have, from somite level 15 onwards, a curvature which is somewhat less compared with the CD-1.

From developmental stage 28-29 onwards, carly tail embryos are split up in the phenotypes "normal" and "delayed". The curvature of the normal curly tail embryos is identical to that of the CD-1 embryos, except for the enhanced curvature at the somite levels 15-25 from stage 30-31 onwards. The general axial unbending, starting in the non-discriminative group of carly lail embryos, continues in the embryos of the normal phenotype. In comparing the curvature of the delayed corly tail embryos with the curvature of the normal ones, five aspects stand out. Delayed curly lait embryos of developmental stage 28-29 have an axial curvature which is enhanced at almost all somite levels. Moreover, the caudal parts of these embryos show a marked increase in curvature, whereas the caudal curvatures of the normal ones are rather stable. Delayed embryos of stage 30-31 show a steep decrease of curvature in the caudal part, but this occurs at a more caudal level, beyond somite 30. At stage 32-34, the local maximum curvature of the delayed embryos has shifted back to the same somite level and the same curvature as found for normal ones. In contrast to the normal curly tail embryos, the delayed ones have, at the somite levels 15-25, curvatures which are comparable to the non-mutants.

\section{Discussion}

The method of measuring curvature at each somite level, as applied in the present study, appeared to be very useful in determining the development of axial curvature along the craniocaudal axis throughout embryonic development. Previous studies in mouse and chick embryos determined angles of axial curvature at one level only (Jacobson and Tam 1982; Brook et al. 1991; Männer et al. 1995; Peeters et al. 1996), or along the craniocaudal axis at distinct levels (Newgreen et al. 1981). By our method, the bending of the caudal region of the embryo is presented continuously both in space and time so that marked changes in axial curvature can be more accurately detected than by the previous methods. 


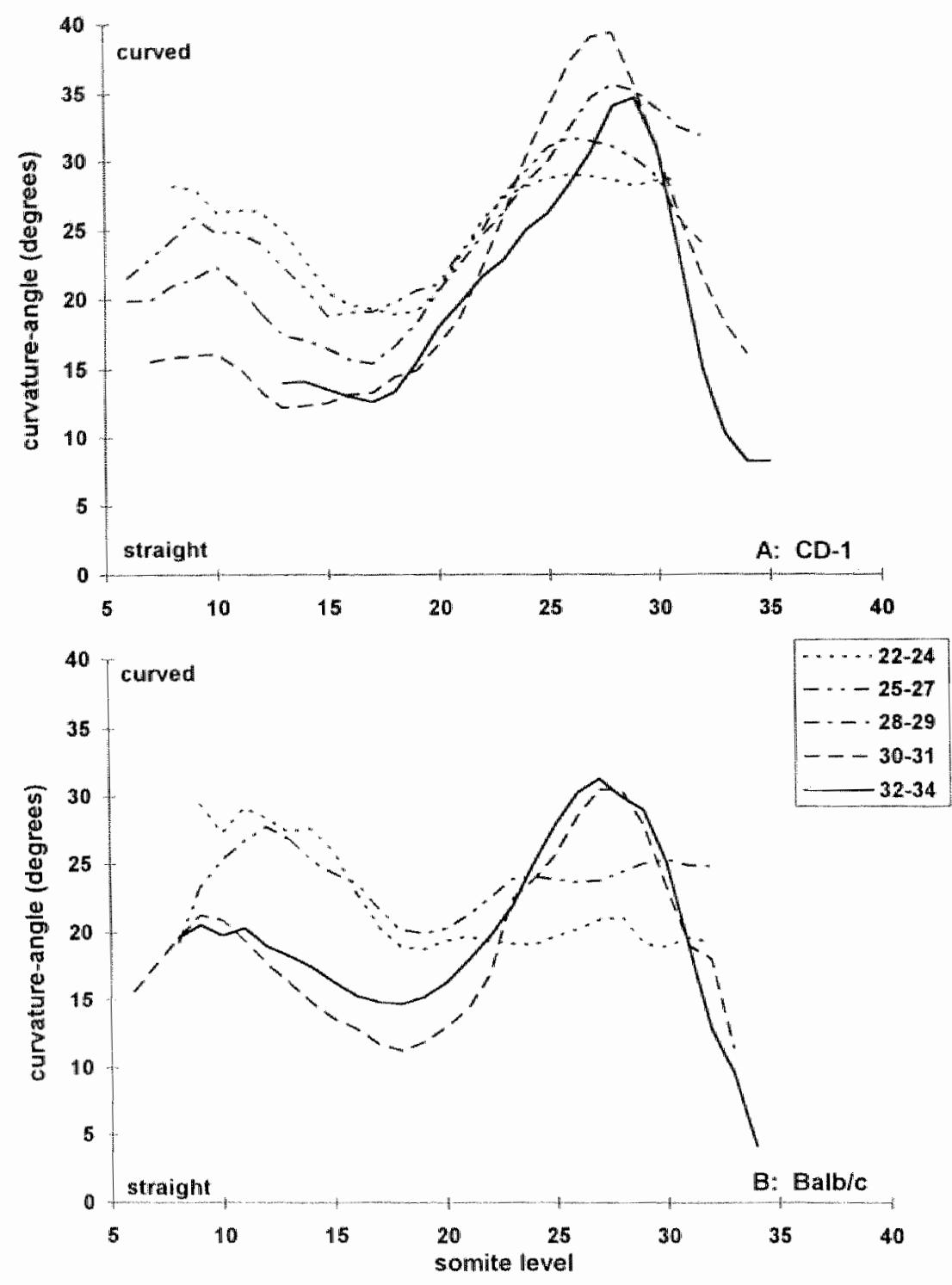

Fig. 4. Segmentangle of CD-1 (A) and Balb/c (B) embryos throughout development. Each dothed the represents the average values for a specific developmental stage, the latter indicated by the somite range as specified in the legend. On the ordinate, the topographic level along the cranio-caudal axis is indicated. The somite levels in the presomitic caudal part have been extrapolated, as has been described in Fig. 1. In the anterior part of both mouse strains (left side of tha $\mathrm{g}$ atob), a decrease of segment-angle is noticed with increasing developmental stage. The posterior part shows the opposite relationship. Embryos from the stage $30-31$ onwards show a steep decrease in segment-angle beyond somite level 29. 


\section{Causal factors in axial curvature}

In elucidating determinants of axial curvature, previous studies concentrated on specific maxima, called flexures, with special attention to the cranial and cervical flexures. It has been suggested that flexure formation is partly based on differential dorsoventral growth (Goodrum and Jacobson 1981), which could be the result of differential proliferation (Takamatsu and Fujita 1987). However, flexure formation could also be the result of overgrowth of the neural tube while the prosencephalon is attached to the slower-growing foregut Jacobson et al. 1979; Pikalow et al. 1994). Besides growth, the distribution pattem of monoamines points to a role in flexure formation. It has been suggested that they influence flexure formation by acting upon the contractile filament system of cells, influencing cell division, cell shape and cellular motility (Lawrence et al. 1973; Newgreen et al. 1981; Wallace 1982; Lauder 1988). Other influences on curvature originate from developmental processes that are spatially and temporally related to flexures, such as looping of the heart to the cranial and cervical flexures (Flynn et al. 1991). Extraembryonic structures are also able to influence axial curvature, as has been experimentally shown for the amnion, which could enhance the curvature of the caudal part (Peeters et al. 1996).

So, flexure formation has been related to various intrinsic and extrinsic factors. Probably, they are acting in a level-specific, combined fashion. In the present study, all three mouse strains (CD-1, Balb/c and corly lail) had maxima of axial curvature at the levels of the limb buds, suggesting that the developing limb buds have an effect on axial curvature. We suggest that these relatively solid blocks of mesenchymal tissue hinder the unbending of the axis of the embryo. The steep decrease in axial curvature of the caudal region involves the tail bud, which is just caudal to the hindlimb bud, and we suggest that its outgrowth is straight at least in part because it is not hindered by the limb bud.

\section{General axial unbending is not due to growth only}

For the description of axial curvature of non-mutant mouse embryos during the stages of neurulation, two parameters were used. The curvature-radius, as measured in the present study, is directly related to the rate of bending to the ventral side of the dorsally situated neurulation and, moreover, the curvature-radius gives information about the dorso-ventral growth through development. In contrast to the curvature-radius, the segment-angle is only related to the outgrowth in craniocaudal direction. If it is supposed that the cranio-caudal outgrowth of the segments is correlated with the dorso-ventral outgrowth, then the outgrowth could be modelled as an increase in the radius and not in the angle of the circle segment. This would then result in a segment-angle constant throughout development, as seen between somite levels 20-25. However, up to somite level 20, both curvatureradius and segment-angle decreased with increasing developmental stage. This indicates that growth of this part of the embryo was not according to the 


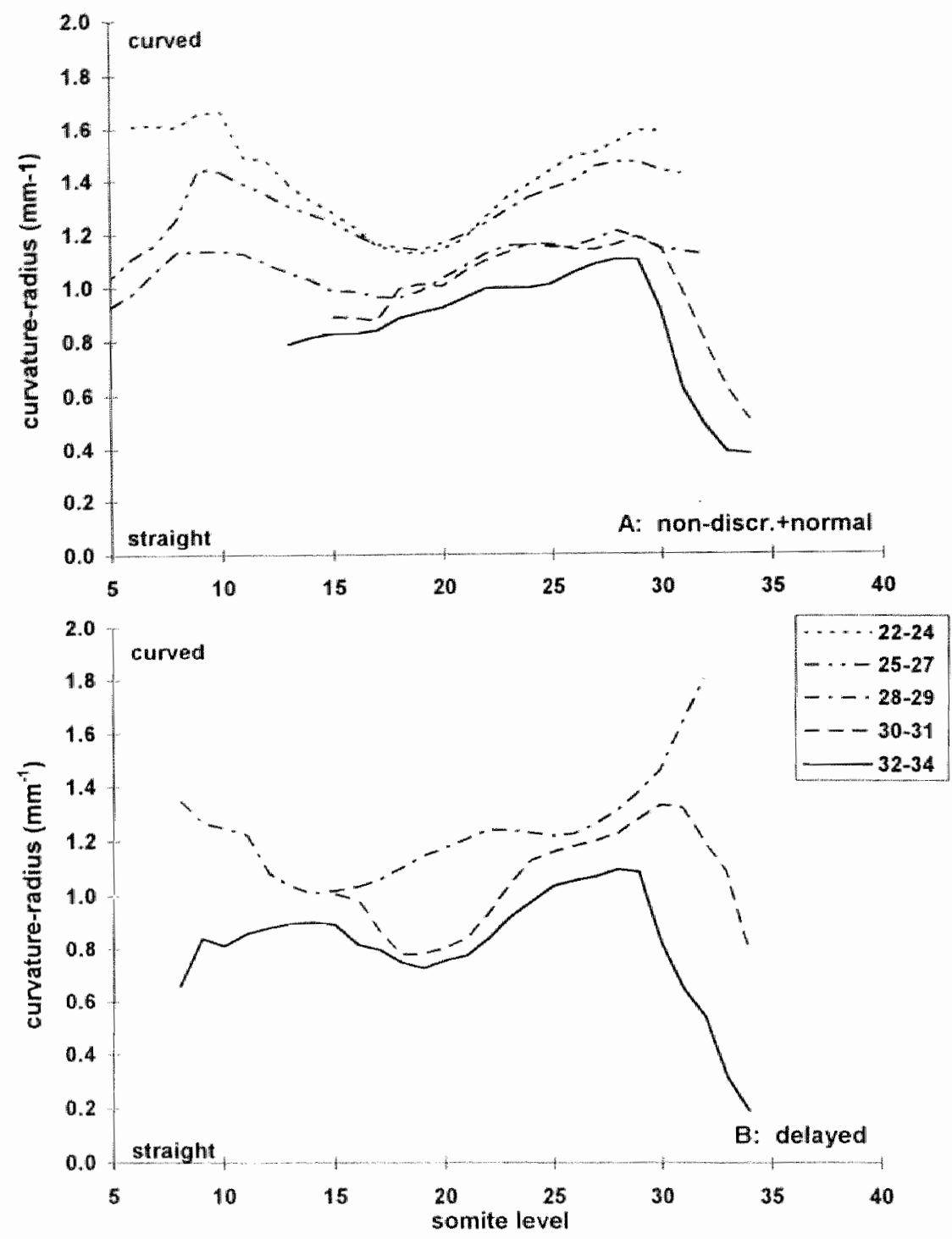

Fig. 5. Curvaturemadius of the surty rail embryos of the non-discriminative (up to stage $28-29$ ) + normal (A) and delayed (B) phenorypes. Fach dotted lime represents the average values for a specific developmental stage, the latter indicated by the somite ange as specified in the legend. On the ordinate, the topographic level along the cranio-caudal axis is indicated. The somite levels in the presomitic caudal part have been extrapolated, as has been described in Fig. 1. Embryos of the normal phenotype exhibit axial curvatures which resemble those of non-mutant mice (Fig. 3). Embryos of the delayed phenotype show an enhancement of curvature beyond somite level 26 initially; this is followed by a decrease of curvature at a more caudal level (somite 31) than in the normal ones (somite 29), and by a correction of this caudal level in cranial direction in the oldest embryos. 
assumption. Therefore, the general axial unbending probably occurs through a combination of growth and other axial unbending factors. In the human embryo a decrease of curvature in the trunk region was also noticed; it has been proposed that this is due to the pressure of the blood within the large blood vessels because these comprised a substantial area in cross sections (Blechschmidt 1955). In mouse embryo cross sections the blood vessels are also large compared with the total cross section, so the same mechanism could account for the process in the trunk region of the mouse embryo.

Beyond somite level 25 , the segment-angle increased with increasing developmental stage, whereas curvature-radius still showed a decreasing trend. This indicates that at the caudal levels, besides segmental outgrow th and blood pressure, other factors have to be involved in the determination of the axial curvature. Therefore, it is very likely that changes in axial curvature during development are the result of a levelspecific combination of factors.

\section{Enhanced axial curvature in curly tail embryos}

As discussed above, the parameter curvature-radius is sufficient to indicate the axial curvature of an embryo. This parameter was used in the present study of the aurby tail mouse mutant to determine axial curvature in relation to an abnormal neural tube closure pattern.

Delayed curly tail embryos had an enhanced axial curvature for their entire caudal region compared with the normal ones. A previous study also showed an enhanced curvature for the delayed arrly tail embryos of stage 27-29 (Brook et al. 1991), but this curvature was measured at one level only. The present study shows that the curvature is enhanced from somite level 26 onwards at an increasing rate.

The enhanced curvature of the delayed ckrby tail embryos is the result of a dorsalventral growth imbalance. Delayed arry kail embryos show a reduced proliferation rate of the gut endoderm and notochord cells in the neuropore region compared with their normal littermates, whereas the proliferation rates of the neurocpithelium are identical (Copp et al. 1988a). The basis of this proliferation imbalance is unclear, but monoamines might play a role as discussed earlier. Other factors that could influence growth balance have also been shown to be altered: the accumulation of the extracellular matrix hyaluronan is abnormally slow around the notochord (Copp and Bernfield 1988), the growth factor transferrin is bound in reduced quantities to the luminal surface of the hindgut endoderm (Hoyle and Copp 1995) and RAR- $\beta$ expression in the hindgut is less (Chen et al. 1995). Cultured at an elevated temperature, curly lail embryos exhibited reduced angles of curvature. It was suggested this may have been achieved by re-balancing of proliferation rates, because temperature would have more impact on fast-growing neuroepithelium than on slower-growing gut endoderm (Copp et al. 1988b; Peeters 
et al. 1996). Thus, some factors involved in growth have been shown to be altered in de caudal part of the delayed curby tail embryos, but the main trigger causing the dorso-ventral differential growth remains unknown.

The above-mentioned factors have been demontrated in the curby tail embryo at the stages at which the delayed and normal phenotypes could be discriminated. However, the onset of aberrant growth has to occur at younger stages. The present study shows that the youngest non-discriminative carly tail embryos exhibited a lower rate of curvature than the CD-1, which was corrected at the next stage. This means that the general axial unbending through development was diminished. This result points to an aberrant growth pattern, present even before the embryos could phenotypically subdivided.

The most conspicous feature of the delayed curly tail embryos at advanced developmental stages is the sudden axial unbending which occurs at a more caudal level than in normal ones, and the gradual unbending in a cranial direction to a normal rate of curvature. Thus, the initial growth imbalance probably normalizes at advanced developmental stages. The curvature of the caudal part at these stages may be determined by RAR-- $y$, which has been found at those caudal levels, and moreover, retinoic acid has been shown to alter the axial curvature of the outgrowth of the tail bud (Chen et al. 1994, 1995).

\section{Axial curvature and neurulation}

Curly tail embryos of the delayed phenotype at the stage 28-29 have been shown to have enhanced axial curvatures at the neuropore region (present study, Brook et al. 1991). This enhanced curvature is thought to cause a delay in PNP closure by inducing mechanical stress upon the neural folds. The neural folds have to elevate in dorsal direction, to converge to the midline and their tops have to fuse for a correct PNP closure. Bending of the caudal part to the ventral side probably impedes both elevation and convergence by the increase of ventrally directed stress while unbending of that region would release this stress (Brook et al. 1991; van Straaten et al. 1993; Peeters et al. 1996). This is in agreement with our finding that the sudden axial unbending coincided spatially and temporally with the final closure of the PNP in both the CD-1 and Balb/c embryos.

At other axial levels of the mouse embryo also, neural tube closure correlated with curvature (Jacobson and Tam 1982). First, the initial fusion of the neural folds in the mouse embryo occurs in the cervical region when this region has a dorsal bending. Second, the mesencephalic flexure has a pause in the progression of its ventral bending that coincides with the closure of the cranial neural tube. Third, the mesencephalon, as the most curved cranial part of the neural tube, is the region where the closure occurs last. For the PNP region of the mouse embryo, it has been shown experimentally that a linear relationship exists between the axial 
curvature and the closure of the PNP (Peeters et al. 1996). Besides the mouse embryo, chick embryos, which have an almost flat appearence, showed a delay in the PNP closure according to the rate of imposed curvature when cultured on sligthly curved substrates (van Straten et al. 1993). These studies indicate that the rate of curvature is an important feature of the embryos during neurulation. Besides this rate, the somite level of the sudden axial unbending is a likely critical factor in determining a correct PNP closure because the delayed curly tail embryos exhibited (besides enhanced curvature) unbending at a more caudal level than the normal carby tail embryos.

In conclusion, the PNP closure in the mouse embryo is probably facilitated by the steep decrease in axial curvature of the caudal part. For a normal closure pattern, both the rate of curvature and the axial level of the onset of this decrease are important.

\section{Acknowledgements}

This work was supported by a grant from the Netherlands Organisation for Scientific Research (431241) (MCEP). We thank H. Rutten and A. Pietersen for their assistance in collecting and measuring the embryos.

\section{References}

Beier DR, Dushkin H, Telle T (1995) Haplotype analysis of intraspecific backcross curly tail mice confirms the localization of $a t$ to chromosome 4. Mamm Genome 6: 269-272

Biechschmidt E (1955) Embryologische Untersuchungen unter funktionellen Gesichtspunkten. Acta Anat 24: 339-392

Brook FA, Shum ASW, Straten HWM van, Copp AJ (1991) Curvature of the caudal region is responsible for failure of neural tube closure in the curly tail (on) mouse embryo. Development 113: $671-678$

Chen WH, Morris-Kay GM, Copp AJ (1994) Prevention of spinal neural rube defects in the curly tail mouse mutant by a specific effect of retinoic acid. Dew Dyn 190:93-102

Chen WH, Morris-Kay GM, Copp AJ (1995) Genesis and prevention of spinal ncural tube defects in the curly tat mutant mouse: involvement of retinoic acid and its nuclear receptors RAR- $\beta$ and RAR- $\gamma$. Development 121: 681-691

Copp AJ (1985) Relationship between timing of pasterior neuropore closure and development of spinal neural tube defects in mutant (curly tail) and normal mouse embryos in culture. I Embryol Exp Morphol 88: 39-54

Copp AJ, Bernfield M (1988) Accumulation of basement membrane-associated hyaluronate is reduced in the posterior neuropore region of mutant (curly tail) mouse embryos developing spinal neural tube defects. Dev Biol 130: 583-590

Copp AJ, Brook FA, Roberts H] (1988a) A cell-type-specific abnomality of cell proliferation in mutant (curly tail) mouse enbryos developing spinal neural tube defects. Development 104: 285-205

Copp AJ, Crolla JA, Brook FA (1988b) Prevention of spinal newral tube defects in the mouse embryo by growth retardation during neurulation. Development 104: 297-303 
Embury $\$$, Seller M], Adinolf $M$, Polani PE (1979) Neural tube defects in curly tail mice. I. Incidence and expression. Proc R Soc Lond B Biol Sci 206: 85-94

Flynn ME, Pikalow AS, Kimmelman RS, Searls RL (1991) The mechanism of cervical Alexure Formation in the chick. Anat Embryol 184: 411-420

Goodrum $G R$, Jacobson $A G$ (1981) Ceptalic fexure formation in the chick embryo. I Exp Zool 216:399-408

Gruneberg H (1954) Genetical studies on the skeleton of the mouse. VII. Curly tall. J Genet 52 : $52-67$

Hanks JH, Wallace RE (1949) Relation of oxygen and temperature in the preservation of tissues by reftigetation. Proc Soc Exp Biol Med 71: 196

Hoylc C, Copp AJ (1995) Transferrin and transferrin receptor in the development of the curly tail mouse cmbryo. Proc EDBC 95, Toulouse, July 9-13

Jacobson AG, Tam PPL. (1982) Cephalic neurulation in the mouse embryo analyzed by SEM and morphometry. Anat Rec 203: 375-396

Jacobson AG, Miyamoto DM, Mai SH (1979) Rathke's pouch morphogenesis in the chick embryo. J Exp Zool 207: 351-366

Lauder JM (1988) Neurotransmitters as morphogens. Prog Brain Res 73: 365-387

Lawrence $\mathbb{I E}$, Burden HW (1973) Catecholamines and morphogenesis of the chick neutal tube and notochord. Am J Anat 137: 199-208

Letts VA, Schork NJ, Copp AJ, Bernfield M, Frankel WN (1995) A curly-tail modifier locus, met1, on mouse chromosome 1.7. Genomics 29:719-724

Männer J, Seidl W, Steding G (1995) Formation of the cervical flexure: an experimental study on chick embryos. Acta Anat 152:1-10

Neumann PE, Frankel WN, Letts WA, Coffrn JM, Copp AJ, Bernfield M (1994) Multifactorial inheritance of neural tube defects: localization of the major gene and recognition of modifiers in of mutant mice. Nat Genet 6: 357-362

Newgreen DF, Allan IJ, Young HM, Southwell BR (1981) Accumulation of exogenous catecholamines in the neural tube and non-neural tissues of the early fowl embryo. Correlation with morphogenetic movements. Wilhelm Roux'Arch Entwicklungsmech Org 190: $320-330$

Peeters MCE, Shum ASW, Hekking JWM, Copp AJ, wan Straaten HWM (1990) Relationship between altered axial curvature and neural tube closure in normal and mutant (owty taib) mouse embryos. Anat Embryol 193: 123-130

Pikalow AS, Flynn ME, Searls RL. (1994) Development of cranial flexure and Rathke's pouch in the chick embryo. Anat Rec 238: 407-414

Straten HWM van, Hekking JWM, Copp Af, Bernfteld M (1992) Deceleration and acceleration in the rate of posterior neuropore closure during neurulation in the curly tall (ct) mouse embryo. Anat Embryol 185: 169-174

Straten HWM van, Hekking JWM, Consten C, Copp AJ (1993) Intrinsic and extrinsic factors in the mechanism of neunatation: effect of curvature of the body axis on closure of the posterior neuropore. Development 117: 1163-1172

Takamatsu T, Fujita $S$ (1987) Growth of the notochord and formation of cranial and mesencephalic flexures in chicken embryo. Dev Growth Differ 29: 497-502

Wallace $J A$ (1982) Monoamines in the early chick embryo: demonstration of serotonin synthesis and the regional distribution of serotonin-concentrating cells during morphogenesis. Am I Anat 165:261-276 


\section{Chapter 3.2}

\section{Effects of axial curvature alterations in the mouse}

\section{Published as:}

Relationship between altered axial curvature and neural tube closure in normal and mutant (curly tail) mouse embryos. Marian C.E. Peeters, Alisa S.W. Shum, Johan W.M. Hekking, Andrew J. Copp and Henny W.M. van Straaten. Anatomy and Embryology (1996) 193: 123-130

\section{Abstract}

Neural tube defects, including spina bifida, develop in the corby tail mutant mouse as a result of delayed closure of the posterior neuropore at 10.5 days of gestation. Affected embryos are characterized by increased ventral curvature of the caudal region. To determine whether closure of the neuropore could be affected by this angle of curvature, we experimentally enhanced the curvature of non-mutant embryos. The amnion was opened in 9.5 day embryos; after $20 \mathrm{~h}$ of culture, a proportion of the embryos exhibited a tightly wrapped amnion with enhanced curvature of the caudal region compared with the control embryos in which the opened amnion remained inflated. Enhanced curvature correlated with a higher frequency of embryos with an open postetior neutopore, irrespective of developmental stage within the range, 27 to 32 somites. Thus, within this somite range, caudal curvature is a more accurate determinant for normal spinal neurulation than the exact somite stage. Enhanced ventral curvature of the carly tail embryo correlates with an abnomal growth difference between the neuroepithelium and ventral structures (the notochord and hindgut). We experimentally corrected this imbalance by culturing under conditions of mild hyperthermia and subsequently determined whether the angle of curvature would also be corrected. The mean angle of curvature and length of the posterior neuropore were both reduced in embryos cultured at $40.5^{\circ} \mathrm{C}$ by comparison with control embryos cultured at $38^{\circ} \mathrm{C}$. We conclude that the sequence of morphogenetic events leading to spinal neural tube defects in curly tail embryos involves an imbalance of growth rates, which leads to enhanced ventral curvature that, in turn, leads to delayed closure of the posterior neuropore. 


\section{Introduction}

Neural tube defects (NTD) are among the commonest severe congenital malformations in humans. Attempts to teveal the underlying developmental defects have included the study of mouse mutants in which neunalation is disturbed. The mouse mutant curty tail has NTD with similarities in location and form to human NTD (Embury et al. 1979). The homozygous carly tail mouse develops spinal NTD in about $60 \%$ of cases, which comprise tail flexion defects $(40 \%)$ or spina bifida with tal flexion defects $(20 \%)$. A few $(3 \%)$ embryos develop cranial neural tube defects. The other $40 \%$ of the homozygotes are morphologically normal (Grüneberg 1954; Embury et all. 1979; Copp et al. 1982). A major gene responsible for the curly lail defects has been mapped to distal chromosome 4, and modifier genes affecting the penetrance have been mapped to chromosome 3 and 5 (Neumann et al. 1994; Beier et al. 1995).

Spina bifida and tail flexion defects develop in curly tail embryos as a consequence of disturbed closure of the posterior neuropore (PNP). Curly tail embryos with 8-23 somites show a slow but progressive decrease in PNP size in the same way as nonmutant CD-1 embryos. However, from the 24 somite stage onwards, while the PNP decreases rapidly in size and closes between the stages of 27-32 somites in CD. 1 embryos, in curty tail embryos both the mean and range of PNP size increase progressively, reaching a maximum at the 33 somite stage (van Straaten et al. 1992). Embryos with a small neuropore at this stage subsequently close the PNP and develop normally in most cases, in contrast to embryos with an enlarged neuropore, which either close the PNP with several hours' delay, leading to the development of tail flexion defects, or fail to close the PNP at all, leading to spina bifida (Copp 1985).

Several studies have suggested a morphogenetic mechanism for the delayed PNP closure that characterizes curly tail embryos. Measurement of the angle of curvature of the caudal body axis revealed that curly tail embryos with a severely enlarged PNP also have an enhanced ventral curvature compared with somite-matched embryos with a small PNP (Brook et al. 1991). Enhanced ventral curvature of the neuropore region is postulated to result in mechanical forces that oppose the elevation, convergence and subsequent fusion of the neural folds. Data in support of this mechanism come from a study in which curvature of the caudal body axis of corly tail embryos was altered experimentally. An eyelash implanted in the hindgut lumen prevented enhanced curvature of the caudal region, and closure of the PNP was accelerated in these embryos (Brook et al. 1991). Also, the caudal region exhibited axial unbending during the stages of 27-29 somites, which was suggested to facilitate the final closure (Brook et al. 1991). Related findings have been described for the cranial region of the mouse embryo where neural tube closure in the 
mesencephalic region closely correlates with axial unbending (Jacobson and Tam 1982).

To establish definitively a role for ventral curvature in regulating neuropore closure, however, it will be necessary to demonstrate delay of PNP closure in non-mutant embryos in which ventral curvature has been imposed experimentally. "To date, the only study of this type relates to the chick where culture of embryos on curved substrates showed that both the incidence and extent of delayed PNP closure correlate with the degree of curvature imposed (van Straten et al. 1993). In the present study, we have extended this analysis to the mouse by establishing. enhanced ventral curvature in non-mutant CD.1 embryos caused by a deflated amnion. This experiment showed that enhanced ventral curvature in non-mutant embryos leads to delayed closure of the PNP.

A further aspect of the morphogenetic mechanism of delayed PNP closure in curly tail embryos relates to the cause of the ventral curvature. We previously demonstrated an imbalance of growth in the caudal region of the ourty tail embryo with a diminished proliferation of ventral tissues, the notochord and hindgut endoderm, accompanied by normal proliferation of the overlying neuroepithelium (Copp et al. 1988a). Culturing embryos at an elevated temperature re-balanced the growth rates in the caudal region and normalized PNP closure (Copp et al. 19881). It was not determined in that study, however, whether re-balancing of the growth rates affected the angle of ventral curvature. In the present study we have examined this question and found a reduction in the angle of curvature, as well as a reduction in PNP length, in curly tail embryos cultured at high temperature.

\section{Materials and Methods}

\section{Mouse strains and explantation of embryos}

Random-bred CD-1 mice (Charles River Wiga, Germany) served as a source of non-mutant embryos, whille mutant corby tail (c) mice were maintained as a closed, random-bred colony of $a / d$ individuals (Brook et al. 1991). Males and females were paired for mating overnight and checked for a vaginal plug the next moming. The day of finding the plug was designated day 0 of gestation. On day 9 , dams were sacrificed by cervical dislocation, and CD- $\$$ conceptuses were explanted into prewarmed Hanks' buffer (Tanks and Wallace 1949) containing $1 \%$ penicillin/1\% streptomycin (Gibco) and $10 \%$ newborn calf serum (Gibco). Curly anil conceptuses were explanted on day 10 into PB1 medium (Cockroft 1990) containing $10 \%$ fetal calf serum (Flow Labs, UK). The mural trophoblast and Reichert's membrane were removed while the yolk sac was left intact. Crown-rump and head (rostrorhombencephalic) length were measured by transillumination of the yolk sac using an eyepiece graticule fitted on a Wild stereo microscope. Due to the opacity of the 
yolk sac, the number of somites could not be counted accurately. In order to assess somite stage, the extratmbryonic membranes were removed from a group of embryos ( $n=38$ for $C D-1 ; n=62$ for curly tail) and the number of somites was determined and correlated with crown-tump and head length. Linear correlations were found (Fig. 1A,B), which were used to determine the somite stage of embryos priot to culture.

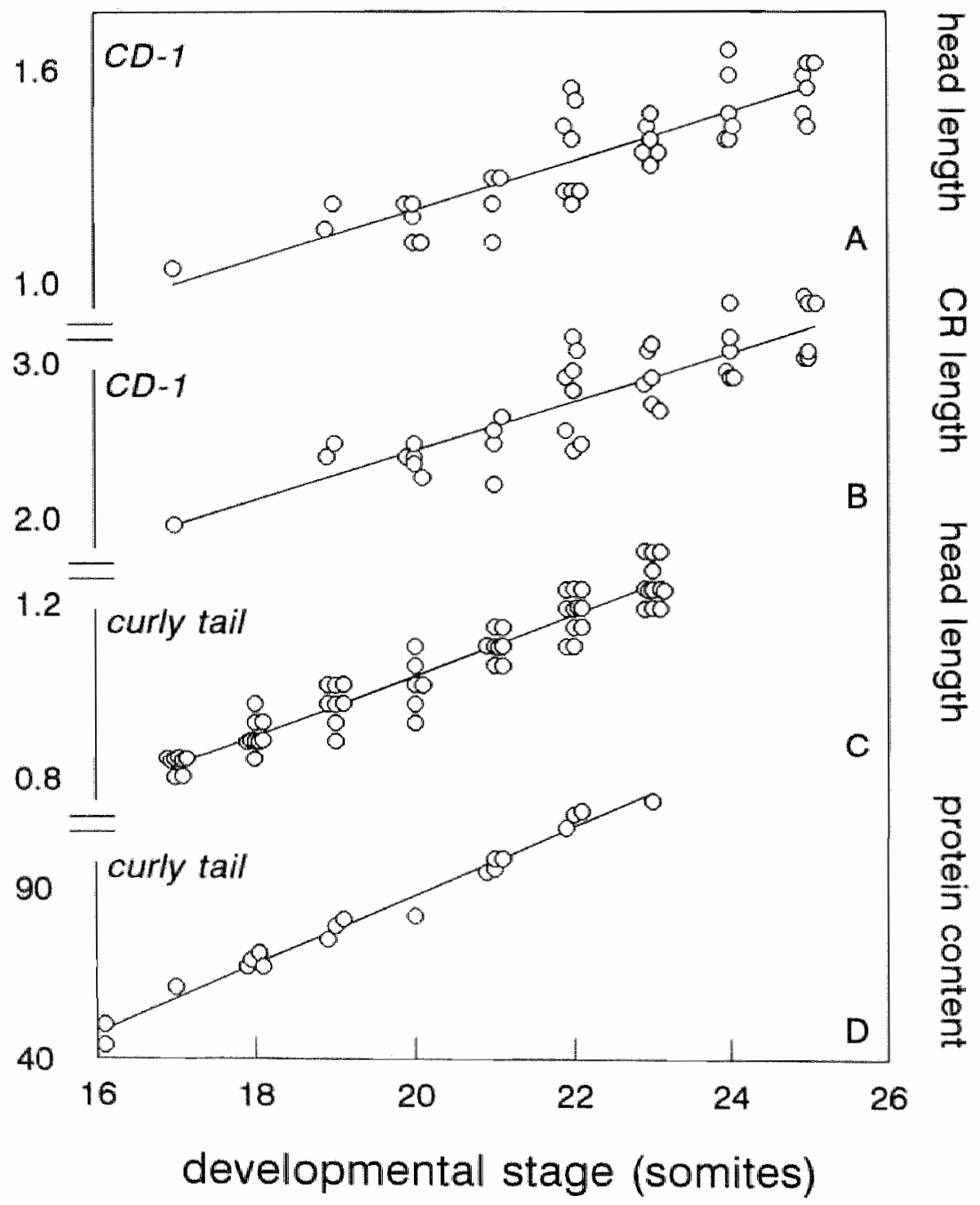

Fig. 1. Standard graphs of (A) head and (B) crown-rump lengths plotted against somite number in $C D-1$ embryos, and (C) head length and (D) proten content plotted against somite number in arly tail embryos. For description of techniques see Materials and Methods. 


\section{Experimental enhancement of ventral curvature in $C D-1$ embryos}

The ventral curvature of non-mutant $C D-1$ mice was experimentally enhanced by culturing embryos within a collapsed amnion. Embryos with 17-24 somites, well before the final phase of PNP closure, were selected and an opening was made in the yolk sac, using watchmaker's forceps, taking care not to damage blood vessels. Next, an opening was made in the amnion, close to the caudal part of the embryo, near the ectoplacental cone. Two explants were placed in each culture bottle containing $2 \mathrm{ml}$ of heat-inactivated rat serum with $1 \%$ penicillin $/ 1 \%$ streptomycin. One of the explants was marked with a suture (Copp 1985) through the ectoplacental cone, which did not damage the extraembryonic membranes. Cultures were maintained. for $20 \mathrm{~h}$ by the method of New et al. (1973).

At the end of culture, embryos were checked for viability, as judged by the presence of a heart beat and yolk sac circulation. Viable explants were transferred to a petri dish containing pre-warmed Hanks' buffer. Crown-rump and head length wete measured, the yolk sac was removed and the explant was classified according to the state of the amnion. A pilot study had revealed that operated embryos could be divided into three groups after culture: (A) "collapsed", because the amnion was very tight around the embryo (Fig. 2A); (B) "inflated", because there was a clearly defined spacious amniotic cavity surrounding the embryo, closely resembling the unoperated situation (Fig. 2B); (C) "outside", because the caudal region was outside the amnion in direct contact with the culture medium. The latter group comprised a minor proportion $(<2 \%)$ of the embryos and was excluded from further analysis. It was not possible to predict whether the amnion would collapse or inflate during culture.

After classification, the amnion was removed and the somites were counted. Only embryos with 27-32 somites were processed further, resulting in a total of 109 embryos in the collapsed group and 63 in the inflated group. Mean values of crown-rump and head length, and somite number before and after culture, wete compared between these two groups using Student's $t$-test. Embryos were fixed in Bodian's fluid $(90 \mathrm{ml}$ of $80 \%$ ethanol, $5 \mathrm{ml}$ of $99 \%$ acetic acid and $5 \mathrm{ml}$ of $37 \%$ formaldehyde) for 1-5 days and dehydrated in a graded series of ethanols. The embryos were processed for scanning electron microscopy (SEM). Dehydrated embryos were critical-point-dried using liquid $\mathrm{CO}_{2}$, attached with sillwer paint to aluminium stubs and coated with gold/palladium. The embryos were viewed at 15 keV using a SEM (505 Philips) and the PNP was scored as open or closed. SIM was used because the removal of the amnion could be checked: embryos of the collapsed group had a tightly wrapped atnnion that was difficult to see under the dissecting microscope. Moreover, pictures from the lateral side of the embryo were easy to use for the measurement of the angle of curvature. 


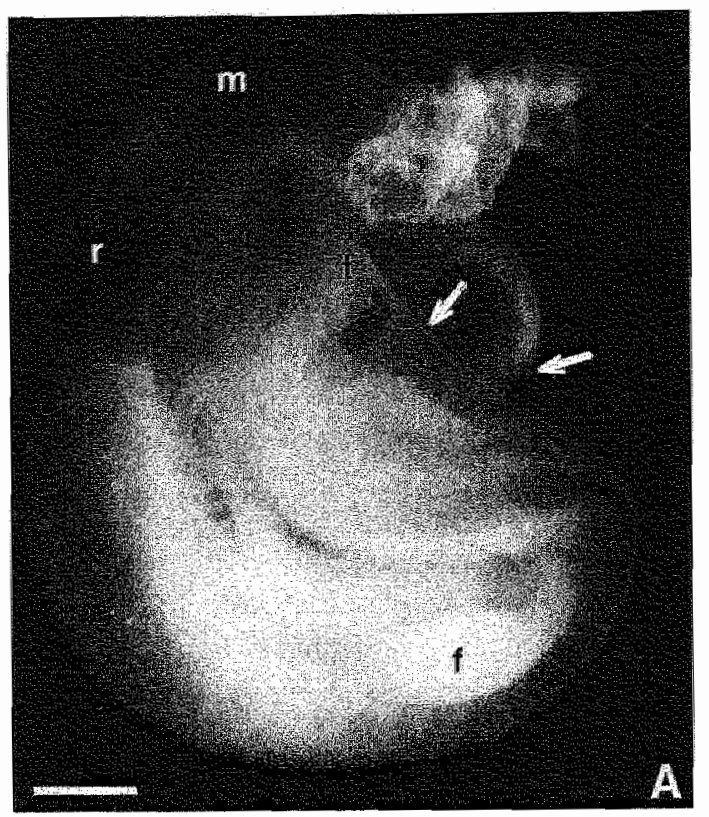

Fig. 2. The appearance of the amnion in $C D$ - 1 embryos after culture. A Enbryo of the collapsed group. The amnion (arrow) is tightly apposed to the embryo and as a result dificult to see. The amnion has forced the caudal part to bend. B Embryo of the inflated group. The amnion (arrows) can be seen surrounding the embryo, separated from it by a distinct amniotic cavity. Of fore limb bud, $n$ mesemcephalon, $r$ thombencephalon, $t$ tail bud). Bar $500 \mathrm{~mm}$

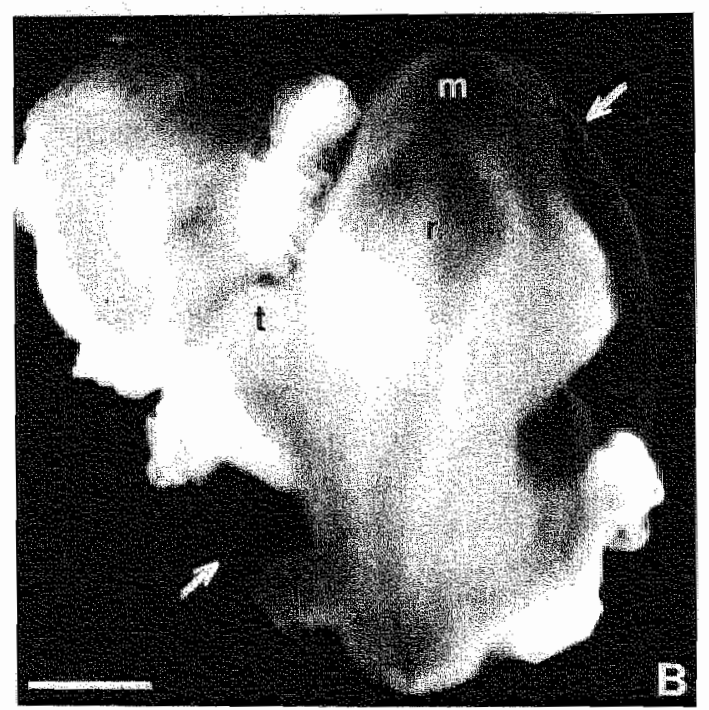

\section{Experimental re-balancing of growth rates in curly tail embryos}

Embryos with 18-22 somites were selected and allowed to resume growth under optimal conditions at $38^{\circ} \mathrm{C}$ for $1 \mathrm{~h}$ (Cockroft 1990). A tandomly chosen "hightemperature" group was transferred to an incubator at $40.5^{\circ} \mathrm{C}$ while the control "nomal-temperature" group remained at $38^{\circ} \mathrm{C}$. Embryos were cultured by the method of New et al. (1973) for approximately $20 \mathrm{~h}$. Culture was terminated when 
embryos were expected to have reached the $27-29$ somite stage. This somite stage was chosen for further analysis so that the size of the PNP could be compared with data from previous studies of arly lail embryos. (Brook et al. 1991). The explants were transferred to pre-warmed PB1 $+10 \%$ FCS and checked for viability. Yolk sac and amnion were dissected from the embryo, PNP length was measured and the somites were counted. Only embryos with $27-29$ somites were processed further. The portion of the embryo caudal to the insertion of the allantois was removed for measurement of the angle of ventral curvature. Subsequently, the protein content of the entire embryo was determined by a standard method (Lowry et al. 1951). The protein content of the embryos before culture was estimated using the standard graph (Fig. 1C). The rates of increase in somite number and protein content were compared between the high-temperature and normal-temperature groups using Student's $t$ test.

\section{Measurement and analysis of ventral curvature}

The ventral curvature of cultured CD-1 embryos was measured on a SEM photograph of a lateral view of the caudal region. The fixation and processing of the embryos for SEM did not appear to affect axial curvature: in a group of 22 embryos, the angle of curvature was measured both before fixation and after SEM, and the mean difference of the two measurements $\left(2^{\circ}\right)$ was not significant (Wilcoxon signed rank test). Ventral curvature of the carly tail embryos was measured as described previously (Brook et al. 1991), using camera lucida drawings of the caudal region of the embryos. In both $C D-1$ and curby tail embryos, the angle of curvature was defined as described in Fig. 3, a larger positive angle corresponding to increased ventral curvature and a negative angle indicating dorsal curvature.

Logistic regression was used to test the differences in proportion of open PNP, taking into account three covariates: state of the amnion, class of ventral curvature and developmental stage of $C D \cdot 1$ embryos. Whether the covariates contributed significantly to the model was tested by calculating the logistic regression with and without the covariate and comparing these using the likelihood tatio test. Two-way analysis of variance was used to compare the average angle of curvature between the collapsed and inflated groups at different developmental stages. With the chisquare test of two proportions the frequency of open PNP was compared between the collapsed and inflated group. In arry lail embryos, angle of curvature, PNP length and head length were compared between the high-and normal-temperature groups at the different developmental stages by two-way analysis of variance adjusted for non-proportional replications (Armitage and Berry 1987). 

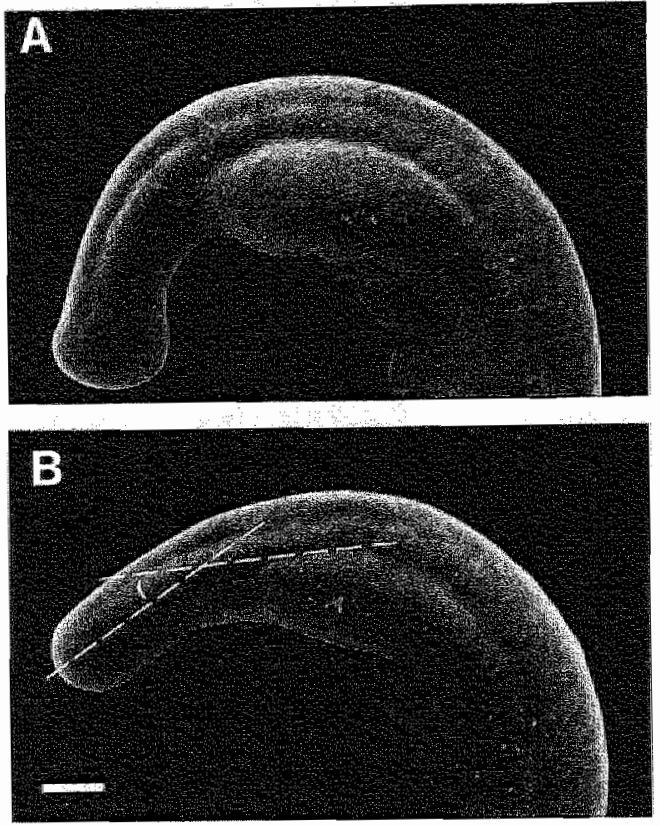

Fig. 3. SEM of the caudal region of cultured $C D-1$ embryos. A Detail of an embryo of the collapsed group with an angle of curvature of $50^{\circ}$. B Detail of an embryo of the inflated group with an angle of curvature of $30^{\circ}$. Angles of curvature were measured as indicated by the lines: owe lise was drawn along the midline of the tail bud, and the olber line tangential to the ventral edge of the penultimate somite. Bar $200 \mathrm{~mm}$

\section{Results}

Deflation of the amnion promotes enhanced ventral curvature and delays neuropore closure in $C D$ - 1 embryos

Irrespective of the developmental stage, $C D-1$ embryos cultured within a collapsed amnion had significantly $(\mathrm{P}<0.05)$ enhanced ventral curvature of the caudal region compared with those cultured within an inflated amnion (Figs. 3, 4). In addition, the range of curvature angles was about twice as wide in the collapsed group $\left(-2^{\circ}\right.$ to $\left.110^{\circ}\right)$ as in the inflated group $\left(0^{\circ}\right.$ to $\left.62^{\circ}\right)$. Thus, the experimental procedure of deflating the amnion was effective in producing a phenocopy, in non-mutant CD-1 cmbryos, of the enhanced curvature and the wider range of angles that characterize curly iail embryos. In both groups (Fig. 4) the angle of caudal curvature decreased by $15-17^{\circ}$ when the developmental stage increased from 27 to 32 somites $(\mathrm{P}<0.005)$.

From Fig. 5 it appears that within the wide range of curvature angles in the collapsed group, a striking correlation was found between angle of curvature and the proportion of embryos with an open PNP. The embryos of the inflated group demonstrated a smaller range of curvature angles, but the same relationship was found. The increasing proportion of embryos having an open PNP with increasing curvature was statistically significant in both groups $(\mathrm{P}<0.005)$. "This analysis is 
based on pooled data of the total group since we found that, at the stages studied, the relationship between proportion of embryos having an open PNP and angle of curvature was independent of somite number (data not shown). Thus, it appears that the likelihood of an embryo having an open PNP is closely related to its angle of curvature at all somite numbers between 27 and 32 . Within each corresponding class of curvature, the frequency of open PNP was higher in the collapsed group than in the inflated group $(\mathrm{P}=0.05)$. Since embryos of the total collapsed group had, on average, larger angles of curvature than embryos of the total inflated group (Fig. 4), the collapsed group had a significantly $(\mathrm{P}<0.005)$ higher incidence of open PNP $(36 / 109)$ than the inflated group $(7 / 63)$.

\section{Deflation of the amnion does not affect the rate of embryonic development}

Development of the CD-1 embryos from the collapsed and inflated groups was compared. The average crown-rump and head lengths before culture were 2.37 $( \pm 0.03) \mathrm{mm}$ and $1.23( \pm 0.01)$ for the collapsed group, and $2.39( \pm 0.03) \mathrm{mm}$ and 1.23 ( \pm 0.01$)$ for the inflated goup. After culture, these lengths were increased to $3.98( \pm 0.04) \mathrm{mm}$ and $2.36( \pm 0.02)$ for the collapsed group, and $3.91( \pm 0.04) \mathrm{mm}$

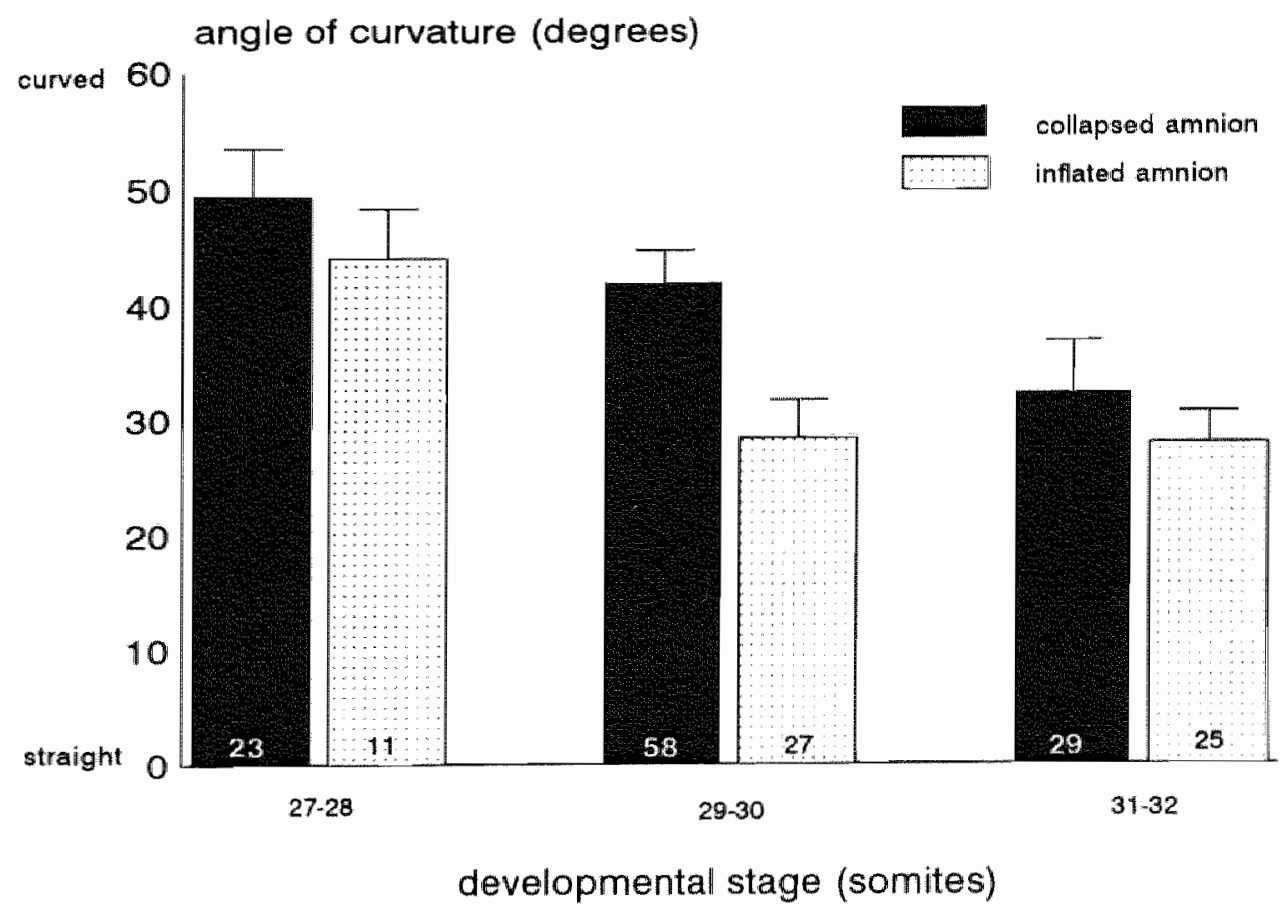

Fig. 4. Effect of culturing CD.t embryos within a collapsed or an infated amion on their caudal axial curvature at three developmental stages. Mean+SE; wabbers on the bars are sample sizes. The average ventral curvature of embryos cultured within a collapsed amnion is significantly higher when compared to the curvature of those cultured within an inflated amnion $(\mathrm{P}<0.05)$. The angle of curwature decreases significantly with increasing number of somites in both groups $(\mathrm{P}<0.005)$. 
and 2.31 ( \pm 0.03$)$ for the inflated group. The differences between the two groups were not significant. Also, no significant differences were found in somite number: in the collapsed group, the average number of somites rose from 20.5 to 29.7 , while in the inflated group, the corresponding values were 20.6 and 30.0 somites. The rates of increase of the above parameters in the two groups were not significantly different (Table 1).

\section{Growth retardation of curly tail embryos reduces ventral curvature and enhances neuropore closure}

We previously showed that growth retardation in vitro restores the growth balance in the caudal region of curby tail embryos (Copp et al. 1988b). In the present study, embryos of the high-temperature group showed a significant retardation in the rate of development ( $11 \%$ reduction in somite increase, $\mathrm{P}<0.001$ and $14 \%$ reduction in protein increase, $\mathrm{P}<0.001)$ compared with the embryos of the normal-temperature group (Table 1). To determine whether growth retardation served to reduce caudal curvature, the curvature angles were compared between the high- and normal-

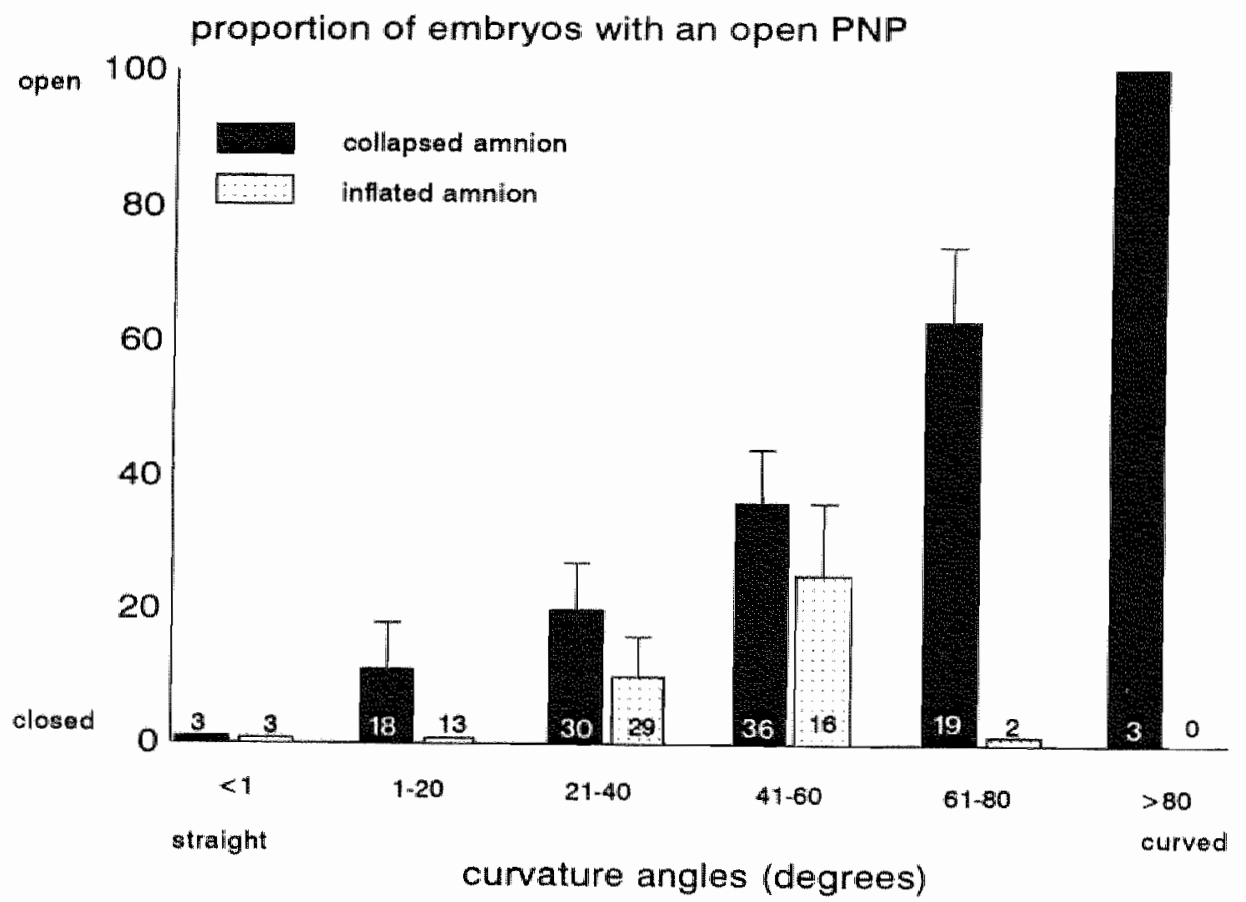

Fig. 5. Proportion of CD.t embryos with an open PNP plotted against the angle of caudal axial curvature for CD-f embryos with 27-32 somites, with a collapsed or inflated amnion. Mean $+5 E$; mumbers on the bars are sample sizes. Since proportions are binomially distributed, the SE is computed in a standard way. Both groups of embryos exhibit a significandy increasing proportion of open PNPs with increasing curvature $(\mathrm{P}<0.005)$, which is independent of developmental stages in the range of $27-32$ somites but, due to the wide range of angles in the collapsed group, this relation is particularly clear in the latter. 
temperature groups. The high-temperature group exhibited significantly reduced curvature compared with the normal-temperature group $(\mathrm{P}<0.001$, Fig. 6A). There was also a significant decrease in angle of curvature with increasing somite number as in the CD-1 embryos $(\mathrm{P}<0.005$, Fig. 6A). This decrease was more pronounced in the normal-temperature group than in the embryos cultured at high-temperature. Figure $6 \mathrm{~B}$ shows the relation between growth retardation and neurulation defects. The high-temperature group had a significantly reduced PNP length compared with the normal-temperature group $(\mathrm{P}<0.001)$. The effect was clear in 28 and 29 somite embryos, where PNP length was reduced by more than $50 \%$.

Table 1. Growth and development during culture of the experimental versus control group of the $C D-1$ embryos (collapsed versus inflated amnion) and of the curly tail embryos $\left(40.5^{\circ} \mathrm{C}\right.$ vs $38.0^{\circ} \mathrm{C}$ culture temperature).

\begin{tabular}{|c|c|c|c|c|c|c|c|}
\hline & \multicolumn{7}{|c|}{ Rate of increase during culture } \\
\hline & \multicolumn{3}{|c|}{ Experimental } & \multicolumn{3}{|c|}{ Contral } & \multirow[t]{2}{*}{ Difference $^{:}$} \\
\hline & $n$ & Mean & $\mathrm{SE}$ & $n$ & Mean & $\mathrm{SE}$ & \\
\hline \multicolumn{8}{|l|}{ CD-1 } \\
\hline CR length $(\mu \mathrm{m}$ per $h)$ & 110 & 81 & 2.0 & 63 & 76 & 2.0 & $6.6 \%$ \\
\hline Head length ( $\mu \mathrm{m}$ per $h)$ & 110 & 56 & 1.0 & 63 & 54 & 1.0 & $3.7 \%$ \\
\hline Number of somites (per h) & 110 & 0.46 & 0.01 & 63 & 0.47 & 0.01 & $-1.9 \%$ \\
\hline \multicolumn{8}{|l|}{ arby tail } \\
\hline Number of somites (per h) & 25 & 0.37 & 0.005 & 25 & 0.42 & 0.004 & $-11.1 \%$ \\
\hline Protein content $(\mu \mathrm{g}$ per $h)$ & 25 & 8.63 & 0.25 & 25 & 10.03 & 0.28 & $-14.0 \%$ \\
\hline
\end{tabular}

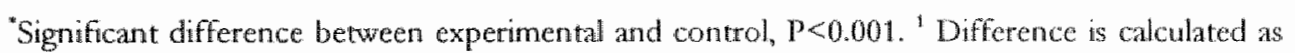
the mean of the experimental minus the mean of the control group divided by the mean of the control group. 


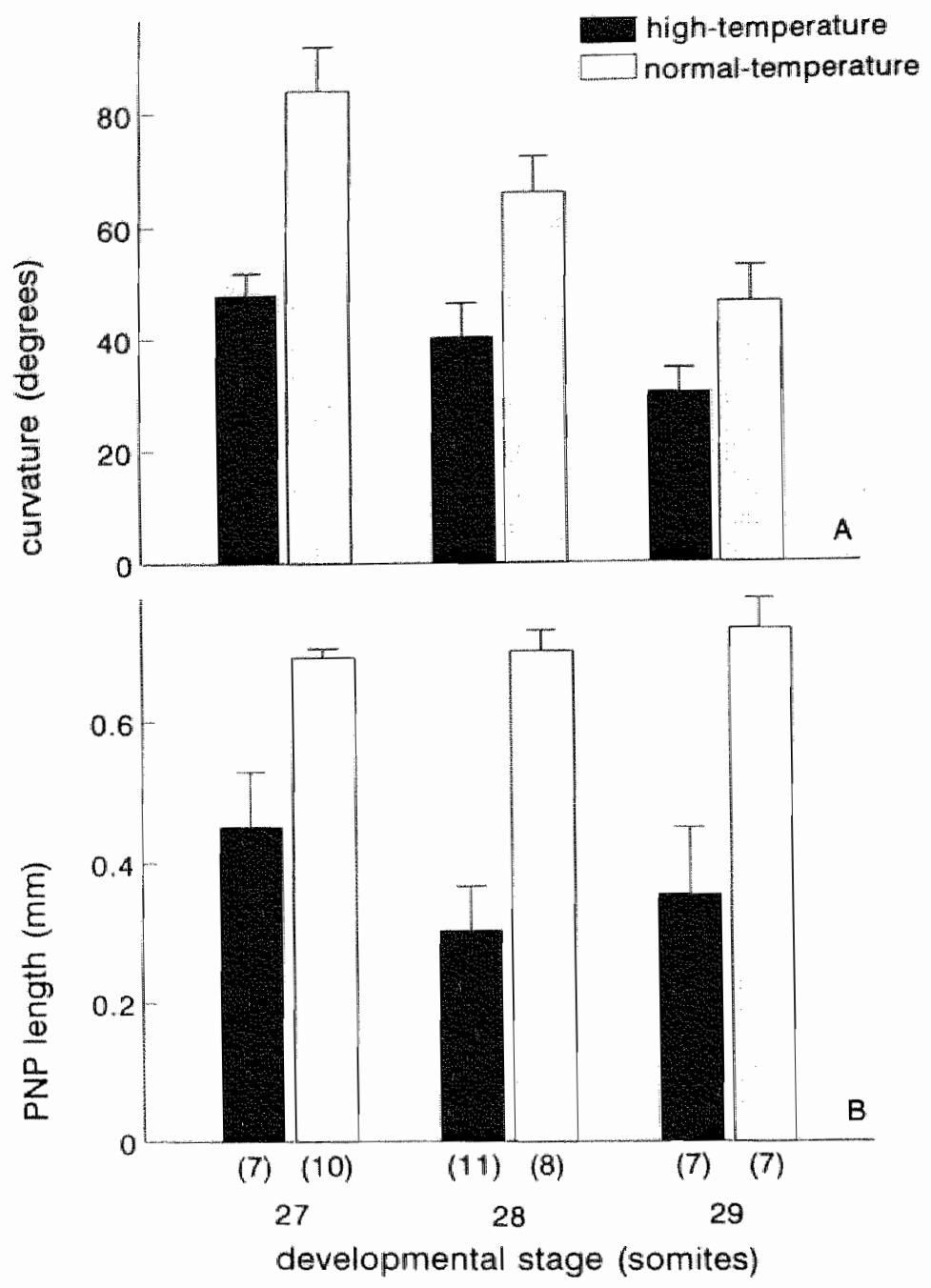

Fig. 6. Effect of elevated culture temperature on the development of curty tail embryos. Mean+SE; swmbers betwath bar are sample sizes. A Ventral curvature of the neuropore region is significantly reduced in embryos cultured at $40.5^{\circ} \mathrm{C}$ compared with the control group cultured at $38^{\circ} \mathrm{C}(\mathrm{P}<0.001)$. The angle of curvature decreases significantly with somite number $(\mathrm{P}<0.005)$. B The length of the PNP is significantly reduced in embryos cultured at $40.5^{\circ} \mathrm{C}$ compared with $38^{\circ} \mathrm{C}(\mathrm{P}<0.001)$ 


\section{Discussion}

In this study, two experiments were carried out to further examine the relationship between the curvature of the caudal body axis and closure of the posterior neuropore in the mouse embryo. These experiments tested the hypothesis that dorsal-ventral growth imballance in the curby tail mutant can lead to an increased ventral curvature, which can delay the closure of the PNP (Fig. 7). Enhanced curvature and a wider range of angles of curvatures were induced experimentally in non-mutant $C D-1$ embryos by deflation of the amnion; the proportion of embryos with an open PNP increased with increasing axial curvature. On the other hand, rebalancing of growth rates by high temperature culture reduced axial curvature in the curly tail embryos and prevented the delay of PNP closure. These data provide support for our hypothesis (Fig. T) and suggest, moreover, that the angle of curvature of the caudal region can modulate the rate of PNP closure in non-mutant embryos, demonstrating a general relationship between axial morphogenesis and neurulation.

The normal range of curvature of the caudal part of the embryo is not constant during development. Brook et al. (1991) showed that in curly kail embryos the caudal region gradually unbends during development. The present data from CD-1 embryos also demonstrate such an unbending (Fig. 4). During this period of unbending, the PNP size reduces markedly in CD-1 mice (van Straaten et al. 1992). Because the relationship found in the present study between curvature and PNP closure was independent of developmental stage ranging from 27 to 32 somites, it seems likely that the normally occurring axial unbending is a factor underlying the relationship between decreasing PNP size and increasing developmental stage. Thus, axial unbending during the final phase of primary neurulation is a requirement for PNP closure.

The complexity and heterogeneity of the process of neurulation are illustrated in the genotypic and phenotypic pattern of the various NTD mouse mutants. Although the final malformation (exencephaly, myeloschisis) is the common tesult, the etiology is different for each mutant (Copp et al. 1990; Linder and Davisson 1994). Axial curvature as underlying factor has only been reported for the carly lail mouse so far, though it is well possible that curvature disturbances may occur in several NTD mutants, since a correct curvature appears to be a pretequisite to normal closure of the PNP (this study). In man, several genetic and environmental factors are related with NTD, but little is known about underlying morphogenetic processes. However, similarities ate described between human and curly ail NTD (Embury et al. 1979). It is possible that the human axial curvature is also a factor influencing the closure of the neural tube. 


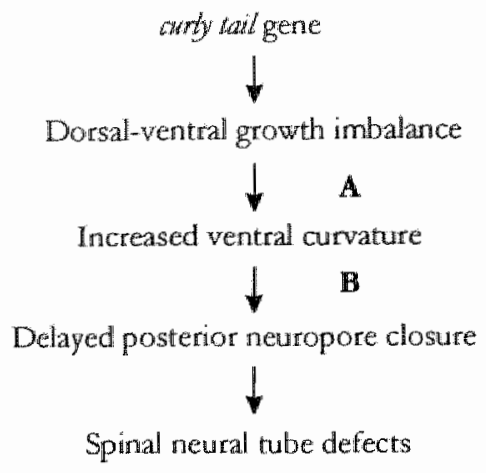

Fig. 7. Postulated sequence of pathogenetic events responsible for development of spinal neural tube defects in curby tail mice. $A$ and $B$ indicate the causal relationships tested in the present study. A The cell proliferation imbalance was corrected experimentally in amb tail embryos to test whether increased ventral curvature is prevented. $B$ Increased ventral curvature was imposed experimentally on non-mutant CD.7 embryos to test whether neuropore closure is related to axial curvature.

\section{Embryonic development in an opened amnion}

During normal embryonic development, the amniotic volume is positively correlated with crown-rump length, body weight and total protein content of the tat embryo (Park and Shepard 1994). For the mouse embryo it has been demonstrated that the amount of extraembryonic fluid increases up to about day 16 of gestation (Renfree et al. 1975) but specific data on the mouse amniotic volume are not available. In our study, the relationship between amniotic volume and embryonic growth was disturbed experimentally by opening the amnion. During subsequent culture, in a proportion of the embryos operated upon, the deflated amnion became tightly wrapped around the caudal region of the embryo, forcing this regton to adopt enhanced ventral curvature. Figure $2 \mathrm{~A}$ was specifically selected as example of the collapsed appearance because it demonstrates an abnormal torsion of the caudal part, which illustrates the ability of the amnion to impose forces on the embryo. In other operated embryos, the amnion was found to be inflated after culture, probably because the opening had become obstructed or closed. These embryos did not appear to have experienced extemal forces on their caudal axis, and therefore they served as controls.

It has been suggested that one of the causes of anomalies of the human caudal neural tube may be constraints during embryonic development caused by amniotic membranes owing to a lack of amniotic fluid (Higginbottom et al. 1979). Such lack of amniotic fluid could result from a defect in formation or rupture of the amnion, leading to temporary leakage (McLone and Stephens 1990). However, a possible 
relationship between the volume of the amnion and curvature of the body axis does not appear to have been considered in these studies.

Another mechanism that could explain the developmentai effects of culture in an open amnion relates to changes in the biochemical environment of the embryo due to the direct connection that is created between the amniotic cavity, the yolk sac and the culture medium. "The neurulation stage embryo needs glucose in the amniotic fluid that serves as the main source of energy for the neuroepithelium (Park and Shepard 1994) as for the whole embryo during early organogenesis (Shepard et al. 1970; Tanimura and Shepard 1970; Cockroft 1988; Hunter and Sadler 1988). The embryo also needs amino acids, which are supplied by the yolk sac, where the breakdown of proteins from the culture medium takes place (Freeman and Lloyd 1983). Since all cultured embryos in our study exhibited blood circulation through the yolk sac vessels, irrespective of a collapsed amnion, and glucose can also diffuse through the amnion and yolk sac, we expect that the amounts of available amino acids and glucose were sufficient. Indeed, embryonic growth did not differ between the collapsed and the inflated groups of embryos, and their appearance in the SEM was similar. Moreover, embryos of both groups formed new somites at the same rate, approximately 1 pair every $2 \mathrm{~h}$, which is normal for embryos at this stage (Brown 1990). Thus, it does not seem likely that alterations in the nutrient concentration of the fluid bathing the embryo could have been responsible for the enhanced axial curvature of the embryos cultured within a collapsed amnion. We consider it more likely that mechanical forces resulting from the reduced amniotic volume were directly responsible for the enhanced axial curvature leading to delay of PNP closure.

\section{Effect of growth retardation on the development of curly tail defects}

In a previous study, we showed that culturing wrly tail embryos at $40.5^{\circ} \mathrm{C}$ causes growth retardation, re-balances growth rates within the neuropore region and diminishes the PNP closure delay (Copp et al. 1988b). It was not clear, however, whether the axial curvature that accompanies delayed PNP closure was also corrected by the growth retardation; therefore, this question was tested in the present study. By culturing carly lail embryos at $40.5^{\circ} \mathrm{C}$ tather than the usual $38^{\circ} \mathrm{C}$ we found that growth retardation was induced and that both the abnormal ventral curvature and the delay of PNP closure were diminished.

Growth retardation reduces the proliferation of all tissues, but the rapidly proliferating neuroepithelium is affected to a greater extent than the more slowly proliferating notochord and hindgut (Copp et al. 1988b), thereby restoting the growth balance within the caudal region and reducing the angle of curvature. Growth retardation, caused by other factors than hyperthermia, has similarly been shown to prevent the development of spinal NTD in curty lail embryos. Three antineoplastic drugs: hydroxyurea (Seller and Perkins 1983), mitomycin C (Seller 
and Perkins 1986) and 5-fluorouracil (Seller 1983), when administered in utero to curly tail pregnant females at 9.5 days of gestation, all caused a significant reduction in the incidence of spinal NTD in the offspring. The three drugs have different sites of action (Langenbach et al. 1972; Herken 1980), but all have growth-retarding effects (Tanimura 1968; Scott et al. 1971), making it seem likely that these drugs, like hyperthermia, diminish ventral curvature, prevent delay of PNP closure and thus reduce the incidence of spinal NTD.

\section{Molecular basis of spinal NTD in curly tail embryos}

The present study has been concerned with the morphogenetic basis of PNP closure in the mouse embryo. Evidence is accumulating, however, to implicate several classes of molecules in the causation of the curly tail neurulation defect. Since enhanced ventral curvature appears to be the direct result of a growth imbalance in the caudal tegion (Copp et al. 1988a,b; this study), several studies have attempted to identify gtowth-related molecules whose distribution or expression is disturbed in the vicinity of the slowly growing notochord and hindgut. Extracellular matrix hyaluronan accumulates abnormally slowly around the notochord (Copp and Bernfield 1988; van Straaten and Bernfield, unpublished material), the growth factor transferrin is bound in reduced quantities on the luminal surface of the hindgut endoderm (C. Hoyle and A.J. Copp, in preparation) and the retinoic acid receptors (RAR- $\beta$, RAR- $\gamma$ ) are down-regulated in the hindgut and tail-bud regions respectively (Chen et al. 1995) in affected carly tail embryos. At present it is not possible to conclude which, if any, of these molecules are directly involved in the pathogenesis of spinal NTD: this is the subject of current reseatch.

\section{Acknowledgements}

This work was supported by a grant from the Netherlands Organisation for Scientific Research (431241) (MCEP), the Imperial Cancer Research Fund (ASWS and $\mathrm{AJC}$ ), and as a part of a Multicenter Agreement for Studying Neural Tube Defects in Mutant Mice funded by the National Institutes of Child Health and Human Development, U.S.A., through Cooperative Agreement HD 28882 (AJC). The authors thank the EM service of the Department of Pathology of the University of Limburg for technical support. 


\section{References}

Armitage P, Berry G (1987) Statistical Methods in Medical Research, 2nd edn. Blackwell, Oxfond

Beier DR, Dushkin H, "Telle $\mathrm{T}$ (1995) Haplotype analysis of intra-specific backcross wiblat mice confirms the localization of of to chromosome 4. Mamm Genome 6:269-272

Brook FA, Shum ASW, Straten HWM van, Copp AJ (1991) Curvarure of the caudal region is responsible for failure of neural fold closure in the owry tal (d) mouse embryo. Dexelopment 113: 671-678

Brown NA (1990) Routine assessment of morphology and growth: scoring systems and measurements of size. In: Copp AJ, Cockroft DI (eds) Postimplantation Mammalian Embryos: A Practical Appraach. IRL Press, Oxtord, pp. $93-108$

Chen WH, Morris-Kay GM, Copp AJ (1995) Genesis and prevention of spinal neural tube defects in the chy cail mutant mouse: involvement of retinoic acid and its nuclear reccptors RAR- $\beta$ and RAR- $\gamma$. Development 121:681-691

Cockroft DL (1988) Changes with gestational age in the nutritional requirements of postimplantation rat embryos in culture. Teratology 38: $281-290$

Cockroft DL (1990) Dissection and culture of postimplantation embeyos. In: Copp AJ, Cockroti: DL (eds) Postimplantation Mammalian Embryos: A Practical Approach. IRL. Press, Oxford, pp. $15-40$

Copp Al (1985) Relationship between timing of posterior neutopore closure and development of spinal neural tube defects in mutant (cumb tail) and normall mouse embryos in culture. I Embiyol Exp Morphol 88: 39-54

Copp AJ, Bernfield $M$ (1988) Accumulation of basement membrane-associated hyaluronate is reduced in the posterior neuropore region of mutant (corly tail) mouse embryos developing spinal neural tube defects. Dev Biol 130: 583-590

Copp A], Seller M], Polani PE (1982) Neural tube development in mutant (curby tail) and normal mouse embryos: the timing of posterior neuropore closute in wivo and in witro. I Enbryol Exp Morphol 69: 151-167

Copp A], Brook FA, Roberts H] (1988a) A cell-type-specific abnormality of call proliferation in mutant (curly tail) mouse embryos developing spinal neural tube defects. Development 104: 285-295

Copp A., Crolla JA, Brook FA (1988b) Prevention of spinal neural wbe defects in the mouse embryo by growth retardation during neurulation. Development 104: 297-303

Copp AJ, Brook FA, Estbeiro JP, Shum ASW, Cockroft DL (1990) The embryonic development of mammalian neural tube defects. Prog Neurobiol 35: 363 403

Embury S, Seller MJ, Adinolfi M, Polani PE (1979) Neural tube defects in carly-lat mice. I. Incidence and expression. Proc R Soc Lond [Biof] 206: 85-94

Freeman SI, Lloyd JB (1983) Evidence that protein ingested by the rat viscenal yolk sac yields amino acids for synthesis of embryonic protein. I Embryol Exp Morphol 73: 307-315

Gruneberg H (1954) Genetical studies on the skeleton of the mouse. VIll. Curly tail. J Gonet 52 : $52-67$

Hanks WH, Wallace RE (1949) Relation of oxygen and temperature in the preservation of tissucs by refrigeration. Proc Soc Exp Biol Med 71:196

Herken R (1980) Cell cycle phase specificity of hydroxyurea and its effects on the cell kinetics in embryonic spinal cord. Teratology 21:9-14

Higginbottom MC, Jones KL, Hall BD, Smith DW (1979) The amniotic band distuption complex: timing of amniotic rupture and variable spectra of consequent defects. I Pediatr 95 : 544-549

Hunter ES III, Sadler TW (1988) Embryonic metabolism of foetal fuels in whole-embryo culture. Toxicol In Vitro 2: 163-167 
Jacobson $A G$, Tam PPL (1982) Cephalic neurulation in the mouse tembryo analysed by SEM and morphometry. Anat Rec 203: 341-359

Langen bach RJ, Daryenberg PV, Heidelberger C (1972) Thymidylate synthetase: mechanism of inhibition by 5-fuoro-2'-deoxyuridylate. Biochem Biophys Res Commun 48: 1565-1571

Linder CC, Dayisson MT (1994) Mouse models for studying neural tube defects. Neurology News; The Jackson Laboratory, Bar Harbor, ME

Lowry OH, Rosebrough NJ, Farr $\mathrm{N}$, Randall RJ (1951) Protein measurement with the Folin phenol reagent. J Biol Chem 193: 265-275

Mclone DG, Stephens $\mathrm{FD}(1990)$ Amniotic constraints as a cause of embryonic neural deformation. Concepts Pediatr Neurosurg 10: 22-29

Neumann PE, Frankel WN, Letts VA, Coffin JM, Copp AJ, Bernfield M (1994) Multifactorial inheritance of neural tube defects: localization of the major gene and recognition of modifiers in $a$ mutant mice. Nat Genet 6: 357-362

New DAT, Coppola PT, Terry S (1973) Culture of explanted rat embryos in rotating tubes. J Reprod Fertil 35: 135-138

Park HW, Shepard TH (1994) Volume and glucose concentration of tat amniotic fluid: effects on embryo nutrition and axis rotation. "Teratology 49: 465-469

Renfree MB, Hensleigh HC, McLaren A (1975) Developmental changes in the composition and amount of mouse fetal fluids. J Embryol Exp Morph 33: 435-446

Scott WJ, Ritter EJ, Wilson JG (1971) DNA synthesis urmibition and cell death associated with hydrowyurea teratogenesis in rat embryos. Dev Biol 26: 306-315

Seller MJ (1983) The cause of neural tube defects: some experiments and a hypothesis. J Med Genet 20: $164-168$

Seller MJ, Perkins KJ (1983) Effect of hydroxyurea on neural tube defects in curly tail mouse. J Craniofac Genet Dev Biol 3:11-17

Seller M], Perkins KJ (1986) Effect of mitomycin $C$ on the neural tube defects of curly tail mouse. Teratology 33: 305-309

Shepard "T"H, Tanimura T, Robkin MA (1970) Energy metabolism in early mammalian embryos. Dev Biol [Suppl] 4: 42-58

Straaten HWM van, Hekking JWM, Copp AJ, Bemfield M (1992) Deceleration and acceleration in the rate of posterior neuropore closure during neurulation in the corly tail ( $c$ ) mouse embryo. Anat Embryol 185: 169-174

Straten HWM van, Hekking JWM, Consten C, Copp AJ (1993) Intrinsic and extrinsic factors in the mechanism of neurulation: effect of curvature of the body axis in closure of the posteriot meuropore. Development 117: 1163-1172

Tanimura $\mathrm{T}$ (1968) Effects of mitomycin $\mathrm{C}$ administered at various stages of pregnancy upon mouse feruses. Okaimas Folia Anat Jpn 44:337-355

Tanimura T, Shepard 'TH (1970) Glucose metabolism by rat embryos in vitro. Proc Soc Exp Biol Med 135: 51-54 


\section{Chapter 3.3}

\section{Neurulation in the rabbit embryo}

\section{Published as:}

Neurulation in the rabbit embryo. Marian C.E. Peeters, Christoph Viebahn, Johan W.M. Hekking and Henny W.M. van Straaten. Anatomy and Embryology (1998) 197: $167-175$

\section{Abstract}

Among a broad range of factors and mechanisms involved in the complex process of neurulation a relationship between the curvature of the craniocaudal body axis and rate of neural tube closure has been proposed, but mote examples and models are needed to further substantiate the existence of this relationship. This is particularly true for mammals, where marked differences in embryonic body curvature between species exist. The rabbit embryo has virtually no curvature during the main phase of neurulation and is therefore a suitable model, but neurulation is hardly documented in this species. In the present study, therefore, neural tube closure in the rabbit embryo is presented in detail by morphological and morphometrical parameters, as well as from scanning electron microscopic investigations. At the stages of 6-8 somites, the flat neural plate transforms into a $\mathrm{V}$-shaped neural groove, beginning at the thombo-cervical level. Between the stages of 8 and 9 somites, multiple closure sites occur simultaneously at three levels: at the incipient pros-mesencephalic transition, at the incipient mes-rhombencephalic transition, and at the level of the first pairs of somites. This results in four transient neuropores. The anterior and rhombencephalic neuropores close between the stages of 9-11 somites. The mesencephalic neuropore is very briefly present. The posterior neuropore is the largest and remains longest. Its tapered (cranial) portion closes fast within somite stages 9-10. Subsequently its wide (caudal) portion closes up to a narrow slit, but further closure slows down till full closure is achieved at the 22-somite stage. In comparing rabbit neurulation with that of chick and mouse, the sequence of multiple site closure resembles that of the mouse embryo, but other important aspects of neurulation resemble those of the chick embryo. In contrast to mouse and chick, no time lag between closure at the three closure sites in the rabbit was seen. 


\section{Introduction}

During the process of neurulation the lateral parts of the initially flat neural plate elevate relative to the midline. The lateral edges, the neural folds, converge and subsequently appose, adhete and fuse. Although several differences exist between species and between the axial levels of neurulation, this general description fits most species. Neurulation is a multifactorial process driven by a number of fundamental cell behaviors, which include both neural plate and surrounding tissues. The events in neurulation as well as several mechanisms underlying these events ate described in an abundance of studies on neurulation in amphibian, mouse and chick embryos (for reviews see Karfunkel 1974; Gordon 1985; Copp et al. 1990; Schoenwolf and Smith 1990; Jacobson 1991; Schoenwolf 1994). Wellestablished mechanisms involved in the process of neurulation are intrinsic factors such as apical constriction of neuroepithelial cells, formation of hinge points in the neural plate, differential cellular proliferation and intercalation, and extrinsic factors such as mesoderm expansion and ectoderm expansion. In the last decade another extrinsic factor, axial curvature, was found to influence neurulation as well, and it was proposed that increased axial curvature correlates with a decreased rate of closure of the posterior neuropore (Copp 1985; Copp et al. 1988; Brook et al. 1991; van Straaten et al. 1993a; Peeters et al. 1996, 1997). Since the rabbit embryo is flat at corresponding stages, closure is expected to occur at a high rate. However, surprisingly less information is available on neurulation in the rabbit embryo, and the information given is very limited (Gottschewsky 1967; Edwards 1968; Evans and Sack 1973). In a more extensive study (Minot and Taylor 1905), eight embryos were described during the whole process of neurulation, and although the descriptions ate rather detailed, the small number of embryos do not elucidate neurulation as a continuous process. In another study (Waterman 1943), six embryos between 4 and 12 somites were shown in photographs and described in rather general terms; progress of closure was seen from the stage of 4 somites onward, and at the stage of 10 somites large anterior and posterior neuropores were seen. In an immunohistochemical study the expression of cytokeratin 8 and 18 appeared to be gradually lost from the neural plate cells, which was mirrored by a gradual increase of vimentin expression in a highly ordered manner. These findings were related to the morphogenetic processes of shaping of the neural plate (Viebahn et al. 1995), but could only be indirectly correlated with the mechanism of neural tube closure because detailed morphogenetic analysis of this process is still lacking in the rabbit.

In the present study a detailed morphological and morphometric description of neurulation in the rabbit embryo was formulated. Special care was taken not to deform the embryo in order to avoid changes in the delicate morphology of neural folds and neuropores during closure. 


\section{Materials and Methods}

Embryos were obtained from timed pregnancies of New Zealand White rabbits (Lammers, Euskirchen, Germany), which had been kept strictly in line with the regulations of the German law on the Protection of Animals, through cesarean section under an overdose $(90 \mathrm{mg}$ intravenously) of Nembutal (CEVA c/o Wirtschaftsgenossenschaft deutscher Tierärzte, Hannover, Germany). After removing the uterus, uterine swellings were opened at the abdecidual site and flushed with pre-warmed phosphate buffered saline (PBS). Subsequently $2 \mathrm{ml}$ Bodian's fluid $(90 \mathrm{ml}$ ethanol, $80 \% ; 5 \mathrm{ml}$ acetic acid, $99 \% ; 5 \mathrm{ml}$ formaldehyde, $37 \%$ ) was applied in order to briefly fixative the embryo from its ventral side onwards. The trophoblast and yolk sac were carefully cut around the embryonic disc and the disc was removed by blunt dissection from the adherent decidua. The embryo was placed in a Petri dish with excess PBS in order to minimize disturbance of morphology of the neuropores. A photograph (LM) was taken. Embryos were postfixed in Bodian's fluid. In embryos beyond the stage of 8 somites the posterior neuropore (PNP) appeated capped with the caudal amniotic fold, which was therefore removed. Embryos were prepared for scanning electron microscopy: after ethanol-dehydration they were critical-point-dried using liquid $\mathrm{CO}_{2}$, attached to aluminium stubs with silver paint, coated with gold/palladium, and viewed at $15 \mathrm{kV}$ with a Philips-505 scanning electron mictoscope. A photograph (SEM) was taken.

A total of 73 embryos between the stages of 4 and 22 somites were used, ranging from 8.2-9.2 days of development. The equation of the relation of both parameters is as follows: no. of somites $=19.5 *$ developmental days -156 . From this equation, the gain of somites was computed as one somite pair per 74 min. The following morphometrical parameters were determined on the LM photographs: length of the neuraxis, length of the neuropores, width of the posterior portion of the neural groove of of the PNP (defined in Fig. 1D, E), number of somites, the craniocaudal length of somites and the location of the neural plate extremities telative to somite 1. A neuropore is defined as a dorsal opening of the neural groove, but the very small openings in between button-like closure sites during PNP closure where excluded from this definition. Where neural folds appose a raphe becomes visible; this raphe was not considered to be part of the neuropore in our definition. Also the embryonic length (anterior extremity of the neural plate/tube to the caudal extremity of the allantoic diverticle) was measured; these data were fitted to a linear equation, resulting in the following relationship: length $(\mu \mathrm{m})=103.7 *$ no. of somites +2699 . Several faintly delimited structures in these LM photographs, such as the borders of the neuropores, were extrapolated from the SEM photographs before measurement. In some embryos not every parameter could be determined; therefore, the numbers of data presented in Figs. 4 and 5 differ. Data from one litter (12 embryos with 17-20 somite pairs) were mixed, and presented as one average value in $\mathbb{F i g} 4$. 
From the above data the process of neural tube closure was reconstructed (Fig. 7 ). The position of the first somite was used as a reference. The cranio-caudal length of the somites ranged between 100 and $130 \mu \mathrm{m}$ at all stages studied and was therefore assigned to an average of $112 \mu \mathrm{m}$. Progression of closure was drawn as a continuous, curved line; its irregularities at the stages of 9 somites, as well as the shape of the neutopores and of the neural folds were deduced from the LM and SEM photographs. Due to embryonic torsion a reliable reconstruction could not be made beyond the stage of 14 somites.
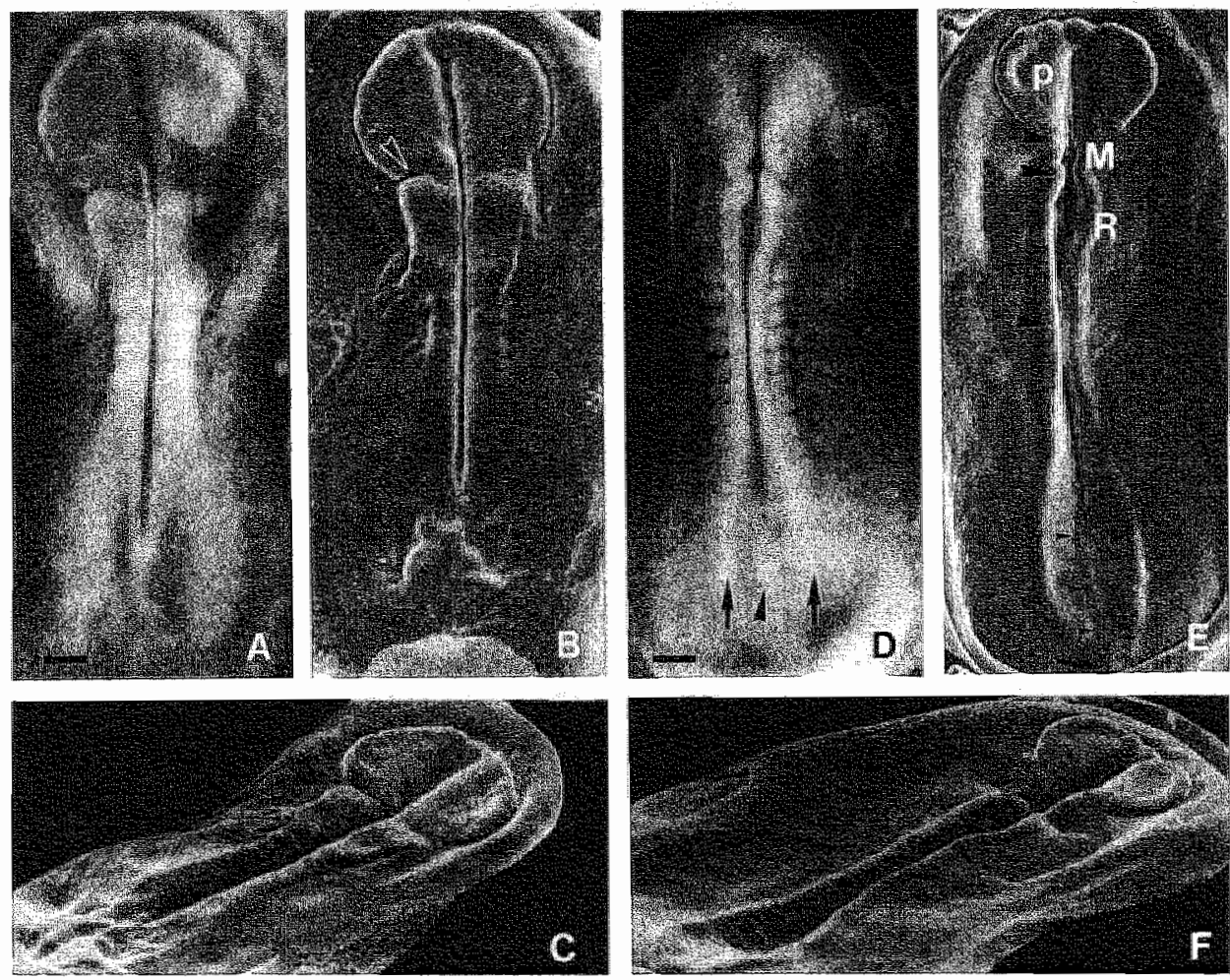

Fig. 1. Neurulation in the rabbit embryo up to the first closure of the neural groove. A-C Embryo with 4 somite pars. A Embryo immediately after dissection from its membranes. B, C Scanning electron micrograph of the same embryo. The cranial neural plate is dearly recognizable, with a sulcus (amwhad) demarcating a border between the incipient pros and thombencephalon. The neural groove is narrow and deep over most of its length, except for its caudal portion. D-F Fimbryo with 7 somite pairs. An incipient mes $(M)$ - and rhombencephalon $(\mathrm{R})$ are indicated, botdered by neural folds being closely approached at three sites (amoubeads in E). In $\mathbf{D}$, the width of the widest portion of the caudal neutal plate (arrows) and the primitive node (anvowbead) are indicated. In E, the optic pit (b), the arbitary caudal extremity of the neural plate (amm) and the primitive streak (small amowheads) are indicated. Bars in A and D $200 \mu \mathrm{m}$ 


\section{Results}

\section{Initiation of closure of the neural groove}

At the youngest stage studied ( 4 somites) the neural plate of the rabbit embryo is flat. In the cranial region, the lateral edges slightly elevate above the adjacent epidermal ectoderm, and a transverse indentation demarcates the transition of prosand thombencephalon. A small but deep medial groove exists over most of the length of the neural plate, except for its caudal extremity (Fig. 1A-C).
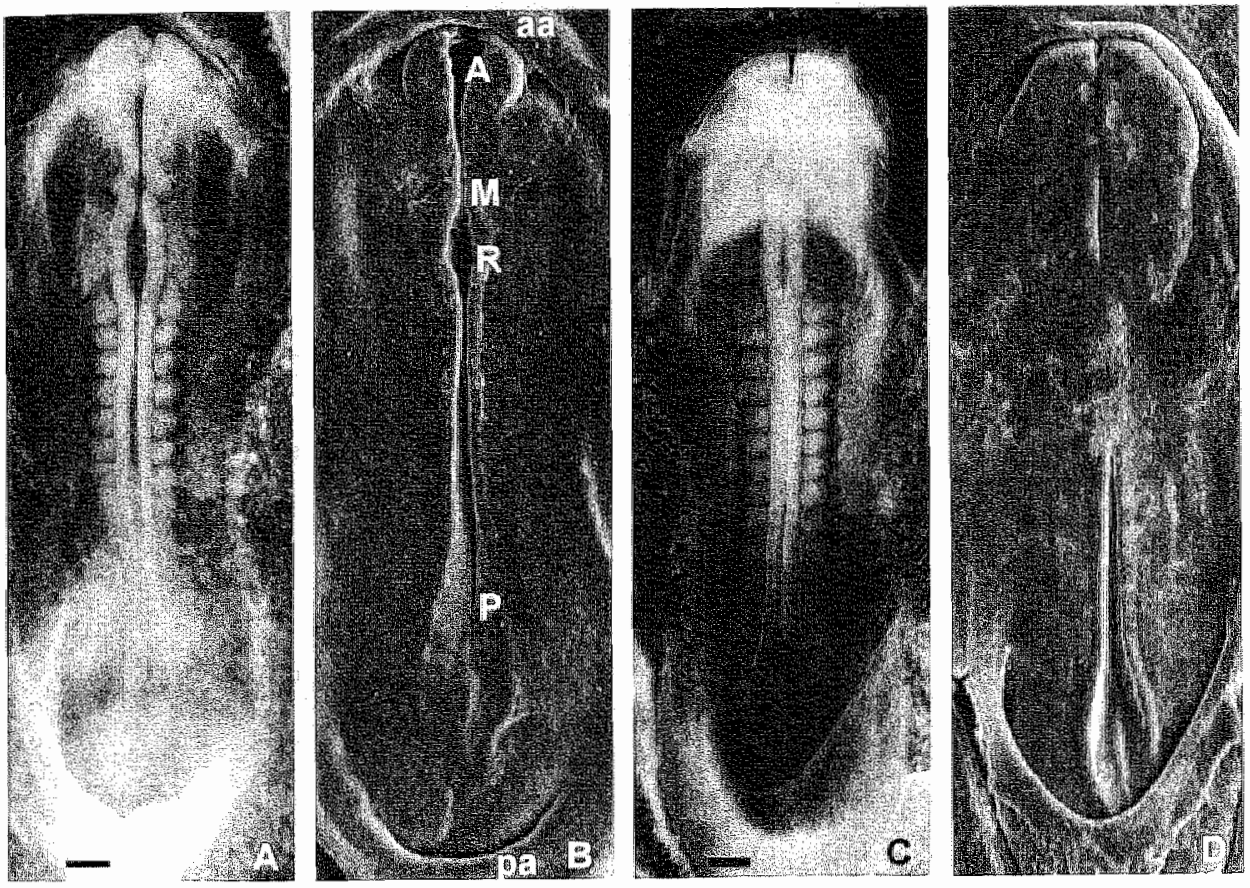

Fig. 2. Initial closure of the neural groove in the rabbit embryo. A, B Embryo with 8 somite pairs. The neural folds clo not appose yet, but 4 neuropores are about to arise: the anterior (A), mesencephalic $(M)$, thombencephalic $(R)$ and posterior neuropore ( $P$ ). Both the anterior amniotic fold (ad) and the posterior amniotic fold (pa) have started to develop. C, D Entoryo with 9 somite pairs. Compared with the previous embryo, closure has occurred rapidly in the posterior thombencephalic and diencephalic region, leawng an open ANP and PNP only, while a narrow slit is left from the other neuropores. In $\mathbf{C}$, the mesencephalic vesicle (arromhed) is indicated. In D, the primitive knot (armwhead) and streak (small arroubeali) are indicated. Bars in $A$ and $C 200 \mu \mathrm{m}$ 
At the stages of 6-8 somites, the profile of the neural groove is more pronounced (Fig. 1D.F). The cervical portion of the neural plate, in between the somites, demonstrates a $V$-shaped appearance with tather steep neural walls. These walls will probably close like a book. The caudal portion of the plate becomes delimited by a slight rise of its edges. In the thombencephalic region the neural groove is roughly U-shaped, while less elevated neural walls subsequently extend up to the prosencephalic level. The transverse indentation is still present at the future mesencephalic level. The subsequent displacement of the neural groove walls in a medial direction is not uniformly distributed, but is most pronounced at three levels: at the incipient pros-mesencephalic transition, at the incipient mesrhombencephalic transition and at the level of the first pairs of somites. The length of the neural plate amounts to about 3,000 $\mu \mathrm{m}$ at these stages (Fig. 4).

\section{Short-living cranial neuropores}

At the stage of 8 somites, the three levels with enhanced fold approach are evident, but in none of the four embryos investigated were the neural folds actually apposed. Apposition at those sites must theoretically lead to four transient neuropores: anterior, mesencephalic, thombencephalic and posterior (Fig. 2A, B). At the stage of 9 somites, apposition and fusion of the neural walls or folds had occurred (Fig. 2C, D) in all nine embryos investigated. The anterior neuropore (ANP) is present at somite stage 9 only; subsequent convergence and apposition of its neural folds, resulting in a median raphe, is seen at somite stages 9-11; closure is completed by fusion of the neural folds at somite stage 12 , allhough a view of its rostral extremicy is obscured by ventral bending of the prosencephalic region and its subsequent capping by the anterior amniotic fold. The mesencephalic neuropore (MNP) must have been present very briefly only, since it was not actually seen in any of the embryos with 9 somites; however, the local widening of the neural groove at somite stages 7 and 8 (Fig. 2A), and its subsequent development into the mesencephalic vesicle (Fig. $2 \mathrm{C}$ ) are indicative for such a transient neuropore. A prominent rhombencephalic neuropore (RNP), as arising at somite stage 8 (Fig. 2A, B) was not seen either; this neuropore was already narrowed into a (open) slit at somite stage 9 in all nine embryos (Fig. 2D). The subsequent raphe was seen up to the stage of 11 somites, regarding the region of both the MNP and RNP. It thus appears that closure of the MNP and RNP occurs very fast. The changes in shape of the neural groove, the multi-site pattern of closure, and the high closure rate of the neuropores in the rabbit embryo are summarized in Fig. 7.

\section{Posterior neuropore}

Of the four neuropores, the posterior neuropore (PNP) is the largest and remains present longest. After its formation at the 9-somite stage, this neuropore is long and slender, with a tapered and a wide portion, whereby the latter also comprises the primitive knot and streak in its midline area (Fig. 2D). The groove of the tapered portion is V-shaped and likely continues to close like a book, but at the 
transition to the wide portion the neural folds converge (Fig. 3A). The groove closes very fast, probably in a cranio-caudal sequence, at the stages of 9 and 10 somites (Fig. 3B, 4). Subsequently, the wide portion of the PNP closes, aided by convergence of the neural folds (Fig. 3B). Closure continues up to a natrow but open slit of 100-200 $\mu \mathrm{m}$ at the stage of 12-13 somites, and several closure sites are seen simultaneously, indicating a button-like rather than a zipper-like progression of closure (Fig. 3C). Although closure of the PNP proceeds fast from the stage of 8 somites onwards, the width of the wide portion decreases linearly already from somite stage 4 onwards (Fig. 5). From somite stage 13 onwards, the PNP persists as a small slit (Fig. 3C, D) and shifts in caudal difection during a relatively long period (Figs. 4, 5): in all embryos up to 20 somites, none had a closed PNP. In the one embryo at somite stage 22 the PNP was closed.
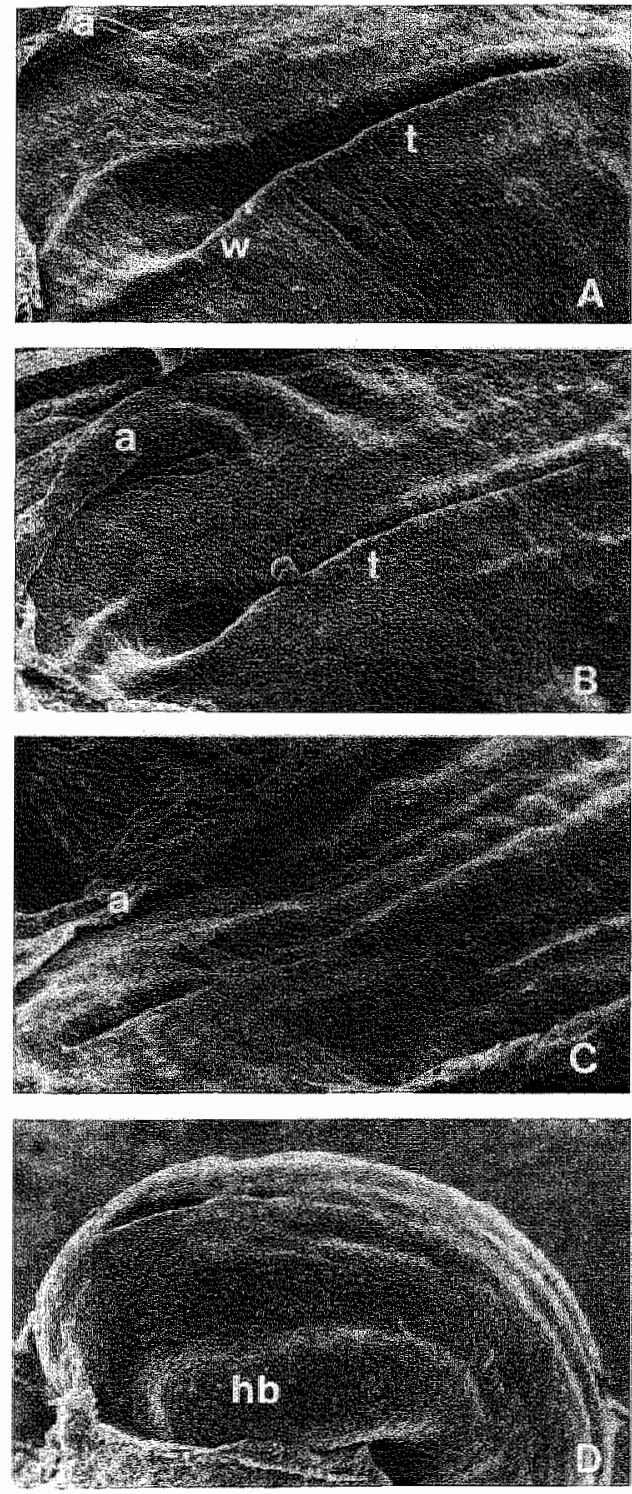

Fig. 3. Closure of the PNP in the tabbit embryo. A 9 somite pairs, PNP length 1660 Hm. B 10 somite pairs, PND length $540 \mu \mathrm{m}, \mathrm{C}$ 13 somite pairs, PNP length $160 \mu \mathrm{m}, \mathrm{D} 18$ somite pars, PNP length $100 \mu \mathrm{m}$. The tapered portion of the neuropore $(d)$ closes almost instantaneously. "The wide portion (ai) clloses later, with several closure sites (amombodo), while the persistence of an open slit in $\mathbf{D}$ indicates that final closure is delayed. The caudal part of the embryo is flat initially $(\mathbf{A}-\mathbf{C})$, but bends ventrally during final closure of the PNP (D). a amniotic fold, partly dissected away, bb hindlimb bud 


\section{Curvature of the embryonic axis}

The body length of the abbit embryo increases linearly during neurulation from $3,100 \mu \mathrm{m}$ at somite stage 4 till $4,150 \mu \mathrm{m}$ at stage 14 . During this period the main portion of the embryonic axis is straight; only the prosencephalic portion slightly bends in a ventral direction from the stage of 9 somites onwards (Fig. 6). From the stage of $13 / 14$ somites onwards, the embryo turns onto its left side, beginning cranially. This longitudinal torsion is complete at the stage of 17 somites. The caudal extremity begins to bend ventrally beyond the stage of 14 somites and includes the region of the PNP (Fig. 3D).

\section{length ( $\mu \mathrm{m})$}

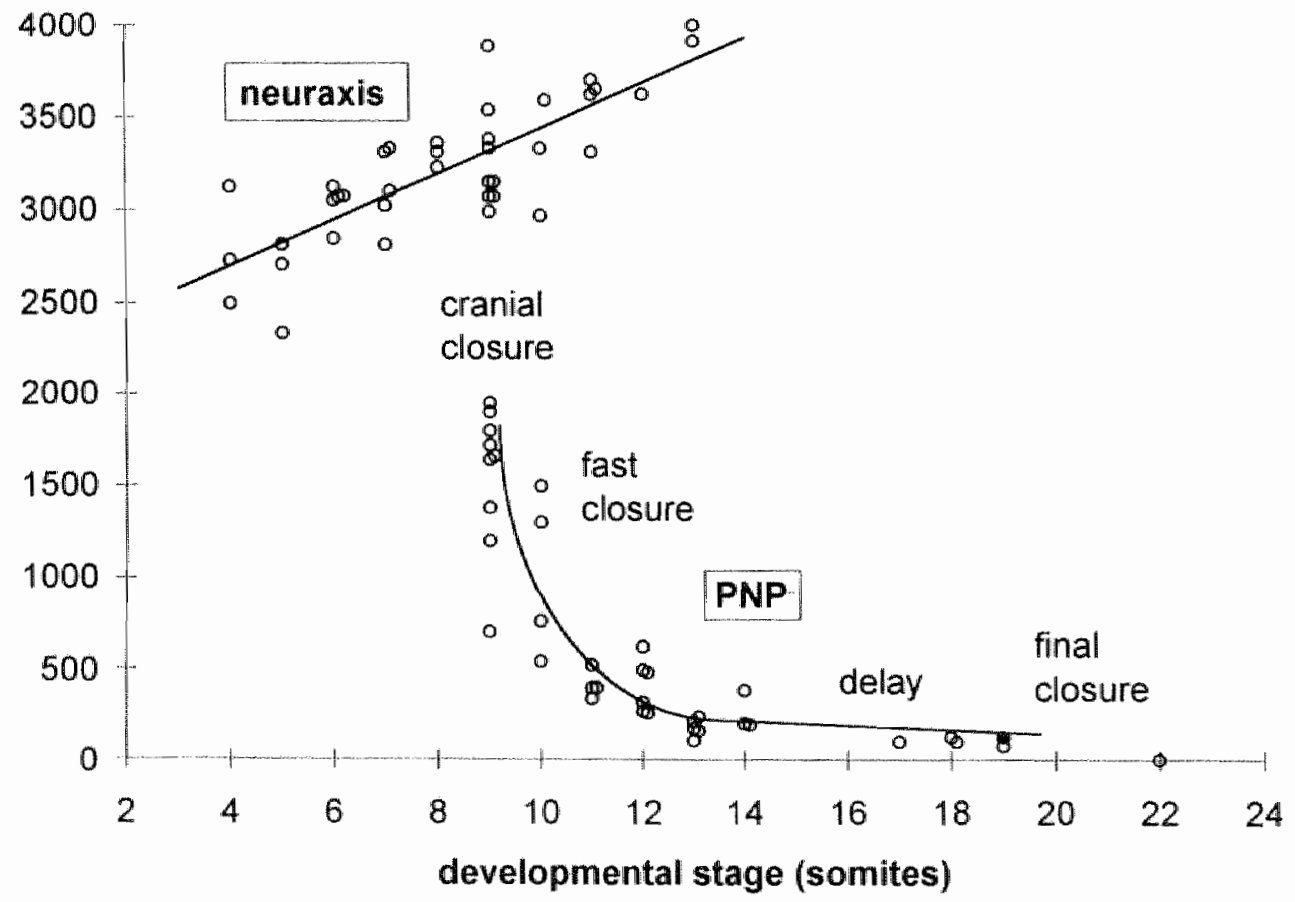

Fig. 4. Length of the neuraxis (neural groove or neural tube) and of the PNP during neurulation in the rabbit embryo. The arbitrary caudal extremity of the neural plate or PNP is indicated in Fig. 1E. The neuraxis increases linearly in length during neurulation as determined up to the stage of 14 somites. Between the stages of $8-9$ somites the walls of the neural groove appose in the cranial region, resulting in a large PNP. Closure of the PNP proceeds very fast initrally, but slows down almost completely until final closure. Filled arte average of data from 12 embryos with $17-20$ somite pairs 


\section{Discussion}

In the rabbit embryo, the flat neural plate transforms into a $V$-shaped neural groove at the stages of 6-8 somites, beginning at the thombo-cervical level. Between the stages of 8 and 9 somites, multiple site closure occurs simultaneously at three levels: at the incipient pros-mesencephalic transition, at the incipient mesrhombencephalic transition and at the level of the first pairs of somites. The ANP and RNP close between the stages of 9-11 somites; the MNP is very briefly present. Within somite stages 9-10, the tapered portion of the PNP closes fast and very much as a book is closed, followed by closure of its wide portion, which is aided by elevation and convergence of the neural folds. Final closure is delayed and subsequently completed at the 22 -somite stage. The changes in shape of the neural groove and the high closure rate are summarized in Fig. 7.

\section{width (um)}

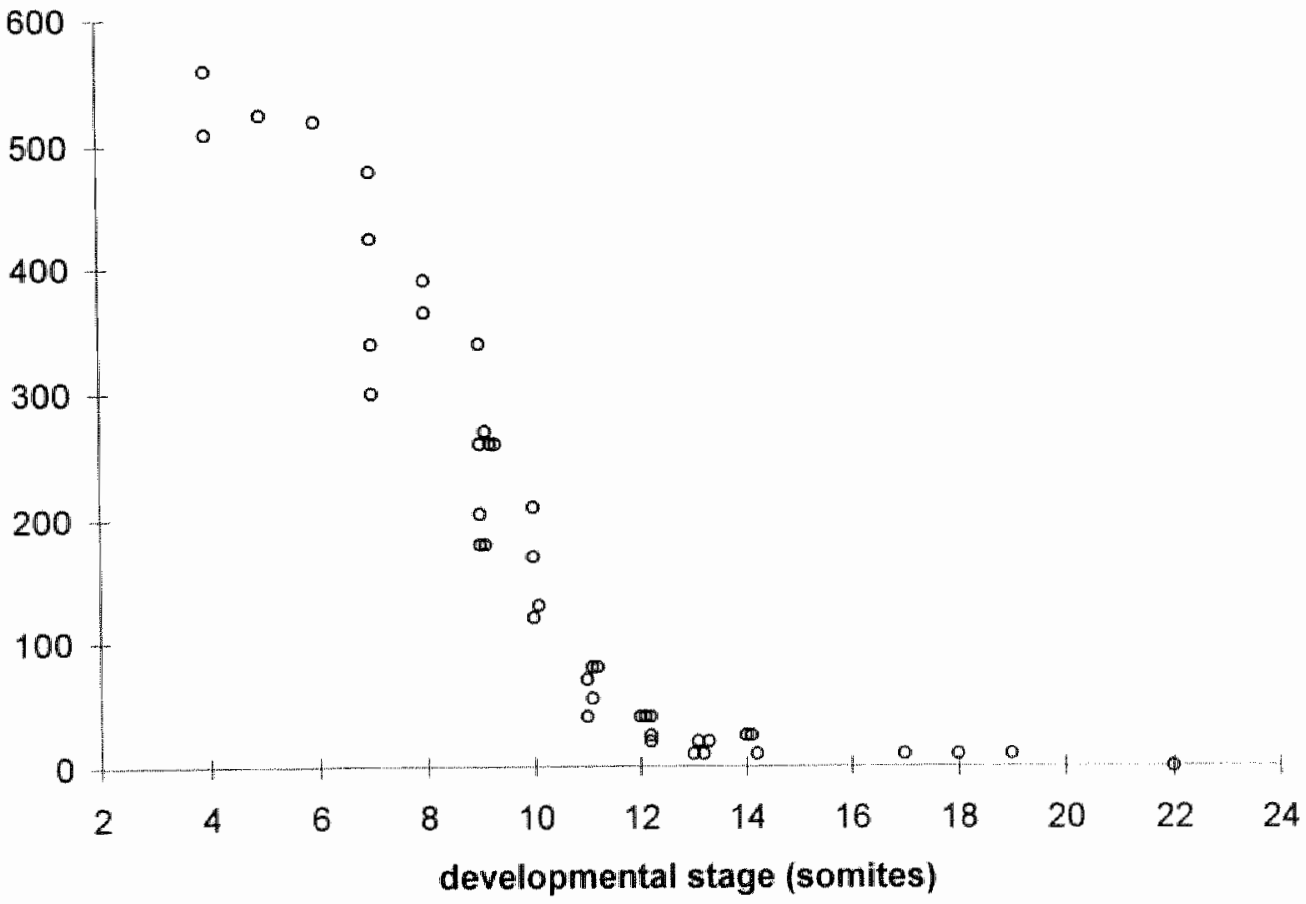

Fig. 5. Width of the neural groove and of the PNP during neurulation in the rabbit embryo, as determined at the wide caudal portion (indicated by arrow in Fig. 1D). The width decreases linearly between the stages of 6 and 12 somites. Thereafter the PNP is present as an open but very narrow slit until final closure 


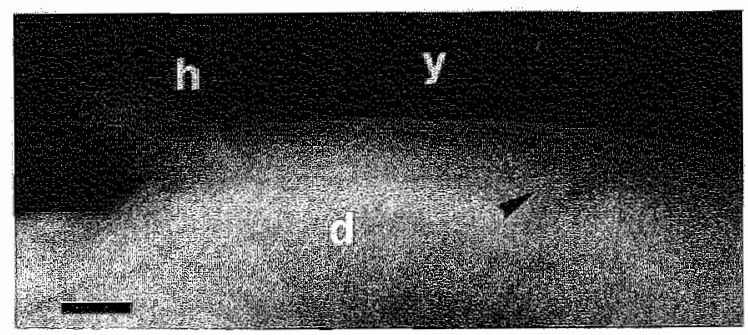

Fig. 6. Rabbit embryo of 13 somites in situ. Oblique latero-wentral view. At this stage the dorsal side of the embryo is directed towards the decidua ( $d$, seen through yolk sac endoderm and trophoblast), and its ventral side towards the yolk sac (p). The main portion of the embryo, including the region of the $\mathrm{PNP}$, is $\mathrm{flat}$. The head area is slightly bend in ventral direction and the heart protrudes ventrally (h). Caudally, the allantoic fold (amrowbead) begins to protrude in ventral direction. Bar $500 \mu \mathrm{m}$

\section{Preparative artifacts}

From a previous study in the chick embryo it appeared that the shape of a neuropore becomes easily disturbed by slight mechanical manipulations; in particular, newly closed trajectories of neural folds readily reopen as long as fusion has not occurred, and folds not yet in contact become apposed (van Straaten et al. 1993b). Such disturbance is largely avoided by viewing chick embryos in ovo after opening the egg shell only. In the rabbit embryo it is not possible to study neurulation in situ after gently opening the uterine swelling, since the dorsal side of the embryo is directed toward the deciclua and therefore not readily accessible. Moreover, during the stages of neurulation the embryo is completely flat and thin, like the chick embryo. When such embryos were dissected free from the decidua, they inevitably deformed. This is what probably happened in previous studies, when embryos were stretched before fixation (e.g., Waterman 1943). In order to prevent unwanted disturbances of morphology as much as possible, embryos were briefly fixed in situ, and the subsequent dissection and transport to a Petri dish were performed in excess PBS. Although deformation is unlikely with this approach, we cannot exclude some disturbance of the morphology of the neuropores.

\section{Multiple site closure pattern}

In the face of the very few data available on neurulation in the rabbit, the present study describes multiple closure sites in detail for the first time in this species. Multiple closure sites can be seen, in fact, on pictures (Waterman 1943; Gottschewsky 1967) and a drawing (Evans and Sack 1973), but are not further explained. An intermittent initial closure with the RNP present was described 
previously by Minot and Taylor (1905) in two embryos ( 8 and 9 somites), but at MNP was not mentioned.

Multiple closure sites, however, are a well-known feature of neurulation in several species (for literature overview see Golden and Chemoff 1993). The descriptions are especially detailed for the mouse embryo, where four different closure sites were indicated (Golden and Chernoff 1983) and confirmed by others (Macdonald et al. 1989; Sakai 1989; Juriloff et al. 1991; Tom et al. 1991). Closure site 1 begins at the (future) upper cervical region and proceeds bidirectionally. This closure is described in many studies - 11 studies in the mouse reviewed by Sakai (1989): the starting point ranged from the rhombencephalon to the cervical region, on average at the level of the 4th-5th somite, and occurring at somite stage 7. Closure site 2 is generally described as occurring at the pros-mesencephalic border. In comparing fout normal mouse strains, in one strain $(\mathrm{SWV} / \mathrm{Bc})$ closure 2 was initiated much further rostrally, in the prosencephalic region, while in another strain (ICR/Bc) the closure rostral to this initiation site was delayed (Juriloff et al. 1991). The latter study indicated closure site 2 to be initiate at the stage of 13 somites, thus 6 somites stages beyond closure site 1 . Closure site 3 initiates at the rostral extremity of the neural tube and proceeds in caudal direction. Closure site 4 is regarded as the rostral continuation of closure 1 , until it meets closure site 2 . A fifth closure site was mentioned by Sakai (1989), starting at the caudal end of the neural plate, progressing in cranial direction and resulting in a cavity in the caudal extremity of the neural groove. However, such a cavitation might also be the result of the process of secondlary neurulation (Schoenwolf 1984).

The multiple closure sites are also reported for human embryos; since several closure trajectories occur as a consequence of several start points the multisite closure pattern was adapted to explain the different locations along the neural axis where neural tube closure defects may arise (Müller and O'Rahilly 1985; Van Allen et al. 1993; Seller 1995a, b; Golden and Chemoff 1995). In the chick embryo the location of closure sites 1 and 2 are approximately identical to those in the mouse (rhombo-cervical boundary and mesencephalon, respectively), but their sequence is the other way around, and a time lag of only 3 somite stages was found (Jaskoll et al. 1991; van Straaten et al. 1996).

In the rabbit embryo, three de novo closure sites are found. Site 1 and 2 correspond to identical sites in the mouse embryo, while another site is seen in between, at the border of mes- and rhombencephalon. "This third closure site delimits an additional neuropore, the MNP, which is located at the level of a ventrally directed transverse fold of the neural plate. It is possible that this folding, which is not seen in mouse and chick, causes a mechanical local widening of the neural groove. In contrast to mouse and chick, no time lag between closure at the three closure sites was seen in the rabbit, all sites initiating at the stage of 8-9 
somites. Closure sites 3 and 4 were not elucidated in the present study, the latter probably because of the high speed of closure. Closure site 5 is not likely to occur in the rabbit, since the PNP blends with the primitive streak throughout closure, as is seen in Fig. 3D.

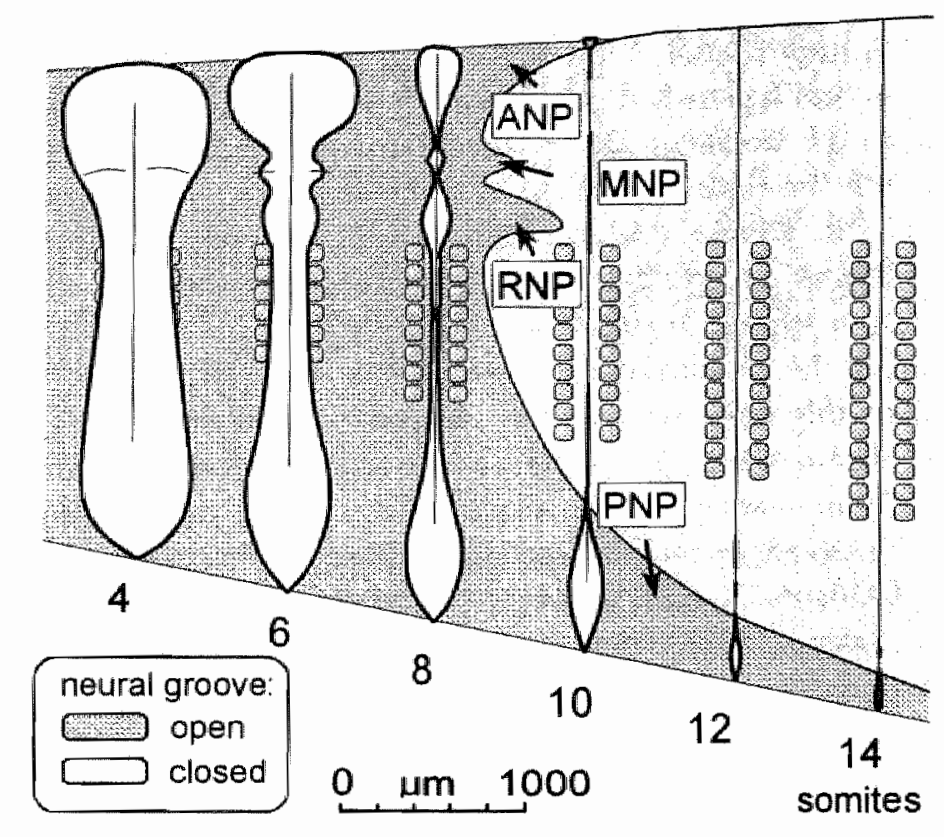

Fig. 7. Schematic representation of the neunlation process in the rabbit embryo. The drawing is based on morphometrical data of neuraxis elongation and neuropore sizes and also incorporates morphological data with respect to the shape of neuropores and neural folds. The outlines of a neuropore as well as the presence of a raphe are indicated with thick fines. progression of closure is indicated by the curved borderline between "open" and "closed" shading. This drawing reveals three de novo closure sites initiating simultaneously at the borders between the future prosencephalon, mesencephalon, rhombencephalon and spinal cord between the stages of 8 and 9 somites. This results in four temporary neuropores, as indicated. Subsequently all neuropores close very fast, with the exception of the PNP

\section{High closure rate in the rabbit embryo}

In the rabbit embryo, the neural groove closes between 8 and 22 somites, the largest portion of the neural rube being closed at 13 somites already. This closure occurs very fast when compared to the closure in the mouse embryo, which occurs between somite stages 7 and 28 on average (Sakai 1989), the latger portion being closed at 26 somites (van Straaten et al. 1992). 
The neural groove comprises an important proportion of the embryo. It is expected, therefore, that a mutual relationship exists between grow th of the neural groove (especially its growth in length), and growth of the surrounding structures of the embryo, the balance in both growth rates being an important factor in determining the axial curvature. Besides this intra-embryonic interaction, the yolk sac and amnion may also play a role in determining the curvature of the embryo during the early phase of neurulation: in the case of the yoik sac, there is a purse string-like action at the ventral rim of the embryo affecting curvature, while on the dorsal side, the mode of amnion formation (by splitting or folding) may have similar effects. It is to be noted that mammals are special compared to birds in that implantation, in tum, affects amnion cavity formation, and rodents are a special case amongst mammals in their yolk sac development.

Mutual relationships in embryonic development as mentioned above form the basis of several discussions, e.g., the relationship between the cervical flexure and development of the heart in the chick embryo (Flynn et al. 1991; Manner et al. 1995; Kosaki et al. 1996; Hogers et al. 1997). Another relationship concems the rate of closure of the PNP and the curvature of the caudal axis. An open, relatively flat PNP probably allows the caudal region to curve in a ventral direction, while, on the contrary, an enhanced ventral curvature of the caudal axis might prohibit closure of the PNP. At these stages the caudal portion of the embryo is beyond the influence of the purse string-like action of the amnion and yolk sac. In the arry tail mouse, mutant for spina bifida, a coincidence in enhanced axial curvature and a closure delay of the PNP has been suggested (Copp 1985; Copp et al. 1988). It was proposed, that enhanced ventral axial bending of the region of the PNP would counteract the elevation and convergence of its neural folds, and, as a consequence, would delay progression of closure. Further research revealed that experimentally reduced axial curvature was followed by normal closure and that experimentally imposed axial curvature in the chick and in the normal mouse embryo delayed closure (Brook et al. 1991; van Straten et al. 1993a; Pecters et al. 1996, 1997). The facts that the chick embryo is flat during neurulation and has a higher closure rate of the PNP than the mouse (van Straaten et all. 1993b, 1996) fits in with the above idea.

In many aspects of neurulation, the rabbit embryo resembles the chick cmbryo more than the mouse embryo: the rabbit embryo is, like the chick embryo, completely flat during the main period of neural tube closure, and both species demonstrate a relatively high closure rate. Also, the peculiar shape of the PNP, with a tapered and a wide portion, occurs in both species, and the sequence of closure the tapered portion first closing like a zipper, followed by the wide portion closing more button-like - is similat, too. The presence of a delay in final PNP closure in the rabbit embryo can be explained by incremental caudal axial curvature beyond the stage of somite 14 . 
However, the present study is a descriptive one, and therefore the causality of the relationship between the flat axis and the fast closure in the rabbit embryo cannot be deduced from it. At least, the pattern and rate of neurulation adds further evidence to the postulation of a relationship between axial curvature and closure rate of the PNP.

\section{Regional differences in neural tube shape}

In the chick embryo, the shape of the neural groove, as seen in a transverse plane, changes in cranio-caudal sequence as during development. Cranially, a wide thomboid-shape is seen, due to the presence of one medial and two lateral hinge points. At the rhombo-cervical transition and beyond, a $V$-shape is present, and the neural groove closes like a book. In a caudal direction, both a medial and two lateral hinge points ate present again, and the converging neural folds give the neural groove the appearance of a diamond-shape. Further caudally, well-defined hinge points are not present, but the entire neural plate is slightly bowl-shaped (Portch and Barson 1974; Schoenwolf 1982, 1985; Schoenwolf and Smith 1990). Moreover, a $\mathrm{V}$-shaped closure pattern also occurs at the mesencephalic site during initiation of closure (van Straaten et al. 1997). In the mouse embryo, regional differences in morphogenesis of the neural groove were also found; in a detaled study in three strains of mice, three modes of spinal neural tube formation occurring consecutively as neurulation progresses along the spinal region, have been described (Shum and Copp 1996), largely in accordance with the modes described for the chick embryo. Scanning electron microscopic studies of the PNP in mouse embryos indeed showed converging folds cranially and a flattened appearance caudally (Waterman 1976; Geelen and Langman 1979; Wilson and Wyatt 1988). In the cranial region of the embryo wide converging neural folds were shown (Kaufman 1979; Jacobson and Tam 1982; Sakai 1989; Juriloff et al. 1991; Morriss-Kay and Tuckett 1991). The different modes of closure suggest different intrinsic and extrinsic mechanisms of neurulation, which are extensively described in several review papers (Karfunkel 1974; Gordon 1985; Copp et al. 1990; Schoenwolf and Smith 1990; Jacobson 1991; Schoenwolf 1994). In the rabbit embryo, the neural groove in the somitic area has a V-shape (Fig. 1F), while later, and more caudally, there are convergent neural folds in the wide PNP portion, and a shallow gutter at the caudal extremity of the neural plate (Fig. 3A, B). Moreover, clear convergent neural folds are present during cranial closure (Fig. 2B). The same heterogeneity of neurulation mechanisms as proposed for mouse and chick might therefore apply to the rabbit as well.

\section{Acknowledgements}

The authors thank Professor J. Drukker for critical evaluation of the manuscript and H. Lüttenberg and W. Langmann for their dedicated assistance. This study was supported by a grant from the Netherlands Scientific Organization (431.241) and the Deutsche Forschungsgemeinschaft (V1 151/1-2). 


\section{References}

Brook FA, Shum ASW, van Stranten HWM, Copp Al (1991) Curvature of the caudal region is responsible for failure of neural rube closure in the anty tail ( $m$ ) mouse embryo. Development 113:671-678

Copp AJ (1985) Relationship between timing of posterior neuropore dosure and development of spinal neural tube defects in mutant (curly fail) and normal mouse cmbryos in culture. I Embryol Exp Morphol 88:39-54.

Copp A], Crolla JA, Brook FA (1988) Prevention of spinal neural tube defects in the mouse embryo by growth retardation during neurulation. Development 104:297-303

Copp AI, Brook FA, Estibeiro JP, Shum ASW, Cockroft DL (1990) The embryonic development of mammalian neural tube defects. Prog Neurobiol 35:363-403

Edwarcis $J$ A. (1968). The extemal development of the rabbit and rat embryo. In: Woollam DHM (ed) Adwances in teratology, vol. 3 Academic Press, New york, pp. 239-263.

Evans HE, Sack WO (1973) Prenatal development of domestic and laboratory mammals: growth curves, external features and selected references. Anat Histol Embryol 2:11 45

Flynn ME, Pikalow AS, Kimmelman RS, Searls RL (1991) The mechanism of cervical flexure formation in the chick. Anat Embryol 184:411-420

Geelen JAG, Langman J (1979) Ultrastructural observations on closure of the neural tube in the mouse. Anat Embryol 156:73-88

Golden JA, Chemoff GF (1983) Anterior neural tube closure in the mouse: fuel for disagreement with the classical theory. Clin Res $31: 127 \mathrm{~A}$

Golden JA. Chernoff GF (1993) Intermittent pattern of neural tube closure in two strains of mice. "Teratology 47:73-80

Golden JA, Chernoff GF (1995) Multiple sites of anterior neutal tube closure in humans: evidence from anterior neural tube defects (anencephaly). Pediatrics 95:506-510

Gordon R (1985) A review of the theories of vertebrate neurulation and their relationship to the mechanics of neural tube birth defect. Review. J Embryol Exp Morph 89:229-255

Gottschewsky GHM (1967) Aus der Embryonalentwicklung des Kaninchens. Zeiss 14:128-131

Hogers B, de Ruiter MC, Gittenbergerdegroot AC, Poelmam RE (1997) Unilateral vitelline vein ligation alters intracardiac blood. How patterns and morphogenesis in the chick embryo. Circ Res 80:473-481

Jacobson AG (1991) Experimental analyses of the shaping of the neural plate and tube. Am Zool 31:628-643

Jacobson AG, Tam PPL (1982) Cephalic neurulation in the mouse embryo analyzed by SEM and morphometry. Anat Rec 203:375-396

Jaskoll $T$; Greenberg $G$, Melnick M (1991) Neural tube and neural crest - fu new wiew with rimulapse high-definition photomicroscopy. Am J Med Genet 41:333 345

Jurilof DM, Harris MJ, Tom C, Macdonald KB (199) Normal mouse strans differ in the site of initiation of closure of the cranial neural tube. Teratology 44:225-233

Karfunkel P (1974) The mechanism of neural mbe formation. Int Rev Cytol 38:245-271

Kaufmar M (1979) Cephalic neurulation and optic vesicle formation in the carly mouse embryo. Am J Anar 155:425-444

Kosaki K, Mendoza A, Jones KL (1996) Cervical flexion: Its contribution fo nomal and abnormal cardiac morphogenesis. Teratology 54:135.144

Macdonald KB, Juriloff DM, Harris MJ (1989) Developmental study of neural tube closure in a mouse stock with a high incidence of exencephaly. Teratology 39:195-213

Manner J, Seidl W, Steding $G$ (1995) Formation of the cervical flexure: an experimental study on chick embryos. Acta Anat 152:1-10

Minot CS, Taylor E. (1905). Normal plates of the development of the rabbit. In: Keibel F (ed) Normentafeln zur Entwicklungsgeschichte der Wirbeltiere, vol. 5. Fischer, Jena, pp 1-27 
Morriss Kay $G_{*}$ Tuckett $F$ (1991) Early events in mammalian craniofacial morphogenesis. Ciraniofac Genet Dev Biol

Muller F, ORahily $\mathrm{R}$ (1985) The furst appearance of the neural nube and optic primordium in the human embryo at stage 10. Anat Embryol (Berl) 172:157-169

Peeters MCE, Shum ASW, Hekking JWM, CopP AJ, wan Straten HWM (1996) Relationship between alrered axial curvature and neural tube closure in normal and mutant (curby tait) mousce embryos. Anat Embryol 193:123 130

Pecters MCE, Hekking JWM, Vainas T, Drukker J, wan Straten HWM (1997) Spatio-temporal curvature partern of the caudal body axis for non-mutant and cumb tail mouse embryos during the period of neural tube dosure. Anat Embryol 195:259-266

Portch PA, Barson AJ (1974) Scanning electron microscopy of neurulation in the chick. J Anat 117:341-350

Sakai $Y$ (1989) Neurulation in the mouse: manner and timing of neurall tube closure. Anat Rec 223:194-203

Schoenwolf GC (1982) On the morphogenesis of the early rudiments of the developing central nerwous system. Scanning Electron Microsc 1982:289-308

Schoenwolf GC (1984) Histological and ultrastructural studies of secondary neurulation in mouse embryos. Am I Anat 169:361-76

Schoenwolf GC (1985) Shaping and bending of the avian neuroepithelium: morphometric analyses. Dev Biol 109:127-39

Schocnwolf GC (1994) Formation and patterning of the avian neuraxis: one dozen hypotheses. Neural tube defects. CIBA Found Symp 181:25-50

Schoenwolf GC, Smith JL (1990) Mechanisms of neurulation - traditional viewpont and recent advances. Development 109:243-270

Seller MJ (1995a) Further evidence for an intermittent pattern of neural tube closure in humans. Am J Med Genet 32:205-207

Seller M] (1995b) Sex, neural tube defects, and multisite closure of the human neural tube. Am J Med Genet 58:332 336

Shum ASW, Copp AJ (1996) Regional differences in morphogenesis of the neuroepithelium suggest multiple mechanisms of spinal neurulation in the mouse. Anat Embryol 194:65-73

'Tom C, Juriloff DM, Harris M) (1991) Studies of the effect of retinoic acid on anterior neural tube closure in mice genetically liable to exencephaly. Teratology $43: 27-40$

Van Allen MI, Kalousck DK, Chemoff GF, Juriloff D, Larris M, McGillivray BC, Yong SL, Langlois S, Macleod PM, Chitayat D (1993) Exidence for multi-site closure of the neural tulbe in hurmans. Am J Med Genet 47:723-743

van Straten HWM, Hekking JWM, Copp AJ, Bernfield M (1992) Deceleration and acceleration in the rate of posterior neuropore dosure during neurulation in the $c a b y$ tatl $(c b$ mouse ambryo. Anat Embryol 185:169-174

wan Straten HWM, Hekking JWM, Consten C, Copp AJ (1993a) Intrinsic and extrinsic factors in the mechanism of neurulation - effect of curvature of the body axis on closure of the posteriot meuropore. Development 117:1163-1172

wan Straten IWWM, Jaskoll "T, Rousscau AMJ, Terwindt-Rouwenhorst EAW, Greenberg G, Shankar K. Melnick M (1993b) Raphe of the posterior neural nube in the chick embryo - its closure and reopening as studied in living embryos with a high definition light microscope. Dev Dyn 198:65-76

van Straten HWM, Janssen HCJP, Peeters MCE, Copp AJ, Hekking JWM (1996) Neural tube closure in the chick embryo is multiphasic. Dev Dyn 207:309-318

van Straten HWM, Peeters MCE, Szpak KWF, Hekking JWM (1997) Initial closure of the mesencephalic neural groove in the chick embryo involves a releasing zipping-up mechanism. Dev Dyn 209:333-341

Vicbahn C, Lane EB, Ramackers FCS (1995) Cytoskeleton gadients in three dimensions during neunlation in the rabbit. ) Comp Neurol 363:235-248 
Waterman AJ (1.943) Studies of normal development of the New Zealand white strain of rabbit. II. Oogenesis. II. External morphology of the embryo. Am ] Anat 72:473-515

Waterman RE (1976) Topographical changes along the neurat fold associared with neunulation in the hamster and mouse. Am I Anat 146:151-172

Wilson DB, Wyatt DP (1988) Closure of the posterior neuropore in the of mutant mouse. Amat Embryol 178:559-563 
Chapter 3.3 


\section{Chapter 3.4}

\section{Comparisons in five species}

Inpress as:

Differences in axial curvature correlate with species-specific rate of neural tube closure in embryos of chick, rabbit, mouse, rat and human. Marian C.E. Peeters, Johan W.M. Hekking, Kohei Shiota, Jan Drukker, Henny W.M. Van Straaten. Anatomy and Embryology

\section{Abstract}

Studies in the mouse strain curby kail, mutant for neural tube defects, have indicated that axial curvature is an important factor in neural tube closure. Previously reported results from experimental interventions in both mouse and chick embryos indicated that curvature along the craniocaudal axis and closure of the posterior neuropore (PNP) are inversely related, a correlation which is also proposed for the rabbit embryo. It was hypothesized that this relationship is a sign of a more general mechanism. Therefore, in the present report the number of species in which axial curvature is described along the craniocaudal axis was extended to include the rat and human. Next, the closure rate of the neural tube as well as the curvature of the PNP region was determined morphometrically for embryos of the following species: chick, rabbit, mouse, rat and human. Although the relationship between neural tube closure and axial curvature appeared specific for each species in the comparative analysis, a general association of increased rate of closure with a decreased curvature emerged. It is concluded that axial curvature is an important factor in neurulation. 


\section{Introduction}

Neural tube defects (NTD) arise when neurulation is disturbed. Although NTD are among the most common congenital malformations, little is understood about the underlying developmental mechanisms. Neural tube formation is a multifactorial process, determined by both extrinsic and intrinsic factors (Karfunkel 1974; Gordon 1985; Copp et al. 1990; Schoenwolf and Smith 1990; Smith and Schoenwolf 1997). Of these, axial curvature is a factor likely important for neurulation in the mouse embryo: during closure of the posterior neuropore (PNP), the embryo has a curved appearance, but this curvature decreases during final stages of PNP closure. "This suggests that final closure is facilitated by unbending (Brook et al. 1991; Peeters et al. 1997). Moreover, experimental enhancement of axial curvature appeared to delay PNP closure to an extent corresponding to the degree of curvature (Peeters et al. 1996). The idea for an interaction between axial curvature and PNP closure came from the mouse mutant curby tail, of which part of the offspring exhibited a delay in the closure of the PNP (Copp 1985; Van Straaten et al. 1992). This delay was accompanied by an enhanced axial curvature of the PNP region and it was proposed that this enhancement could delay neurulation by counteracting elevation and convergence of the neural folds (Brook et al. 1991; Peeters et al. 1997). Experimental prevention of enhanced curvature in carly tail embryos resulted in a notmal closure pattern of the PNP, supporting the above idea (Brook et al. 1991; Van Straaten et al. 1993).

Recently, neural tube closure in chick and rabbit embryos was described in detail (Van Straten et all. 1996; Peeters et al. 1998). In both species, closure appeared to occur very fast. Since embryos of both species have a flat appearance, it was suggested that the closure can proceed fast because it is not hindered by any axial curvature. Introduction of curvature by culturing the chick embryo on a curved substrate indeed resulted in a PNP closure delay of which both the incidence and extent correlated with the degree of curvature imposed (Van Straaten et al. 1993). NTD in the chick embryo in vivo were observed after the insertion of air bubbles between the shell membranes and the underlying vitelline membrane (Fineman et al. 1986); this was likely caused by the deformation of the straight axis of the embryo. It is thus conceivable that axial curvature influences neural tube closure not only in the mouse embryo, but also in the chick and rabbit.

We hypothesize that the relationship between axial curvature and neurulation is a more general phenomenon. "Therefore, in the present study the number of species in which parameters of curvature and neurulation are determined is extended to include rat and human. 'The former is included because its appearance resembles that of the mouse, and the latter is included because nothing is known about such a relationship in this species, so far. Next, axial curvature is related to PNP closure 
and to neural tube closure rate in embryos of the following species: chick, rabbit mouse, rat and human.

\section{Materials and Methods}

\section{Embryo collecting and staging}

Female rats (Lewis) (bred at the Animal Care Facility, University Maastricht) were sacrificed on day $9.5-11$ of pregnancy (day of finding a copulation plug $=$ day 0 ) by overdosis ether anaesthesia. Embryos were isolated from the uterus in pre-warmed Hanks' solution, their extraembryonic membranes removed and their somites counted. A total of 103 embryos of somite stages ranging from 6 to 35 were collected. Embryos of the somite stages 15-34 were fixed in Bodian's fluid (90ml $80 \%$ ethanol, $5 \mathrm{ml} 99 \%$ acetic acid, $5 \mathrm{ml} 37 \%$ formaldehyde) for $1-5$ days. Subsequently, embryos were dehydrated in a graded series of ethanol, attached to aluminium stubs with silver paint, critical point dried using liquid $\mathrm{CO}_{2}$, coated with gold/palladium and viewed at $15 \mathrm{keV}$ with a scanning electron microscope (SEM, 505 Philips). Lateral-view photographs of the caudal region were taken.

Human embryos of the Kyoto Collection were used (Nishimura et al. 1968; Nishimura 1975). All embryos were procured from heal thy pregnant women after artificial interruption of pregnancy. The embryos used in the present study were considered normal (no gross malformations) and showed no signs of intrauterine death (Nishimura 1975). The embryos had been fixed in 10\% formalin or Bouin"s solution within one hour (usually immediately) after operation for several days and then transferred to $70 \%$ ethanol. After this fixation, chorionic sacs had been opened and photographs had been taken. These photographs were at the base of the present study. The developmental stage and body length of each embryo used are listed in Table 1. A second set of data was retrieved from previous papers about human embryos of the Camegie Collection (O'Rahilly and Gardner 1979; Müller and O'Rahilly 1986, 1987; O'Rahilly and Müller 1987, 1994). These cmbryos had come from spontaneous abortions and from hysterectomies; most had been fixed in formalin.

The developmental stages of embryos of all species are expressed as somitc number, except for the human embryos, which are staged according to the Carnegie stages.

\section{Determination of PNP length}

PNP lengths of rat embryos were measured prior to fixation, using an eyepiece graticule fitted on a stereomicroscope. The PNP lengths of the human embryos of the Kyoto Collection were determined on both dorsal- and lateral-view photographs; the PNP lengths of the human embryos of the Camegie Collection were retrieved from published drawings and data (O'Rahilly and Gardner 1970; 
Table 1. Features of the human embryos of the Kyoto collection, as used in the present study

\begin{tabular}{lccc}
\hline embryo & $\begin{array}{c}\text { Carnegie } \\
\text { stage }\end{array}$ & $\begin{array}{c}\text { somite } \\
\text { number }\end{array}$ & $\begin{array}{c}\text { bodylength } \\
\text { (mm) }\end{array}$ \\
\hline 23058 & 10 & 7 & 2.1 \\
20297 & 10 & 10 & 2.65 \\
31142 & 10 & 10 & 2.85 \\
33222 & 10 & 9 & 2.8 \\
4354 & 11 & 13 & 3.6 \\
6396 & 11 & 15 & 2.87 \\
4380 & 12 & 24 & 4 \\
9907 & 12 & 20 & 3.4 \\
12239 & 12 & 20 & 2.8 \\
50622 & 12 & 21 & 3.2 \\
50838 & 12 & & 2.3 \\
\hline
\end{tabular}

Embryos of the Carnegie stage 13 were not included because all PNPs were closed at that stage.

Müller and O'Rahilly 1986,1987; O'Rahilly and Müller 1987, 1994). PNP lengths of chick, rabbit and mouse embryos were extracted from previously reported data (Van Straaten et al. 1992, 1996; Peeters et al. 1998). In all species, PNP lengths were averaged per somite stage and smoothed once by a moving average procedure over 3 stages. In embryos of the chick, rabbit, mouse and rat, the appearances of the PNP at two developmental stages were illustrated using the SEM.

\section{Determination of axial curvature along the craniocaudal axis}

Axial curvature along the craniocaudal axis of the rat embryo was determined at each somite level as described previously for the mouse embryo (Peeters et al. 1997). Briefly, at each somite level (existing or presumptive) a marker was put on the dorsal contour of the embryo in the lateral-view photograph. The $x-y$ coordinates of all markers were digitized. From sets of 3 markers (defining a circle segment) the radius was calculated, and axial curvature was expressed as curvatureradius by radius.". This implies that if the radius of a circle segment decteases, the curvature parameter radius ${ }^{-1}$ and consequently the axial curvature both increases. The axial curvature was determined in rat embryos which had completed their axial rotation (from somite stage 15 onwards).

Because presumptive somites were difficult to determine on photographs of the human embryo, markers were not placed at somites but were evenly spaced along the craniocaudal axis; their axial levels were expressed as distances from the caudal tip. The reproducibility of this modified method was similar (variation of less than 
$5 \%$ ) to the originally reported method (Peeters et al. 1997). In one embryo ( $\$ 9907$; Table 1) curvature could be determined on both a left and a right lateral-view photograph; comparing the two curvature patterns yielded also variation of less than 5\%. In one embryo (\#33222) axial curvature could not be determined. Some of the embryos exhibited a prominent lordosis. Axial curvature was then only determined in the PNP region, which was caudal to the lordosis.

\section{Neural tube closure rate}

"The neural tube (NT) closure rate indicates the caudal progression of the cranial fusion point of the PNP, referred to a given somite level. For that purpose, the length of the closed neural tube in rat embryos was measured along the dorsal contour on lateral-view SEM photographs from somite level 11 onwards. This length was determined accordingly for mouse embryos, using embryos described previously (Peeters et al. 1997). For chick and rabbit embryos, these lengths were extracted from previously reported data (Van Straten et al. 1996; Peeters et al. 1998). For the human embryo this length was determined using the data regarding PNP length of the present study combined with the previously described pattern of neural tube closure (Gardner et al. 1975). For the chick, rabbit and human embryos, somite level 2 was chosen as reference point because somite 11 was not present at the earliest stages studied. The transition of this reference point appears valid, since the previous reports indicated that the axial length between somite 2 and 11 was almost constant throughout neural tube closure.

The NT closure rate was defined as the increase in length of closed neural tube per somite stage, for all five species, and was determined at developmental stages which were thought to be informative, based on the pattern of PNP length reduction during development. For each species three (mouse: four) stages were selected, yiclding a similar representation. These stages are listed in Table 2.

Table 2. Somite stages at which both the curvature and NT closure rate are determined

\begin{tabular}{lllll}
\hline Human & Rat & Mouse & Rabbit & Chick \\
\hline $7-10$ & $15-16$ & 18 & $10-11$ & $7-10$ \\
$13-15$ & $20-21$ & $22-24$ & $13-14$ & $10-14$ \\
$20-24$ & $23-24$ & $25-27$ & $15-21$ & $15-22$ \\
& & $28-29$ & & \\
\hline
\end{tabular}




\section{Determination of curvature of PNP region}

Axial curvature of the whole PNP region was determined for each species at identical stages as the NT closure rate (Table 2). In the rat and human embryo curvature was determined by averaging the curvature-radius of the axial levels corresponding to the open PNP. Accordingly, a mean curvature was calculated for the mouse embryo at four developmental stages using the previously reported data (Peeters et al. 1997). Axial curvature of the PNP region in the rabbit embryo was estimated at the 10-11 and 13-14 somite stages by measuring the curvature of the whole PNP region in two embryos, using three markers only (Peeters et al. 1998); at the 15-21 somite stage, curvatute could be determined in five embryos. For the chick embryo it was reported that axial curvature was about $0.4^{\circ}$ per mm throughout neurulation (Van Straten et al 1993), corresponding to a curvatureradius of $0.01 \mathrm{~mm}^{4}$. This value was adopted for the three developmental stages.

\section{Statistics}

The curvature-radii of rat embryos of each developmental stage were averaged for each somite level and the $95 \%$ confidence interval around the mean was calculated $\left( \pm t_{95 \%} * \mathrm{SE}\right)$. A difference in curvature was considered statistically significant if a given curvature was outside the confidence interval of another and mentioned in the text as such. Additionally, the overall pattem of curvature during development was analyzed using regtession analysis with axial curvature as dependent variable and developmental stage and axial level as independent variables.

In order to test whether axial curvature of the PNP region of the human embryo changes during development, a mean curvature-radius for this region was determined for each embryo, followed by the calculation of Spearman correlation coefficient between the mean curvature-radii and developmental stages. Between NT closure rate and curvature of the PNP region of all 5 species, Spearman correlation coefficient was determined, too.

\section{Results}

\section{Axial curvature and PNP closure in the rat embryo}

The courses of axial curvature of the rat embryo along its craniocaudal axis and during development are shown in Figure 1. Overall curvature decreases statistically significantly with increasing developmental stage. At most stages, a local curvature maximum around somite levels 10 is present, corresponding with the region of the forelimb bud. From somite level 20 onwards, curvature increases towards the caudal end of the embryo; only embryos of the 15-16 somite stage show a reduction in curvature at their caudal extremity. 


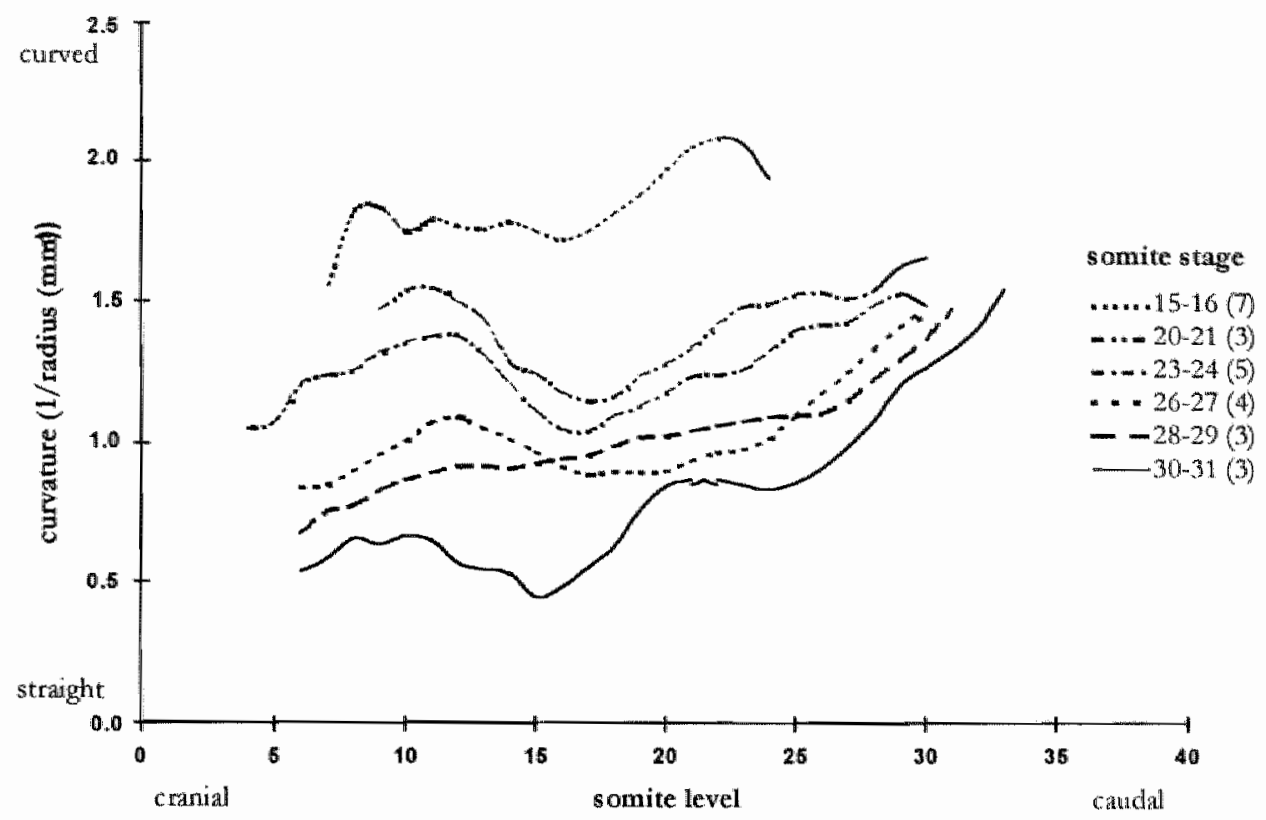

Fig. 1. Axial curvature of the rat embryo during development.

Each line represents the course of curvature for a developmental stage and is composed of average curvature values (radius ${ }^{-1}$ ) based on the number of embryos as indicated in parenthesis. The axial levels at which the PNP is open are shown by a solid line for the youngest stages; the PNP was closed from the 25 somite stage onwards. For each line, a confidence interwal was calculated. These intervals indicated a decrease in curvature along a considerable portion of the embryonic axis as follows: somite stage (15-16) $>(20-24)>(26-29)>(30-31)$. Aso with regression aralysis, the decrease in curvature during development was statistically significant.

The length of the PNP decreases gradually between somite stages $5-20$, followed by a steep decrease and a completion of closure at somite stage 25 (Fig. 2). This PNP closure pattern is also plotted in Figure 5.

\section{Axial curvature and PNP closure in the human embryo}

The photographs of the human embryos at the three developmental stages (Fig. 3) are representative for those used to determine curvature along the craniocaudal axis. The curvature in the PNP region increases with increasing developmental stage, although this correlation $(\mathrm{r}=0.61)$ is not statistically significant $(\mathrm{P}=0.06)$. At all developmental stages, a maximum of curvature is located in the PNP region, but the most caudal tip demonstrates a decreased curvature (Fig. 3).

Our data regarding PNP lengths in the embryos of the Kyoto Collection fit well. with the PNP lengths as reported for embryos of the Carnegie Collection (11g. 4). Based on both sets of data, the PNP length decreases at a high tate from the youngest stages till somite stage 14. From somite stage 14 to 24 , there is hardly at 


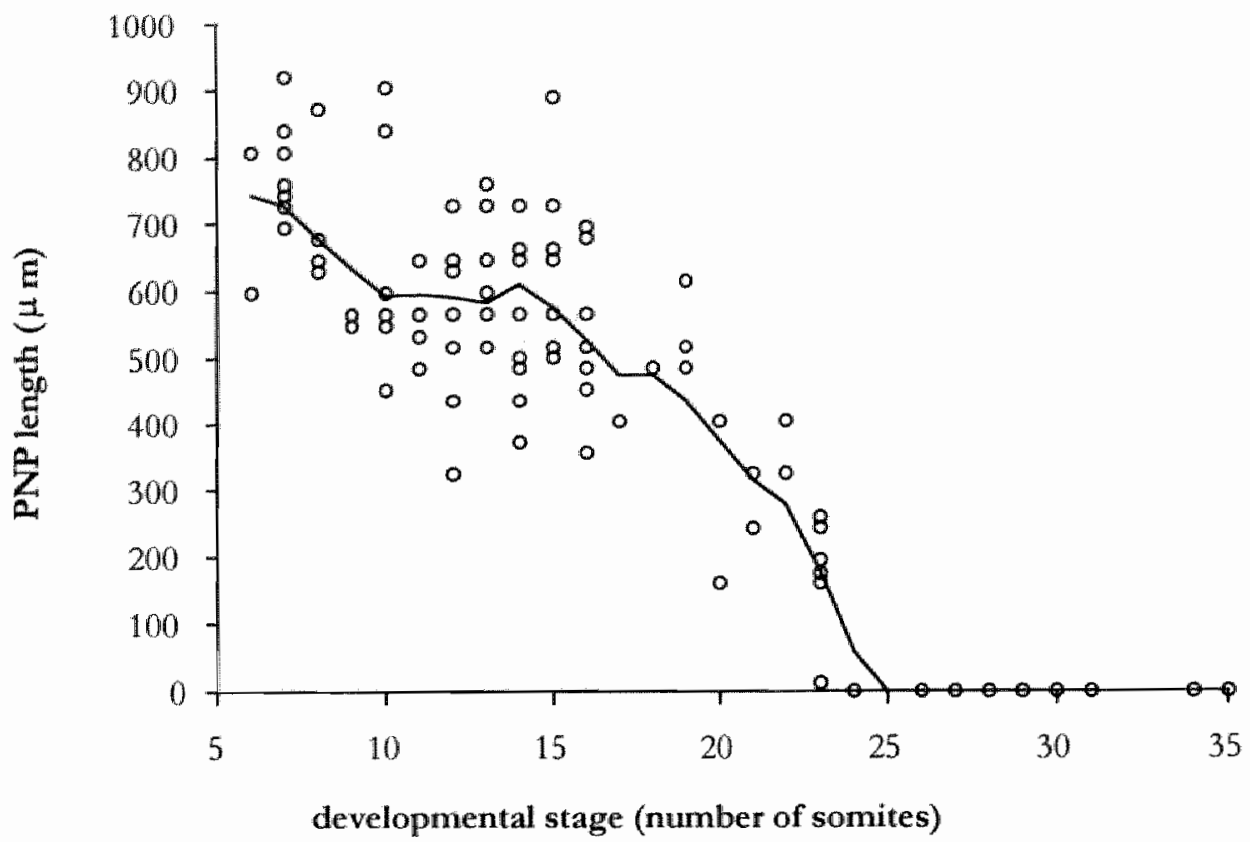

Fig. 2. Length of the PNP in the rat embryo during development.

Marks represent data from individual embryos; from somite stage 26 onwards marks represent 1.3 individual embryos. The line represents the pattern of PNP length through development as abtained by averaging the PNP lengths per somite stage followed by a moving average procedure over 3 stages.

reduction in PNP length. Subsequently, the length decreases fast, resulting in a final PNP closure within two somite stages. The PNP is closed from the 26 somite stage onwards, cotresponding to data reviewed by $O^{\prime}$ Rahilly and Gardner (1979). Since data points from both collections appeared to fit well, they were combined; the resultant average PNP length is used in Figure 5.

\section{PNP length during embryonic development}

In Figure 5, the patterns of PNP length reduction during development are shown for five species; the PNP lengths of chick, rabbit and mouse embryos were extracted from previous reported data (Van Straten et al. 1992, 1996; Peeters et al. 1998). The patterns in chick and rabbit embryos are similar. Both exhibit an initially fast reduction of the PNP length, followed by a period of gradual reduction. The mouse and rat embryos demonstrate a more gradual decrease in PNP length at the younger stages, with an acceleration at the stages of final PNP closure; the latter occurs earlier in the tat than in the mouse. The human embryo exhibits an initially fast reduction in PNP length, thereby resembling the chick and rabbit embryos, but the pattern subsequently shifts towards that of the mouse and rat, with an 

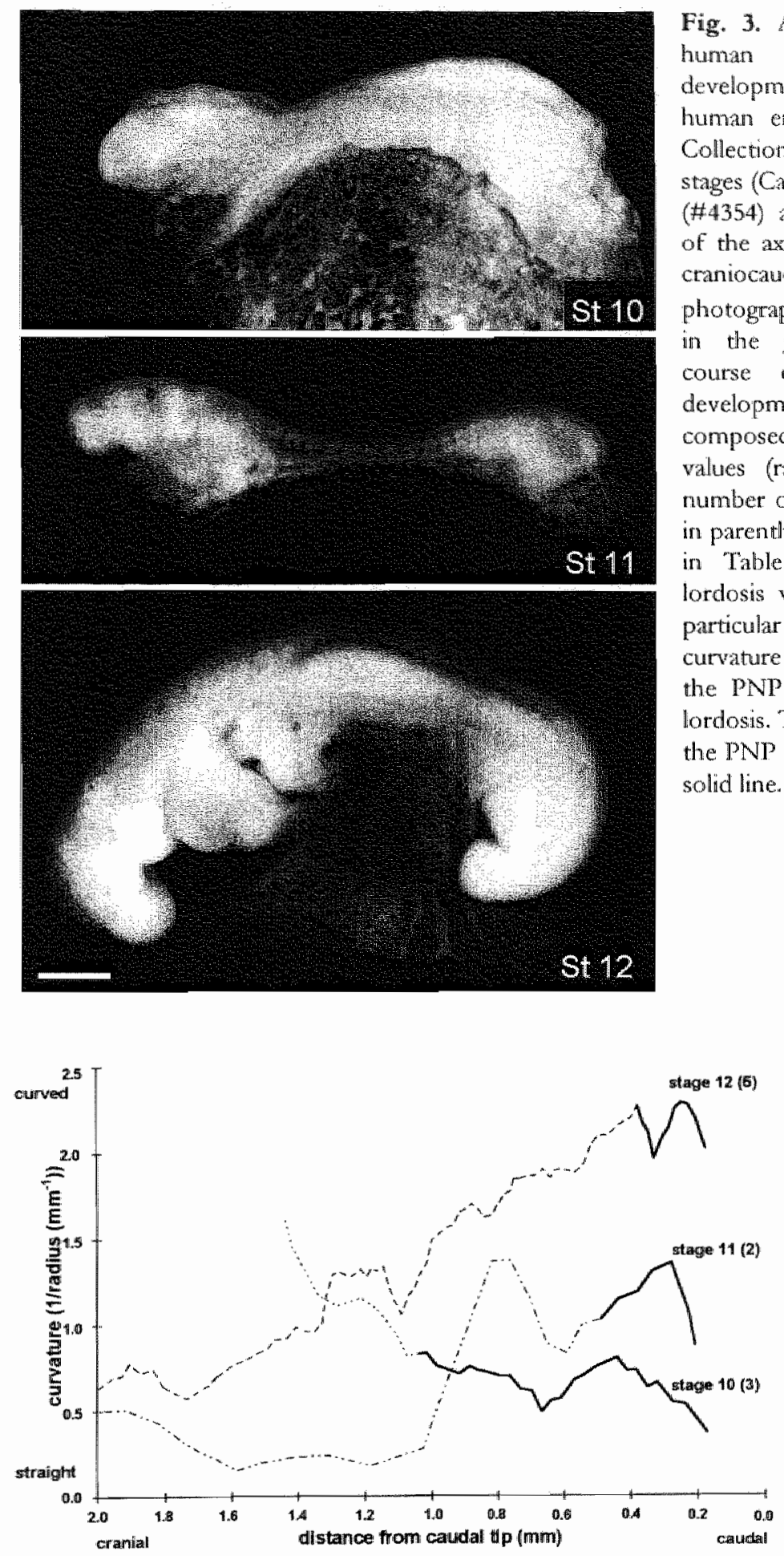
acceleration at the stages of final PNP closure. "The PNP closure is completed at somite stage 23 for the chick and tabbit embryos, at somite stage 25-26 for the rat and human embryos and at somite stage 32 for the mouse embryo.

The appearances of the PNP of chick and rabbit embryos were rather similar: the PNP is pear-shaped at the younger stages and becomes slit-like at the advanced stages (Fig. 6). The PNP in rat and mouse reduce also in size during development, but are ovoidal at both stages.

\section{NT closure rate versus axial curvature}

Next, a relationship between the NT closure rate and axial curvature was determined for all species (Fig. 7). The mouse and rat embryos show a relatively curved caudal axis and a relatively slow NT closure rate at the younger stages; subsequently, an unbending occurs simultaneously with an increase in NT closure rate. The rabbit and human embryos are flat at the younger stages and demonstrate a high rate of closure. Subsequently, they become curved and the NT closure rate decreases. The axis in the chick embryo is straight throughout the period of PNP closure; the NT closure rate increases initially, but decreases during the stages of final PNP closure. Combining these data of the various species results in a statistically significant correlation between an increase in NT closure rate and a decrease in axial curvature.

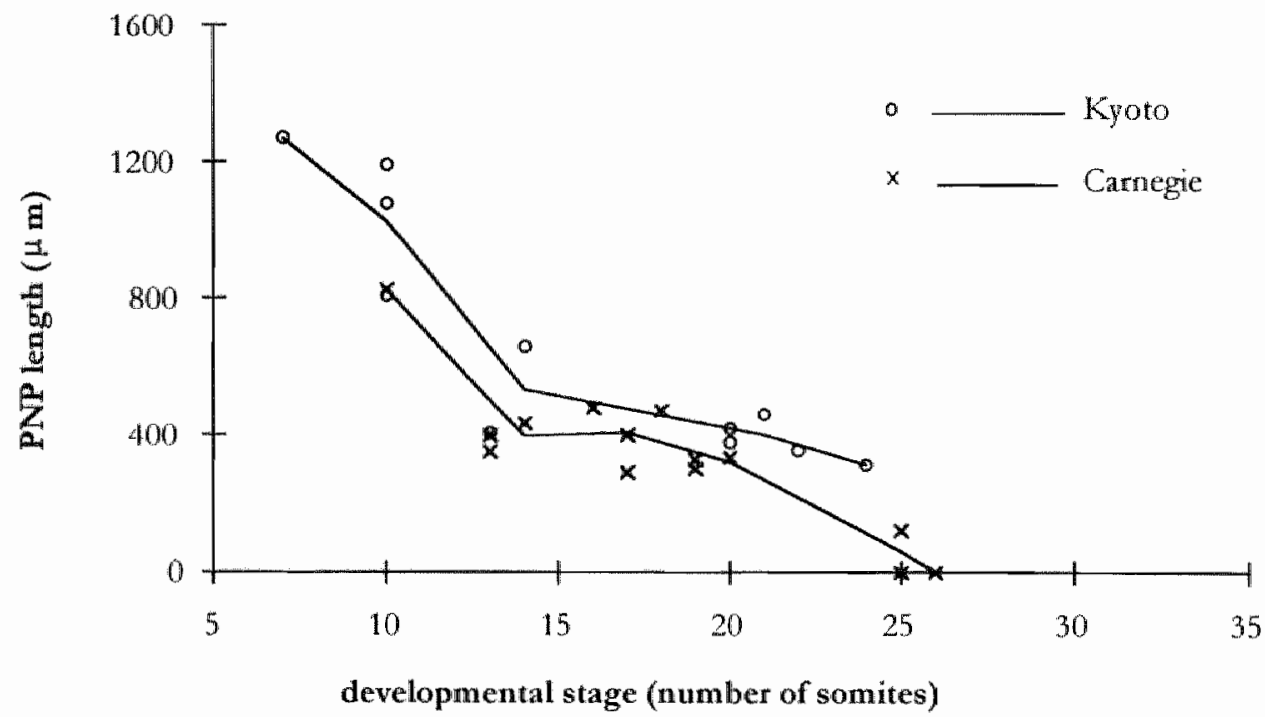

Fig. 4. Length of the PNP in the human embryo during dewelopment.

Data marks (o) are derived from measurement of PNP length of the embryos from the Kyoto Collection as listed in Table 1; data marks ( $x$ ) are from the Carnegie Collection. For both data sets, a line indicates the pattern of PNP length through development as abtained by connecting the average PNP lengths. 


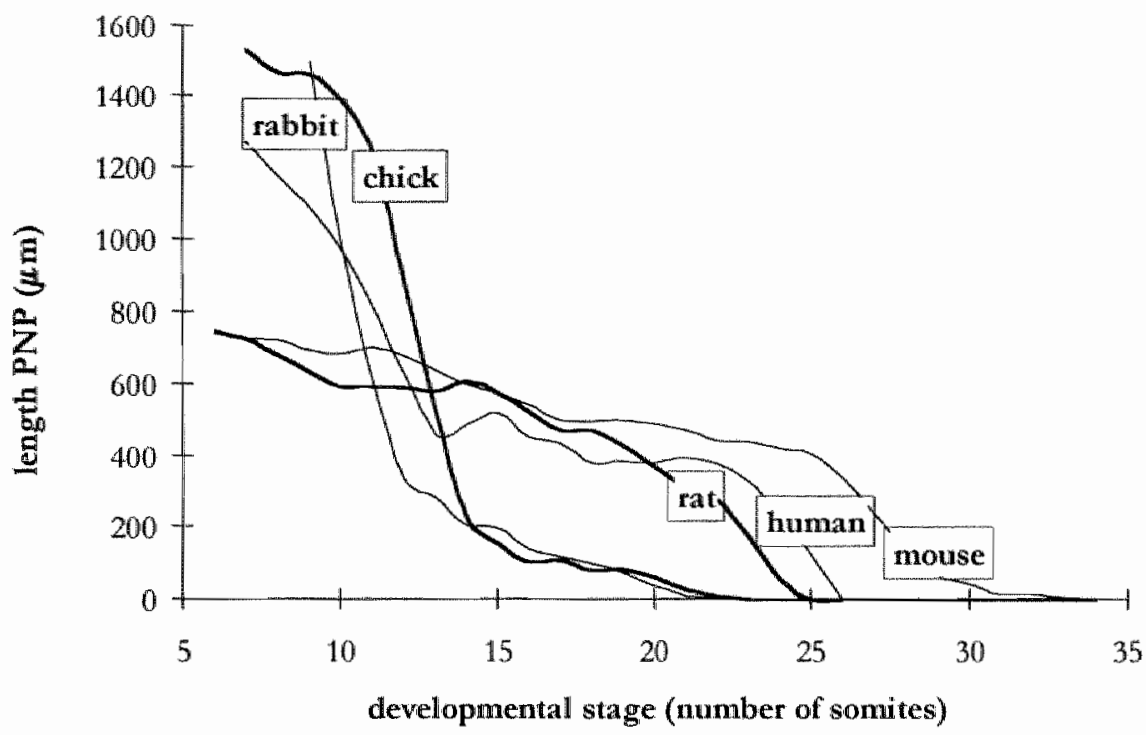

Fig. 5. Length of the PNP during development of 5 species.

The pattern of PNP length reduction during development is indicated for each species by a line, obtained by averaging the PNP length per somite stage followed by a moving average procedure over 3 stages.

\section{Discussion}

\section{Differences in axial curvature between species}

The course of axial curvature as described for the rat embryo in the present study demonstrates 2 maxima along the craniocaudal axis and a decrease in curvature during development. This resembles the course of curvature in the mouse embryo (Peeters et al. 1997). However, at analogous somite stages, the rat embryo exhibits consistently a less curved axis than the mouse. In contrast to mouse and rat, axial curvature in human embryos appeared to increase during development. "This discrepancy might partly be caused by differences in developmental stages at which curvature was determined. A difference in the fixation procedure did also exist between the human and other embryos, but we do not expect that this caused curvature changes. We expect that the described course of curvature for the human embryo represents a normal one because only embryos which were classified normal were used. Unlike the mouse, rat and human embryos, the rabbit and chick embryos are rather flat, with only a curved caudal region at later stages in the former. 

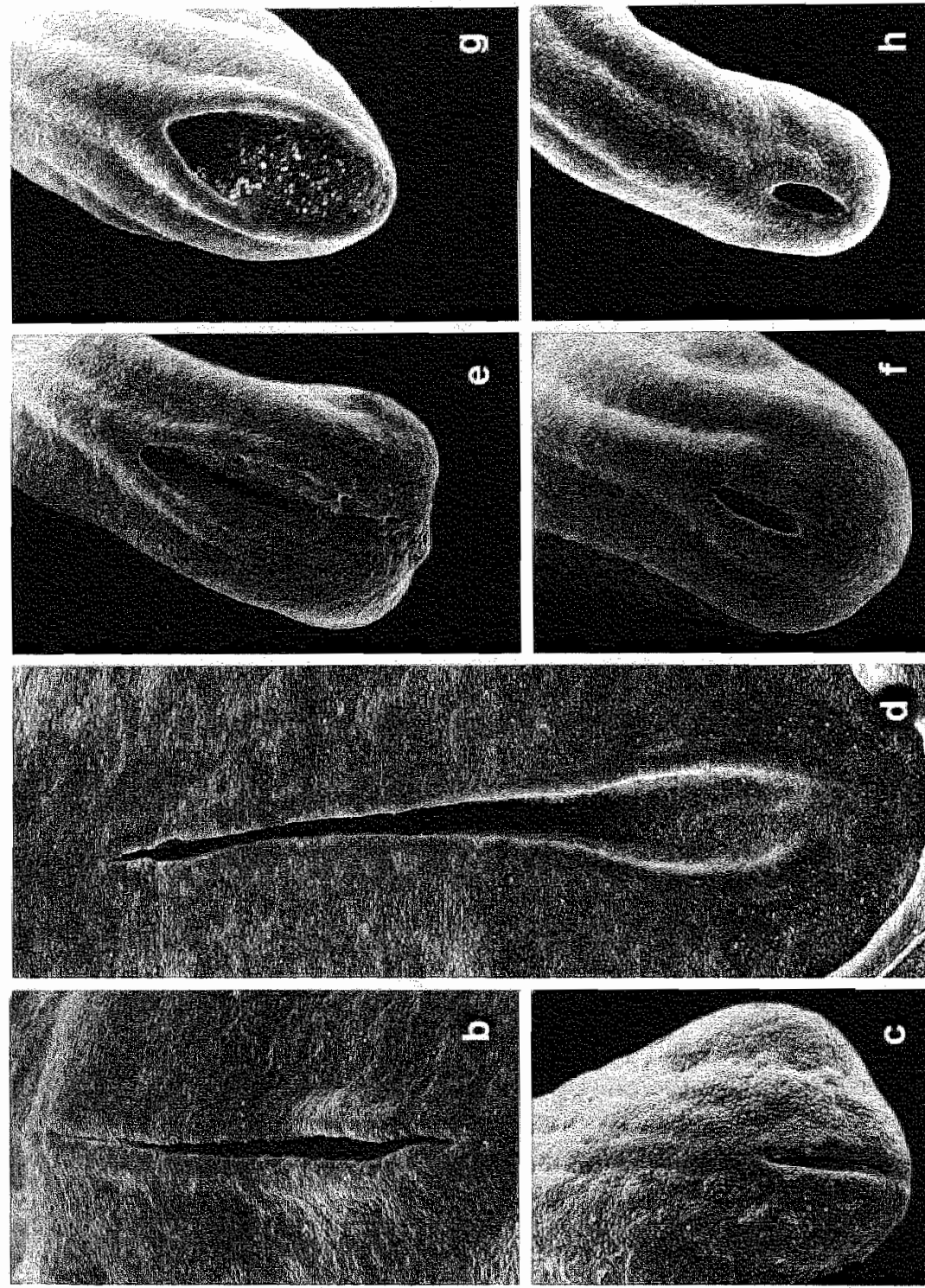

\section{(3)}

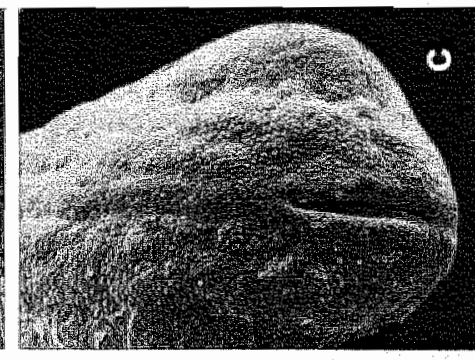

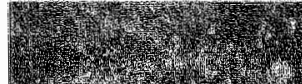

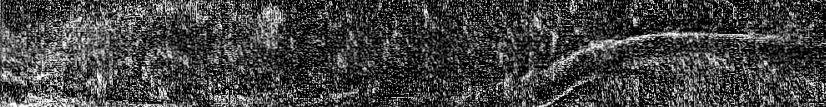

1.7.

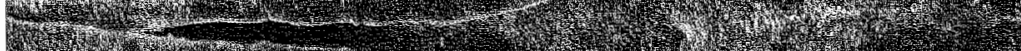

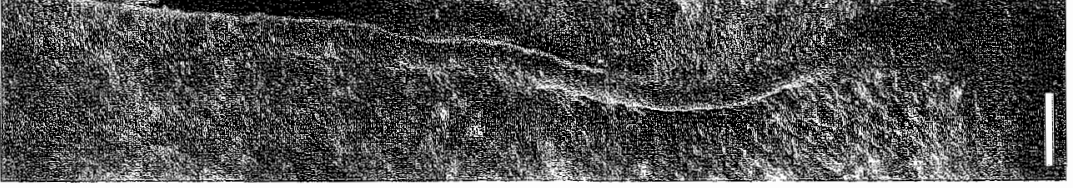

O 211

80

B

电 0

政

$.0 \mathrm{~b}$

$3 \div$.

造要

$\pm \frac{0}{2}$

$5 \mathrm{~g}$

3 둔

$\propto 0$

\& 5

$E .50$

需

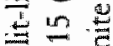

so 8

$B$ 要

$\angle \pm$

\&

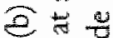

난

$50 \stackrel{8}{3}$

E 5

등

62

证

$D E$

0

+ ती

$2 \frac{1}{9} \pm 5$

co

$\infty 8$

舟

एक

$5 D E$

$E \rightarrow \pm$

000

Q 5 .

\& $-\frac{9}{7}$

D.

ㄴ. 0

- Son

䋯焉

z

L 5

है

넝

ง. $\frac{U}{2}$

ए $\frac{c}{\infty} ?$

5 5

5.50

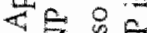

$6 Z \frac{2}{2}$ काषण 
Thus, combining 5 species yielded 3 general courses of curvature: a reduction in curvature as in mouse and rat, an increase in curvature as in man and a rather constant curvature for a considerable period of neurulation as in chick and rabbit.

\section{PNP closure and NT closure rate in relation to axial curvature}

The pattern of PNP length reduction during development differs for the five species studied. The reduction in the chick and rabbit embryos is initially fast and subsequently slow, whereas in the mouse and rat the rate of reduction is reversed. The pattern in the human embryo shifts from a pattern closely resembling that of chick and rabbit to a pattern resembling that of mouse and rat. During development, the timing of completion of PNP closure also differs: first the chick and rabbit embryo, followed by the tat and human embryo and finally the mouse embryo.

Combining the data on PNP lengths with data on axial curvature reveals the following interesting pattern. The chick and rabbit embryos, which exhibit a fast reduction of PNP length and an early completion of PNP closure, have a flat appearance, while the mouse and rat embryos, which close their PNP at later stages, have a curved appearance. Moreover, the mouse embryo is mote curved

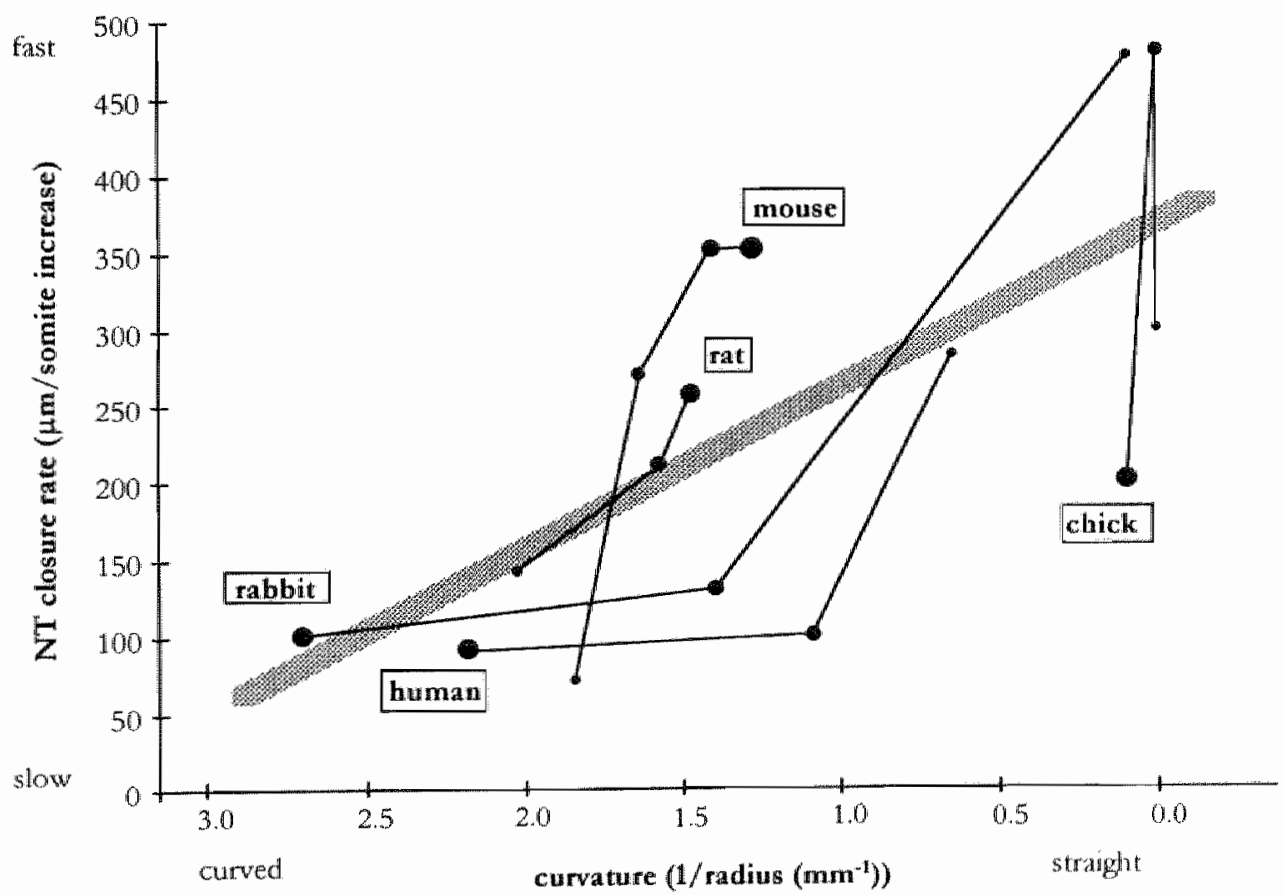

Fig. 7. Relationship between NT closure rate and axial curvature for 5 species.

Each line represents the relationship as determined for a given species during development. "The increase in size of the dots indicates the increase in developmental stage; the latter are listed in Table 2. The grey bar represents the regression line through all data, and shows a decrease of NT closure rate with an increase of axial curvature $(\mathrm{P}<0.005)$. 
than the rat at analogous somite stages and the PNP closure is completed at a later stage than in the rat. These data suggest that axial curvature reduces the pace at which the PNP closes.

Data on PNP length clearly illustrate the progression of closure of this neuropore. However, these data give no information about the actual progression of neural tube closure: a steady PNP length during development, as especially seen in the human embryo around the somite stage 20 , suggests no progression, white in fact the cranial fusion point of the PNP is still moving caudally, but it does this at a speed similar to the extension of the neural plate at its caudal site. We assume that the progression of neural tube closure is influenced by axial curvature as well. Therefore, the NT closure rate was determined for the five species at several developmental stages.

The NT closure rate decreased in the rabbit and human embryo during development while axial curvature increased. Conversely, the NT closure rate increased in the mouse and rat embryo simultaneously with an axial unbending. The PNP region in the chick, however, demonstrated a variation in NT closure tate without a variation in curvature. Thus, all eutherians in the present study demonstrate an inverse relationship between NT closure rate and axial curvature; a correlation which is not present in the avian embryo.

\section{Axial curvature as a determinant of neural tube closure}

The mouse mutant corry tail exhibits an enhanced axial curvature of the PNP region, which has been hypothesized to counteract elevation and convergence of the neural folds, and thereby delay closure of the PNP (Brook et al. 1991; Van Straaten et al. 1993; Peeters et al. 1996). Accordingly, the curved axis at the youngest stages of the mouse and rat embryos might prevent elevation and convergence, and indeed, convergence is found to be almost absent in the PNP (Fig. 6). "The axial unbending, which occurs during development in these species, is accompanied by an increased NT closure rate. Simultaneously, the width of the PNP natrows (Van Straaten et al. 1992). Additionally, the PNP length reduced fast at the final stages of PNP closure, a period for which a steep decrease in caudal curvature has been described (Peeters et al. 1997). At the same time, convergence of the neural folds is observed as well. All these coincidences support the idea that a decrease of curvature during development facilitates PNP closure, probably by releasing the counteracting forces acting upon neural folds.

In the chick embryo, PNP closure undergoes no natural influence of axial curvature, due to its straight axis. According to the above idea, closure is expected to occur fast, as is indeed observed initially. However, at the final stages of PNP closure the closure rate is reduced, while, in agreement with a minor influence of curvature, the appearance of the PNP is rather slit-like and the neural folds are almost touching each other. It is therefore likely, that other processes besides axial 
curvature have an impact on this final PNP closure. A process which is still involved during the slow phase of neuropore closure is neural plate elongation, based on cell rearrangement and cell prolifetation (Schoenwolf and Alvarez 1989; Jacobson 1991). This process continues until the most caudal level of primary neurulation is reached, and it can be expected that the PNP does not close before elongation is completed.

At the youngest stages of the rabbit embryo, the neural folds will not be hindered in their elevation and convergence by ventrally directed forces, as appears from a high NT closure rate. Subsequently, the caudal region becomes curved and, consequently, this is expected to reduce the rate of closure as seen in our data. However, the appearance of the PNP at that stage is slit-like, as in the chick. We suppose that the neural fold convergence and subsequently the neural tube closure is only minor affected by axial curvature since the neural folds exhibit already convergence at the onset of bending of the axis. "The slit-like PNP points towards a similar mechanism for rabbit and chick: after an initially fast closure, the subsequent delay is probably caused by neural plate elongation, instead of axial curvature. Because the shape of the PNP of the human embryo is less clear, it is difficult to predict the impact of curvature during final PNP closure.

\section{Validity of comparing various species}

Nowadays, developmental biologists compare the expression of genes between various species and a lot of similarities have been reported. Especially at the stage succeeding the completion of PNP closure, a high degree of tesemblance is proposed (Slack et al. 1993). However, it has been mentioned recently that similarities are stressed too much and that species do differ at this stage more than hitherto assumed (Richardson et al. 1997). Moreover, the mechanisms deduced from the proposed similarities are often founded on a biased group of selected species (Bolker 1995). In the present study, four eutherian and an avian embryo are compared, and although the correlation between axial curvature and NT" closure rate is species-specific, all eutherian embryos demonstrate an inverse relationship between the two parameters. Therefore, it can be concluded for those embryos that axial curvature is very likely an important factor in neurulation. Whether axial curvature is important in other mammals, too, can only be speculated upon by looking at the external appearance of those embryos. For example, we suggest that curvature influences completion of NT closure in the sheep and pig embryo, because it is preceded by a curvature in the caudal region (Patten 1948; Evans and Sack 1973).

In the present study it is shown that axial curvature is related to closure of the PNP. Besides curvature, the factors embryo elongation, mesoderm expansion, ectoderm expansion and apical constriction are very likely important for neural tube closure, too (Karfunkel 1974; Gordon 1985; Copp et al. 1990; Schoenwolf and 
Smith 1990). The impact of each factor is specific for both the species and the axial level of neurulation. Nevertheless, increase of NT closure rate coinciding with decrease of axial curvature is demonstrated as a general mechanism in eutherians while such a mechanism is not relevant in avian embryos due to the absence of curvature changes. Therefore, it would be worthwhile to unravel the mechanisms which determine axial curvature, as for example the role of genes important for the growth balance in the PNP region.

\section{Acknowledgment}

We are grateful to Ms. Chigako Uwabe for her technical assistance in observation and staging of human embryos. This work was supported by a grant of the Netherlands Organisation for Scientific Research (431241) (MCEP).

\section{References}

Bolker JA (1995) Model systems in developmental biology. BioEssays 17: 451-455

Brook FA, Shum ESW, Van Straten HWM, Copp AJ (1991) Curvature of the caudal region is responsible for failure of neural tube closure in the curly tail (a) mouse embryo. Development 113: $671-678$

Copp AJ (1985) Relationship between timing of posterior neuropore closure and development of spinal neural tube defects in mutant (arly tail) and normal mouse embryos in culture. I Eimbryol Exp Morphol 88: 39-54

Copp AJ, Brook AJ, Estiberro JP, Shum ASW, Cockroft DL (1990) The embryonic development of mammalian newral tube defects. Prog Neurobiol 35: 363-403.

Evans HE, Sack WO (1973) Prenatal development of domestic and laboratory mammals. Anat Histol Embryal 2: 11-45

Fineman RM, Schoenwolf GC, Huft M, Davis PL. (1986) Animal model: causes of windowinginduced dysmorphogenesis (neural tube defects and early ammion deficit spectrum) in chicken embryos. An J Med Genet 25: 489-505

Gardner E, ORathilly R, Prolo D (1975) The Dandy-Walker and Arnold-Chati malformations. Arch Neurol 32: 393-407

Gordon R (1985) A review of the theories of vertebtate neurulation and their relationship to the mechanios of nenral tube birth defects. I Embryol Exp Morphol 89: 229-255 Jacobson AG (1991) Experimental analysis of the shaping of the neural plate and tube. Amer
Zool 31: 628-643

Karfunkel $P$ (1974) The mechanisms of neural tube formation. Int Rev Cytol 38: 245-271

Müller F, O'Rahilly R (1986) The development of the human brain and the closure of the rostral neuropore at stage 11. Anat Embryol 175: 205-222

Müller $F$, O'Rahilly R (1987) The development of the human brain, the closure of the caudal neuropore, and the beginning of the secondary neurulation at stage 12. Anat Embryol 176:
413-430

Nishimura H. (1975). Prenatal versus postnatal malformations based on the Japanese experience on induced abortions in the human being. In "Aging Gametes." (R. J. Blandau, Ed.), PP. 349-
368. Karger, Basel.

Nishimura H, "Takano K, Tanimura T, Yasuda M (1968) Nornal and abnormal development of human enbryos: First report of the analysis of 1,213 intact embryos. Teratology 1:281-290

O'Rahilly R, Gardner E (1979) The initial dewelopment of the human brain. Acta Anat 104: 123-
133 
O'Rahilly R, Müller F. (1987). "Developmental stages in human embryos, including a revision of Streeter"s "Horizons" and a survey of the Carnegie Collection." Camegie Institution of Washington Publ 637,

O'Rahilly R, Müller F (1994) Neurulation in the notmal human embryo. Ciba Foundation Symposium 181: 70-89

Patten (1948) Embryology of the pig.

Peeters MCE, Hekking JWM, Vainas T, Drukker J, Van Straten HWM (1997) Spatio-temporal curvature pattern of the caudal body axis for non-mutant and carby ail mouse embryos during the period of caudal neural tube closure. Anat Embryol 195: 259-266

Peeters MCE, Shum ASW, Hekking JWM, Copp AJ, Van Straten HWM (1996) Relationship between altered axial curvature and neumal tube closure in nomal and mutant (awly tais) mouse embryos. Anat Embryol 193: 123-130

Peeters MCE, Viebalvn C, Hekking JWM, Van Straten FWM (1998) Neurulation in the rabbit embryo. Anat Embryol 197: 167-175

Richardson MK, Hanken J, Gooneratne ML, Pieau C, Raynaud A, Selwood L, Wright GM (1997) There is no highly conserved embryonic stage in the vertebrates: implications for current theorives of exolution and development. Anat Embryol 196: 21-106

Schoenwolf GC, Alvarez IS (1989) Roles of neuroepithelial cell rearangement and division in shaping of the avian neural plate. Development 106: 427-439

Schoenwolf GC, Smith JL (1990) Mechanisms of neurulation: traditional viewpoint and recent advances. Development 109: 243 270

Slack JMW, Holland PWT, Graham CF (1993) The zootype and the phylotypic stage. Narure $361: 490-492$

Smith JL, Schoenwolf GC (1997) Neunlation: coming to closure. Trends Neurosel 20:510-517

Van Straaten HWM, Hekking JWM, Consten C, Copp AJ (1993) Intrinsic and extrinsic factors in the mechanism of neurulation: effect of curvature of the body axis on closure of the posterior neuropore. Development 117:1163-1172

Van Straten HWM, Hekking JWM, Copp AJ, Bernfield M (1992) Deceleration and acceleration in the rate of posterior neuropore closure during neurulation in the corrly lail ( $d$ ) mouse embryo. Anat Embryol 185: 169-174

Van Straaten HWM, Janssen HCJP, Peeters MCE, Copp AJ, Hekking JWM (1996) Neural tube closure in the chick embryo is multiphasic. Dev Dyn 207: 309-318 


\section{Chapter 4}

\section{Determinants of axial curvature}

4.1 Role of cell proliferation in the tail bud

4.2 Role of embryonic glucose consumption 
Chapter 4 


\section{Chapter 4.1}

\section{Role of cell proliferation in the tail bud}

\section{Published as:}

Role of differential cell proliferation in the tail bud in aberrant mouse neurulation. Marian C.E. Peeters, Bert Schutte, Marie-Hélène J.N. Lenders, Johan W.M. Hekking, Jan Drukker and Henny W.M. van Straaten. Developmental Dynamics (1998) 211: 382-389

\section{Abstract}

In the mouse mutant curly tail, the phenotypes spina bifida and curled tail result from a delay in closure of the posterior neuropore (PNP). At the developmental stage when this delay can first be recognized, the caudal region of the embryo demonstrates a transiently enhanced curvature of the body axis which likely inhibits elevation, convergence, and fusion of the neural folds. The enhanced curvature is thought to be the result of a decreased proliferation in the ventrally located gut endoderm and notochord, together with a normal proliferation of the overlying neuroepithelium of the PNP. However, the proliferation defect and the enhanced curvature were originally demonstrated at the same developmental stage, while it is expected that reduced proliferation should precede enhanced curvature and delayed PNP closure.

The caudal region originates from the tail bud and we therefore propose that the enhanced curvature is induced by a disturbed dorso-ventral proliferation pattern in the tail bud. Using flow cytometry, proliferation patterns were determined separately for the dorsal and ventral halves of the tail bud of arly tail and of control embryos as well as of recombinant embryos having the curly tail phenotype with a genetic backgtound which is matched to the BALB/C control strain. In general, it appeared that about half of the cell cycle duration in tail bud cells was occupied by $S$ phase, about $40 \%$ by $G_{n} / G_{1}$ and the rest by $G_{2} / M$. For the control embryos, no dorso-ventral differences in relative phase duration were demonstrated. However, ourly tail and recombinant embryos at the 21-25 somite stage, prior to the onset of enhanced curvature, exhibited ventrally a higher proportion of $G_{0} / G_{1}$ phase cells than dorsally, and a complementary relationship for $S$ phase cells. We interpret these observations as indicating a prolonged $G_{1}$ phase at the ventral side of the tail 
bud, resulting in a prolongation of the cell cycle and thus a decreased proliferation. In 26-30 somite stage embryos, priot to the normalization of curvature in warly tail embryos, the dorso-ventral proliferation balance was re-established.

We conclude that a reduced proliferation in the ventral part of the tail bud of the aurly tail embryo precedes both the onset of enhanced curvature and the previously observed reduction in proliferation of the hindgut and notochord, and is a likely candidate for an early event in the pathogenetic sequence leading to the curly tail phenotype.

\section{Introduction}

Neural rube defects (NTD), including spina bifida, ate the result of multifactorial disturbances of the developmental process of neurulation. The aetiological and pathogenetic factors underlying NTD can be elucidated by studying mutant mouse strains in which one or more factors interfere directly or indirectly with the formation of the neural tube. One such mouse mutant is the carly sail which was first described by Grüneberg (1954). Among curby tail mice, in our stock the frequencies of the phenotypes are $52 \%$ curled tail, $8 \%$ spina bifida along with curled tail, $0.07 \%$ spina bifida along with straight tail, and $40 \%$ straight tail; anencephaly has not been observed. Both the curled tail and spina bifida are the likely result of a delay in closure of the posterior neuropore (PNP). While in nonmutant mouse embryos the PNP decreases rapidly in size and closes at the 30 somite stage, the delayed closure in ourly tail embryos can be recognized from the 25 somite stage onwards by an abnormal sized PNP and which remains open beyond the 30 somite stage (Copp 1985; Van Straten et al. 1992). It has been shown that 'affected' curby tail embryos, with such a delay in PNP closure, exhibit an enhanced axial curvature of the caudal region at the $27-29$ somite stage compared to their unaffected littermates (Brook et al. 1991). This enhanced curvature is proposed to cause the delay in closure by counteracting elevation, convergence, and fusion of the neutal folds. This hypothesis was confirmed by studies in which experimentally altered curvature was shown to modulate PNP closure rate (Brook et al. 1991; Van Straaten et al. 1993; Peeters et al. 1996). In a more detailed study, in which curvature was described along the craniocaudal axis at several developmental stages, we found that the enhanced curvature of the PNP region in affected curly tail embryos is a temporary phenomenon: affected curly tail embryos with 28-31 somites exhibit an enhanced curvature, from the level of somite 26 onwards, whereas curvature normalizes at the 32-34 somite stage (Peeters et al. 1997).

Axial curvature may be determined by differences in growth rates at the ventral and dorsal side of the body axis. Growth is the resultant of vatiations in the components cell proliferation, cell volume, cell death, cell migration, and volume of 
the extracellular matrix. A cell proliferation defect has been demonstrated in affected curly tail embryos: proliferation of hindgut endoderm and notochordal mesoderm appeared to be reduced, while proliferation of the neuroepithelium appeared normal, when compared to unaffected curby tail embryos (Copp et al. 1988). It was therefore hypothesized that the reduced proliferation of the ventrally located tissues results in an imbalance of growth which causes an enhanced axial curvature of the caudal region (Brook et al. 1991). However, proliferation was determined in that study only at the stage at which the aberrant curvature becomes manifest (i.e., 27-29 somites), while it might be predicted that aberrant curvature should be preceded by reduced ventral proliferation.

The caudal region of the embryo onginates from the tail bud, which is the continuation of the node and primitive streak. The tail bud is a dense mass of cells located at the posterior end of the embryo and its cells have the potential to give rise to the variety of tissues in the caudal region (Schoenwolf 1977; Tam 1984; Griffith et al. 1992; Catala et al. 1995; Kanki and Ho 1997). We therefore propose that enhanced axial curvature of the caudal region in carly tail embryos arises as a consequence of earlier dorso-ventral differential growth in the tail bud. Moreover, the subsequent normalization of curvature likewise may be preceded by a rebalancing of growth in the tail bud.

In order to determine whether differential grow th in the tail bud is indeed present: and is correlated with axial curvature of the PNP region, proliferation patterns (i.e., relative cell cycle phase durations) were determined for the dorsal and ventral halves of the tail bud at the developmental stage immediately preceding onset of enhanced curvature and at the subsequent stage that precedes re-establishment of normal curvature. The proliferation patterns were determined in curly tail and nonmutant (BALB/C and $\mathrm{CBA} / \mathrm{J}$ ) embryos. Because the arrly fail strain differs in genetic background from all existing inbred strains, a $B A L B / c-c u r l y$ tait recombinant strain, which possesses the curly tail characteristics on a BAJB/c genetic background, was included. By this, diffetences between the recombinant strain and the control can be ascribed to curby wilspecifically.

\section{Materials and Methods}

\section{Mouse strains and embryo preparation}

The arry tail mutation arose spontaneously in a female of the GFF inbred strain; this female was subsequently mated with a CBA/Gr male (Gruneberg 1954). The curby tail stock has been derived from this mating and is kept as a closed, randombred colony. The nonmutant inbred $B A L B / C$ and $C B A / J$ mice were obtained commercially (Charles River, Wiga GmbH, Germany). The BALB/c-curly tait recombinant strain was constructed according to a cross-interctoss design. Briefly, 
curly tail mice were mated with $B A L B / c$ mice, followed by an intercross of the heterozygous offspring. The descendants of the intercross bearing a curby tail phenotype (curled or kinked tail, with or without spina bificla) were selected and mated for the second cross-intercross cycle with BALB/c. The curty tail phenotypes of the offspring of the intercross, having a genetic background of $75 \% \mathrm{BALB} / \mathrm{c}$ and $25 \%$ curly tail, were kept as a separate collony (recombinant-2). Mice received water and food adl libitum and were maintained on a light-dark cycle with the dark period 8.00 p.m. to $6.00 \mathrm{a} . \mathrm{m}$.

Mice (curly tail, recombinant-2, $B A L B / c$ and $C B A / J)$ were paired for mating overnight, after which females were checked for copulation plugs (= day 0 ). On day $9,9.5$, or 10 , females were sacrificed by cervical dislocation and the uterine horns were explanted into pre-warmed $\left(37^{\circ} \mathrm{C}\right)$ Hanks' buffer containing $1 \%$ penicillin (Gibco), $1 \%$ streptomycin (Gibco) and 10\% newborn calf serum (Gibco, Life Technologies, Breda, The Netherlands). After removing myometrium, endometrium, Reichert's membrane, yolk sac, and amnion, appropriate embryos were selected for analysis based on their somite numbers.

\section{Measurement of proliferation}

Embryos of the developmental stages of 21-25 somites (prior to onset of enhanced curvature) and 26-30 somites (prior to te-establishment of normal curvature) were collected for determination of the proliferation pattern. Each embryo was washed in PBS. The tail bud was split into a dorsal and ventral half (Fig. 1) and, subsequently, both halves were isolated by a transverse cut across the body axis. Each half was placed in a Falcon vial (F2058, Becton/Dickinson, San Jose, CA) in approximately $50 \mu \mathrm{l}$ PBS using a glass pipet. Cell cycle parameters were determined according to the method of Vindelav (1983b). Briefly, nuclei were extracted by adding $450 \mu \mathrm{l} 0.003 \%$ trypsin (Worthington Biochemical Corporation, Freehold, NJ) in citrate buffer. During an incubation period of $15 \mathrm{~min}$ at room temperature, the suspension was gently mixed every $3 \mathrm{~min}$. Next, $450 \mu \mathrm{l}$ trypsin inhibitor

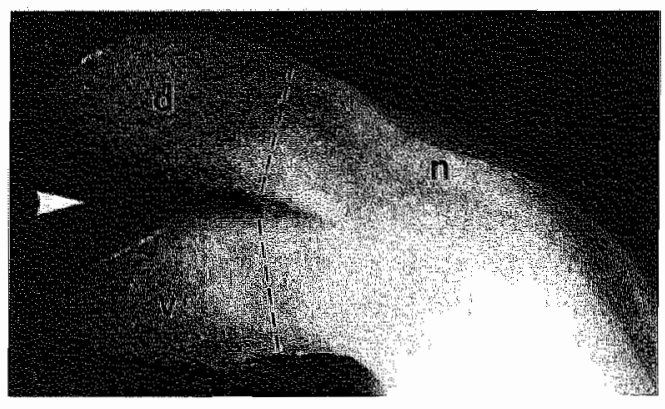

Fig. 1. A 27 somite stage chrly lail embryo of which the tail bud is split into a dorsal (d) and ventral (v) hali. Dotted lines indicate the position of the transverse cut for isolating the tail bud halves. This example showing a similar amount of tissue in the dorsal and ventral halves is representative for the isolations made. $m$, Right lateral fold of the neuropore. 
solution $(0.05 \%$ trypsin inhibitor [type II-O, Sigma, St Lous, MO], $0.01 \%$ ribonuclease [RNAse, Serva, Heidelberg, Germany] in citrate buffer, $\mathrm{pH}=7.6$ ) was added and mixed gently for 15 min. DNA was labeled by the addition of $375 \mu \mathrm{l}$ propidium iodide (PI) solution (0.0415\% PI [Calbiochem 53705\%], $0.116 \%$ spermine [Sigma] in citrate buffer, $\mathrm{pH}=7.6$ ). After at least 15 min in the dark, the suspension was sieved through a $50 \mu \mathrm{m}$ nylon mesh (Stokvis \& Smits, IJmuiden, the Netherlands). Using the eluate, the DNA content per nucleus was established using a FACSORT (Becton Dickinson): PI was excited with a single 488nm Argon laser and PI fluorescence was detected through a $600 \mathrm{~nm}$ LP filter. Pulse processing was used to exclude doublets and larger cellular aggregates. A DNA histogram was constructed for each half of the tail bud. Based on this histogram, cell cycle analysis (determination of the proportions of nuclei in cell cycle phases $G_{0} / G_{1}, S$ and $\left.\mathrm{G}_{2} / \mathrm{M}\right)$ was performed using the CellFIT software (Becton Dickinson). Tail buds with a coefficient of variation (CV) for $\mathrm{G}_{0} / \mathrm{G}_{1}$ above $10 \%$ were excluded; the mean CV for $G_{0} / G_{1}$ was between $5 \%$ and $6 \%$ in all gtoups studied.

The procedure of embryo preparation and tail bud isolation required maximal 20 min, which is very short compared to the total cell cycle duration and therefore will hardly affect the proliferation pattern. Cell cycle changes do not occur after adding the trypsin solution to the isolated halves of the tail bud and fluorescence of the nuclei is reported to be stable for at least $3 \mathrm{hr}$ after adding the PI (Vindelov et al. 1983b).

\section{Proliferation pattern and statistical analysis}

Data were grouped by mouse strain and developmental stage. Mean proportions for $G_{0} / G_{1}, S$, and $G_{2} / M$ were calculated for all groups for the dorsal and ventral halves of the tail bud. In order to compare the proliferation patterns of the dorsal and ventral tail bud halves, embryos were classified according to whether the proportion $G_{0} / G_{1}$ was highest in the dorsal or in the ventral half. A similar analysis was done separately for $S$ phase and for $G_{2} / M$. The percentage of embryos with dorsal dominance versus the percentage of embryos with ventral dominance, within each group, was analysed using a sign test. A possible shift in dorsal or ventral dominance from the 21-25 somite stage to the 26-30 somite stage was tested using a chi-square test. The percentages of nuclei in the various cell cycle phases were compared between the two developmental stages using MANOVA with $\mathrm{G}_{2} / \mathrm{G}_{1}, \mathrm{~S}$, and $G_{2} / M$ as dependent variables and developmental stage as factor (Wilk's test). Differences werc considered statistically significant when $\mathrm{p}<0.05$. 


\section{Results}

Proliferation pattern in the tail bud at the developmental stage prior to onset of enhanced curvature

Proliferation pattern in the tail bud was determined separately for dorsal and ventral halves, which were isolated as shown in Figure 1. In greneral, for young embryos (21-25 somites) of all strains of mice it appeared that approximately half of the nuclei in the dorsal tail bud were in $\mathrm{S}$ phase, one-third of the nuclei were in $\mathrm{G}_{0} / \mathrm{G}_{1}$ phase and less than $15 \%$ were in $\mathrm{G}_{2} / \mathrm{M}$ phase (Table 1 ).

When the proliferation patterns were compared within embryos an interesting strain difference emerged (Fig. 2). In the nonmutant strains, there was an approximately even distribution of embryos with dorsal-dominance and those with ventral-dominance for each cell cycle phase. Thus, five out of $14 \mathrm{BALB} / \mathrm{c}$ embryos had a higher proportion of nuclei in $S$ phase dorsally than ventrally. For the $G_{0} / G_{1}$

\section{$21-25$ somites}

$\mid \begin{aligned} & \text { ardy tal (15) } \\ & \text { recomb-2 (16) } \\ & \text { BALB/c (14) } \\ & \text { CBA/J (16) }\end{aligned}$
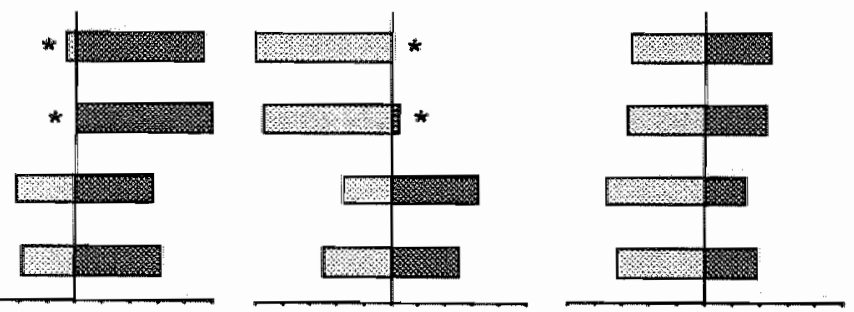

$26-30$ somites
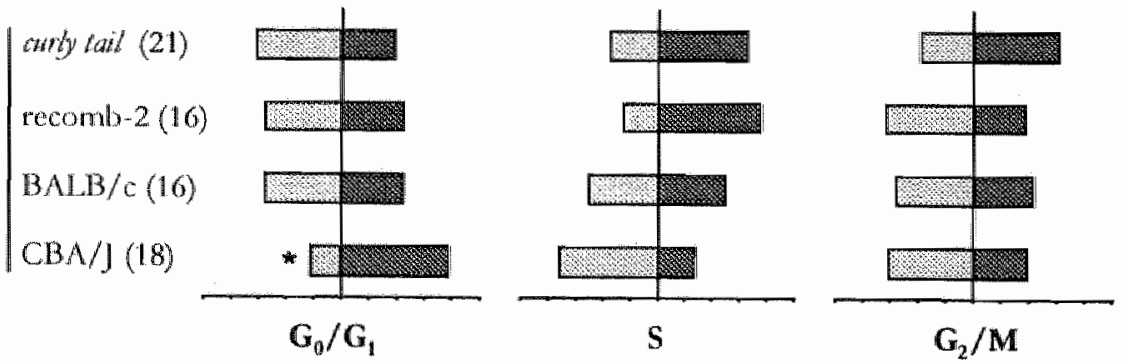

\section{dorsal ventral}

Fig. 2. The proportion of embrycs with a dorsal dominance (light gray) vs. the proportion with a ventral dominance (dark gray) indicated for each cell cycle phase. Length of bar represents all embryos (100\%) of a mouse strain at that developmental stage; number of embryos per group are in parentheses. Two mutant (ombly tail and recombinant-2) and two nonmutant (BALB/c and $C B A / D)$ mouse strains are used at the developmental stages prior to onset of entariced $(21-25$ somites) and prior to re-establishment of normal (26-30 somites) curvature. Statistically significant differences are indicated (*). 
six out of 14 exhibited dorsal-dominance, and for $G_{2} / M 10$ out of 14 embryos showed dorsal-dominance. These dorso-ventral distributions are not significantly different from a 50/50 distribution, indicating that the proliferation pattems of the dorsal and ventral halves evenly balanced in the $B A L B / c$ embryos. A similar finding was obtained from the $\mathrm{CBA} / \mathrm{J}$ embryos. In contrast, proliferation patterns differed markedly between the dorsal and ventral halves in the mutant (curby tail and recombinant-2) embryos. All 15 curly tail embryos exhibited a higher proportion of nuclei in $S$ phase dorsally than ventrally ( $\mathrm{P}<0.0001)$, and, conversely, only one out of 15 had a higher proportion in $G_{0} / G_{1}$ dorsally than ventrally $(P=0.001$ ). An identical tendency was seen in recombinant- 2 embryos; 15 out of 16 had a higher $S$ proportion dorsally than ventrally $(P=0.0005)$, and all 16 exhibited a lower $G_{0} / G_{1}$ proportion dorsally than ventrally $(\mathrm{P}<0.0001)$. In both mutant strains, the $\mathrm{G}_{2} / \mathrm{M}$ proportions were similar in the dorsal and ventral halves of the tail bud. Thus, whereas the proliferation patterns in control embryos were balanced between the dorsal and ventral halves of the tail bud, a dorsal preference for $S$ together with a ventral preference for $G_{0} / G_{1}$ was demonstrated in the mutant embryos.

\section{Proliferation pattern in the tail bud at the developmental stage prior to re- establishment of normal curvature}

As with embryos at the earlier developmental stage, embryos at the 26-30 somite stage also had about half of their nuclei in $S$ phase, about one-third in $G_{0} / G_{1}$ phase and less than $15 \%$ in $\mathrm{G}_{2} / \mathrm{M}$ phase (Table 2).

The dorso-ventral distribution of cell cycle phases in nonmutant embryos at this more advanced stage did not differ from a $50 / 50$ distribution, except for the $G_{0} / G_{1}$

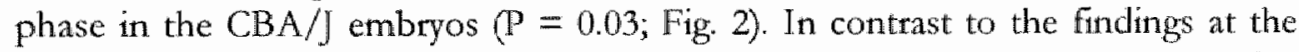
21-25 somite stage, curly tail and recombinant- 2 embryos with 26-30 somites also demonstrated an equal proliferation pattem between the dorsal and ventral halves of the tail bud. The shift from $S$ phase dominance dorsally at the 21-25 somite stage to an equal dorso-ventral distribution at the 26-30 somite stage was

Table 1. Proliferation patterns in tail bud of embryos at the stage of $21-25$ somites

\begin{tabular}{|c|c|c|c|c|c|c|c|}
\hline \multirow{2}{*}{$\begin{array}{l}\text { Mouse } \\
\text { strain }\end{array}$} & \multirow{2}{*}{$\begin{array}{l}\text { Number } \\
\text { of embryos }\end{array}$} & \multicolumn{3}{|c|}{ dorsal half } & \multicolumn{3}{|c|}{ ventral half } \\
\hline & & $\% / 0 G_{0} / G_{1}$ & $\% S$ & $\% \mathrm{G}_{2} / \mathrm{M}$ & $\% / G_{\mathrm{n}} / \mathrm{G}_{1}$ & $0 / 65$ & $\% / \% \mathrm{G}_{2} / \mathrm{M}$ \\
\hline curly bail & 15 & $35(1.5)$ & $51(1.8)$ & $14(0.9)$ & $41(0.9)$ & $45(0.7)$ & $14(0.7)$ \\
\hline reconb. -2 & 16 & $36(1.2)$ & $51(1.8)$ & $13(1.1)$ & $41(1.1)$ & $46(1.5)$ & $13(0.7)$ \\
\hline $\mathrm{BALB} / \mathrm{C}$ & 14 & $34(0.8)$ & $55(1.4)$ & $11(0.9)$ & $34(1.3)$ & $56(1.8)$ & $9(1.0)$ \\
\hline $\mathrm{CBA} / \mathrm{I}$ & 16 & $36(1.2)$ & $49(1.2)$ & $15(0.7)$ & $38(1.3)$ & $47(1.8)$ & $15(0.8)$ \\
\hline
\end{tabular}

"Figures are the number of embryos used, the mean (and SEM) of the proportions for each cell cycle phase. 
statistically significant for both the carly lail and the recombinant-2 $(\mathrm{P}<0.001)$ embryos. A complementary shift occurred for the $G_{0} / G_{1}$ phase dominance in the ventral tail bud for both $(\mathrm{P}<0.005)$ mutant strains.

When comparing the proliferation patterns of the nonmutant strains of mice at the two developmental stages, several consistent differences could be noted, although the magnitude of the differences were small (Tables 1 and 2). The proportion of nuclei in $G_{0} / G_{1}$ was increased at the older stages, although not significantly for the ventral tail bud of $B A L B / c$ embryos. The decrease in proportion of nuclei in $S$ was consistent, al though not statistically significant.

\section{Discussion}

We have shown that cells of the tail bud of mouse embryos, at the developmental stages during which the PNP closes, have a cell cycle of which half is occupied by $S$ phase, about one-third by $G_{0} / G_{1}$, and the rest by $G_{2} / M$. For nonmutant embryos no dorso-ventral difference in proliferation patterns could be demonstrated. However, both mutant mouse strains (curly tail and recombinant-2) showed, at the stage prior to the onset of enhanced curvature, a ventral dominance for $G_{0} / G_{\|}$ phase together with a dorsal dominance for $S$ phase. These proliferation patterns were no longer evident at the later developmental stage studied, just prior to reestablishment of normal curvature. In the nonmutant mouse strains, the contribution of the $G_{0} / G_{1}$ phase showed a tendency to increase during development.

\section{Changes in the proliferation pattern of the tail bud during development}

The prolifetation pattern in the tail bud of the mouse embryo was determined using flow cytometry on cells isolated from separated dorsal and ventral halves of the tail bud. The percentages of nuclei in $G_{0} / G_{1}, S$ and $G_{2} / M$ were determined as a

Table 2. Proliferation patterns in tail bud of embryos at the stage of $26-30$ somites

\begin{tabular}{|c|c|c|c|c|c|c|c|}
\hline \multirow{2}{*}{$\begin{array}{l}\text { Mouse } \\
\text { strain }\end{array}$} & \multirow{2}{*}{$\begin{array}{l}\text { Number } \\
\text { of embryos }\end{array}$} & \multicolumn{3}{|c|}{ dorsal half } & \multicolumn{3}{|c|}{ ventral half } \\
\hline & & $\% \mathrm{G}_{0} / \mathrm{G}_{3}$ & $\% \mathrm{~S}$ & $\% \mathrm{G}_{2} / \mathrm{M}$ & $\mathrm{O}_{0} / \mathrm{G}_{1}$ & $\% \mathrm{~S}$ & $\% G_{2} / \mathrm{M}$ \\
\hline wrbl tail & 21 & $38(0.8)$ & $48(1.0)$ & $14(0.7)$ & $37(0.9)$ & $49(1.1)$ & $14(0.7)$ \\
\hline recomb-2 & 16 & $39(1.3)$ & $50(1.5)$ & $12(0.7)$ & $38(1.2)$ & $52(1.9)$ & $10(0.9)$ \\
\hline $\mathrm{BALB} / \mathrm{c}$ & 16 & $38(1.3)$ & $51(1.7)$ & $12(0.7)$ & $38(1.3)$ & $51(1.9)$ & $11(1.0)$ \\
\hline$C B A / J$ & 18 & $39(0.8)$ & $47(1.2)$ & $14(0.7)$ & $41(0.8)$ & $46(1.0)$ & $13(0.6)$ \\
\hline
\end{tabular}

"Figures are the number of embryos used, the mean (and SEM) of the proportions for each cell cycle phase. 
reflection of their contribution to the total cell cycle duration. "The method used in this study has been described by Vindelov(1983b) and produces histograms of sufficient resolution for cell cycle analysis (mean coeffrcients of variation of 5-6\% for the $G_{0} / G_{1}$ peak) (Vindelov et al. 1983a).

Proliferation characteristics of embryonic cells, particularly in the rodent neural tube, have previously been determined by the measurement of incorporation of ${ }^{3} \mathrm{H}$ thymidine or BrdU. These studies describe an $S$ phase duration of about 5 hours in neuroepithelial cells, which corresponds to approximately $50 \%$ of total cell cycle duration, in good agreement with our findings. Data from the previous studies on the length of $G_{0} / G_{1}$ and $G_{2} / M$ phases show more variation (Kauffman 1968; Wilson and Center 1974; Peters and De Geus 1981; Wilson 1982). Flow cytometry has previously been used to determine proliferation patterns of complete rat embryos at the stage of about 20 somites (Rogers et al. 1995). The pool of various cell types showed an overall proliferation pattern of $38 \% \mathrm{G}_{0} / \mathrm{G}_{1}, 49 \% \mathrm{~S}$, and $13 \%$ $\mathrm{G}_{2} / \mathrm{M}$ phase, which is almost identical to the proliferation pattern of the mouse tail bud as observed in the present study.

During development, the contribution of cells in $G_{0} / G_{1}$ phase in nonmutant mouse embryos increased, while the contribution of $S$ phase tended to decrease. This is in agreement with the results of incorporation studies in neural tissue, which showed that the contribution of $\mathrm{G}_{0} / \mathrm{G}_{1}$ increased from about $2 \mathrm{hr}$ on day 10 ( $22 \%$ of total cell cycle duration) to $9.3 \mathrm{hr}$ on day $14(62 \%)$, while $\mathrm{S}$ phase decreased from $6.4 \mathrm{hr}$ on day $7(>80 \%)$ to about $5 \mathrm{hr}$ on day $10(55 \%)$ and subsequently to $3.8 \mathrm{hr}$ on day 14 (25\%) (Kauffman 1968; Wilson and Center 1974; Poelmann 1980; Peters and De Geus 1981; Wilson 1982; Mirkes et al. 1989; Takahashi et al. 1993). The largest change was an increase in $G_{1}$ and, as a consequence, total cell cycle duration increased. The lengthening of $G_{1}$, and of the total cell cycle, are likely related to the initiation of cell differentiation. This increase of $G_{0} / G_{1}$ during differentiation has also been corroborated in studies using flow cytometry: the proportion of cells in $\mathrm{G}_{0} / G_{1}$ phase was low (about $25 \%$ ) in gastrulating embryos (MacAuley et al. 1993) and over $50 \%$ in more differentiated tissue of the fore limb bud (Francis et al. 1990). We have now demonstrated that such a shift in the proliferation pattern also occurs in tail buds of two closely related stages.

Incorporation studies have the disadvantage of the relatively extended time period necessary for incorporation of thymidine or its analog BrdU into DNA. As the embryo continues to develop during the labelling period, it is difficult to determine proliferation differences between closely-spaced developmental stages. Flow cytometry does not suffer from this disadvantage and proliferation pattems can be established at any developmental stage. Our study of proliferation in the tail bud agrees closely with previously reported proliferation patterns of mouse and rati 
embryos at comparable developmental stages and suggests that flow cytometry is a valuable method for cell cycle analysis in the early mouse embryo.

\section{Proliferation is reduced in the ventral tail bud}

The flow cytometry technique necessitates that all nuclei pass individually through the laser beam. So, nuclei have to be extracted and the position of the cells within the tail bud is lost. Therefore, the tail bud was split mechanically before analysis, and the proliferation pattern was established for each half separately. As a consequence, the pool of cells from each half of the tail bud comprised mesoderm as well as ectoderm cells, and likewise, cells from more caudal and cranial positions within the tail bud. This could be important if heterogeneity of proliferation pattern exists within the tail bud, as has been shown for the tail bud of the zebrafish (Kanki and Ho 1997). Because in a tail bud the lengths of the dorsal and ventral halves were identical, comparing the proliferation pattern of the dorsal and ventral halves within each embryo, therefore, tends to rule out potential complications caused by a possible cranio-caudal gradient in proliferation.

Dorso-ventral comparisons in the mutant embryos at the stage prior to onset of enhanced curvature revealed a ventral dominance for $G_{0} / G_{1}$ phase together with a dorsal dominance for $S$ phase, while in the nonmutant embryos no dorso-ventral differences were detected. The ventral dominance for $G_{0} / G_{1}$ and the dorsal dominance for $S$ could be the result of several dorso-ventral differences, as follows.

(a) Cell loss at a particular phase may occur in one of the halves of the tail bud, due to apoptosis. In a previous proliferation study of corly tail embryos it was reported that the incidence of cell death was very low in the caudal region (Copp et al. 1988). For the developing tail of the chick embryo, an incidence of cell death of $1-10 \%$ has been demonstrated, with dead cells concentrated mainly at the site of the ventral ectodermal ridge and at the tip of the tail (Mills and Bellairs 1989). In a pilot study of cell death in curly kail and nonmutant mouse embryos, we only found few scattered dead cells in the tail bud. Therefore, apoptosis is probably not an important factor in producing the dorso-ventral differences, although it remains to be determined more precisely whether the incidence of cell death is different for the dorsal and ventral halves of the tail bud as well as how cell death in the tail bud is related to phases of the cell cycle.

(b) With flow cytometry, no distinction between $G_{0}$ and $G_{1}$ cells can be made, due to their equal amount of DNA. However, the growth fraction in the caudal region of ourly tail embryos is neatly $100 \%$ (Copp et al. 1988) and this is likelly to be the case in nonmutant embryos as well. Therefore, any change in $G_{0} / G_{1}$ distribution must be due to changes in $G_{1}$, and not in $G_{0}$.

(c) The ventral dominance for $G_{1}$ phase together with the dorsal dominance for $S$ phase seems likely to result from significant variation in one of these phases only. 
Thus, the $G_{1}$ phase is longer or the $S$ phase is shorter at the ventral side of the tail bud when compared to the dorsal side. There are three reasons to think that prolongation of the $G_{1}$ phase at the ventral side of the tail bud is the principal alteration in the cell cycle. (1) Previous proliferation data of affected corby tail embryos at the stage of 27-29 somites demonstrated a slightly prolonged $S$ phase in the ventrally located tissues (gut and notochord) when compared to dorsally (neural plate) (Copp et al. 1988), making it less likely that the $S$ phase in the ventral tail bud half is shortened.

(2) Neuroepithelial cells of rodent embryos at stages similat to the present study have been reported to have a cell cycle duration of about $10 \mathrm{hr}$, with an $\mathrm{S}$ phase of about 5 hr (Kauffman 1968; Wilson and Center 1974; Peters and De Geus 1981; Wilson 1982). Moreover, the various cell types in the caudal region of arly tail embryos also exhibit an S phase of about $5 \mathrm{hr}$ (Copp et al. 1988). Accordingly, we suppose that cell cycle duration in the dorsal half of the tail bud is about $10 \mathrm{hr}$ with an $\mathrm{S}$ phase of $5.1 \mathrm{hr}$, and consequently a $\mathrm{G}_{0} / \mathrm{G}_{1}$ of $3.5 \mathrm{hr}$ and $\mathrm{a} \mathrm{G}_{2} / \mathrm{M}$ of $1.4 \mathrm{hr}$. If $S$ and $G_{2} / M$ in the ventral half of the tail bud would also take 5.1 resp. $1.4 \mathrm{hr}$, according to Table $1 G_{0} / G_{1}$ would take $4.7 \mathrm{hr}$. As a result, cell cycle duration would be increased to about $11.2 \mathrm{hr}$, which is in agreement with the cell cycle duration observed in hindgut endoderm of affected curly tail embryos (Copp et al. 1988). Thus, the prolonged cell cycle duration in the ventral half of the tail bud compared to the dorsal half indicates that proliferation is decreased ventrally.

(3) A reduced rate of cell proliferation would result in a reduced DNA content of the caudal region. This has indeed been demonstrated: at the stage prior to the onset of enhanced curvature, the DNA content of caudal regions in curly tail embryos is $0.93 \mu \mathrm{g}$ instead of the $1.25 \mu \mathrm{g}$ for BALB/c (Peeters et al., submitted).

Taken together, our findings suggest a reduction in proliferation due to $G_{1}$ prolongation and increase in total cell cycle duration in the ventral part of the tail bud in the corrly tail mouse embryo in the period preceding onset of enhanced axial curvature.

\section{Decreased ventral proliferation and enhanced axial curvature}

Previous studies of curly tail embryos have demonstrated a dorso-ventral discrepancy in growth between hindgut/notochord and the neural plate, which correlates spatially and temporally with enhanced curvature of the body axis (Copp et al. 1988; Brook et al. 1991; Peeters et al. 1997). The present study extends those observations by showing that the tail bud at the $21-25$ somite stage also exhibits a dorso-ventral proliferation imbalance. The tail bud at this early stage contains progenitor cells for the hindgut and caudal notochord and for the neural plate at the later 26-30 somite stage, suggesting that a dorso-ventral proliferation discrepancy in the tail bud leads, via enhancement of axial curvature, to failure of 
neural tube closure. By the 26-30 somite stage, the balance of growth has been restored in the tail bud and, subsequently, normal axial curvature is re-established. The disturbed proliferation in the tail bud occurs at a stage before affected curly tail embryos can be distinguished from their unaffected \ittermates, indicating that the disturbed proliferation in the tail bud is an early marker of the cotrly tail pathogenesis.

The recombinant- 2 embryos showed an identical reduction of proliferation in the ventral part of the tail bud. Although the genetic backgtound contains $75 \%$ $\mathrm{BALB} / \mathrm{c}$, its proliferation pattern tesembles that of arily tail rather than that of $\mathrm{BALB} / \mathrm{c}$. This emphasizes that it is the curly lail genetic defect specifically which influences the proliferation in the tail bucl.

\section{Regulation of proliferation in the tail bud}

In order to investigate further the origin of the dorso-ventral discrepancy in proliferation in the tail bud, genes must be identified that exhibit a dorso-ventral gradient of expression in the tail bud. Many genes which appear to play key roles in caudal development have been studied recently in carby tail embryos at the developmental stage prior to re-establishment of normal curvature. The expression of HNF-3 $\alpha$, HNF-3 $\beta$, Shh, T, Hox-b1, Fgf-8, Evx-1, and Wnt-5b are all reported to be normal in curby tail embryos, while expression of Wnt-5a is reduced in the caudal mesoderm at both stages investigated in the present study (Gofflot et al. $1996,1997)$. Moreover, the expression of the retinoid acid receptors RAR- $\beta$ and RAR- $\gamma$ has also been found to be reduced in the rurly tail embryo (Chen et al. 1995). $U$ pregulation of RAR- $\beta$ either by RA or inositol administration results in a normalization of PNP closure and a reduction of the incidence of spinal NTD in curly tail mice (Seller et al. 1979; Chen et al. 1994, 1995; Greene and Copp 1997). This indicates that RAR- $\beta$, RAR- $\gamma$, and Wint-5a are among the genes likely involved in the pathogenesis of the arry tail. However, the relationship between their expression pattern and the dorso-ventral discrepancy in proliferation in the tail bud still has to be clarified.

In conclusion, the present study has demonstrated a cell proliferation imbalance possibly inwolving lengthening of the cell cycle owing to prolongation of $G_{1}$ in the ventral part of the tail bud of the curly tail mouse embryo at the stage prior to the development of enhanced axial curvature, which precedes development of neural tube defects. Like the enhanced curvature, the proliferation imbalance in the tail bud is a transient feature, with rebalancing at the stage prior to re-establishment of normal axial curvature. "The proliferation disturbance of the tail bud is an early feature in mutant embryos of the pathogenetic sequence that leads to the ourly tail phenotype. Genes which determine the dorso-ventral proliferation pattern may include RAR- $\beta$, RAR- $\gamma$, and Wnt-5a. 


\section{Acknowledgements}

We acknowledge Andrew J. Copp for critically reading the manuscript.

\section{References}

Brook FA, Shum ESW, Van Straten HWM, Copp AJ (1991) Curvature of the caudal region is responsible for failure of neural tube closure in the curly tail (ct) mouse embryo. Development 113: 671-678

Catala M, Teillet MA, Le Douarin NM (1995) Organization and development of the tail bud analyzed with the quail-chick chimaera system. Mech Dev 51: 51-65

Chen WH, Morriss-Kay GM, Copp AJ (1994) Prevention of spinal neural tube defects in the curly tail mouse mutant by a specific effect of retinoic acid. Dev Dyn 199: 93-102

Chen WH, Morriss-Kay GM, Copp AJ (1995) Genesis and prevention of spinal neural rube defects in the wry fail mutant mouse: involvement of retinoic acid and its nuclear receptors RAR- $\beta$ and RAR- $\gamma$. Development 121: 681-691

Copp AJ (1985) Relationship between timing of posterior neuropore closure and development of spinal neural tube defects in mutant (cmblat) and normal monse embryos in culture. J Embryol Exp Morphol 88: 39-54

Copp AJ, Brook FA, Roberts HJ (1988) A cell-type-specific abnormality of cell prolifration in mutant (curly tail) mouse embryos developing spinal neural tube defects. Development 104: 285-295

Francis BM, Rogers JM, Sulik KK, Alles AJ, Elstein KH, Zucker RM, Massararo EJ, Rosen MB, Chernoff N (1990) Cyclophosphamide teratogenesis: evidence for compensatory responses to induced cellular toxicity. Teratology $42: 473-482$

Gofflot F, Hall M, Morriss-Kay GM (1996) Gene expression in the posterior neuropore region of $\mathrm{C} 57 \mathrm{Bl} / 6$ and curly tail mutant mouse embryos. Proc. Arrat. Soc. Gr. Britain/Ireland, Dec $196 \mathrm{p} 44$

Gofflot F, Hall M, Morriss-Kay GM (1997) Mollecular analysis of the posterior neuropore and tail region of C57Bi/ 6 and carly tail mouse embryos. Dev Biol 186: B198

Greene NDE, Copp AJ (1997) Inositol prevents folate-resistant neural tube defects in the mouse. Nature Med 3: 60-66

Griffith CM, Willey MJ. Sanders EJ (1992) The vertebrate tail bud: three germ layers from one tissue. Anat Embryol 185: 101-113

Gruneberg H (1954) Genetical studies on the skeleton of the mouse. Vlll cutly tail. J Genet 52 : $52-67$

Kanki JP, Ho RK (1997) The development of the posteriot body in zebrafish. Development 124: $881-893$

Kauffman SL (1968) Lengthening of the generation cycle during embryonic differentiation of the mouse neural tube. Exp Cell Res 49: 420-424

MacAuley A, Werb Z, Mirkes PE (1993) Characterization of the unusually rapid cell cycles during gastrulation. Development $117: 873-883$

Mills CL, Bellairs R (1989) Mitosis and cell death in the tail of the chick embryo. Anat Embryol $180 * 301-308$

Mirkes PE, Ricks JL, Pascoe-Mason JM (1989) Cell cycle analysis in the carciac and neuroepithelial tissues of day 10 rat embryos and the effects of phosphoramide mustard, the major teratogenic metabolite of cyclophosphamide. Teratology 39: 115-120

Peeters MCE, Hekking JWM, Vainas I, Drukker J, Van Straten HWM (1997) Spatio-tempotal curvature pattern of the casdal body axis for non mutant and chrly lail mouse embryos during the period of caudal neural tube closure. Anat Embryol 195: 259-260 
Peeters MCE, Shum ASW, Hekkng JWM, Copp AJ, Van Straten HWM (1996) Relationship between altered axial curvature and neutal tube closure in tromal and mutant (curly taih) mouse embryos. Anat Embryol 193: 123-130

Peters PWJ, De Geus D (1981) Cell proliferation of the neuroepithelium in embryonic stages of induced spina bifida. Acta Morphologica Neerlando-Scandinawica 19: 197-204

Poelmann RE (1980) Differential mitosis and degeneration patterns in relation to the alterations in the shape of the embryonic ectoderm of early post-implantation mouse embryos. I Embryol Exp Morphol 55: 33-51

Rogers JM, Weldon-Taubeneck M, Daston GP, Sulk KK, Zucker RM, Elstein KH, Jankowski $M A$, Keen CL (1995) Zinc deficiency causes apoptosis but not cell cycle alterations in organogenesis-stage rat embryos: effect of varying duration of deficiency. Teratology $52: 149$ 159

Schoenwolf GC (1977) Tail (end) bud contributions to the posterior region of the chick embryo. $\int \operatorname{Exp} Z$ Zool 201: 227-246

Seller MI, Embury S, Polani PE, Adinolfi M (1979) Neural tube defects in curly-tail mice. II. Effect of maternal administration of vitatmin A. Proc R Soc Lond B Biol Sci 206: 95-107

Takahashi T, Nowakowski RS, Caviness VS, Jr. (1993) Cell cycle parameters and patterns of nuclear mowement in the neocortical proliferative zone of the fetal mouse. J Neurosc 13: 820833

Tam PPL (1984) The histogenetic capacity of tissues in the caudal end of the embryonic axis of the mouse. J Embryol Exp Morphol 82: 253-266

Van Straaten HWM, Hekking JWM, Consten C, Copp AJ (1993) Intrinsic and extrinsic factors in the mechanism of neurulation: effect of curvature of the body axis on closure of the posterior neuropore. Development 117: 1163-1172

Van Straten HWM, Hekking JWM, Copp AJ, Bernfield M (1992) Deceleration and acceleration in the rate of posterior neuropore closure during neurulation in the curly tail (ct) mouse embryo. Anat Embryol 185: 169-174

Vindelov LL, Christensen IJ, Jensen $G$, Nissen NI (1983a) Limits of detection of nuclear DNA abnormalities by flow cytometric DNA analysis. Results obtained by a set of methods for sample-storage, staining and internal standardization. Cytometry 3: 332-339

Vindeløv LL, Christensen IJ, Nissen NI (1983b) A detergent-trypsin method for the preparation of nuclei for flow cytometric DNA analysis. Cytometry 3: 323-327

Wilson DB (1982) The cell cycle during closure of the neural folds in the C57BL mouse. Dev Brain Res $2: 420-424$

Wilson DB, Center EM (1974) The neural cell cycle in the looptail (Lp) mutant mouse. I Embryol Exp Morphol 32: 697-705 


\section{Chapter 4.2}

\section{Role of embryonic glucose consumption}

\section{In press as:}

Reduced glucose consumption in the carby tail mouse dloes not initiate the pathogenesis leading to spinal neural tube defects. Marian C.E. Peeters, Jan L.M.C. Geelen, Johan W.M. Hekking, Niels Chavannes, Joep P.M. Geraedts and Henny W.M. van Straaten. Joumal of Nutrition

\section{Abstract}

At embryonic stages of neural tube closure, the mouse embryo exhibits a high rate of glycolysis with glucose as the main energy source. In the curby tail mouse, often used as a model system for human neural tube defects, a delay in closure of the posterior neuropore (PNP) is proposed to be indirectly caused by a proliferation defect in the caudal region. Because glucose is important for proliferation, we tested glucose uptake in corby tail and control embryos as well as in a BALB/c-atry tail recombinant strain. The structure and expression of Glut-1, a glucose transporter molecule which is abundantly present during those embryonic stage and which has been mapped in the region of the major curly tail gene, was also studied; however, no strain differences could be demonstrated. Glucose uptake was determined by measuring glucose depletion from the medium in long-term embryo cultures which encompassed the stages of PNP closure and by measuring accumulation of ${ }^{3} \mathrm{H}$-deoxyglucose in short-term cultures at the stages of early and of final PNP closure. Both approaches indicated a reduced glucose uptake by carty tail and recombinant embryos. Surprisingly, the uptake per cell appeared normal, accompanied by a reduced DNA content of the mutant embryos. Therefore, it is unlikely that reduced cell proliferation is caused by a reduction in glucose supply during the pathogenesis of the defects in anty tail embryos. The reduced DNA content as well as the reduced glucose uptake per errbryo are likcly downstream effects of the aberrant proliferation pattern. 


\section{Introduction}

Multivitamin supplementation containing folic acid prevents the occurrence of ncutal tube defects (NTD), like spina bifida, in humans in $70 \%$ of the cases, leaving a significant number of NTD that do not respond (Wald et al. 1991; Caeizel and Dudas 1992). The mouse mutant carby wat exhibit NTD which closely resembles human NTD (Seller and Adinolfi 1981). However, this NTD cannot be prevented by supplementation of folic acid or its metabolites folinic acid and methionine. Thus, the curb lail is a genetic model of folate-resistant NTD and might therefore be used to unravel the pathogenesis of this subcategory of human NTD (Seller 1994; Van Straten et al. 1995; Greene and Copp 1997).

Among wry wail, several phenotypes can be recognized: cutled taul $(52 \%)$, spina bifida along with curled tail ( $8 \%$ ), and straight tail (40\%). The genetic defect in owrly tail mice is unknown. The mutant arose spontaneously in 1950 and was first reported as an autosomal recessive trait with incomplete penetrance (Grüneberg 1954). More recently, the curly caildefect has been considered poly-genic, involving a major gene on Chromosome 4 and probably two or three modifier genes (Neumann et al. 1994; Beier et al. 1995; Letts et al. 1995). Several aspects of the pathogenetic processes leading to the arly lail phenotypes are known. The curled tail and spina bifida are probably both the result of a delay in closure of the posterior neuropore (PNP), which can be recognized in embryos at the developmental stages of 27-29 somites (Copp 1985; Van Straaten et al. 1992). It has been shown that a temporary enhancement of axial curvature in the caudal region is related to the degree of delay in PNP closure and is proposed to induce the delay by counteracting the ellevation, convergence and fusion of the neural folds (Brook et al. 1991; Peeters et al. 1997). Experimental prevention of the enhanced curvature indeed resulted in normal PNP closure, whereas experimentally enhanced curvature delayed the closure of the PNP (Brook et al. 1991; Van Straaten et al. 1993; Peeters et al. 1996). The enhanced curvature in the curby tail embryo is likely the result of dorso-ventral proliferation differences in the caudal region: ventral tissues like notochord and gut endoderm exhibit a decreased proliferation in embryos showing a delay in PNP closure compared to embryos with a normal PNP closure, while the proliferation of the dorsal tissues like neuroepithelium did not differ (Copp et al. 1988).

During the process of neurulation, the rodent embryo is highly dependent on ghucose as its main energy source (Cockroft 1979). Prior to establishment of a functional chorioallantoic circulation (up to the 30 somite stage), the embryo consequently experiences a low oxygen concentration, and mote than $90 \%$ of the consumed glucose is used for glycolysis, while the pentose phosphate shunt (PPS) is the major oxidative pathway for the remainder. A gradual shift to oxidative 
glucose metabolism based on the citric acid cycle and electron transport pathway, and a simultaneously relative reduction in glycolysis and PPS, occurs during the final stage of PNP closure and thereafter (Shepard et al. 1970; Clough and Whittingham 1983; Hunter and Sadler 1988; Akazawa et al. 1994). The importance of glucose for neurulation-stage embryos is also demonstrated by the ease with which NTD can be induced by aberrant glucose concentrations: both hyperglycemic and hypoglycemic circumstances disturb neurulation (Cockroft and Coppola 1977; Sadler 1980; Eriksson et al. 1984; Reece et al. 1985, 1996; Akazawa et al. 1989; Smoak and Sadler 1990; Maeda et al. 1993). In the caudal part of the curly tail embryo, the aberrant proliferation pattern is related to the delay in PNP closure at a stage during which the energy metabolism is dependent on glycolysis and PPS, a type of metabolism associated with rapid cell proliferation (Papaconstantinou 1967). "Therefore, glucose uptake might be reduced in corly tail embryos, causing the reduced proliferation.

Glucose can be utilized by a cell only after it is transported across the cell membrane to the intracellular compartment by a carrier protein. 'The carrier Glut-1 is abundantly present in the neurulation-stage embryo and, moteover, is expressed in neuroepithelial cells at an increasing level during neural tube closure (Matsumoto et al. 1993; "Trocino et al. 1994). Because of the close proximity of arly lail and Glut-1 on Chromosome 4 (Hogan et al. 1991; Neumann et al. 1994), Glut-1 might be involved in a reduced glucose uptake in carly tail.

In the present study we tested glucose uptake in curly tail and control (BAL,B/c and $\mathrm{CBA} / \mathrm{J}$ ) embryos and in a $\mathrm{BALB} / \mathrm{c}$-curly tail recombinant strain, in which curly tait has been placed on a $B A L B / c$ genetic background. The latter strain was constructed in order to provide a background-matched comparison between $\mathrm{BALB} / \mathrm{c}$-curby tail and $\mathrm{BALB} / \mathrm{c}$, since the parental curly tail strain has a different backgtound from all existing inbred strains. It appeared that the glucose consumption, which was determined in vitro from the stages of early to final PNP closure, was lower in carly tail and recombinant embryos than control embryos. In order to determine more precisely the developmental stage and the embryonic region of altered consumption, we measured the accumulation of 2-deoxy-D- $\left[1{ }^{3} \mathrm{H}\right]$ glucose (DO-glucose), separately at the stages of eatly and final PNP closure for the caudal and cranial embryonic regions and for the extraembryonic membranes. Curby tail and recombinant embryos proved to take up less glucose than control embryos. Unexpectedly, the uptake per cell appeared to be normal, which is in agreement with our finding of an apparently normal structure and expression of Glut-1 in curly tail 


\section{Materials and Methods}

\section{Mouse strains}

The mouse mutant aurly tail arose spontaneously in a female of the GFF inbred stock, and this female was subsequently mated with a CBA/Gr male (Grüneberg 1954). The curly tail stock has been derived from this mating and is kept as a closed, random-bred colony. The non-mutant inbred $\mathrm{BALB} / \mathrm{c}$ and $\mathrm{CBA} / \mathrm{J}$ mice were obtained commercially (Charles River Wiga GmbH, Germany). The BALB/c-curly tail recombinant strain was constructed via cross-intercross cycles as follows: curly tail mice were mated with $\mathrm{BALB} / \mathrm{c}$ mice, followed by an intercross of the heterozygous offspring; the descendants of the intercross were subdivided into those with a curly tail phenotype (curled or kinked tail, with or without spina bifida) and those with a normal phenotype (straight tail without spina bifida). Mice with a curly tail phenotype were mated with BALB/c, again followed by an intercross. Offspring of this intercross, with a curly tail phenotype (genetic background of $75 \% \mathrm{BALB} / \mathrm{c}$ and $25 \%$ curly tail) were kept as a separate colony (recombinant-2). Recombinant- 3 mice $(87.5 \% \mathrm{BALB} / \mathrm{c}$ and $12.5 \% \mathrm{curly}$ tail) were obtained after a third cross-intercross cycle. Mice received water and commercial diet pellets (SRMA diet, Hope Farms, Woerden, Netherlands) ad libitum and were maintained on a light-dark cycle with dark period 8.00 p.m. to $6.00 \mathrm{a}$.m. Animal care and handling was in compliance with applicable guidelines from the Dutch Ministry of Agriculture.

\section{Glucose consumption during PNP closure}

Males and females of the mouse strains curby tail, recombinant-2, BALB/c and $\mathrm{CBA} / \mathrm{J}$ were paired for mating overnight; females were checked for copulation plugs the following morning $(=$ day 0 ). On day 9 , female mice were killed by cervical dislocation and the uterine homs were explanted into pre-warmed $\left(37^{\circ} \mathrm{C}\right)$ Hanks" buffer containing 1\% penicillin (Gibco), 1\% streptomycin (Gibco) and $10 \%$ newborn calf serum (Gibco). Myometrium, endometrium and Reichert's membrane were removed, leaving extraembryonic membranes (amnion and yolk sac with ectoplacental cone) around the embryo intact. Head and crown-tump lengths were measured as described previously (Van Straaten et al. 1992). These lengths were subsequently used to select embryonic developmental stages varying from 18 to 22 somites (= stage of carly PNP closure) (Peeters et al. 1996).

Eimbryos were cultured according to the method of New (1973) as follows. Each embryo was transferred to a separate culture bottle containing $1.0 \mathrm{ml}$ culture medium, using a glass pipet, containing a minimum amount of Hanks' buffer. 'The culture medium consisted of immediately-centrifugated, heat-inactivated serum from adult Wistar rats, supplemented with $1 \%$ penicillin (Gibco) and $1 \%$ streptomycin (Gibco). Culture bottles were gassed and placed on a rotator at $38^{\circ} \mathrm{C}$. After 16.5 hours of culture, embryos were checked for viability (presence of heart 
beat and yolk sac circulation), and transferred to pre-warmed Hanks" buffer. The culture medium was immediately frozen and stored at $-20^{\circ} \mathrm{C}$ for the determination of the glucose level. Extraembryonic membranes were dissected from the cultured embryos, and the number of somites was counted. Only embryos of the developmental stages of $27-33$ somites were processed further because these are the stages of final PNP closure. Head length, crown-rump length and PNP length were measured, and the PNP was classified according to the degree of delay of PNP closure (Copp 1985). Because glucose is the main energy source at the stages studied, we expected the glucase consumption to be related to the amount of increase in embryonic size. Therefore, embryonic growth had to be determined. Growth was defined as gain in head length during the culture period (=head length at the end minus head length at the start of the culture).

Control samples of culture medium were taken prior to and following culture in order to determine the initial glucose concentration and the effect of culture conditions on the glucose concentration. Glucose concentration in the culture media was determined using COBAS BIO (Roche diagnostica), according to a standard spectrophotometric hexokinase method (Boeringer Mannheim). Glucose consumption per embryo was defined as the percentage depletion of glucose from the culture medium during the culture period, calculated as:

\section{$\{$ (concentration after culture)-(initial concentration) / (initial concentration) $\} * 100 \%$}

\section{Intra-embryonic accumulation of DO-Glucose at 2 developmental stages}

On day 9 of pregnancy, embryos of the curly tail, tecombinant 3 and BALB/c mice were collected as described above (stage of 16-23 somites, early PNP closure). Recombinant -3 instead of recombinant -2 embryos were used in this part of the study because they had become available in the mean time. On day 10 , embryos of carly tail and BALB/c were collected (stage of 26-33 somites, final PNP closurc). In each culture bottle, two embryos were placed in $1.0 \mathrm{ml}$ culture medium, and kept for an adaptation period of at least 30 minutes at $38^{\circ} \mathrm{C}$ on a rotator. "The culture medium was then supplemented with $20 \mu$ 2-deoxy-D $-\left[1{ }^{3} \mathrm{H}\right]$ glucose (Amersham) (14 $\mathrm{nM}$ final concentration, $0.2 \mu \mathrm{Ci} / \mathrm{ml}$ ). Embryos were further cultured for 1.5 hours. After checking for viability (see above) and rinsing in Hanks" buffer the extraembryonic membranes were removed and collected in a scintillation tube containing $200 \mu \mathrm{l}$ Hanks' buffer. The embryo was measured and staged as described above, and then bisected transversely at the level of the penultimate somite, and the length of the caudal part was measured. The cranial and caudal fractions were collected separately in scintillation tubes containing $200 \mu \mathrm{l}$. Hanks' buffer. The cranial, caudal and membrane fractions were sonicared (5-10 sec., 20 Khz, $2 \mu \mathrm{m}$ amplitude; MSE sonicator type L667); samples of 20, 100 and $40 \mu \mathrm{l}$, respectively, were taken for DNA assay. To the remainder of each fraction $4 \mathrm{ml}$ 
formula 989 (Du Pont) was added and radioactivity was measured using a Liquid Scintillation Counter 1414 (Win Spectral).

The accumulation of DO-glucose was evaluated as an accumulation per fraction and as an accumulation related to the cellulat part of each fraction. For the latter evaluation, DNA contents of the fractions had to be determined. DNA samples were supplemented with an autoclaved saline buffer $\left(10 \mathrm{mM} \mathrm{NaH} \mathrm{PO}_{4}, 40 \mathrm{mM}\right.$ $\mathrm{Na}_{2} \mathrm{HPO}_{4}, 2 \mathrm{M} \mathrm{NaCl}, 2 \mathrm{mM} \mathbb{E D T A} ; \mathrm{pH}=7.4$ ) to a total volume of $1000 \mu \mathrm{l}$. After adding $50 \mu \mathrm{l}$ Foechst 33258 the DNA content was determined spectrofluorimetrically (ZFM4 Zeiss). A dilution series of calf thymus DNA was used for calibration.

DO-glucose accumulation was evaluated separately for the caudal, cranial and membrane fractions and was expressed as mean DO-glucose (pmol) per fraction. Moreover, these accumulations per fraction were corrected for head length (pmol/ $/ \mathrm{mm})$, for crown-rump length $(\mathrm{pmol} / \mathrm{mm}$ ) and for somite number. The accumulation in the caudal fraction was also corrected for the length of the caudal part $(\mathrm{pmol} / \mu \mathrm{m})$. Additionally, the accumulations per fraction were corrected for DNA content (pmol/ $\mu \mathrm{g})$.

\section{cDNA sequencing and probe construction}

Total cellular RNA was extracted from spleens of adult female curly tail, BALB/c and $\mathrm{CBA} / \mathrm{J}$ mice using the Qiashredder and RNeasy system according to the manufacturer's protocol (Qiagen). First strand cDNA synthesis was performed using the total RNA sample and SUPERSCRIPT II RT (Qiagen).

The sequence of the primers for amplification and sequencing were derived from the published Glut-1 cDNA sequence (Kaestner et al. 1989), as shown in Table 1. PCR amplification was performed in a $100 \mu \mathrm{l}$ reaction with Taq polymerase. Samples were initially denatured for $2^{\prime}$ at $95^{\circ} \mathrm{C}$, followed by 35 cycles of $1^{\prime}$ at $94^{\circ} \mathrm{C}$, $1^{\prime}$ at $65^{\circ} \mathrm{C}$ and $2^{\prime}$ at $72^{\circ} \mathrm{C}$, and an extension after the last cycle of $7^{\prime}$ at $72^{\circ} \mathrm{C}$. Smaller fragments for sequencing were constructed under the same PCR conditions for 25 cycles. Before sequencing, the PCR products were purified on an agarose gel using QlAquick gel extraction kit (Qiagen). Products were sequenced automatically using an $\mathrm{ABI} 377$ Sequencer (Perkin-Elmer).

\section{RFLP analysis}

DNA was isolated from spleens of adult female courly tail, $\mathrm{BALB} / \mathrm{c}$ and $\mathrm{CBA} / \mathrm{J}$ mice by a high salt extraction procedure (Müllerbach et al. 1989). The DNA was tested for restriction fragment length polymorphisms at the Glut-1 locus, using the enzymes Hind III, Xba I, Bgl II, Bam I, Eco RI, Stu I, Pvu II (Boehringer, Mannheim). 


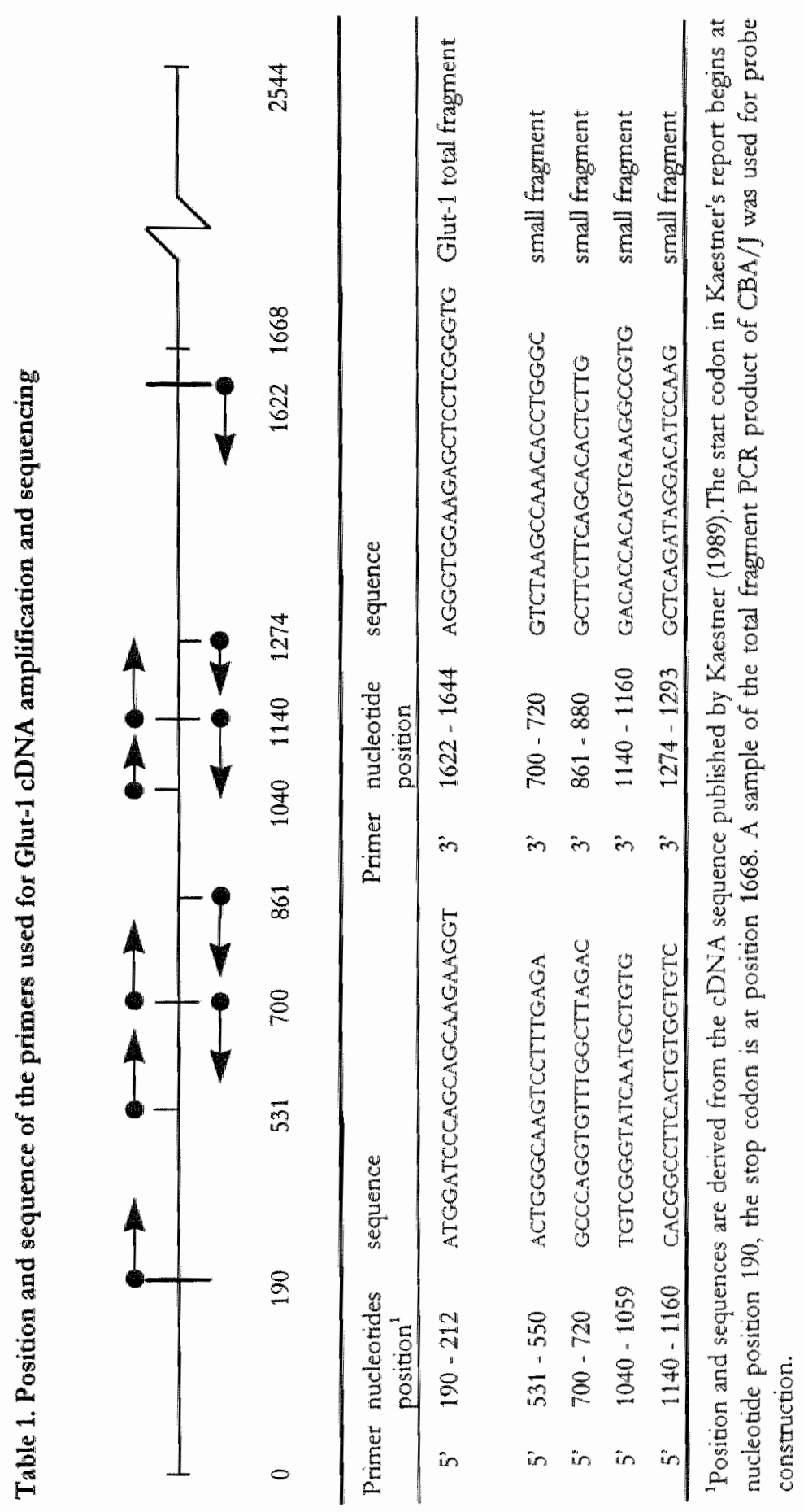


The cDNA probe (total fragment CBA/J mouse; Table 1) was labeled with [ $\left.\alpha^{-{ }^{32}} \mathrm{P}\right]$ dCTP by the RadPrime DNA labeling system (GIBCO BRL). The probe was purified on a Sephadex column and used for hybridization to the Southern blots in Rapid-hyb buffer (Amersham).

\section{Immunohistochemistry}

On day 9 and 10 of pregnancy, embryos of carly tail, BALB/c and recombinant-3 wete collected as described above and, additionally, extraembryonic membranes were removed. Embryos were fixed for 1 hour using $4 \%$ paraformaldehyde in PBS, rinsed in PBS, immersed in $20 \%$ sucrose (overnight), embedded in O.C.T. compound (Tissue-Tek, Miles Inc., IN, USA) and quick-frozen in liquid nitrogen. Sections of the PNP region were cut at $10 \mu \mathrm{m}$ on a cryostat (Anglia 600), collected on polylysine-coated glass slides and ait-dried. After pre-treatment with $0.3 \% \mathrm{H}_{2} \mathrm{O}_{2}$ $(10 \mathrm{~min})$ and goat serum in $1 \% \mathrm{BSA}(1: 5)$, sections were incubated overnight at $4^{\circ} \mathrm{C}$ with anti-Glut-1 (rabbit polyclonal antiserum AB1340, Chemicon) at a dilution of 1:5000. Control slides were incubated with $1 \%$ BSA only. Subsequently, the slides were incubated with the secondary antibody (peroxidase-conjugated goat antirabbit; P0448, DAKO) at a dilution of $1: 100$ for $90 \mathrm{~min}$ at room temperature. Immunolabels were stained by incubation with 3, 3'-diaminobenzidine with $0.03 \%$ $\mathrm{H}_{2} \mathrm{O}_{2}$ for $5 \mathrm{~min}$.

Staining intensities of neuroepithelium, gut endoderm, dorsal and ventral part of mesoderm were measured in at least 3 sections per embryo of 3-5 embryos per strain at both developmental stages using a Leica Quantimet 500 image-analyzer.

\section{Statistical analysis}

Glucose consumption by the embryos of the four different mouse strains from the stage of early to the stage of final PNP closure was compared using an ANOVA model with the mouse strains as factor, embryonic growth (=gain in head length) as covariate, and Bonferroni correction. The covariate was included in the model because embryos had differential growth during the culture period and, moreover, glucose consumption appeared closely related to growth.

In order to test for a difference in glucose consumption between embryos with notmal versus delayed PNP classifications, the data from curly tail and recombinant2 strains were pooled and PNP classifications were compared with a $/$ test for independent samples.

The intra-embryonic accumulation of DO-glucose by embryos of the different mouse strains at the stage of early PNP closure was compared using a one-way ANOVA with Bonfertoni correction. The accumulation of DO-glucose of curly tail and BALB/c embryos at final PNP closure was evaluated using the $t$ test for independent samples. 
Staining intensities after Glut-1 immunolabeling were compared using the KruskalWallis test. Statistical analysis were performed using SPSS for Windows, release 6.0.

\section{Results}

\section{Glucose consumption during PNP closure}

In a long-term culture of 16.5 hours, the glucose consumption of embryos during the critical phase of PNP closure was established for the two mutant and two wild type mouse strains. Figure 1 shows a positive relationship between embryonic growth and glucose consumption, as expected. The increase in consumption is similar in the four mouse strains used. However, the consumption is substantially lower (about $10 \%$ ) for curty tail and recombinant-2 embryos when compared to $\mathrm{BALB} / \mathrm{c}$ and $\mathrm{CBA} / \mathrm{J}$ embryos $(\mathrm{p}<0.001)$.

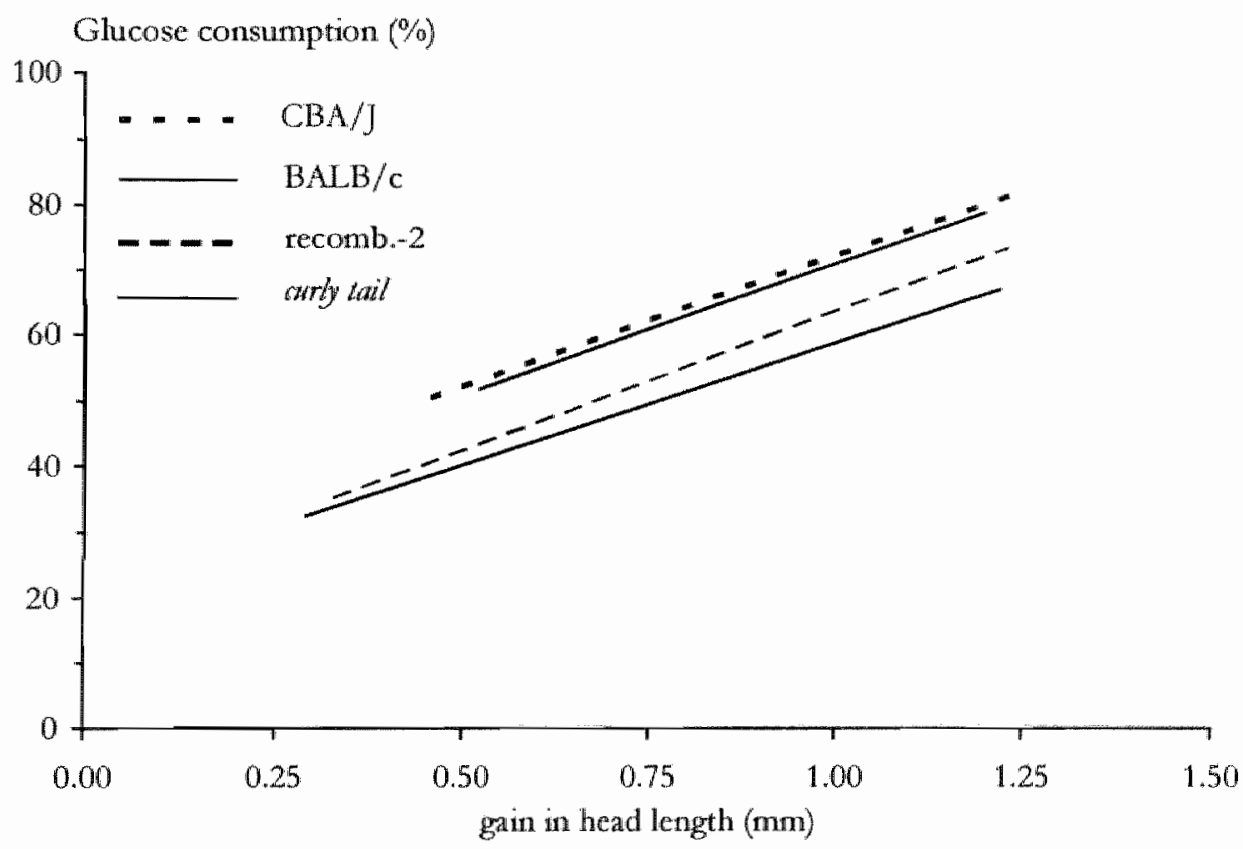

Fig. 1. Glucose consumption in mutant and control embryos during PNP closure. The relationship between the consumption of glucose and embryonic growth (as defined by head length gain obtained during the $16.5 \mathrm{hr}$ culture period) is shown. "The amount of glucose consumption increase is almost identical for the mutant and control embryos. However, the glucose consumption is substantially lower (about $10 \%$ ) for the curty tail and recombinant-2 embryos, compared to the non-mutant $B A L B / c$ and $C B A / J$ embryos $(p<0.001)$. In the statistical evaluation, an ANOVA model was used with growth as covariate, so that strain differences were evaluated with correction for embryonic growth. For clarity of graphical presentation, regression lines are drawn, only individual data points being omitted. 
Both curty tail and recombinant-2 embryos had normal as well as delayed classified PNPs, whereas the control embryos were all of the normal phenotype (Table 2). When the data for the mutant embryos were pooled and analyzed separately for each phenotype, we found that the delayed phenotypes exhibited a slightly lower glucose consumption (52.8\%) compared to the normal phenotypes (55.9\%), although this difference was not statistically significant. No correlation could be demonstrated between the length of the PNP and the glucose consumption (data not shown).

The mean initial glucose concentration in the culture medium was $9.84 \mathrm{mM}$; the mean concentration in the control samples, in which no embryo had been present, after the culture period was $10.15 \mathrm{mM}$. This implies that culture conditions caused a $3 \%$ increase in glucose concentration, probably caused by evaporation at the moment that the gas mixture was added to the culture bottle.

Table 2. Number of embryos used in the analysis of glucose consumption in long-term cultures encompassing the stages of PNP closure

PNP classification

\begin{tabular}{lcc} 
mouse strain & Nomal & Delayed \\
\hline curly iail & $20^{1}$ & 15 \\
recombinant-2 & 32 & 8 \\
BALB/c & 24 & 0 \\
CBA/J & 30 & 0 \\
\hline
\end{tabular}

${ }^{1}$ Values are numbers.

\section{Intra-embryonic accumulation of DO-glucose at 2 developmental stages}

The accumulation of DO-glucose was evaluated in several ways. At the stage of early PNP closure (16-23 somites), corly tail embryos accumulated less DO-glucose, as expressed as mean accumulation per embryonic fraction, than BALB/c embryos in both their cranial and caudal fractions (Table 3). The lower accumulation in the membrane fraction was not statistically significant. The cranial fraction of recombinant- 3 embryos showed DO-glucose accumulation comparable to curly tail, whille the accumulation in the caudal fraction was higher than in the curby tail (Table 3). When DO-glucose accumulation in the caudal fraction at the stage of early PNP closure was corrected for head length or length of the isolated caudal part, curly tail embryos showed reduced accumulation compared to BALB/c embryos (data not shown). The same tendencies were observed after correction for crown-rump length and somite number. However, the cranial and membrane fractions did not show a consistently different accumulation for the mouse strains. Evaluating those 
corrected accumulation in the fractions of the recombinant-3 embryos, demonstrated similar accumulations as for the carby tail embryos (data not shown).

However, in contrast to our findings for DO-glucose accumulation per fraction, accumulation per $\mu \mathrm{g}$ DNA showed no significant differences in the caudal, cranial and membrane fractions for the curly tail, recombinant- 3 and $B A L B / c$ embryos, except for the caudal region which had a higher accumulation for tecombinant-3 than for BALB/c embryos (Table 4).

In embryos at the stage of final PNP closure (26-33 somites), accumulation of DOglucose in curby tail and BALB/c embryos was not different, either when expressed per fraction (Table 3), or after correction for embryo size or somite number (data not shown), or after correction for DNA (Table 4).

\section{Structure and expression of Gllut-1}

Before constructing smaller fragments of Glut-1 cDNA for sequencing, the total cDNA fragment constructed by PCR with Glut-1 primers (Table 1) was run on an agarose gell and appeared to have the expected 1.4-1.5 kb. Sequence analysis of Glut-1 cDNA resulted in identical sequences for the arrly tail, $\mathrm{BALB} / \mathrm{c}$ and $\mathrm{CBA} / \mathrm{d}$ mice.

Table 3. DO-glucose accumulation per embryonic fraction in different mouse strains at two stages of neural tube closure'

\begin{tabular}{|c|c|c|c|c|c|}
\hline stage of PNP closure & fraction & $\mathrm{BALB} / \mathrm{c}$ & conty tail $^{\prime}$ & recomb. -3 & Significance \\
\hline \multirow{6}{*}{ early } & & & $10^{-3} \mathrm{pmol}$ & & \\
\hline & & $24^{2}$ & 30 & 31 & Anova \\
\hline & embryo & $130^{\circ} \pm 7$ & $105^{b} \pm 8$ & $109 \pm 5$ & $<0.03$ \\
\hline & - crudal & $22.0^{4} \pm 0.7$ & $17.1^{\mathrm{b}} \pm 1.2$ & $20.4^{0} \pm 0.7$ & $<0.01$ \\
\hline & - cranial & $108^{a} \pm 6$ & $88.2^{3} \pm 6.6$ & $88.6^{6} \pm 4.5$ & $<0.03$ \\
\hline & membrane & $60.8 \pm 2.8$ & $53.9 \pm 2.7$ & $53.3 \pm 1.6$ & $\mathrm{n.s.} \mathrm{s}^{3}$ \\
\hline \multirow{5}{*}{ final } & & $18^{2}$ & 11 & & 1. test \\
\hline & embryo & $425 \pm 20$ & $413 \pm 28$ & & n.s. \\
\hline & - caudal & $7.4 \pm 1.0$ & $15.4 \pm 0.9$ & & 17.5. \\
\hline & - craniall & $408 \pm 29$ & $398 \pm 28$ & & $n . s$ \\
\hline & membrane & $112 \pm 5$ & $102 \pm 9$ & & n.s. \\
\hline
\end{tabular}

Walues are mean \pm SEM; ${ }^{2}$ numbers of embryos are indicated. "Not statistically significant $\left.\mathbb{Q}^{P}>0.05\right)$. Within each row, "and" are significantly different. 
Figure 2 shows the results of the test for Glut-1 polymorphisms using the restriction enzymes Eco RI, Stu I and Pvu II: identical patterns were found for the mouse strains curty lail, $\mathrm{CBA} / \mathrm{J}$ and $\mathrm{BALB} / \mathrm{c}$. With the enzymes Hind III, Xba I, Bgl II and Bam I identical patterns were found for those mouse strains as well (data not shown). This means that for these enzymes no restriction fragment length polymorphisms exist at the Glut-1 locus.

Use of Glut-1 antiserum to stain cross-sections of the PNP region at the early and final PNP closure stages gave strongest staining in gut endoderm and neuroepithelium, weaker staining in dorsal mesoderm and weakest staining in ventral mesoderm (Fig. 3). The expression at the stage of final PNP closure appeared to be reduced compared to the younger stage. Within the PNP region a craniocaudal gradient of expression was observed which was most pronounced at the stage of final PNP closure: a reduction in the expression in gut endoderm and neuroepithelium and an increase in the dorsal and ventral mesoderm. At the stage of early PNP closure, the expression of Glut-1 was similar in corresponding tissues of the corly lail, recombinant-3 and $\mathrm{BALB} / \mathrm{c}$ embryos. At the stage of final PNP closure, a slightly reduced expression was found in all tissues of the curly tail embryos compared to recombinant-3 and BALB/c; however, this reduction was not statistically significant (data not shown).

"Table 4. DO-glucose accumulation per DNA of embryonic fractions of different mouse strains at 2 stages of neural tube closure ${ }^{1}$

\begin{tabular}{|c|c|c|c|c|c|}
\hline stage of $\mathrm{PND}$ closure & fraction & $\mathrm{BALB} / \mathrm{c}$ & carbly sail & recomb.-3 & Significance \\
\hline \multirow{6}{*}{ early } & \multicolumn{5}{|c|}{$10^{3} \mathrm{pmol} / \mu \mathrm{g}$ DNA } \\
\hline & & $24^{2}$ & 30 & 3.1 & Anova \\
\hline & embryo & $14.9 \pm 0.7$ & $15.6 \pm 0.6$ & $15.9 \pm 0.7$ & n.s. ${ }^{3}$ \\
\hline & - caudal & $18.2^{2} \pm 0.7$ & $19.2 \pm 1.5$ & $23.0^{\mathrm{b}} \pm 1.2$ & $<0.03$ \\
\hline & - cranial & $14.4 \pm 0.8$ & $15.2 \pm 0.6$ & $14.8 \pm 0.7$ & ins. \\
\hline & membrane & $6.6 \pm 0.5$ & $7.5 \pm 0.5$ & $6.9 \pm 0.5$ & n.s. \\
\hline \multirow{5}{*}{ final } & & $18^{2}$ & 11 & & $t$-test \\
\hline & embryo & $18.0 \pm 1.1$ & $23.2 \pm 3.8$ & & n.s. \\
\hline & - caudal & $22.7 \pm 1.3$ & $22.0 \pm 1.5$ & & ns. \\
\hline & - cranial & $17.9 \pm 1.1$ & $23.4 \pm 4.0$ & & $\mathrm{n}_{w} \mathrm{~s}$. \\
\hline & membrane & $6.2 \pm 0.5$ & $7.4 \pm 11.1$ & & n.s. \\
\hline
\end{tabular}

"Values are means $\pm S E M$; "numbers of embryos are indicated. "Not statistically significant $(\mathrm{P}>0.05)$. Within each row, and "are significantly different. 

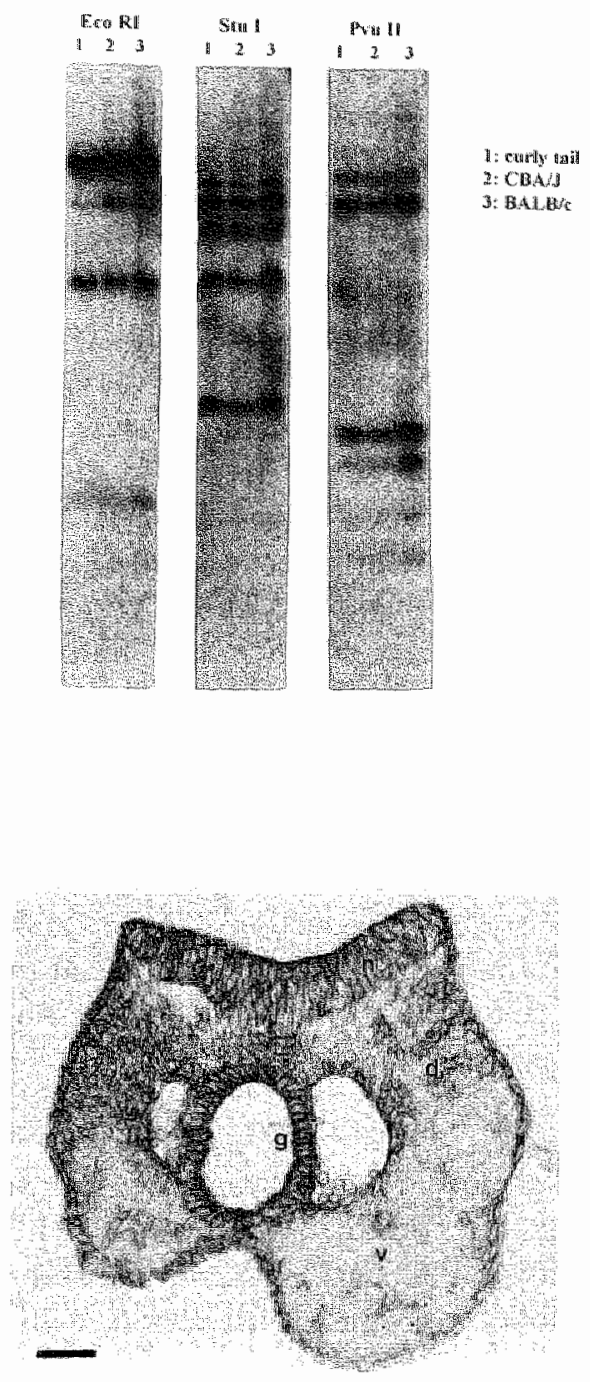

Fig. 2. RFLP analysis at Giut-1.

Size of the DNA fragments on an agarose gel after incubation of total DNA with restriction enzymes, electrophoresis and labeling with the Glut-1 probe. The restriction enymes Eco RI, Stu I and Pvu II each resulted in identical fragment lengths for the ow tail, $\mathrm{CBA} / \mathrm{J}$ and $\mathrm{BALB} / \mathrm{C}$ mice. This means that the sites of recognition of the enzymes were identical in the 3 mouse strains, indicating that no mutation was present at those sites.

Fig. 3. Glut-1 immunostaining in the PNP region of a curly tail mouse embryo at the stage of carly PNP closure. High levels of Glut-1 staining are observed in the gut endoderm (g) and neuroepithelium (n), lower levels in the dorsal mesoderm (d), whereas the ventral mesoderm $(v)$ is stained weakest. Bar $=$ $50 \mu \mathrm{m}$. 


\section{Discussion}

Consumption of glucose during PNP closure was determined in a long-term embryo culture, by measuring the depletion of glucose from the culture medium. The depletion was less in curly tail cultures than in $\mathrm{BALB} / \mathrm{c}$ and $\mathrm{CBA} / \mathrm{J}$ cultures. This means that the glucose consumption of curly tail embryos was less during the developmental stages at which the closure of the caudal neural tube occurs. However, it was not clear whether the glucose consumption was reduced during the whole period of PNP closure. Therefore, a short-term embryo culture using DOglucose was set up to test the glucose uptake of embryos at the stages of early and final PNP closure, which corresponded to the developmental stages at the start and end of the long-term culture. DO-glucose competes with glucose at the cellular level for binding to the glucose transporter and for phosphorylation. When the concentration of DO-glucose is kept below the level at which it has inhibitory effects, as performed in the present study, DO-glucose accumulation can be used as a measure for glucose uptake (Hunter and Tugman 1995). In order to check whether the reduction in glucose uptake varied in different parts of the conceptus, the DO-glucose accumulation was measured separately in the caudal, cranial and membrane fractions. Evaluating the glucose accumulation as mean per fraction as well as after correcting for embryonic length displayed a reduction for the caudal and cranial fractions but not for the membrane fraction of curly lail embryos at the stage of early PNP closure compared to BALB/c embryos. At the stage of final PNP closure, the accumulation of glucose by curby tail and BALB/c embryos was not significantly different.

Thus, both culture methods indicate a reduced glucose uptake by curly tail embryos compated to non-mutant embryos during the period of PNP closure when evaluated per embryo or per fraction. The reduction appears especially marked at the stage of early PNP closure and most pronounced in the caudal region, with a nomalization of glucose uptake at the stage of final PNP closure.

\section{Reduced glucose uptake is not due to the extraembryonic membranes}

In both experimental designs used in the present study, glucose in the culture medium has to be absorbed by the yolk sac in order to reach the embryo. This is facilitated by several transporter molecules of the Glut family, which transport glucose across the cell membrane according to a concentration gradient (Smith and Gridley 1992). After uptake by the yolk sac, glucose is transported to the embryo via the yolk sac vessels and via diffusion through the yolk sac cavity, amnion, amniotic cavity and embryonic surface. Inside the embryo, transport of glucose across the cell membrane is also mediated by several Glut isoforms, of which Glut1 is abundantly present at this stage of development (Maeda et al. 1993; Trocino et 
al. 1994; Matsumoto et al. 1995). Subsequently, the enzyme hexokinase converts glucose to glucose-6-phosphate, which is then used in several metabolic pathways.

For the membrane fraction, it appeared that the DO-glucose accumulation was almost identical between the mouse strains. It is therefore unlikely that the reduced glucose uptake by the curly tail and recombinant embryos, as found in the present study, is due to a reduced uptake by the yolk sac. A suboptimal function in any other part of the transport route could therefore be responsible for the reduced glucose uptake.

\section{Normal structure and expression suggest a normal function of Glut-1}

The BALB/c-carly tail recombinant strain is the result of selection for the curly tail phenotype while backcrossing the carly tail gene onto the BALB/c-genetic background. The recombinant-2 embryos have $75 \%$ of the genetic background of $\mathrm{BALB} / \mathrm{c}$, but their glucose consumption is almost identical to that of the corly tail embryos and lower than the consumption of the BALB/c embryos. Moreover, the recombinant-3 embryos have $87.5 \%$ of the genetic background identical to $\mathrm{BALB} / \mathrm{c}$, and yet their glucose accumulation resembles more that of the carly tail embryos. This suggests that the carly tail genetic defect itself is responsible, either directly or indirectly, for the reduced glucose uptake. The major gene responsible for the curly tail defect has been mapped on Chromosome 4. Glut-1 also maps on Chromosome 4, close to the curly tail gene and, moreover, is important for glucose metabolism in mouse embryos during neurulation. In man, polymorphisms for Glut-1 have been described (Shows et al. 1987; Xiang et al. 1987; Fukumoto et al. 1988; Kaku et al. 1990); which are probably related to functional properties of Glut-1 ( $\mathrm{Li}$ et al. 1988; Tao et al. 1995). It was therefore postulated that the function of Glut-1 has a regulatory role in the curly tail defect.

In the present study, restriction enzyme analysis and DNA sequencing were used to test whether the structure of Glut-1 could be involved in the curly tail defect. Both approaches failed to show differences in Glut-1 between the curly tail and nonmutant $\mathrm{BAL} B / \mathrm{c}$ and $\mathrm{CBA} / \mathrm{J}$ mouse strains. However, five differences were found between the sequence obtained and the sequence reported by Kaestner (1989) and one difference was found compared with the data of Reed (1990) (Table 5). All differences result in amino acid substitutions. The substitution at codon 250, at the cytoplasmic loop between transmembrane domains 6 and 7, differs from both previously reported sequences. This substitution is within the group of positively charged polar amino acids, and probably does not markedly alter the function of Glut-1. The substitution at codon 403 has also been published by Iogan (1901). The amino acid substitutions found in the present study do not correspond with amino acids of Glut-1 to which functional properties have been ascribed (Garcia et al. 1992; Mueckler et al. 1994; Wellner et al. 1995). 
Strain differences were not detected in the expression pattern of the Glut-1 protein which was studied immunohistochemically using a polyclonal antiserum. Expression was strongest in the neutoepithelium and gut endoderm and weaker in the dorsal and ventral mesoderm. Moreover, there was reduced expression at the stage of final PNP closure compared to the younger stage. The expression pattem of Glut-1 found in the present study closely matches that described in other studies (Maeda et al. 1993; 'Trocino et al. 1994; Matsumoto et al. 1995).

Because structure and expression of Glut-1 are identical for curly tail and BALB/c embryos, it is unlikely that an aberrant function of Glut-1 is causally involved in the processes underlying N"TD in curly tail. However, both recombinant-2 and -3 embryos demonstrated glucose uptake which more closely resembles curly tail than $\mathrm{BALB} / \mathrm{c}$. This indicates that glucose may be linked to the pathogenetic process leading to a delay in the closure of the PNP, although Glut-1 is not the primary defect.

\section{Relationship between glucose and neurulation}

Neurulation appears to become disturbed easily by abnormalities of the surrounding glucose level (Cockroft and Coppola 1977; Sadler 1980; Eriksson et al. 1984; Reece et al. 1985, 1996). Maternal hyperglycemia during pregnancy is associated with an intra-embryonic depletion of inositol, which is thought to be partly responsible for the defects of neurulation (Cockroft 1979, 1988; Sussman and Matschinsky 1988). Closure of the hindbrain in the curly tail strain is extremely sensitive to inositol deficiency compared to other mouse strains (Cockroft et al. 1992), although it has recently been shown that inositol uptake by arly tail embryos is normal. Nevertheless, administration of additional inositol can prevent spinal NTD in arby tail mice (Greene and Copp 1997). In the present study, the initial glucose concentration in both long-term and short-term cultures was about $10 \mathrm{mM}$, which is below the level that appears to be teratogenic for mouse embryos (Sadler

\section{Table 5. Differences in sequence analysis of Glut-1}

\begin{tabular}{|c|c|c|c|c|c|c|c|}
\hline $\begin{array}{l}\text { nucleoticle } \\
\text { position }\end{array}$ & this paper & $\begin{array}{l}\text { Kaestner } \\
\text { etal. } 1989 \\
\end{array}$ & $\begin{array}{l}\text { Reed } \\
\text { et al. } 1990\end{array}$ & $\begin{array}{l}\text { Hogan } \\
\text { et al. } 1991\end{array}$ & codon & $\begin{array}{l}\text { Amino acid } \\
\text { domain }\end{array}$ & difference \\
\hline 343 & $\mathrm{~T}$ & A & $\mathrm{T}$ & & 52 & extracellular & $\mathrm{Ile} \rightarrow \mathrm{Tyr}$ \\
\hline 766 & $A$ & $\mathrm{G}$ & $A$ & & 193 & transmembrane & Vail $\rightarrow$ Ile \\
\hline 772 & A & $\mathrm{G}$ & $A$ & & 195 & transmembrane & $\mathrm{Val} \rightarrow$ Ile \\
\hline 939 & $A$ & $\mathrm{G}$ & $\mathrm{G}$ & & 250 & cytoplasmic & $\operatorname{Arg} \rightarrow \mathbb{L}$ ys \\
\hline 1396 & $G$ & $\mathrm{C}$ & $\mathrm{G}$ & $\mathrm{G}$ & 403 & cytoplasmic & $\mathrm{Arg} \rightarrow \mathrm{Ala}$ \\
\hline
\end{tabular}

'Nucleotide positions, codons and substitutions in curly tail, $\mathrm{BALB} / \mathrm{C}$ and $\mathrm{CBA} / \mathrm{J}$ mice as compared with previously reported sequences. The positions are derived from Kaestner (1989)). 
1980). Thus, the curly lail embryos were not exposed to a hyperglycemic milieu in the present study. In fact, the carby tail embryos demonstrated a reduced glucose uptake, thereby possibly creating an intra-embeyonic hypoglycemic situation. It is unlikely therefote that the delay in PNP closure in curb tail embryos is due to a hyperglycemia-induced inositol depletion.

\section{Glucose uptake per cell is normal in curly tail embryos}

In the short-term culture, the DO-glucose accumulation was not only evaluated per fraction but also per $\mu \mathrm{g}$ DNA. Surprisingly, this latter analysis yielded equal results for the carly tail and non-mutant embryos. This means that the glucose uptake by curly tail embryos at the stage of early $\mathrm{PNP}$ closure is reduced per embryo, but normal per embryonic cell. Because of this discrepancy, the DNA values were evaluated more precisely. From Table 6 it appeats that the DNA content of the atrly tail embryo is reduced, indicating a reduced number of cells. At the stage of final PNP closure, the glucose uptake by carly tail and BALB/C embryos was not different irrespective of the evaluation per embryo or per cell. The DNA content at these stages is slightly reduced in carby tail, however not significantly different (Table 6). The indication that the glucose uptake per cell is normal, fits with the results in the present study of normal structure and expression of Glut-1, which implies a normal function.

Table 6. DNA contents of embryos of different mouse strains at 2 developmental stages after a short-term embryo culture using DO-glucose ${ }^{1}$

\begin{tabular}{|c|c|c|c|c|c|}
\hline stage of $\mathbb{P N D}$ closure & Fraction & $B A L B / c$ & ardy tait & recomb. -3 & Statistics \\
\hline \multirow{6}{*}{ early } & & & $\mu g$ & & \\
\hline & & $24^{2}$ & 30 & 31 & Anova \\
\hline & embryo & $8.92^{a} \pm 0.45$ & $6.90^{\mathrm{b}} \pm 0.52$ & $7.18^{b} \pm 0.44$ & $<0.02$ \\
\hline & - caudal & $1.25^{\mathrm{a}} \pm 0.09$ & $0.23^{12} \pm 0.06$ & $0.94^{10} \pm 0.09$ & $<0.008$ \\
\hline & - cranial & $7.67^{a} \pm 0.42$ & $5.97^{\mathrm{b} x} \pm 0.47$ & $6.24 \pm 0.39$ & $<0.03$ \\
\hline & membrane & $9.95 \pm 0.79$ & $7.90 \pm 0.67$ & $8.60 \pm 0.5^{\circ}$ & n.s.". \\
\hline \multirow{5}{*}{ final } & & $18^{2}$ & 11 & & $t-t e s t$ \\
\hline & embryo & $24.9 \pm 2.52$ & $10 \pm 2.62$ & & n.s. \\
\hline & - caudal & $0.81 \pm 0.06$ & $0.73 \pm 0.07$ & & n.s. \\
\hline & - cranial & $24.1 \pm 2.52$ & $20.3 \pm 2.61$ & & $\mathrm{n} . \mathrm{s}$ \\
\hline & membrane & $19.5 \pm 1.43$ & $15.8 \pm 2.10$ & & n.s. \\
\hline
\end{tabular}

'Values are mean \pm SEM, "numbers of embryos are indicated. Not statistically significant $(\mathrm{P}>0.05)$. Within each row, "and "are significantly different. 


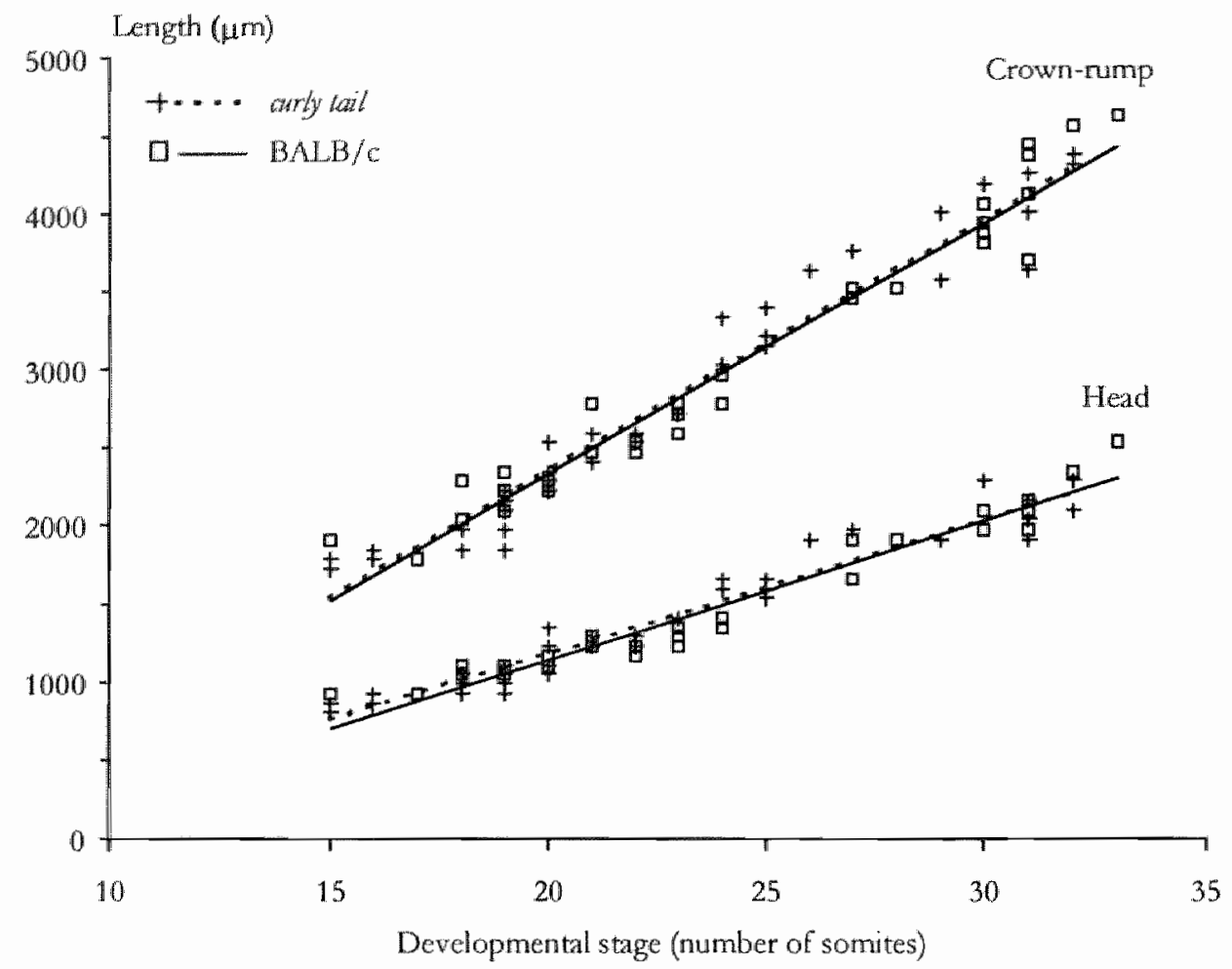

Fig. 4. Embryonic sizes of curly tail and BALB/c embryos.

The relationship between the size (head length and crown-rump length) and the developmental stage (number of somites) in the embryo are almost identical for arly lail and BALB/C. Individual data points are derived from embryos after the short-term culture and some embryos collected additionally. Regression lines are drawn.

A reduced number of cells in the whole embryo is the likely result of reduced cell proliferation. Previously, a reduced proliferation has been described for the caudal part of the curly lail embryo at the stage of final PNP closure, especially for the gut cncloderm and the notochord (Copp et al. 1988). In the present study, however, the DNA content was not only reduced in the caudal part, but in the whole embryo as well. Moreover, the DNA content at the stage of final PNP closure was slightly reduced, but the effect was more pronounced at the stage of early PNP closure. "Therefore, it would be worthwhile to study cell proliferation at both stages in the caudal and cranial parts of the embryo.

The reduced proliferation in the curby tail embryo has been proposed to cause the delay in closure of the PNP by its effect on the curvature of the caudal body axis (Brook et al. 1991; Peeters et al. 1997). In order to resolve the basis of the 
proliferation defect, several growth-related molecules have been studied and some are thought to be involved in the pathogenetic process of the awry atil. Hyaluronan, which is located in the extracellulat matrix, is reduced in the PNP region (Copp and Bernfield 1988); the receptors RAR- $\beta$ and RAR- $\gamma$ are down-regulated in hindgut and tail bud, respectively (Chen et al. 1995); transferrin is bound in reduced quantities on the luminal surface of the hindgut endoderm (Hoyle et al. 1996). At present, it is unknown how these and other molecules are related to each other and how they might determine the proliferation pattern in the curly tail embryo.

The reduced DNA content of the carly kail embryo suggests that these embryos would be smaller than the non-mutant embryos. However, embryos from awly tail and $\mathrm{BALB} / \mathrm{c}$ mice had identical numbers of somites, head lengths and crown-rump lengths on embryonic days 9 and 10. Moreover, when the relationship between the embryonic size (head length and crown-rump length) and its developmental stage (number of somites) was considered, it appeared to be equal for the curby tail and BALB /c embryos (Fig. 4). Thus, overall growth retardation of the mutant embryos does not seem to occur, although the length parameters may be insufficient to detect the expected relatively small changes in volume. Moreover, the volume of the embryo is not only determined by the number of cells, but also by cell size and volume of the extracellular matrix which might have been increased in the corty tail embryo. Whether these parameters are involved has to be determined.

From the present study it can be concluded that the glucose uptake by the curly tail embryo is reduced during PNP closure, especially at its early stage. Unexpectedly, the DNA content is reduced, accompanied by a normal glucose uptake per cell. Also, the structure and expression of the glucose carrier Glut-1, which is abundantly present at this stage, appears not affected. It is therefore unlikely that in the pathogenetic process of the carly tail leading to NTD, the reduced proliferation is caused by a reduced glucose supply. On the contrary, the reduced glucose uptake per embryo during early PNP closure is probably due to a temporarily reduced general proliferation pattern in the arry tail embryo, indicating that a disturbed glucose-intake by the embryo might be a downstream effect in the subcatcgory of folate-resistant NTD.

\section{Acknowledgments}

The authors acknowledge R. Jongbloed for her assistance in sequencing, $P$, van Dijk for his histotechnical and photographical assistance, and E. Raadschilder for his technical assistance. We thank A. Copp for critically reading the manuscript. 


\section{References}

Akazawa M, Akazawa S, Hashimoto M, Akashi M, Yamazaki H, D. T, Yamamoto H, Yamaguchi $Y$, Nakanishi T, Nagataki $S(1989)$ Effects of brief exposure to insulin-induced hypoglycemic serum during organogenesis in rat embryo culture. Diabetes 38: 1573-1578

Akazawa $S$, Unterman T, Metager BE (1994) Glucose metabolism in separated embryos and investing membtanes during organogenesis in the rat embryo. Metabolism 43: 830-835

Beier DR, Dushkin $T_{*}$ "Telle $T$ (1995) Haplotype analysis of intra-specific backcross curly tail mice confirms the localization of ct to chromosome 4. Mamm Genome 6: 269-272

Brook FA, Shum ESW, Van Straten HWM, Copp AJ (1991) Curvature of the caudal region is responsible for fallure of neural wbe closure in the curly tail (c) mouse embryo. Development 113: 671-678

Chen WH, Morriss-Kay GM, Copp NJ (1995) Genesis and prevention of spinal neural tube defects in the cuty tail mutant mouse: involvement of retinoic acid and its nuclear receptors RAR-b and RAR-g. Development 121: 681-691

Clough JR, whittingham DG (1983) Metabolism of $\int^{14} \mathrm{C}$ glucose by postimplantation mouse cmbryos in vitro. J Embryol Exp Morphol 74: 133-142

Cockroft DI. (1979) Nutricnt requirements of rat embryos undergoing organogenesis in vitro. I Reprod Fiert 57: 505-510

Cockroft DL (1988) Changes with gestational age in the nutritional requirements of postimplantation rat cmbryos in culture. Teratology $38: 281-290$

Cockroft DL, Brook FA, Copp AJ (1992) Inositol deficiency increases the susceptibility to neural tube defects of genetically predisposed (curly tail) mouse embryos in vitro. Teratology 45: 223-232

Cockroft DL, Coppola PT (1977) 'Teratogenic effects of excess glucose on head-fold rat embryos in culture. Teratology 16: 141-146

Copp AJ (1985) Relationship between timing of posterior neuropore closure and development of spinal neural tube defects in mutant (carly taid) and normal mouse embryos in culture. $f$ Embryol Exp Morphol 88: 39-54

Copp AI, Bernfield M (1988) Accumulation of basement membrane-associated hyaluronate is reduced in the posterior neuropore region of mutant (curly tail) mouse embryos developing spinal neural tube defects. Dev Biol 130: $583-590$

Copp AJ, Brook FA, Roberts H] (1988) A cell-type-specilic abnormality of cell proliferation in mutant (curly tail) mouse embryos developing spinal noural tube defects. Development 104 : 285-295

Cazizel AE, Dudas I (1992) Prevention of the first occurence of neural tube defects by periconceptional vitamin supplementation. $N$ Fingl ] Med 327: 1832 \$835

Griksson UJ, Lewis NJ. Freinkel $N$ (1984) Growth retardation during early organogenesis in embryos of experimentally diabetic rats. Diabetes 33: 281-284

Fikumoto H, Seino $\mathrm{S}_{\mathrm{x}}$ Imura H, Scino $\mathrm{X}$, Beil GI (1988) Characterization and expression of human HepG2/erythrocyte glucose-transporter gene. Diaberes 37: 657-661

Garcin JC, Strube M, Lengang K, Keller K, Mueckler MM (1992) Amino acid substitutions at tryptophan 388 and tryprophan 412 of the HepG2 (GLUTI) glucose transporter inhibit transport activity and targeting to the plasma membrane in Xenopus oocytes. J Biol Chem 267: 7770.7776

Greene NDE, Copp AJ (1997) Inositol prevents folate-resistant neural tube defects in the mouse. Narure Med 3: 60-66

Grineberg $H$ (1954) Genetical studies on the skeleton of the mouse. VIII curly tail. J Genet 52 : 52-67

Hogan A, Heyner S, Charron MJ, Copeland NG, Gilbert DJ, Jenkins NA, Thorens B, Schultz GA (1991) Glucose transporter gene expression in early mouse embryos. Development 113: 363-372 
Hoyle C, Henderson DJ, Matthews DJ, Copp AJ (1996) Transferrin and its receptor in the development of genetically determined neural tube defects in the mouse embtyo. Dev Dym 207: $35-46$

Hunter ES, Sadler TW (1988) Embryonic metabolisn of foetal fuels in whole-embtyo culture. Toxic in Vitro 2: 163-167

Hunter ES, III, Tugman JA (1995) Inhibitors of glycolytic metabolism affect neurulation-staged mouse conceptuses in vitro. "Teratology $52: 317-323$

Kaestner KH, Christy RJ, McLenithan JC, Braiterman LT, Cornelius P, Pekala PH, Lane MD (1989) Sequence, tissue distribution, and differential expression of mRNA for a putative insulun-responsive glucose transporter in mouse 3T3-LI adipocytes. Proc. Natl. Acad. Sci. USA 86: $3150-3154$

Kaku K, Matsutani A, Mueckler M, Permutt MA (1990) Polymorphisms of Hep G2/Erythrocyte glucose-transporter gene. Diabetes 39: 49-56

Letts VA, Schork NJ, Copp A], Bernfield M, Frankel WN (1995) A curly-tail modifier locus, mct1, on mouse chromosome 17. Genomics 29: 719-724

Li SR, Baroni MG, Oelbaum RS, Stock J, Galton DJ (1988) Association of genetic wariant of the glucose transporter with non-insulin-dependent diabetes mellitus. Lancet 2: 368-370

Maeda Y, Akazawa S, Akazawa M, Takao Y, Trocino RA, Takino H, Kawasaki E, Yokota A, Okuno S, Nagataki S (1993) Glucose transporter gene expression in nat conceptus during early organogenesis and exposure to insulin-induced hypoglycemic serum. Acta Dabetol 30 : $73-78$

Matsumoto $\mathrm{K}$, Akazawa $\mathrm{S}$, Ishibashi $\mathrm{M}$, Trocino RA, Matsuo $\mathrm{H}$, Yamasalki $\mathrm{H}$, Yannaguchi $\mathrm{Y}$, Nagamatsu $S$, Nagataki $S$ (1995) Abundant expression of Glut-1 and Glut3 in rat embryo during early organogenesis period. Biochem Biophys Res Comm 209: 95-102

Matsumoto $K$, Takao Y, Akazawa S, Yamo M, Uotani S, Kawasaki E, Takino H, Yamasaki $H$, Okuno S, Yamaguchi $Y$, Nagataki S (1993) Developmental change of Facilitative glucose transporter expression in rat embryonal and fetal intestine. Biochem Biophys Res Comm 193: $1275-1282$

Mueckler M, Weng W, Kruse M (1994) Glutamine 161 of Glut1 glucose transporter is critical for transport activity and exofacial ligand binding. I Biol Chem 269:20533-20538

Müllerbach R, Lagoda PJL, Weller C (1989) An efficient salt-chloroform extmetion of DNA from blood and tissues. Trends Genet 5:391

Neumann PE, Frankel WN, Letts VA, Coffin JM, Copp AJ, Bernfield M (1994) Multifactorial inheritance of neural tube defects: localization of the major gene and recognition of modifiers in ct mutant mice. Nature Genet 6: 357-362

New DAT, Coppola PT, Terry S (1973) Culture of explanted rat embryos in rotating rubes. I Reprod Fert 35: 135-138

Papaconstantinou J. (1967). Metabolic control of growth and differentiation in vertebrate. embryos. In "The Biochemistry of Animal Development, Ed. Weber", Vol. 2, pp. 57-113. Academic Press, New York.

Peeters MCE, Hekking JWM, Vanas T, Drukker J, Van Straten HWM (1997) Spatio-temporal curvature pattern of the caudal body axis for non-mutant and corty tal mouse cmbryos during the period of caudal neural tube closure. Anat Embryol 195: 259-266

Peeters MCE, Shum ASW, Hekking JWM, Copp A), Van Straten HWM (1996) Relationship between altered awial curvature and neural tube closure in normal ard mutant (amb tail) mouse embryos. Anat Embryol 193: 123-130

Reece EA, Pinter E, Leranth CZ, Garcia-Segura M, Sanyal MK, Hobbins JC, Mahoncy MJ, Naftolin F (1985) Ultrastructural analysis of malformations of the embryonic ncural axis induced by in vitro hyperglycemic conditions. Teratology $32: 363-373$

Reece EA, Wiznitzer A, Homko CJ, Hagay Z, Wu YK (1996) Synchronization of the factors critical for diabetic teratogenesis: an in vitro model. Am J Obstet Gynecol 174: 1284-1288 
Reed BC, Shade D, Alperovich, Vang M (1990) 3T'3-L1 adipocyte glucose transporter (HepG2 cllass): sequence and regulation of protein and mRNA expression by insulin, differentiation, and glucose starvation. Arch Biochem Biophys 279: 261-274

Sadler TW (1980) Effects of maternal diabetes on early embryogenesis: 11. Hyperglycemiainduced excncephaly. Teratology 21:349-356

Seller MI. (1994). "Vitamins, folic acid and the cause and prevention of neural tube defects." Wiley, Chichester.

Seller MJ, Adinolfi M (1981) The curly-tail mouse: an experimental model for human neural tube defects. Life Sei 29: 1607-1615

Shepard 'TH, Tanimura T', Robkin MA (1970) Energy metabolism in early mammalian embryos. Dev Biol suppl 4: $42-58$

Shows TB, Eddy RL, Byers MG, Fukushima Y, Dehaven CR, Murray JC, Bell GI (1987) Polymorphic human glucose transporter gene (GLUT) is on chromosome 1 p31.3-p35. Diabetes $36: 546-549$

Smith DE, Gridley $T$ (1992) Differential screening of a PCR-generated mouse embryo cDNA library: glucose transporters are differentially expressed in earlypostimplantation mouse embryos. Dewelopment 116: 555-561

Smoak IW, Sadler TW (1990) Embryopathic effects of short-term exposure to hypoglycemia in tmouse embryos in vitro. Am J Obstet Gynecol 163: 619-624

Sussman I, Matschinsky FM (1988) Diaberes affects sorbitol and myo-inositol levels of neuroectodermal tissue during embryogenesis in rat. Diabetes 37: 74-81

Tao I, Tanizawa Y, Matsutani A, Kaneko T, Kaku K (1995) HepG2/erythrocyte glucose transporter (GLUT1) gene in NIDDM: a population association study and molecular scanning in Japanese subjects. Diabetologia 38: 942-947

Trocino RA, Akazawa S, Takino H, Takao Y, Matsumoto $\mathrm{K}$, maeda $\mathrm{Y}$, Okuno SI, Nagataki S (1994) Cellular-tissue localization and regulation of the GLUT-1 protein in both the embryo and the wisceral yolk sac from normal and experimental diabetic rats during the early postimplantation period. Endocrinology 134: 869-878

Van Straaten HWM, Blom HJ, Peeters MCE, Rousseau AM], Cole KJ, Seller MJ (1995) Dietary methionine does not reduce penetrance in curly tail mice but causes a phenotype-specific decrease in embryonic growth. I Nutr 125: 2733-2740

Van Straten HWM, Hekking JWM, Consten C, Copp AJ (1993) Intrinsic and extrinsic factors in the mechanism of neunlation: effect of curvature of the body axis on closure of the posterior neuropore. Development 117: 1163-1172

Van Striaten IWW, Hekking JWM, Copp AJ, Bernfield M (1992) Deceletation and acceleration in the rate of posterior neuropore closure during neurulation in the curly tail $(c t)$ mouse embryo. Anat Embryol 185: 169-174

Wald N, Sneddon J, Densem J, Frost C, Stone R, Group MVRS (1991) Prevention of neural tube defects: results of the Medical Research Council Vitamin Study. Lancet 338: 131-137

Wellner M, Monden 1, Mueckler MM, Keller K (1995) Functional consequences of proline mutations in the putative transmembrane segments 6 and 10 of the glucose transporter GLUT1. Eur ] Biochem 227: 454-458

Xang K, Cox NJ, Karam JH, Bell Gl (1987) Bgl II RFLP at the human erythrocyte/HepG2type glucose transporter (GLUT) locus on chromosome 1. Nucleic Acid Res 15: 9101 


\section{Chapter 5}

\section{General discussion}


In this thesis, the role of axial curvature in spinal neural tube closure is studied in non-mutant and corly tail mutant mouse strains and in other species. Consequently, two determinants of curvation, i.e. cell proliferation and glucose, have been investigated.

Axial curvature will be discussed in relation to neurulation. Since the curly tail mouse was used as a model system, new insights into the aurly tail pathogenetic pathway leading to neural tube defects (NTD) are subsequently proposed and lead to new insights into undisturbed neurulation. Finally, the role of axial curvature will be placed within the multifactorial threshold model of NTD.

\section{Axial curvature and neurulation}

Since axial curvature alterations in mouse embryos correlate with cranial neural tube closure events, curvation is considered to be one of the processes involved in neurulation (Chapter 1). However, the knowledge about the extent of such a relationship in the spinal region of mouse embryos and other species was limited. In the mouse mutant carly tail, of which half of the embryos exhibited a delayed closure of the posterior neuropote (PNP), axial curvature appeared to be spatially and temporally related with the recognized delay in closure (Chapter 3.1). In addition, the angle of curvature in non-mutant mouse embryos correlated directly with the frequency of embryos exhibiting an open PNP, after the range of curvatures had been experimentally expanded (Chapter 3.2). Axial curvature thus appears to be important in the closure of the PNP in mouse embryos.

Not only in the mouse, but observations on tat, rabbit and human embryos also revealed an association between axial curvature and the rate of caudal neural tube closure for those species: the more the axial curvature was reduced, the more the tate of closure increased. On the contrary, in the chick embryo the rate of neural tube closure did change during development independent of changes in axial curvature (Chapter 3.4). It may therefore be concluded that the process of axial curvation is not important in chick neurulation. However, a disturbed curvature of the normally straight axis of the chick embryo resulted in a delayed neural tube closure, suggesting that axial curvation is important in this species as well (Van Straten et al. 1993). Besides, embryos with a flat appearance (i.e. rabbit and chick) appeared to complete their PNP closure at an earlier developmental stage than embryos with a curved axis (i.e. rat, man, mouse). Moreover, the mouse embryo, which is the most curved one, is last in completion of PNP closure (Chapter 3.4). It is therefore concluded that axial curvature affects spinal neural tube closure, not only in mouse embryos, but also in other species.

Axial curvation is a process which is thought to act upon the neurulation events neural wall elevation and neural fold convergence by generating mechanical forces 
which oppose these events (Brook et al. 1991). Increased curvature would therefore block these events, and the subsequent fusion would then consequently be delayed. During convergence, the neural folds are normally bent in a medial direction. However, the neural folds of corly tail embryos with an increased curvature and a delayed PNP closure are bent in a lateral direction, indicating that convergence indeed failed (Van Straaten 1992). Releasing the mechanical forces in the curby tail embryo, by preventing the increased curvature as a result of eyelash insertion in the hindgut lumen or of isolating the neuroepthelium from the adjacent tissues, normalized PNP closure (Brook et al. 1991; Van Straaten et al. 1993), as expected. Experimental enlargement of the PNP in non-mutant mouse embryos did not produce an increased ventral curvature, suggesting that axial curvature is indeed the cause and not the result of the delayed PNP closure in curly tail embryos (Copp 1985; Brook et al. 1991). Thus, increased axial curvature in the spinal region will likely oppose the elevation and convergence of the neural folds, resulting in a reduced progression of the craniocaudal continuation of neural tube closure in this region, and, consequently, in a delayed closure of the PNP.

\section{The pathogenetic pathway of the curly tail mouse leading to NTD}

The mouse mutant curly tail has been studied as a model system throughout the thesis. The current pathogenetic cascade for curly tail leading to NTD was presented in Chapter 1, but data of this thesis have led to new insights into this cascade (Fig. 1).

In the carly tail mouse strain of the Maastricht Colony, the delayed PNP closure was observed in about half of the embryos. These affected ones appeared to exhibit an increased ventral curvature compared to the unaffected ones. However, the aberration turned out to be a temporary phenomenon since a normal curvature pattern was observed from the 32 somite stage onwards. The axial region of increased curvature was found to be confined between somite level 26 and presumptive 34 (Chapter 3.1). Thus, increased curvature appeared spatio-temporally related to the start of the PNP closure delay. Support for the idea that the increased axial curvature and the PNP closure delay were causally related in the ourly tail mouse, emerged from the correlation between a prevention of the increased curvature and a normalization of PNP closure (Chapter 3.2).

As mentioned in the Introduction (Chapter 1), the increased curvature was thought to be the result of a dorso-ventrally imbalanced cell proliferation in the caudal region. In this thesis, such an imbalanced proliferation also appeared in the progenitor of the caudal region, i.e. the tail bud, and this occurred at stages preceding the increased curvature. Moreover, cell proliferation in the rail bud appeared balanced at stages preceding the normalized curvature (Chapter 4.1). The 
temporally imbalanced proliferation in the tail bud is proposed to result in a reduced number of cells ventrally, and consequently to evoke an increased curvation. Since the cells of the tail bud at this stage are the precursors of the caudal region, it is presumed that the reduced proliferation in the ventral tissues of the caudal tegion (Copp et al. 1988) is the consequence of the imbalance in the tail bud at the preceding stage. Moreover, the imbalance in the caudal region likely results in an additional increase of curvation. A role for growth balance in curvature appeated additionally from re-balancing growth by culturing curby tail embryos at an elevated temperature which was found to prevent the increased curvature (Chapter 3.2). It is therefore hypothesized that the imbalanced proliferation of not only the caudal region but also the tail bud causes the temporarily increased curvature in the curly tail embryo and subsequently results in a PNP closure delay.

Glucose has been reported to be important for embryonic growth during neurulation. In this thesis, the glucose uptake appeared reduced per curly tail embryo, but not per embryonic cell. This discrepancy was due to a reduced amount of DNA which was found for curby tail embryos compared to non-mutant ones (Chapter 4.2). This indicates that the reduced proliferation as demonstrated for the ventral tissues of the caudal region and tail bud resulted in a reduced amount of DNA. Thus, the reduced embryonic glucose uptake is a secondary effect, and leads to the conclusion that glucose is not a causative factor in the increased curvation of the curly tail embryo.

Since the gene of the glucose transporter GLUT-1 is mapped in the same region as the $t$ gene, it was determined whether GLUT-1 was mutated and could be identical to the $d$ gene. Based on the results of the tests using restriction enzymes on isolated DNA and of cDNA sequence analysis, it was concluded that $a t$ is likely not GLUT 1 (Chapter 4.2). Up to now, the $a t$ gene has not been characterized. Several candidate genes, which are located within the region to which the $c t$ gene has been mapped, are: $H_{s p g} 2$ (a basement membrane proteoglycan), Synd 3 (a transmembrane proteoglycan associated with neural tissues), Fgr (a non-receptor tyrosine kinase) and Cdclt (a cell division control related protein kinase) (Neumann et al. 1994). The transcription factor $P a x 7$ was also proposed as a candidate gene, but does not seem to be affected in the warly tail (Beier et al. 1995).

Data on carly lail penetrance in the construction of a $\mathrm{BALB} / \mathrm{c}$ - aurly tait recombinant mouse strain indicated that, besides the $c t$ gene, more than 3 modifier genes are presumably involved in the curly tail trait (Chapter 2.2). Since aberrant axial curvation and growth appears to be important in ourly tail pathogenesis, it is postulated that the modifiers of the curly tail trait ate factors which modulate growth, such as growth factors and their receptors. Even the $c t$ gene itself might be a growth modulator. 


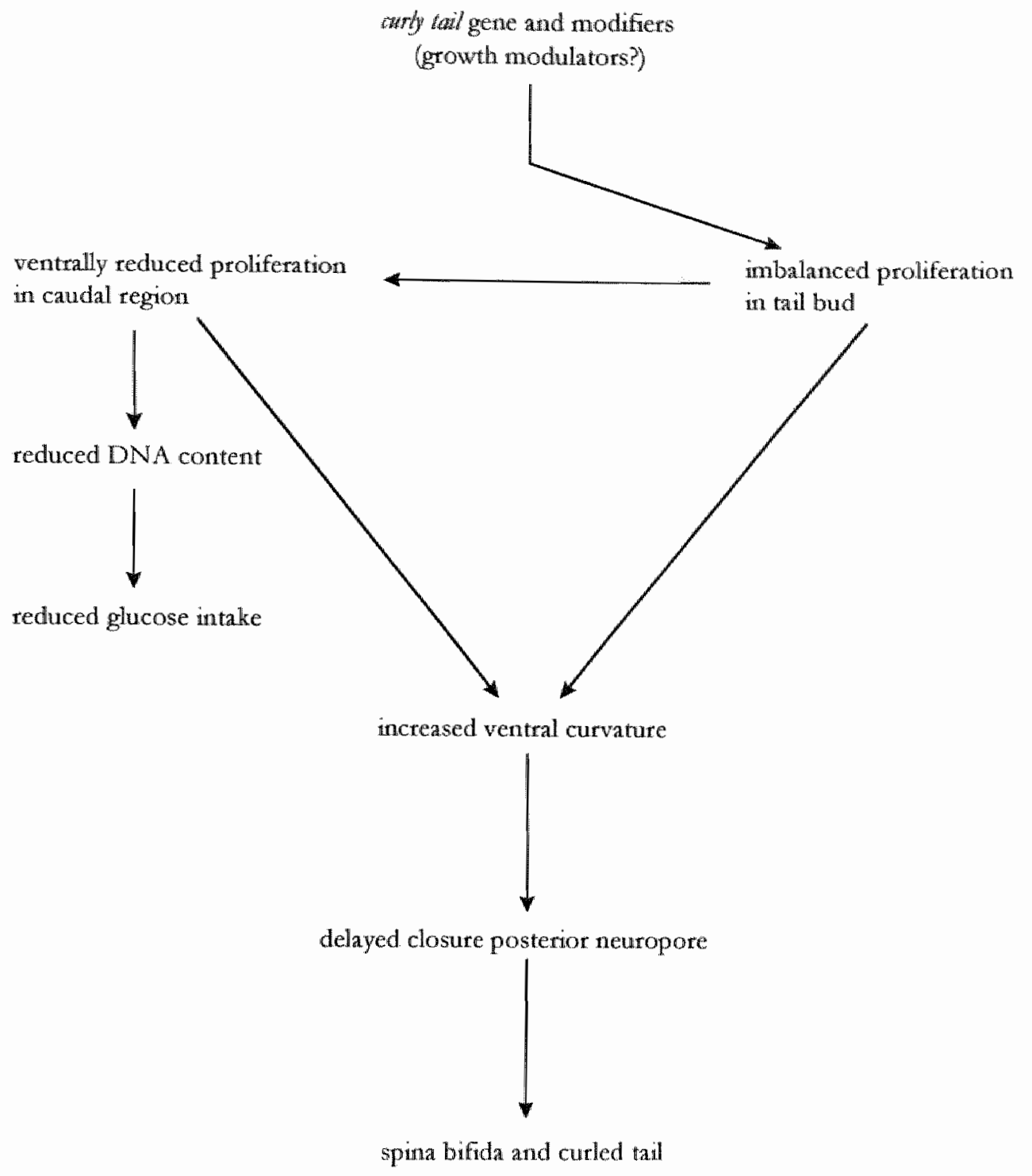

Fig. 1. The newly proposed pathogenetic mechanism of the arrly ailmouse strain

Several studies have concentrated upon growth-related molecules in curly tail embryos. It has been reported that the retinoic acid receptors RAR- $\beta$ and RAR- $\gamma$ are down-regulated in the hindgut and the tail bud, respectively, of affected cwrly lail embryos (Chen et al. 1995), that the expression of W/nt-5a is reduced in the caudal mesoderm (Gofflot et al. 1996, 1997), that hyalutonan accumulates abnormally 
slowly around the notochord (Copp and Bernfreld 1988) and that the growth factor transferrin is bound in reduced quantities on the luminal surface of the hindgut (Hoyle et al. 1996). Which of these molecules are directly related to the at mutation or its modifiers has to be resolved in future studies, which, from now onwards, are supported by the background-matched recombinant strain (Chapter 2.2).

\section{Axial curvature and neural tube defects}

Sevetal intrinsic and extrinsic processes involved in neurulation have been depicted in the Introduction (Chapter 1). Axial curvation is one of these, and its precise impact upon neurulation events will depend on interaction with the other processes and thus on axial level and stage of neurulation in each species. Consequently, a range of curvature values will exist, which will not result in disturbed neurulation, due to the neutralizing effect of the other parameters. This redundancy will differ according to the axial level.

Since the inheritance of NTD in man does not follow simple Mendelian models, NTD aetiology is usually described by a multifactorial threshold model (Chapter 1). "This model is based on the continuous variable "liability", which is a sort of susceptibility determined by both genetic and environmental causative factors. Liability is considered normally distributed with a certain threshold beyond which individuals will be affected. The further beyond the threshold, the more severe the defect (Fraser 1976). Several genetic and environmental factors are involved in NTD, and the combination of these factors determines the distribution of liability. The underlying mechanisms by which the factors determine liability are the processes which affect the neurulation events. As apparent from this thesis, axial curvation is one of these processes, and may result in a shift in the liability distribution. In case the curvature is increased, a shift is expected to the right (Fig. 2), and mote individuals will exhibit NTD.

In man, the study of the relationship between axial curvature and NTD encounters ethical and practical objections. Therefore, model systems as the curly tail mouse ate used. As in man, an excess of fernales has been reported among the anencephalic wrty lail mice. Furthermore, polyhydramnios, hydrocephaly and high levels of alphafoetoprotein in amniotic fluid are NTD-associated anomalies in both czurly tail and man (Embury et al. 1979). Since similarities also exist for axial location, appearance of the NTD and influence of potential teratogens, the curly tail mouse is considered as a valuabie model for human NTD (Seller and Adinolfi 1981). The risk for NTD in man is nowadays considered to be reduced by $70 \%$ by folate supplementation in early pregnancy (Chapter 1). However, treatment of curby tail mice with folate or metabolically related methionine did not alter the NTD incidence (Seller 1994; Van Straten et al. 1995). Therefore, the curly lail mouse is 
nowadays regarded as a model for folate-resistant human NTD. For prevention of this subcategory of NTD, a tole for the vitamin inositol has recently been suggested (Greene and Copp 1997): inositol supplementation in arby tail mice appeared to upregulate the expression of RAR- $\beta$ in the hindgut, and resulted in a nomalization of PNP closure. These authors postulated that the otherwise occurring reduced proliferation of the hindgut was prevented and consequently the increased axial curvature as well.

number of individuals

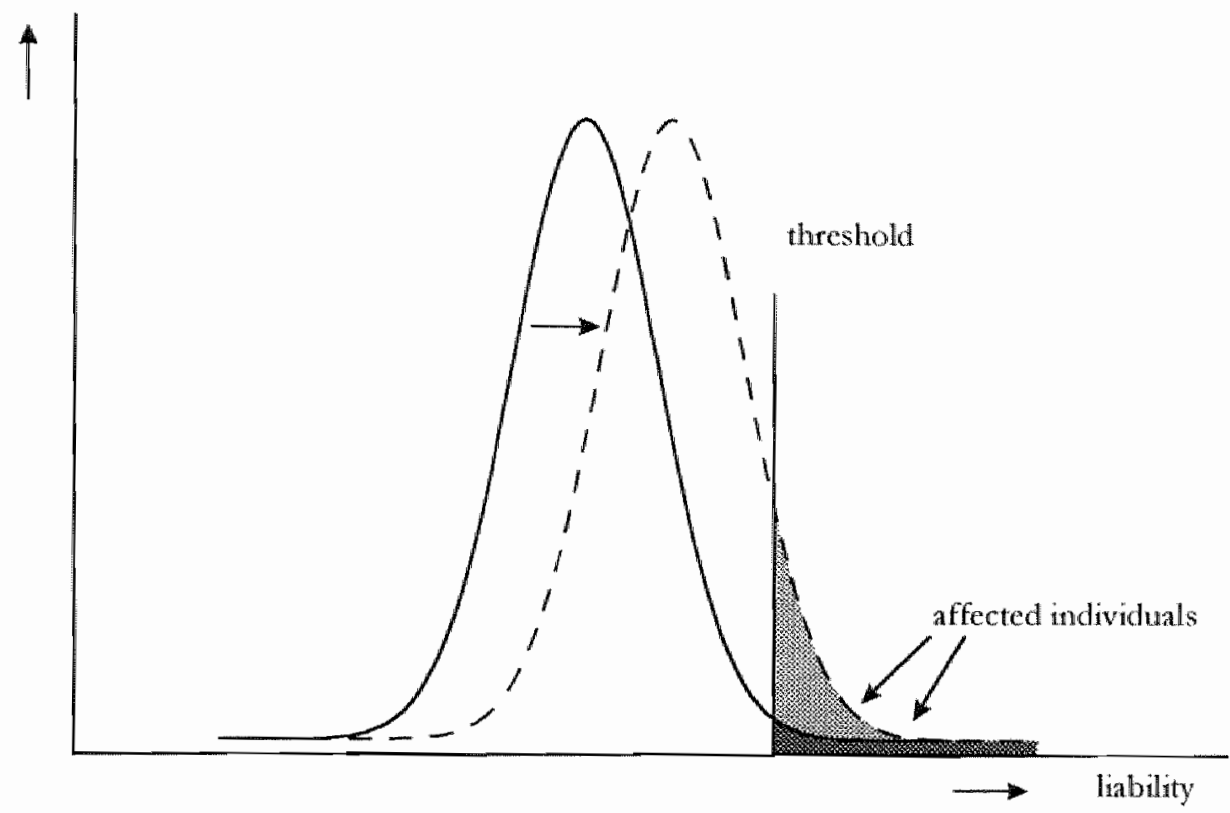

Fig. 2. Shift in liability distribution due to enhanced axial curvature

It is thus likely that aberrant axial curvation is an important factor in folate-resistant human NTD. Axial curvature being determined by the dorso-ventral pattern of cell proliferation in the caudal region and tail bud. Definition of the steps of the atrly tail pathogenetic pathway leading to NTD will be helpful in elucidating the developmental defects of this subcategory of neural tube defects. Moreover, processes, as axial curvation, which are important for primary neurulation will consequently emerge. 


\section{References}

Beier DR, Dushkin H, "Telle T (1995) Haplotype analysis of intra-specific backcross any tod mice confirms the localization of ct to chromosome 4. Mamm Genome 6:269-272

Brook FA, Shum ESW, Van Straten HWM, Copp AJ (1991) Curvature of the caudal region is responsible for failure of neural nube closure in the curly tail ( $c$ ) mouse embryo. Development 113: $671-678$

Chen WH, Morriss-Kay GM, Copp AJ (1995) Genesis and prevention of spinal neural nube defects in the curly ial mutant mouse: involwement of retinoic acid and its nuclear receptors RAR-b and RAR-g. Development 121: 681-691

Copp AJ (1985) Relationship between timing of posterior neuropore closure and development of spinal neural tube defects in mutant (curty tail) and normal mouse embryos in culture. I Embryol Exp Morphol 88: $39-54$

Copp $\mathrm{N}$. Bernfield M (1988) Accumulation of basement membrane-associated hyaluronate is. reduced in the posterior neuropore region of mutant (curly tail) mouse embryos developing spinal neural tube defects. Dev Biol 130: 583-590

Copp AJ, Brook FA, Roberts HJ (1988) A cell-type-specific abnormality of cell proliferation in mutant (curly tail) mouse embryos developing spinal neural tube defects. Dewelopment 104 : 285-295

Embury S, Seller MJ, Adinolfi M, Polani PE (1979) Neural tube defects in curly tail mice. I. Incidence, expression and similarity to the human condition. Proc. R. Soc. London. B 206: $85-94$

Fraser FC (1976) The multifactorial/threshold concept--uses and misuses. Teratology 14: 267 280

Gofflot F, Hall M, Morriss-Kay GM (1996) Gene expression in the posterior neuropore region of C57BI/6 and cwry tail mutant mouse embryos. Proc. Anat. Soc. Gr. Britain/Ireland, Dec $96 \mathrm{p} 44$

Gofflot F, Hall M, Morriss-Kay GM (1997) Molecular analysis of the posterior neuropore and tail region of C57BI/6 and anty kail mouse embryos. Dev Biol 186: B198

Greene $N D E$, Copp $M$ (1997) Inositol prevents folate-resistant neural tube defects in the mouse. Nature Med 3: 60-66

Hoyle C, Henderson DJ, Matthews DJ, Copp AJ (1996) Transferrin and its receptor in the development of genetically detemined newral tube defects in the mouse embryo. Dev Dyn 207: $35-46$

Neumann PE, Frankel WN, Letts VA, Coffin JM, Copp AJ, Bernfeld M (1994) Multifactorial inheritance of neural tube defects: localization of the major gene and recognition of modifiers in er mutant mice. Nature Genet $6: 357-362$

Seller MJ. (1994). "Vitamins, folic acid and the cause and prevention of neural tube defects." Wiley, Chichester.

Seller MJ, Adinolf M (1981) The curly-tail mouse: an experimental model for human neural tube defects. Life Sci 29:1607-1615

Van Straten HWM. (1992). The curlyntail mouse as a model for the study of neural-tube closure. It "Neural tube defects. Pathogenesis and prevention" (T. K. A. B. Eskes, Ed.), pp. 31-38. Medicom Europe B. V.

Van Straten HWM, Blom HJ, Peeters MCE, Rousseau AMJ, Cole KJ, Seller MJ (1995) Dietary methonine does not reduce penetrance in curly tail mice but causes a phenotype-specific decrease in embryonic growth. J Nutr 125: 2733m2740

Van Straten HWM, Hekking JWM, Consten C, Copp AJ (1993) Intrinsic and extrinsic factors in the mechanism of neurulation: effect of curvature of the body axis on closure of the posterior neuropore. Development 117: 1163-1172 


\section{Summary}

Neural tube defects (NTD) are among the most distressing congenital anomalies. They arise when neurulation ( $=$ the formation of the neural tube) during the embryonic period is disturbed. Neurulation comprises four subsequent events: formation of the neural plate, elevation of the neural walls, convergence and fusion of the neural folds. The initial closure is in the cervical region and zippers to the cranial and caudal direction. The openings at both ends are the final closure sites and are called the anterior neuropore and the posterior neuropore (PNP). In each of these events, several processes as cell migration and proliferation are involved. Recently, another process has been recognized, axial curvation of the embryo, but its impact upon neural tube closure is hitherto studied insufficiently. In this thesis, the extent of the relationship between axial curvature and closure of the PNP is determined in embryos of several species, among which the mouse strain cturly tail, mutant for spina bifida. In the past decade, it became obvious that this strain can serve as a model to study the role of axial curvature in spinal neurulation.

In Chapter 2.1, the aurly tail mouse colony which was used throughout the thesis is described in more detail. The mutation arose spontaneously in 1950, but up to now neither the $c t$ gene nor one of its modifiers has been characterized. In $55 \%$ of the newborns an affected phenotype, i.e. kinked or curled tail and spina bificla aperta, was observed. This phenotype is thought to be the result of a disturbed neurulation. The penetrance appeared independent of parental phenotype and parental penetrance, but seemed to be influenced by environmental conditions. Since penetrance and phenotypes of this colony resemble those of the other curly tail colonies, the data obtained from different colonies complete each other.

A good control strain was missing for the corly tail mouse. Not only a difference with respect to the $a$ gene and its modifiers was present, but also with respect to the genetic background of other strains. Therefore, a background-matched $\mathrm{BALB} / \mathrm{c}$ - curly tail recombinant strain was constructed via a cross-intercross design (Chapter 2.2). The penetrance after each intercross amounted to $2-4 \%$. An increase in penetrance up to $48 \%$ was achieved by five subsequent inbreeding cycles of the intercross offspring with selection in favor of affected phenotypes. The results suggest that, besides the $a$ gene, more than 3 modifier genes are involved in the curby tail trait. Since this recombinant mouse strain exhibits the curly tail trait on a known genetic background, the strain will be helpful in revealling the crorty tail pathogenesis, and is used as such in the studies of Chapter 4 .

The central theme of Chapter 3 is the relationship between axial curvature and neural tube closure. The observed tail anomalies and spina bifida aperta in newborn curly tail mice are thought to be the result of a delayed closure of the PNP, as 
obsetved in about half of the embryos at embryonic days 9.5 , more specifically from the developmental stage of 25 somites onwards. These affected embryos had previously been reported to exhibit an increased axial curvature in the region of the PNP. Since the region of increased curvature and its development were unknown, these have been determined (Chapter 3.1). In control mouse embryos, a general axial unbending of the embryonic axis was observed during subsequent stages of PNP closure. An additional matked decrease in curvature occurred at the final stages of PNP closure, indicating that this unbending faclitates the completion of PNP closure. In affected curby tail embryos, however, curvature appeared increased between somite levels 26 and presumptive 34 . This increase turned out to be only temporally, since a normal curvature was observed from the 32 somite stage onwards. Thus, the aberrant curvature in the curly ail embryo coincided spatially and temporally with the start of PNP closure delay. The enhanced curvature probalbly delays the closure by counteracting the elevation and convergence of the neural walls.

The increased curvature in carly tail embryos could be prevented by culture at an elevated temperature (Chapter 3.2). This yielded a normalization of PNP closure. In order to determine whether aberrant axial curvature in control mouse embryos would also result in a delayed PNP closure, axial curvature was experimentally altered in those embryos. The increased curvature appeared indeed to correlate with a higher frequency of embryos with an open PNP.

In contrast to the mouse embryo, the rabbit embryo has a straight axis for a considerable period of PNP closure. Based on the experience with mouse embryos that an increased curvature would delay the closure of the PNP, it was expected that the straight axis would be associated with a fast neural tube closure. Since neurulation in the rabbit was hardly documented in literature, such a study was performed (Chapter 3.3). As hypothesized, closute of the neural tube closure occured fast except for the final phase of PNP closure.

Subsequently, the closure of the PNP was related to axial curvature in five species: mouse, rat, rabbit, man and chick (Chapter 3.4). The closure of the PNP was first completed in the embryos with a flat appearance (i.e. rabbit and chick), subsequently in embryos with a moderately curved axis (i.e. rat and man) and funally in the most strongly curved species (i.e. mouse). Moreover, another general relationship emerged: the more the axial curvature decreased during neurulation, the more the rate of closure increased. Based on these studies, it is concluded that axial curvation is an important process in neural tube closure.

Enhanced axial curvature in the carly tail embryo has been proposed to result from a reduced cell proliferation in the ventral tissues of the PNP region. It might be expected, however, that proliferation is also disturbed in the progenitor structure of this region, i.e the tail bud, at stages preceding the aberrant curvature. Therefore, proliferation was determined in the dorsal and ventral halves of the tail bud 
(Chapter 4.1). It appeared that, at the stage preceding the aberrant curvature, the ventral half, when compared to dorsal, comprised an increased proportion of $\mathrm{G}_{0} / \mathrm{G}_{1}$ phase cells and a decreased proportion of $S$ phase cells in both the curby tail and tecombinant mutant strain. The proliferation appeared re-balanced at the stage preceding the normalized axial curvature. This indicates that the temporally imbalanced proliferation in the tail bud results in a reduced number of cells ventrally and subsequently evokes the temporally increased axial curvature. This imbalanced proliferation is now considered the earliest event in the pathogenetic sequence leading to NTD in the carly tail mouse.

Glucose is reported to be important for embryonic growth at the respective stages of neurulation. Its role in the curly tail pathogenesis has been determined as well (Chapter 4.2). Both in a long-term and short-term embryo culture, glucose uptake seemed to be reduced for the ourly tail and recombinant mouse embryos compared to non-mutant ones. This was accompanied by a reduced amount of DNA in the mutant embryos, resulting in a normal uptake per cell. The gene for the glucose transporter GLUT-1 is mapped to the same region on chromosome 4 as the non-characterized $a$ gene. It was determined whether $a$ and GLUT- $f$ could be alleles of the same gene. Such a relationship was excluded based upon the results of restriction fragment length polymorphism and cDNA sequence analyses. Moreover, since GLUT-1 is important for glucose transport across the cell membranes during neurulation, these GLUT-1 results together with the normal expression of the GLUT-1 protein as immunohistochemically determined support the idea that the glucose uptake per cell is normal in the carly tat mouse embryo. Thus, the imbalanced proliferation in the PNP region and tail bud, as part of the curly tail pathogenesis, is unlikely due to aberrant glucose handling. The aberrant proliferation results, presumably, in a reduced cell number and, consequently, in a reduced glucose uptake.

The results presented in this thesis indicate that the progression of neural tube closure in several species is affected by axial curvature. Most likely, axial curvature is important in human NTD as well. Because of similarities in e.g. location, appearance and influence of potential teratogens, the mouse mutant carly tail is currently considered a valuable model for the folate-resistant subgroup of human NTD. Therefore, the new insights in the pathogenesis of the carly tail, alike the imbalanced proliferation in the tail bud, may elucidate pathogenetic pathways in this subcategory of human NTD. 


\section{Samenvatting}

Neurale buis defekten (NBD) behoren tot de zeer etnstige aangeboren afwijkingen. $\mathrm{Ze}$ ontstaan als de neurulatie (= de vorming van de neurale buis) tijdens de embryonale periode verstoord is. Neurulatie bestaat uit vier opeenvolgende gebeurtenissen: vorming van de neurale plaat, elevatie van de neurale wallen, convergentie en fusie van de neurale vouwen. De sluiting begint in het cervicale gebied, en breidt van daar uit naar craniaal en caudaal. De openingen aan beide uiteinden heten neuroporus anterior en neuroporus posterior (NP), en sluiten als laatste. $\mathrm{Bij}$ ieder van deze gebeurtenissen zijn diverse processen betrokken zoals lokale celmigratie en proliferatie. Recent is een ander proces onderkend, de askromming van het embryo, maar de invloed ervan op de neurale buissluiting is tot nu toe onvoldoende bestudeerd. In dit proefschrift wordt de relatie tussen askromming en sluiting van de NP nader onderzocht in embryo's van diverse species, waatonder de muizenstam curly tail, mutant voor spina bifida. Van deze stam is in het afgelopen decennium duidelijk geworden dat ze als model kan dienen om de rol van askromming in spinale neurulatie te bepalen.

In Hoofdstuk 2.1 wordt de curly tail kolonie die in dit onderzoek gebruikt is in detail beschreven. De mutatie ontstond spontaan in 1950, maar tot op heden zijn noch het $a$ gen noch zijn modifier genen gekarakteriseerd. Een aangedaan fenotype, d.w.z een ktul of knik in de staart en/of spina bifida aperta, werd bij $55 \%$ van de pasgeborenen waargenomen. Dit fenotype wordt waarschijnlijk veroorzaakt door een verstoorde neurulatie. De penetrantie bleek onafhankelijk te zijn van het fenotype of penetrantie van de ouders, maar leek wel beïnloed te worden door omgevingsfaktoren. Omdat de penetrantie en fenotypen van deze kolonie overeenkomen met die van andere curby tail kolonies, kunnen de data vanuit de verschillende kolonies ellkaar aanvullen.

Voor de curly tail ontbrak een goede controle-stam. Er was namelijk niet alleen cen verschil voor wat betreft het $a$ gen en zijn modifiers, maar ook met de genetische achtergtond van andere stammen. Daarom werd een BALB/c - curby tail recombinante stam geconstrueerd via een cross-intercross kruisingsschema (Hoofdstuk 2.2). De penetrantie na iedere intercross bedroeg 2 tot $4 \%$. Een stijging in de penetrantie tot $48 \%$ werd bereikt door vijf opeenvolgende inkruisingscycli van de intercross-nakomelingen met selectie van de aangedane fenotypen. Deze resulltaten suggereren dat, naast het of gen, meer dan drie modifier genen betrokken zijn bij de curly tail expressic. Omdat deze tecombinante muizenstam de curly tail eigenschappen vertoont en een bekende genetische achtergrond bezit, is zij geschikt voor het ontrafelen van de amby lail pathogenese, en als zodanig gebruikt voor de studies welke zijn gerapporteerd in Hoofdstuk 4. 
Het centrale thema in Hoofdstuk 3 is de relatie tussen asktomming en neurale buissluiting. De staartafwijkingen en spina bifida aperta die in pasgeboren curby tail muizen waargenomen worden, zijn waarschijnlijk het resultaat van een vertraagde sluiting van de NP. Deze vertraging wordt in ongeveer de helft van de embryo's van 9.5 dag waatgenomen, ofwel vanaf het ontwikkelingsstadium van 25 somieten. In de literatuur is bekend dat deze aangedane embryo's een toegenomen askromming in de regio van de NP vertoonden. Omdat de locatie en het verloop van deze krommingsafwijking tijdens de ontwikkeling niet bekend was, werd deze bepaald (Hoofdstuk 3.1). In controle embryo's werd een algemene ontkromming van de embryonale as waargenomen tijdens opeenvolgende stadia van NP-sluiting en tijdens de laatste stadia trad bovendien een extra afname in kromming op. Dit is een aanwijzing dat ontkromming de voltooiing van de NP-sluiting faciliteert. In aangedane curby tail embryo's bleek de kromming echter tijdelijk toe te nemen tussen somietniveau 26 en toekomstig niveau 34. Vanaf somietenstadium 32 werd weer een normale kromming waatgenomen. De toegenomen kromming in het carly tail embryo valt dus zowel in plaats als tijd samen met de vertraging van de NP-sluiting. De extra kromming verhindert waatschijnlijk mechanisch de elevatie van de neurale wallen en de convergentie van de neurale vouwen, waardoor de fusie geremd wordt.

De extra kromming in curly tail embryo's kon worden voorkomen door de embryo's te kweken bij een verhoogde temperatuur (Hoofdstuk 3.2). Dit resulteerde in een normalisatie van de NP-sluiting. Om te bepalen of in controlle embryo's een toegenomen askromming ook zou resulteren in een vertraagde NP-sluiting, werd de askromming in deze embryo"s experimenteel veranderd. De toegenomen kromming bleek inderdaad positief te correleren de frequentic van embryo's met een nietgesloten NP.

In tegenstelling tot het muizenembryo heeft het konijnenembryo tijdens een aanzienlijke periode van de NP-sluiting een rechte as. Vanuit de bevinding bij de muis dat een toegenomen kromming de sluiting van de NP vertraagt, werd verwacht dat de rechte as geassocieerd zou zijn met een snelle neurale buissluiting. Omdat de neurulatie in het konijn nauwelijks gedocumenteerd was in de literatuur, werd zo'n studie uitgevoerd (Hoofdstuk 3.3). Zoals verondersteld, bleek de sluiting van de neurale buis snel te vetlopen, met uitzondering van de laatste fase van de NP-sluiting.

Vervolgens werd de relatie van de NP-sluiting en askromming bestudeerd in vijf diersoorten: muis, rat, konijn, mens en kip (Hoofdstuk 3.4). De sluiting van de NP was het eerst voltooid in de embryo's met een vlak uiterlijk (konijn en kip), vervolgens in embryo's met een licht gekromde as (rat en mens) en tenslotte in de meest gekromde diersoort (muis). Bovendien bleek dat er nog een algemene tendens aanwezig was: afname van de askromming tijdens de neurulatie was gecorreleerd met een toename van de sluitingssnelheid. Gebaseerd op deze studies 
werd geconcludeerd dat het ktommen van de as een proces is die de neurale buissluiting beinvloedt.

In de literatuur werd geopperd dat de toegenomen askromming in het curly tail embryo het resultatat zou zijn van een verminderde proliferatie in de ventrale weefsels wan de NP-regio. Het kan echter verwacht worden dat proliferatie met name verstoord is in de voorloper van deze regio, dit is de staartknop, en op een stadium voorafgaand aan de afwijkende kromming. Daatom werd de proliferatie bepaald in de dorsale en ventrale helft van de staartknop (Hoofdstuk 4.1). Het bleek dat in het stadium voorafgaand aan de afwijkende askromming, de ventrale helft in vergelijking met dorsaal meer cellen in de $G_{0} / G_{1}$ fase en minder cellen in de $S$ fase bevatte in zowel de aurly tail als de recombinante muizenstam. De proliferatie bleek weer in balans te komen in het stadium voorafgaand aan de genormaliseerde askromming. Dit wijst erop dat de tijdelijke proliferatie-disbalans in de staartknop tot een verminderd aantal cellen ventraal leidt, welke vervolgens in een tijdelijk toegenomen askromming resulteert. Deze proliferatie-disbalans wordt nu beschouwd als de vroegste stap in de pathogenese van NBD in de curby tail muis.

Glucose is belangrijk voor de embryonale groei tijdens de neurulatie. De rol wan glucose in de corly tail pathogenese werd eveneens bepaald (Hoofdstuk 4.2). Zowel in lang-durende als kort-durende embtyo-kweken, leek de opname van glucose door curly ail an recombinante muizenembryo's verminderd te zijn in vergelijking met controle embryo's. Dit ging echter gepaard met een verminderde hoeveelheid DNA in de mutante embryo's, waardoor de opname per cel normaal bleek te zijn. Het gen voot de glucose-transporter GLUT-1 is in dezelfde regio op chromosoom 4 gelokaliseerd als het nog niet gekarakteriseerde $\alpha$ gen. Daarom werd bepaald of $\alpha$ en GLUT-1 allelen konden zijn van hetzelfde gen. Deze relatie werd uitgesloten op basis van de resultaten van de restrictie-fragmentlengte polymorfisme en cDNA sequentie analysen. De expressie van het GIUT-1 eiwit bleek immunohistochemisch normal te zijn. Omdat GLUT-1. belangrijk is voor het glucosetransport over de celmembraan tijdens neurulatie, bevestigen deze resultaten de bewinding dat de opname van glucose per cel normal is in het arty tail embryo. Het is dan ook niet erg waarschijnlijk dat de proliferatie-disbalans in de NP-regio en in de staattknop wordt veroorzaakt door een afwijkende opname van glucose. De afwijkende proliferatie resulteert watschijnlijk in een verminderd aantal cellen en derhalve in een verminderde opname van glucose.

De resultaten die in dit proefschrift gepresenteend zijn duiden erop dat de sluiting van de neurale buis in diverse diersoorten beinvloed wordt door askromming. Askromming is zeer waarschijnlijk ook belangrijk in humane NBD. Door overeenkomsten in bijwoorbeeld locatic, verschijning en invloed van potentiele teratogenen wordt de muismutant wry tail momenteel beschouwd als een waardevol model voor de folaat-resistente subgroep van humane NBD. Daarom 
zullen nieuwe inzichten in de pathogenese van de carby tail, zoals de proliferatiedisbalans in de staartknop, stappen in de pathogenese van deze subcategorie van humane NBD kunnen gaan ophelderen. 


\section{Curriculum Vitae}

Marian C. E. Peeters werd geboren op 31 oktober 1968 te Dongen. In 1987 behaalde zij het VWO diploma aan het Dr. Schaepmancollege in Dongen. In datzelfde jaar begon zij met de studie Gezondheidswetenschappen aan de Katholieke Universiteit Nijmegen. Het doctoraal examen, met als afstudeerrichting toxicologie, werd afgelegd in april 1992.

Vanaf oktober 1992 was zij bij de Nederlandse Organisatie voor Wetenschappelijk Onderzoek aangesteld als onderzoeker in opleiding en gedetacheerd bij de vakgroep Anatomie en Embryologie van de Universiteit Maastricht. Zij werkte onder begeleiding van Prof. Dr. J. Drukker, Prof. Dr. J.P.M. Geraedts en Dr. H. W. M. van Straaten aan het projekt: Is een juiste kromming van de caudale regio van het embryo noodzakkelijk voor normale sluiting van de neurale buis? De resultaten van dit onderzoek zijn weergegeven in dit ptoefschrift.

Vanaf oktober 1996 tot heden is zij als docent werkzaam bij de vakgroep Anatomie en Embryologie, Universiteit Maastricht. 


\section{List of Publications}

H.A.A.M Dirven, P.H.H. van den Broek, M.C.E Peeters, J.G.P. Peters, W.C. Mennes, B.J. Blaauboer, J. Noordhoek, F.J. Jongeneelen (1993). Effects of the peroxisome proliferator mono(2-ethythexyl)phthalate in primary hepatocyte cultures derived from rat, guinea pig, rabbit and monkey. Biochemical Phamacology $45: 2425-2434$

H.W.M. van Straaten, H.J. Blom, M.C.E. Peeters, A.M.J. Rousseau, K.J. Cole and M.J. Seller (1995) Dietary methionine does not reduce penetrance in why inil mice but causes a phenotype-specific decrease in embryonic growth. Joumal of Nutrition 125: 2733... 2740

M.C.E. Peeters, A.S.W. Shum, JW.M. Hekking, A.J. Copp and H.M.W van Straaten (1996) Relationship between altered axial curvature and neural tube closure in nomal and mutant (owb lail) mouse embryos. Anatomy and Embryology 193: 123-130

H.W.M. van Straaten, H.C.J.P. Janssen, M.C.E. Peeters, A.J. Copp, J.W.M. Hekking (1996) Neutal tube closure in the chick embryo is multiphasic. Developmental Dynamics 207: 309-318

M.C.E. Peeters, J.W.M. Hekking, T. Vainas, J. Dtukker, H.W.M. van Straaten (1997) Spatio-temporal curvature pattem of the caudal body axis for non-mutant and aurly lail mouse embryos during the period of caudal neural tube closure. Anatomy and Embryology 195: 259-266

H.W.M. van Straaten, M.C.E. Peeters, K.W.F. Szpak, J.W.M. Hekking (1997) Initial closure of the mesencephalic neural groove in the chick embryo involves a releasing zipping-up mechanism. Developmental Dynamics 209: 333-341

M.C.E. Peeters, C. Viebahn, JW.M. Hekking, H.W.M. wan Straten (1998) Neurulation in the rabbit embryo. Anatomy and Embryology 197: 167-175

M.C.E. Peeters, B. Schutte, M.H.].N. Ienders, J.W.M. Hekking, J. Drukker, H.W.M. van Straten (1998) Role of differential cell proliferation in the tail bud in aberrant mouse neurulation. Developmental Dynamics 211:382-389

M.C.E. Peeters, I.W.M. Hekking, K. Shiota, J. Dnkker, H.W.M. van Straten. Differences in axial curvature correlate with species-specific rate of neural tube closure in the embryo of chick, rabbit, mouse, tat, and human. Anatomy and Embryology, in press

M.C.E. Peeters, J.L.M.C. Geelen, JW.M. Flekking, N. Chavannes, J.P.M. Geracdts, H.W.M. van Straten (1997). Reduced glucose consumption in the curty tail mouse does not initiate the pathogenesis leading to spinal neural tube defects. Journal of Nutrition; in press 


\section{Dankwoord}

Zonder samenwerking zou het verrichte onderzoek niet mogelijk zijn geweest. De laatste pagina van dit proefschrift wil ik dan ook gebruiken om iedereen die me op een of andere wijze gesteund heeft te bedanken. Met het risico dat de bijdrage van anderen onderbelicht blijft, wil ik toch enkele mensen met name noemen.

Allereerst mijn promotores Jan Drukker en Joep Geraedts. Vooral bij het naderen van de eindstreep werd jullie bijdrage steeds belangrijker.

Henny, als co-promotor stond je zeet dicht bij mijn onderzoek. Je steeds weer nieuwe ideeen en kritiek tijdens alle fasen van het onderzoek hebben me zeer geholpen. Bedankt dat er altijd een gaatje in je agenda te creëren was.

Johan, weel experimenten hebben we samen uitgevoerd. Het was een waat genoegen om het lief en leed van de research met je te delen.

Natuurlijk wil ik ook alle medewerkers van de vakgroep Anatomie en Embryologie bedanken. Door jullie behulpzaamheid, afleiding en vlaai heb ik me altijd thuis gevoeld in de groep.

Het thema Groei en Ontwikkeling ben ik zeer erkentelijk voor de bijdrage in de afgelopen jaren.

De nieuwe congene muizenstam bracht veel werk met zich mee. Hierbij wil ik dan ook alle medewerkers van de Centrale Proefdiervoorziening bedanken voor het verzorgen van "mijn" muizen en de medewerking in de afgelopen jaren.

Veel wan "mijn" embryo"s zijn verguld en met electronen gebombardeerd. Paul Bomans, Peter Frederik en Rein van Gool van de electronenmicroscopie, bedankt voor de prettige samenwerking.

Bij het werk aan het Glut-1 gen werd ik bijgestaan door Jan Geelen, Henk Meijer en Roselie Jongbloed. Het Klinisch Chemisch lab wil ik bedanken voor de vlotte samenwerking als er weer glucosespiegels gemeten moesten worden.

Christoph Viebahn, thanks for the hospitality and for giving me the opportunity to study neurulation in rabbit embryos.

Suzanne, Niels, Tryfon, Ewoud, Felix, Huib, Toan, Tatiane, Karin, Alexandra en Nienke als stage-studenten hebben jullie verschillende aspekten van neurulatie nader bekeken. Ook al is jullie werk misschien niet altijd letterlijk terug te vinden in dit boekje, jullie hebben er zeker ook aan bijgedragen.

Paranimfen, bedankt voor het goede voorbeeld.

Ronald, hoe kan ik je beter bedanken dan met de woorden "I want to express my appreciation and gratitude to Ronald, for putting up with my divided attention during this book's gestation period". 